UNIVERSIDADE DE SÃO PAULO

ESCOLA DE ENGENHARIA DE SÃO CARLOS

DEPARTAMENTO DE ENGENHARIA DE ESTRUTURAS

LUCAS PINHEIRO BUFFON

Formulações do Método dos Elementos de Contorno para a análise mecânica de domínios planos não-homogêneos enrijecidos

VERSÃO CORRIGIDA

A versão original encontra-se na Escola de Engenharia de São Carlos

São Carlos

2018 

LUCAS PINHEIRO BUFFON

\section{Formulações do Método dos Elementos de Contorno para a análise mecânica de domínios planos não-homogêneos enrijecidos}

Dissertação apresentada ao Departamento de Engenharia de Estruturas da Escola de Engenharia de São Carlos, Universidade de São Paulo, como parte dos quesitos para a obtenção do título de Mestre em Ciências, Programa: Engenharia Civil (Estruturas).

Área de concentração: Estruturas

Orientador: Prof. Dr. Edson Denner Leonel 
AUTORIZO A REPRODUČÃO TOTAL OU PARCIAL DESTE TRABALHO, POR QUALQUER MEIO CONVENCIONAL OU ELETRÓNICO, PARA FINS DE ESTUDO E PESQUISA, DESDE QUE CITADA A FONTE.

Ficha catalográfica elaborada pela Biblioteca Prof. Dr. Sérgio Rodrigues Fontes e Seça Técnica de Informática, EESCNUSP com os dados fornecidos pelo(a) autor(a).

Pinheiro Buffon, Lucas

P933f Formulaçdes do Nétodo dos Elementos de Contorno para a análise mecânica de dominios planos nào-homogeneos enrijecidos / Lucas Pinheiro Buffon: orientador Edson Denner Leonel. Sào Carlos, 2018.

Dissertaçào (Nestrado) - Programa de P6s-Graduaçấo em Engenharia Civil(Engenharia de Estruturas) e frea de Concentraçăo em Estruturas -- Escola de Engenharia de Sào Carlos da Universidade de Sào Paulo, 2018.

1. MEC. 2. MEC 1D. 3. Acoplamento MEC/NEF. 4. Acoplamento MEC/MEC 1D. 5. Meios enrijecidos. 6. Nodelagen de enrijecedores. I. Titulo. 


\section{FOLHA DE JULGAMENTO}

\section{Candidato: LUCAS PINHEIRO BUFFON}

Título da dissertação: "Formulações do método dos elementos de contorno para a análise mecânica de domínios planos nãohomogêneos enrijecidos"

Data da defesa: 02/02/2018

Comissão Julgadora:

Resultado:

Prof. Dr. Edson Denner Leonel (Orientador)

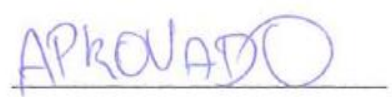

(Escola de Engenharia de São Carlos/EESC)

Prof. Dr. Eduardo Toledo de Lima Junior

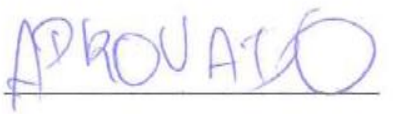

(Universidade Federal de Alagoas/UFAL)

Prof. Dr. Caio Gorla Nogueira

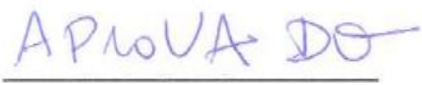

(Universidade Estadual Paulista "Júlio de Mesquita Filho"/Unesp - Bauru)

Coordenador do Programa de Pós-Graduação em Engenharia Civil (Engenharia de Estruturas):

Prof. Titular Humberto Breves Coda

Presidente da Comissão de Pós-Graduação:

Prof. Associado Luis Fernando Costa Alberto 



\section{AGRADECIMENTOS}

Agradeço primeiramente a minha família, em especial meus pais, por todo esforço que investiram na minha formação. Meu pai por ensinar a ver sempre a vida em perspectiva, por mais que os problemas pareçam gigantes no momento. Minha mãe, exemplo de esforço com suas $12 \mathrm{~h}$ de trabalho diário, ensinou a perseguir com afinco meus objetivos.

À Rosalya Coutinho, por cuidar de mim e do meu irmão quando nossos pais não podiam estar presentes devido ao trabalho.

Ao professor doutor Edson Leonel, por todo apoio e paciência, com certeza um exemplo de ao mesmo tempo tranquilidade e profissionalismo.

Agradeço aos colegas de SET. Em especial à Karolinne Coelho, por todo incentivo e suporte para o término da dissertação como aluno parcial. Aos colegas da ME-01, Júlio, Ferrnando, Morkis, Victor, Rodolfo e Jeferson, de Pato Branco. A Serjão, Radaik, Picolo, Serginho, Giovanni, e até mesmo aos colegas da ME-08, Paulo Vitor e Delfino, apesar de serem de uma sala inferior.

Aos professores e funcionários do SET, pela contribuição para minha formação.

À CNPq pelo suporte por 1 ano na forma de bolsa de mestrado.

À USP e ao SET pela oportunidade de fazer um mestrado em local de tão alto nível. 



\title{
RESUMO
}

\author{
BUFFON, L. P. Formulações do Método dos Elementos de Contorno para a análise \\ mecânica de domínios planos não-homogêneos enrijecidos. 2018. 146 p. Dissertação
}

(Mestrado em Engenharia de Estruturas) - Departamento de Engenharia de Estruturas, Escola de Engenharia de São Carlos, Universidade de São Paulo, São Carlos, 2018.

Materiais enrijecidos são encontrados cotidianamente na engenharia, como na construção de aeronaves, veículos, navios e manufaturas diversas. Na Engenharia Civil, são exemplos de materiais enrijecidos o concreto armado e o solo reforçado. A solução aproximada para esse tipo de problema pode ser encontrada pelo uso de métodos numéricos como o Método dos Elementos Finitos (MEF) e o Método dos Elementos de Contorno (MEC). Particularmente, o MEC é muito vantajoso em casos onde se tem elevados gradientes de tensão, como em problemas da mecânica da fratura, além de modelar de forma natural meios infinitos, sendo muito utilizado na análise de interação solo-estrutura ou de túneis. No entanto, como no MEC somente o contorno é discretizado, torna-se necessária a utilização de um acoplamento numérico para que o efeito mecânico dos enrijecedores seja considerado. Para esse acoplamento, podem ser utilizados diversos métodos numéricos, sendo neste trabalho realizado com o MEF e o MEC em sua forma unidimensional (MEC 1D). Dentro desse contexto, o acoplamento com o MEC 1D destaca-se por vantagens, como a compatibilidade dos métodos e a redução de aproximações. Com isso, este trabalho tem como principal objetivo o desenvolvimento e comparação de soluções numéricas para o problema de domínios enrijecidos, no âmbito do MEC aplicado a problemas bidimensionais. Os enrijecedores foram considerados como elementos de treliça, sendo realizado inicialmente na sua forma mais usual, modelando-os por meio do MEF. A seguir foi implementada nova formulação para o acoplamento, na qual os enrijecedores são modelados por meio do MEC 1D. A implementação do MEC 1D foi validada pela comparação de resultados com soluções analítica e do programa computacional FTOOL. No caso do acoplamento, os resultados de ambas formulações foram comparados com resposta do programa computacional ANSYS. Foram avaliados quatro exemplos, sendo dois isotrópicos e dois anisotrópicos. Foram aplicadas diferentes condições de carregamentos, apoios e materiais, sendo utilizadas diversas discretizações e graus de aproximação nos enrijecedores. Verificou-se os efeitos da mudança do grau de aproximação, mantendo-se constante o número de graus de liberdade. Os resultados obtidos foram similares às respostas do ANSYS, foram mecanicamente equivalentes, não havendo diferença relevante em custo computacional. O acoplamento com o MEC 1D levou a resultados estáveis e, em geral, melhores do que com o MEF. No caso de aproximação quadrática, o acoplamento com o MEF frequentemente levou a resultados instáveis. Com o aumento do grau de aproximação, os resultados de ambos métodos se aproximam, se tornando muito próximos com aproximação do quarto grau. Verificou-se que próximo às pontas dos enrijecedores ocorrem concentrações de tensão, havendo maior influência da discretização e grau de aproximação adotado nestas áreas.

Palavras-chave: MEC. MEC 1D. Acoplamento MEC/MEF. Acoplamento MEC/MEC 1D. Meios enrijecidos. Modelagem de enrijecedores. 



\begin{abstract}
BUFFON, L. P. Boundary Element Method formulations for non-homogeneous reinforced plane domains mechanical analysis. 2018. 146 p. Dissertation (M. Sc. in Civil Engineering (Structures)) - Department of Structural Engineering, São Carlos School of Engineering, University of São Paulo, São Carlos, 2018.
\end{abstract}

The reinforced materials are commonly encountered in engineering applications, as in the construction of airplanes, vehicles, ships and general manufactures. In Civil Engineering, the reinforced concrete and the reinforced soil are examples of reinforced materials. The solution of this kind of problem can be found by the use of numerical methods as the Finite Element Method (FEM) and the Boundary Element Method (BEM). Particularly, the BEM use in cases with high stress gradients, such as in fracture mechanics problems, is very advantageous. The BEM models infinite domains in a natural way, being largely used in analysis as soil-structure interaction and tunnel modelling. However, as in the BEM only the boundary is discretized, became necessary the use of a numerical coupling to consider the mechanical effect of the stiffeners. For the coupling many numerical methods can be used, in this study it was realized with the FEM and with the BEM in its unidimensional way (BEM 1D). In this context, the coupling BEM/BEM 1D stands out for its advantages, like the compatibility between the methods and the reduction of approximations. Therefore, the main objective of this study is the development and the comparison of numerical solutions for reinforced media problems, considering the framework of the bidimensional BEM problems. The coupling was implemented considering the stiffeners as truss elements, initially it was implemented in the most usual way, by modelling the stiffeners through the FEM. In the following, a new coupling formulation was proposed, in which the stiffeners are modelled through the BEM 1D method. The BEM 1D implementation was validated by comparing the results with analytical and numerical solutions, the last one obtained with the software FTOOL. Both coupling strategies were compared with the solution obtained by the software ANSYS. Four examples were evaluated, with two isotropic and two anisotropic domains. Different boundary conditions, supports and materials were applied, as many discretization and the approximation degree of the stiffeners were tested. The effects of changing the approximation degree in both coupling strategies keeping the degrees of freedom constant were analysed. The results obtained with the implemented algorithms were mechanically coherent, and they were similar to ANSYS results. For all examples, there is no significant computational costs differences between the two coupling strategies. However, the coupling with the BEM 1D leaded to more stable results and better approximations. It was observed that the MEF results were instable for many results, mainly in the quadratic approximations. When the approximation degree rises, the methods tend to converge to equivalent results, becoming very close in fourth degree approximation. Lastly, it was observed stress concentration in the stiffeners ends. In these regions, the discretization and the approximation degree have large influence to the numerical response.

Keywords: BEM. BEM/FEM coupling. BEM/BEM 1D coupling. Reinforced media. Stiffners modelling. 



\author{
ABREVIAÇÕES \\ EPT - Estado Plano de Tensões \\ MEC - Método dos Elementos de Contorno \\ MEC 1D - Método dos Elementos de Contorno Unidimensional \\ MEF - Método dos Elementos Finitos \\ MEC/MEF - Acoplamento entre o MEC e o MEF \\ MEC/MEC 1D - Acoplamento entre o MEC e o MEC 1D \\ MSS - Método de Subtração de Singularidade \\ PFH - Parte Finita de Hadamart \\ PTV - Princípio dos Trabalhos Virtuais \\ PVC - Problema de Valor de Contorno \\ VPC - Valor Principal de Cauchy
}





\section{LISTA DE FIGURAS}

Figura 1. Costado de navio - Iongarinas e cavernas funcionam como enrijecedores

Figura 2. Fuselagem de avião, vigas e cavernas funcionam como enrijecedores

Figura 3. Armação de laje de concreto protendido.

Figura 4. Esquema da presença de tirantes no solo para suporte de contenção

Figura 5. Estrutura de solo reforçado.

Figura 6. Funçoes de forma linear (à esquerda) e quadrática (à direita)

Figura 7. Separação de núcleo singular. .50

Figura 8. Configuração do elemen to reto a uxiliar - coordenadas adimensionais .

Figura 9. Configuração de el emento reto auxiliar, setas indicam o sentido de integração.

Figura 10. Acoplamento MEC/MEF 55

Figura 11. Elemento com força normal distribuída de forma linear. 65

Figura 12. Resposta do MEC 1D - Força distribuída de forma linear 67

Figura 13. Resposta do MEC 1D - Força distribuída de forma quadrática 69

Figura 14. Resposta do MEC 1D, 41 nós - Força distribuída de forma quadrática .70

Figura 15. Treliça formada por 3 elementos .71

Figura 16. Modelo e sua deformada gerados no programa computacional Ftool. 72

Figura 17. Modelo e Forças Normais gerados no programa computacional Ftool .73

Figura 18. Modelo de painel com enrijecedores (medidas em cm, carregamentos em kN/m) - Exemplo 1 ........75

Figura 19. Model o no ANSYS - Exemplo 1.

Figura 20. Deslocamentos na direção x - Acoplamento Ex. 1, discretização.

Figura 21. Deslocamentos na direção y-Acoplamento Ex. 1, discretização.

Figura 22. Reações de apoio na direção x - Acoplamento Ex. 1, discretização. .78

Figura 23. Reações de apoio na direção y - Acoplamento Ex. 1, discretização......

Figura 24. Deslocamentos em x na fibra inferior - Acoplamento Ex. 1, discretização.

Figura 25. Deslocamentos em y na fibra inferior - Acoplamento Ex. 1, discretização.

Figura 26. Forças normais na fibra inferior - 23 nós - Acoplamento Ex. 1, discretização. .80

Figura 27. Forças normais na fibra inferior - 51 nós - Acoplamento Ex. 1, discretização. 
Figura 28. Forças normais na fibra inferior - 111 nós - Acoplamento Ex. 1, discretização.

Figura 29. Deslocamentos em x na fibra intermediária - Acoplamento Ex. 1, discretização.

Figura 30. Deslocamentos em y na fibra intermediária - Acoplamento Ex. 1, discretização.

Figura 31. Forças normais na fibra intermediária - 23 nós - Acoplamento Ex. 1, discretização.

Figura 32. Forças normais na fibra intermediária - 51 nós - Acoplamento Ex. 1, discretização.

Figura 33. Forças normais na fibra intermediária - 111 nós - Acoplamento Ex. 1, discretização

Figura 34. Deslocamentos em $x$ na fibra superior - Acoplamento Ex. 1, discretização.

Figura 35. Deslocamentos em y na fibra superior - Acoplamento Ex. 1, discretização

Figura 36. Forças normais na fibra superior - 23 nós - Acoplamento Ex. 1, discretização .85

Figura 37. Forças normais na fibra superior - 51 nós - Acoplamento Ex. 1, discretização

Figura 38. Forças normais na fibra superior - 111 nós - Acoplamento Ex. 1, discretização.....

Figura 39. Deslocamentos na direção x - Acoplamento Ex. 1, grau de aproximação......

Figura 40. Deslocamentos na direção y - Acoplamento Ex. 1, grau de aproximação

Figura 41. Reações de apoio na direção x - Acoplamento Ex. 1, grau de aproximação.

Figura 42. Reações de a poio na direção y -Acoplamento Ex. 1, grau de aproximação

Figura 43. Deslocamentos em x na fibra inferior - Acoplamento Ex. 1, grau de aproximação

Figura 44. Deslocamentos em y na fibra inferior - Acoplamento Ex. 1, grau de aproximação

Figura 45. Forças normais na fibra inferior - Grau 2 - Acoplamento Ex. 1, grau de aproximação

Figura 46. Forças normais na fibra inferior - Grau 3 - Acoplamento Ex. 1, grau de aproximação

Figura 47. Forças normais na fibra inferior - Grau 4 - Acoplamento Ex. 1, grau de aproximação 90

Figura 48. Deslocamentos em x na fibra intermediária - Acoplamento Ex. 1, grau de aproximação .91

Figura 49. Deslocamentos em y na fibra intermediária - Acoplamento Ex. 1, grau de aproxima ção..... .91

Figura 50. Forças normais na fibra intermediária - Grau 2 - Acoplamento Ex. 1, grau de a proximação.

Figura 51. Forças normais na fibra intermediária - Grau 3 - Acoplamento Ex. 1, grau de a proximação.

Figura 52. Forças normais na fibra intermediária - Grau 4 - Acoplamento Ex. 1, grau de aproximação.

Figura 53. Deslocamentos em x na fibra superior - Acoplamento Ex. 1, grau de aproximação.

Figura 54. Deslocamentos em y na fibra superior - Acoplamento Ex. 1, grau de aproximação. .93

Figura 55. Forças normais na fibra superior - Grau 2 - Acoplamento Ex. 1, grau de aproximação .94

Figura 56. Forças normais na fibra superior - Grau 3 - Acoplamento Ex. 1, grau de aproximação 
Figura 58. Deslocamentos na direção x-Acoplamento Ex.2

Figura 59. Deslocamentos na direção y - Acoplamento Ex.2

Figura 60. Reações de apoio na direção x - Acoplamento Ex.2

Figura 61. Reações de apoio na direção y -Acoplamento Ex.2

Figura 62. Deslocamentos em $x$ na fibra inferior - Acoplamento Ex.2

Figura 63. Deslocamentos em y na fibra inferior - Acoplamento Ex.2

Figura 64. Forças normais na fibra inferior - Grau 2 - Acoplamento Ex.2

Figura 65. Forças normais na fibra inferior - Grau 3 - Acoplamento Ex.2

Figura 66. Forças normais na fibra inferior - Grau 4 - Acoplamento Ex.2 100

Figura 67. Deslocamentos em x na fibra intermediária - Acoplamento Ex.2 . .100

Figura 68. Deslocamentos em y na fibra intermediária - Acoplamento Ex.2

Figura 69. Forças normais na fibra intermediária - Grau 2 -Acoplamento Ex.2 .101

Figura 70. Forças normais na fibra intermediária - Grau 3 - Acoplamento Ex.2 .102

Figura 71. Forças normais na fibra intermediária - Grau 4-Acoplamento Ex.2

Figura 72. Deslocamentos em x na fibra superior - Acoplamento Ex.2

Figura 73. Deslocamentos em y na fibra superior - Acoplamento Ex.2 .103

Figura 74. Forças normais na fibra superior - Grau 2 - Acoplamento Ex.2...... .104

Figura 75. Forças normais na fibra superior - Grau 3 - Acoplamento Ex.2.

Figura 76. Forças normais na fibra superior - Grau 4-Acoplamento Ex.2 104

Figura 77. Modelo anisotrópico com enrijecedor (medidas em cm, carregamentos em kN/m) - Exemplo 3.....106

Figura 78. Model o no ANSYS - Exemplo 3.

Figura 79. Deslocamentos na direção x - Acoplamento Ex.3

Figura 80. Deslocamentos na direção y - Acoplamento Ex.3 .108

Figura 81. Reações de apoio na direção x - Acoplamento Ex.3

Figura 82. Reações de apoio na direção y - Acoplamento Ex.3

Figura 83. Deslocamentos em x na fibra - Acoplamento Ex.3 .110

Figura 84. Deslocamentos em y na fibra - Acoplamento Ex.3

Figura 85. Forças normais na fibra - 21 nós / Grau 2 - Acoplamento Ex.3 
Figura 86. Forças normais na fibra - 21 nós / Grau 3 - Acoplamento Ex.3.

Figura 87. Forças normais na fibra - 21 nós / Grau 4 - Acoplamento Ex.3 …....................................................112

Figura 88. Forças normais na fibra - 41 nós / Grau 2 - Acoplamento Ex.3 ….....................................................112

Figura 89. Forças normais na fibra - 41 nós / Grau 3 - Acoplamento Ex.3 …....................................................113

Figura 90. Forças normais na fibra - 41 nós / Grau 4 - Acoplamento Ex.3 ….......................................................113

Figura 91. Modelo anisotrópico com inclusões (hachuradas) e condições adversas (medidas em cm, carregamentos em $\mathrm{kN} / \mathrm{m}$ ) - Exemplo 4

Figura 92. Modelo no ANSYS - Exemplo 4

Figura 93. Detalhe da inclusão isotrópica no ANSYS - Exemplo 4

Figura 94. Deslocamentos na direção x - Acoplamento Ex.4

Figura 95. Deslocamentos na direção y - Acoplamento Ex.4.

Figura 96. Reações de apoio na direção x-Acoplamento Ex.4

Figura 97. Reações de apoio na direção y - Acoplamento Ex.4

Figura 98. Deslocamentos em $x$ na fibra inferior - Acoplamento Ex.4

Figura 99. Deslocamentos em y na fibra inferior - Acoplamento Ex.4

Figura 100. Forças normais e forças de aderência na fibra inferior - Grau 2 - Acoplamento Ex.4

Figura 101. Forças normais e forças de aderência na fibra inferior - Grau 4 - Acoplamento Ex.4 120

Figura 102. Deslocamentos em $x$ na fibra superior - Acoplamento Ex.4 .120

Figura 103. Deslocamentos em y na fibra superior - Acoplamento Ex.4

Figura 104. Forças normais na fibra superior - Grau 2 - Acoplamento Ex.4

Figura 105. Forças normais na fibra superior - Grau 4 - Acoplamento Ex.4 


\section{SUMÁRIO}

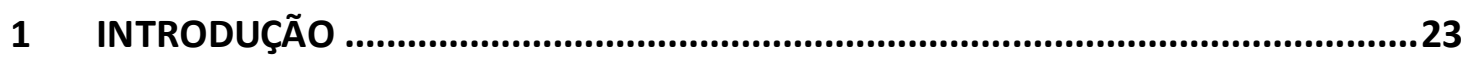

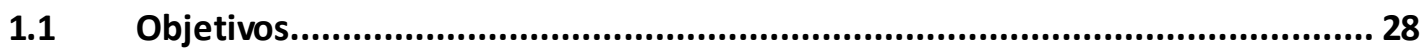

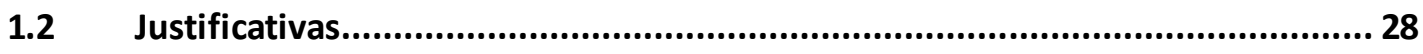

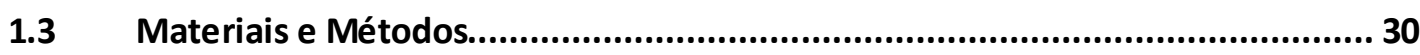

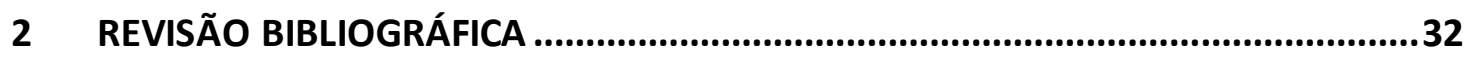

2.1 Breve histórico do desenvolvimento do MEC ....................................................32

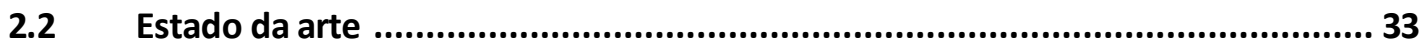

2.2.1 Método dos Elementos de Contorno (MEC) .....................................................................33

2.2.2 Acoplamento do MEC a outros métodos numéricos ......................................................35

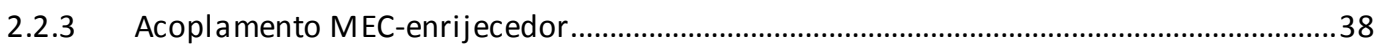

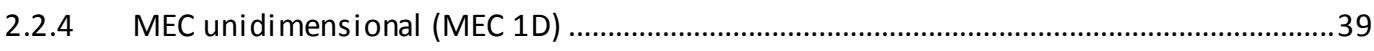

3 MÉTODOS NUMÉRICOS ..........................................................................41

3.1 Método dos Elementos Finitos ........................................................................ 41

M.2 Método dos Elementos de Contorno ............................................... 45

3.2.1 Solução Fundamental de Kelvin - Meio Isotrópico........................................................... 49

3.2.2 Método de Sub tração de Singularidade (MSS) - Meio Isotrópico.......................................50

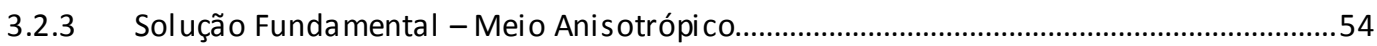

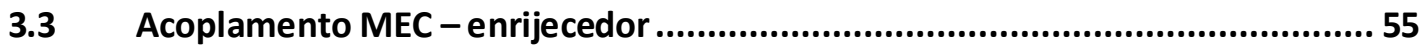

3.4 Método dos Elementos de Contorno Unidimensional (MEC 1D) ...................... 57

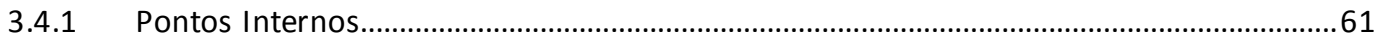

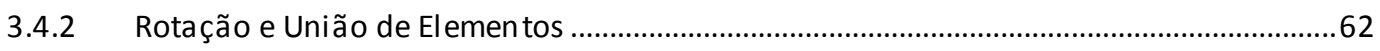

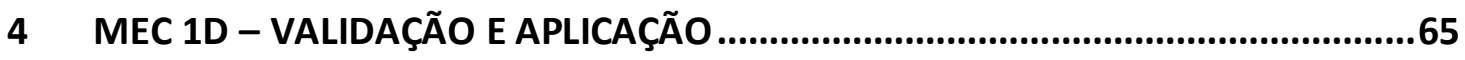

4.1 MEC 1D - Exemplo 1: Elemento com força distribuída linear............................65 65

4.2 MEC 1D - Exemplo 2: Elemento com força distribuída quadrática ...................... 68

4.3 MEC 1D - Exemplo 3: União e Rotação de elementos ....................................... 71 


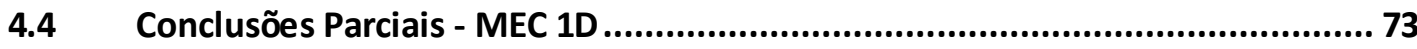

5 ACOPLAMENTO MEC/FIBRA - VALIDAÇÃO E APLICAÇÃO ...................................74

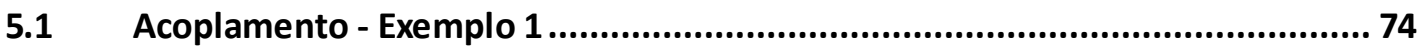

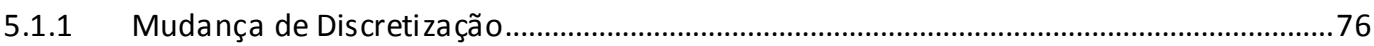

5.1.2 Mudança Grau de Aproxima ção ……….............................................................................86

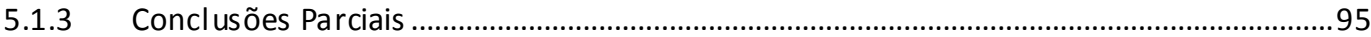

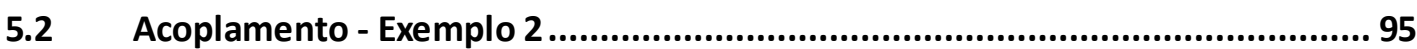

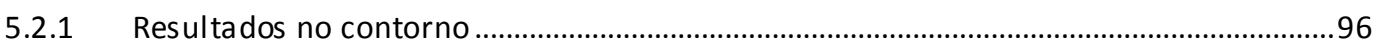

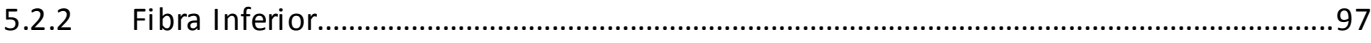

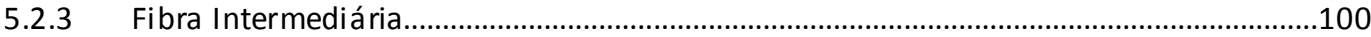

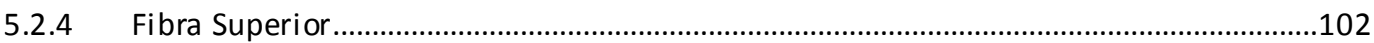

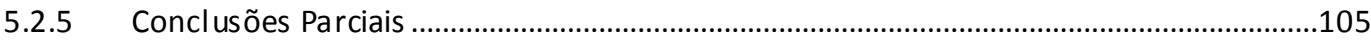

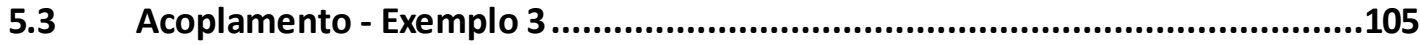

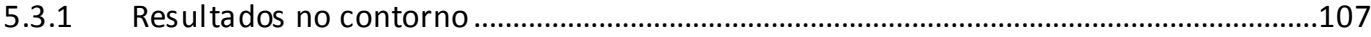

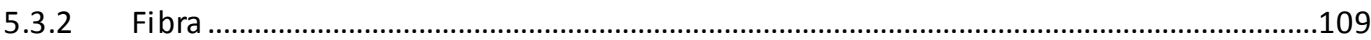

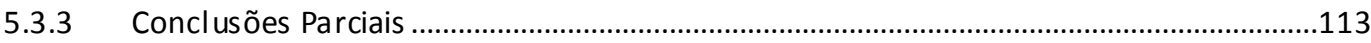

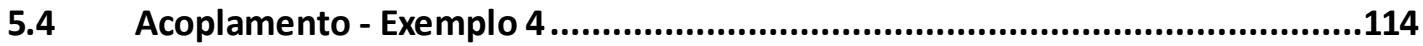

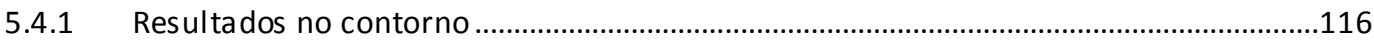

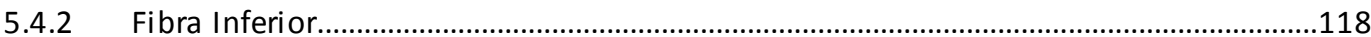

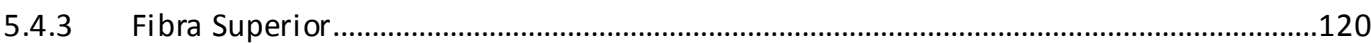

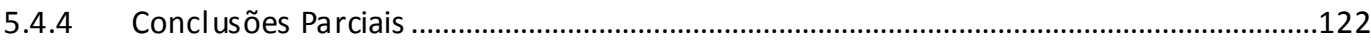

6 CONSIDERAÇÕES FINAIS ..................................................................................123

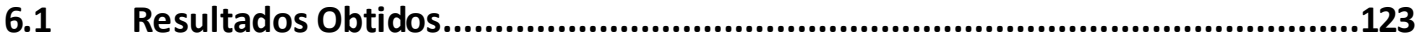

$6.2 \quad$ Conclusões dos Resultados....................................................................124

6.3 Sugestões para pesquisas futuras.............................................................124

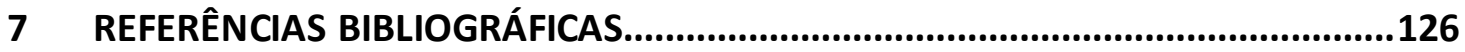

A. APÊNDICE A - CONCEITOS FUNDAMENTAIS ...............................................133

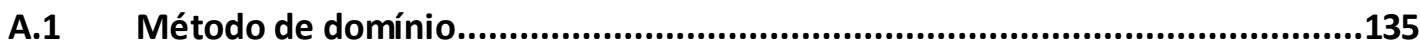




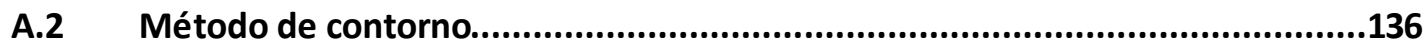

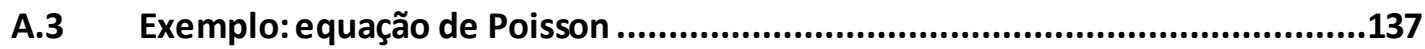

B. APÊNDICE B - TEORIA DA ELASTICIDADE LINEAR .........................................140

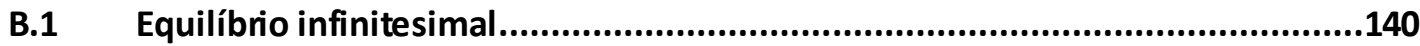

B.2 Relação Constitutiva - Caso Geral .................................................................141

B.3 Relação constitutiva - Material Isotrópico..................................................142

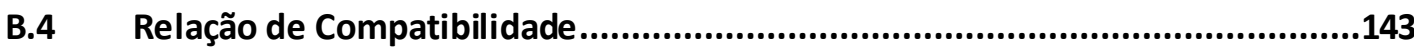

B.5 Equações de Equilíbrio em Deslocamentos (Equações de Navier) ......................143

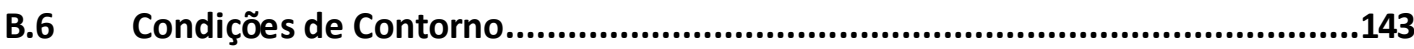

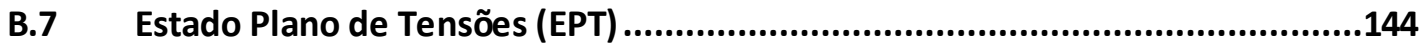

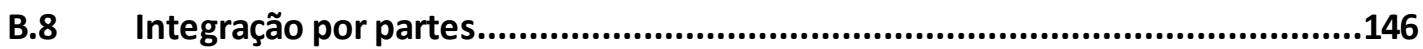





\section{INTRODUÇÃO}

Em um domínio bidimensional, enrijecedor pode ser definido como um elemento linear inserido em um material com o objetivo de melhorar suas propriedades mecânicas. Consequentemente, o domínio do material passa então a ser considerado enrijecido. O uso de enrijecedores pode ser determinante para a viabilidade para a construção da estrutura. Mesmo nos casos onde não é essencial, o uso de enrijecedores pode ser interessante como uma forma de gerar redução de gasto de material, e consequente redução de custos.

Em diversas aplicações de engenharia de estruturas observa-se a presença de domínios enrijecidos, uma vez que esse tipo de estrutura permite o projeto de componentes estruturais mecanicamente eficientes. São exemplos de domínios enrijecidos costados de navios (Figura 1) e a fuselagem de aviões (Figura 2). Chapas de aço suportam pressão e enrijecedores de aço dão rigidez à estrutura, podendo ser entendidas como reforços, formando painéis reforçados.

Figura 1. Costado de navio - longarinas e cavernas funcionam como enrijecedores

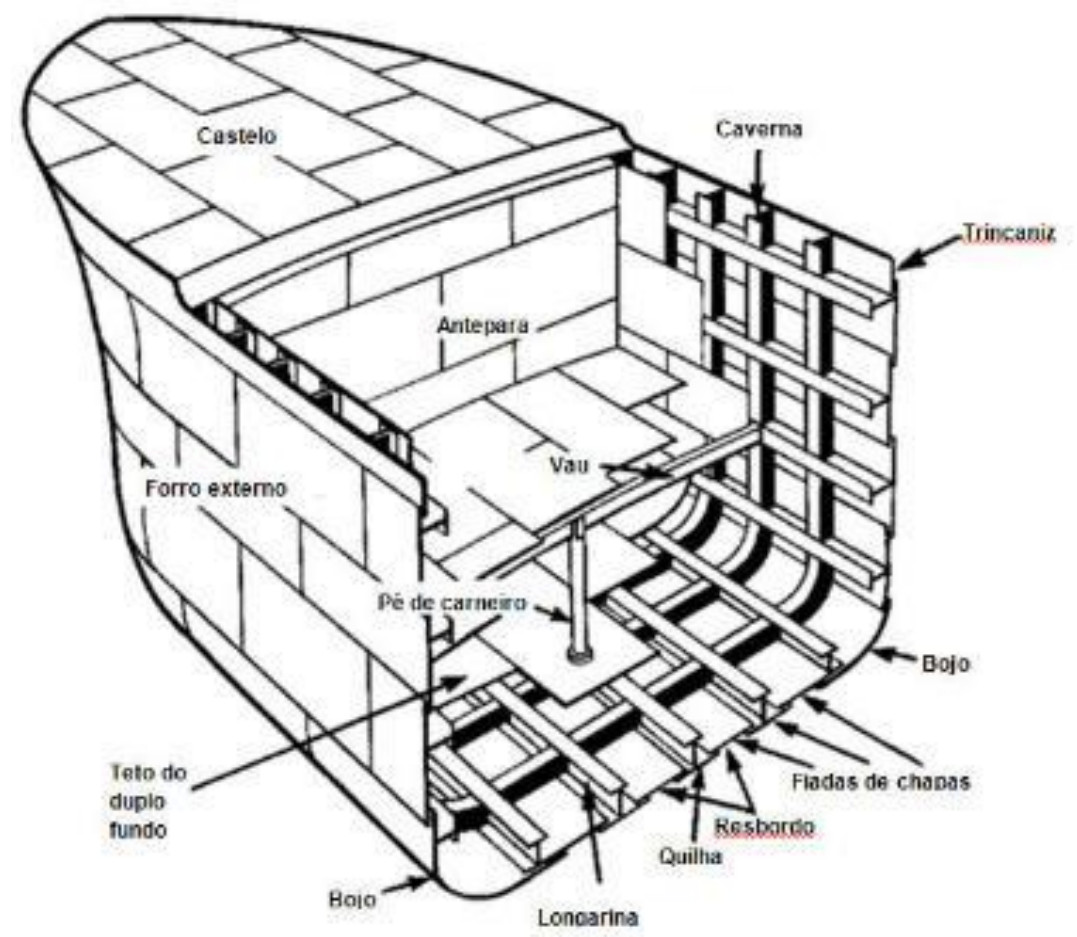

FONTE: Site de empresa ${ }^{1}$

\footnotetext{
${ }^{1}$ Elementos estruturais de navios (arranjo e nomenclatura) - Construção Naval 1. Acesso em 16 de setembro de 2016, disponível em: http://www.ebah.com.br/content/ABAAAe6xgAI/elementos -estruturais-navios-arranjonomeclatura-construcao-naval-1?part=2
} 
Figura 2. Fuselagem de avião, vigas e cavernas funcionam como enrijecedores

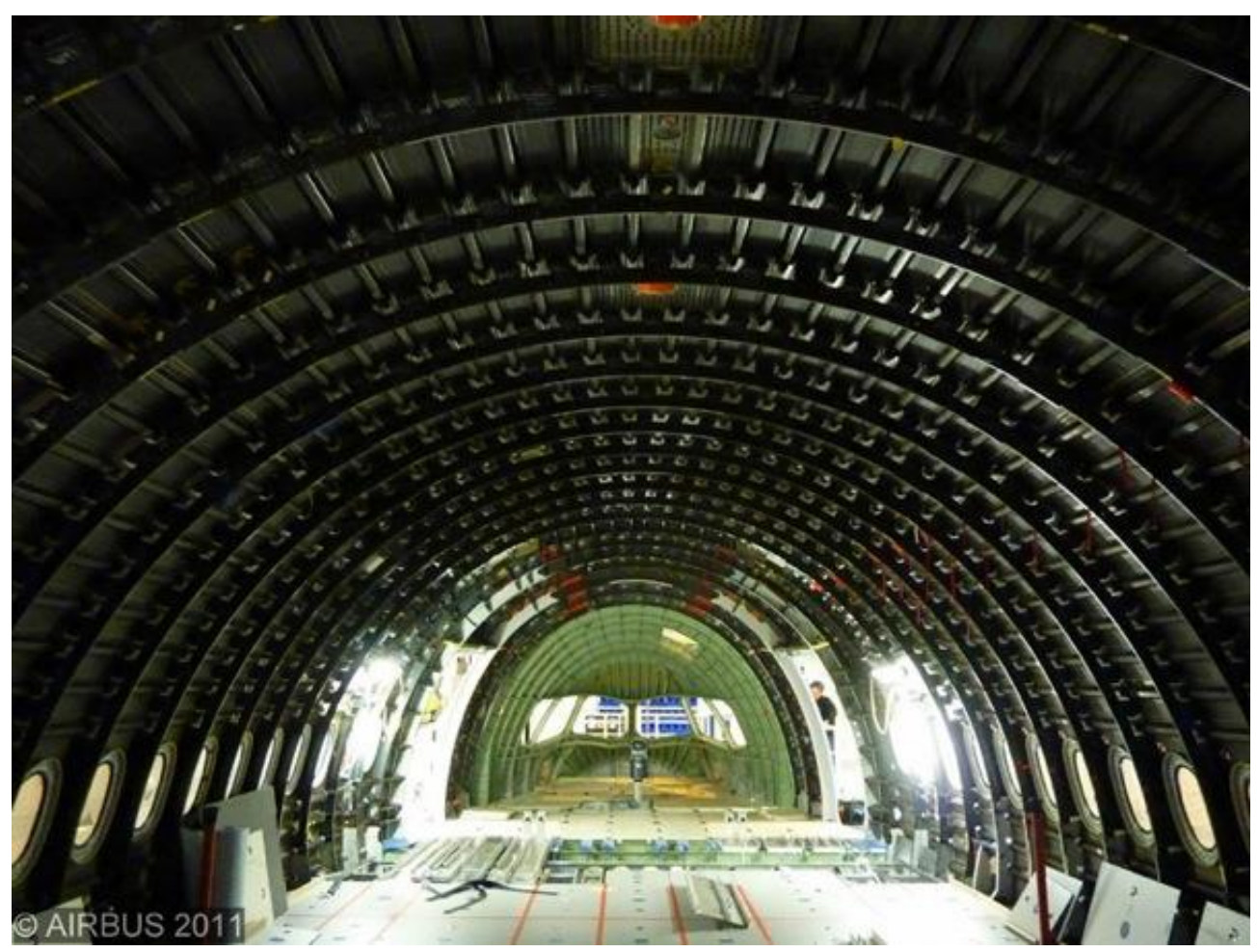

FONTE: Site de empresa ${ }^{2}$

Diversos materiais de uso generalizado na engenharia são de certa forma enrijecidos, como exemplo o caso do concreto armado e protendido (Figura 3), as armaduras passiva e ativa podem ser entendidas como enrijecedores dentro do meio, que nesse caso é o concreto.

\footnotetext{
${ }^{2}$ Aeronaves. Acesso em 16 de setembro de 2016, disponível em: http://rsbals.weebly.com/aeronaves.html
} 
Figura 3. Armação de laje de concreto protendido.

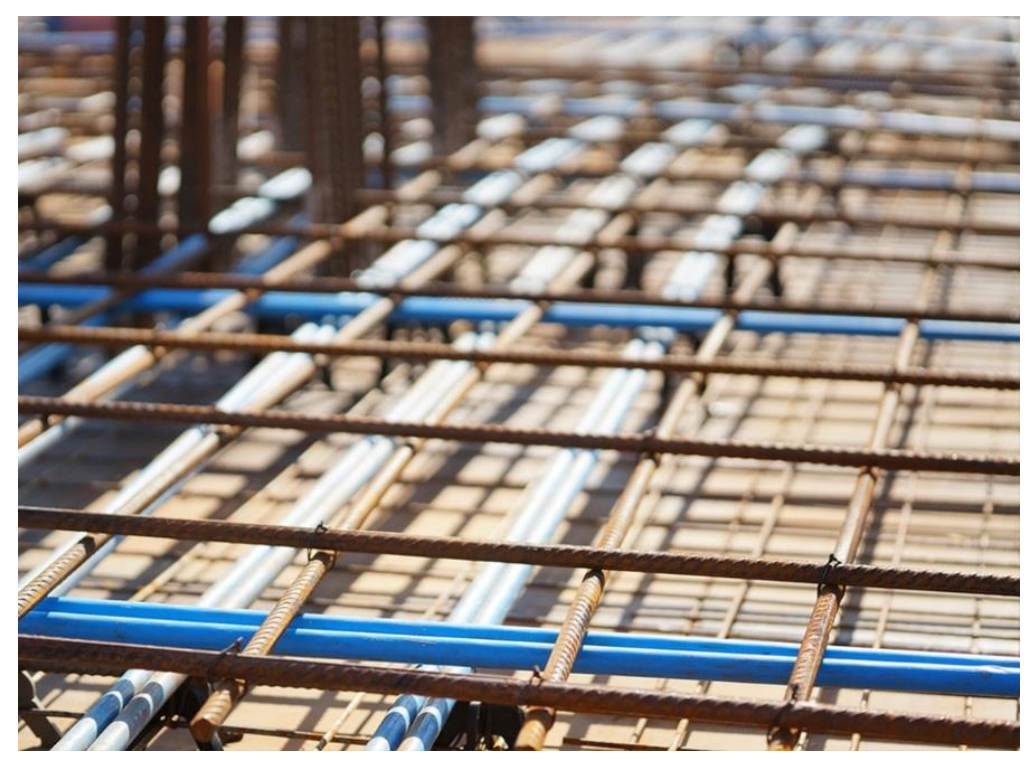

Fonte: Site de empresa ${ }^{3}$

Outra aplicação de domínios enrijecidos envolve a modelagem mecânica do solo. Essa modelagem é comumente realizada utilizando o Método dos Elementos de Contorno (MEC), uma vez que este realiza de forma eficiente a consideração de meio infinito. São exemplos de aplicações geotécnicas o uso de tirantes e estruturas de reforço do solo (Figura 4 e Figura 5 respectivamente).

3 Lorenzini Protensão. (2014). Acesso em 20 de outubro de 2014, disponível em http://www.lorenziniprotensao.eng.br/protensao-nao-aderente/ 
Figura 4. Esquema da presença de tirantes no solo para suporte de contenção

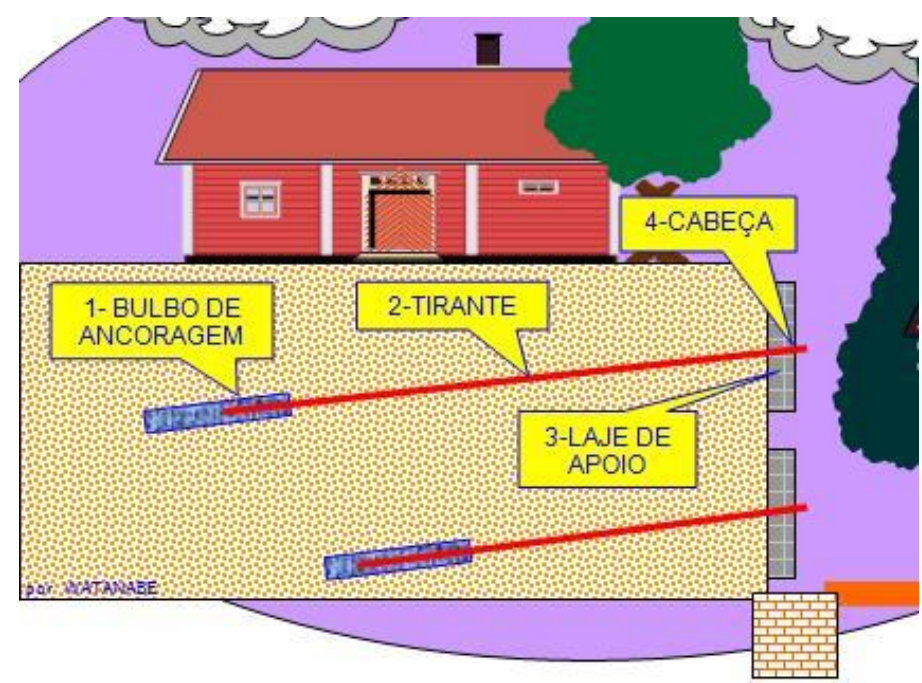

Fonte: Site de empresa ${ }^{4}$

Figura 5. Estrutura de solo reforçado

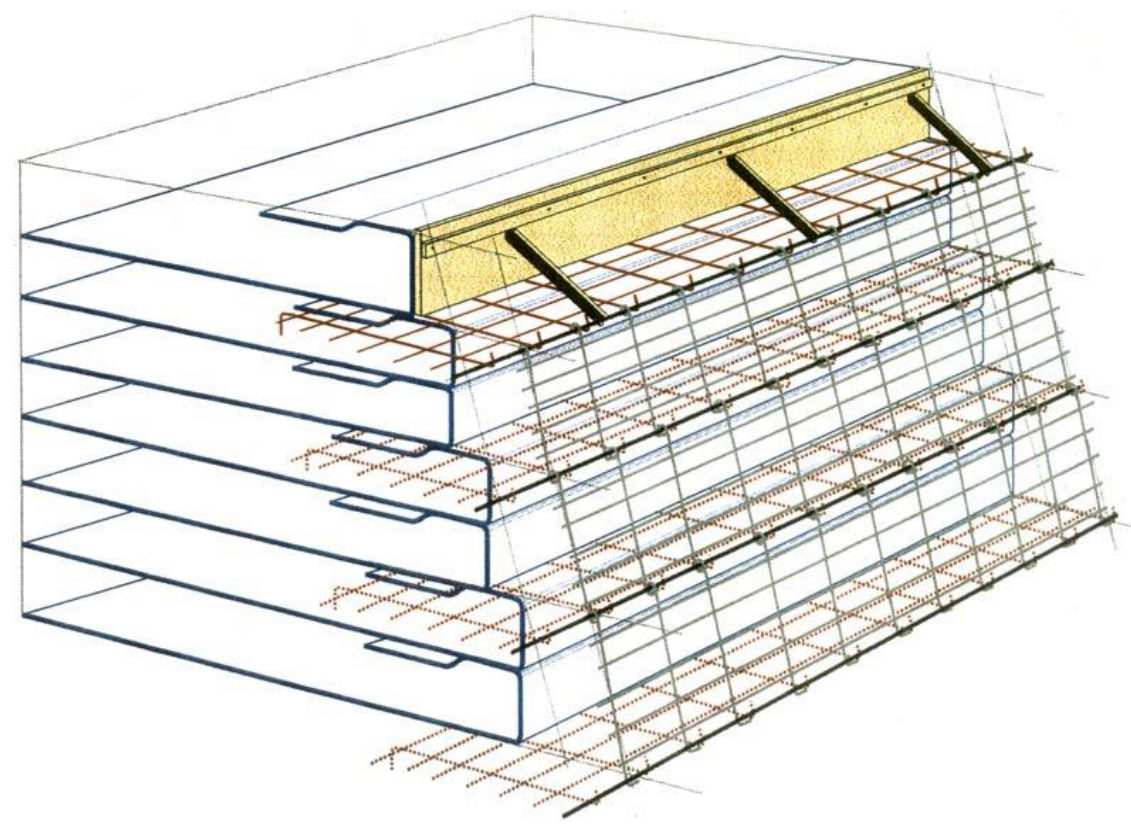

Fonte: Site de empresa ${ }^{5}$

4 Talude atirantado. (2014). Acesso em 23 de outubro de 2014, disponível em http://www.ebanataw.com.br/talude/caso8.htm

${ }^{5}$ Muro de solo reforçado com geossintéticos e face de gabião contínuo MPZ. (2014). Acesso em 23 de outubro de 2014, disponível em MPZ aplicações tecnológicas Ltda.: http://www.ebanataw.com.br/talude/caso8.htm 
Destacada a importância da análise mecânica de domínios enrijecidos, diversos trabalhos presentes na literatura buscam alternativas para encontrar sua solução e melhor representatividade. As equações governantes do problema a ser resolvido se apresentam na forma de equações diferenciais, resolvidas de forma analítica ou numérica. No entanto, a análise do comportamento conjunto de materiais de propriedades mecânicas distintas pode apresentar grande complexidade. No caso de domínios enrijecidos, por exemplo, são utilizados elementos estruturais que são modelados de formas diferentes, tais como placas com treliças ou cascas com vigas. Soluções analíticas são limitadas a casos restritos, demandando diversas simplificações, e por esse motivo são de restrita utilização.

Com o grande crescimento dos recursos relacionados à capacidade de processamento computacional ocorrida nos últimos anos, soluções numéricas ganharam grande destaque. Com este crescimento, expandiu-se o uso de programas computacionais (soluções numéricas) para o dimensionamento de estruturas. No cotidiano da engenharia, o uso dos programas computacionais permite análise mais consistente de problemas, resultando na adoção de solução com maior segurança e, comumente, menor custo. Dessa forma, a análise do comportamento estrutural de domínios enrijecidos pode ser realizada de forma mais consistente utilizando a estratégia da modelagem numérica.

Diversos métodos envolvem a busca de soluções aproximadas para o chamado Problema de Valor de Contorno (PVC). Este consiste em uma equação diferencial com condições de contorno impostas em forma essencial (por exemplo, deslocamentos) ou em forma natural (como no caso de tensões). Dentre os métodos, destaca-se o uso do Método dos Elementos Finitos (MEF), amplamente utilizado atualmente tanto em programas computacionais de uso acadêmico quanto comercial. No MEF é realizada aproximação da resposta no domínio ou subdomínio de um problema com o uso de base de funções polinomiais. De forma a obter a resposta para problemas complexos, os domínios destes são discretizados em subdomínios (chamados de elementos finitos), sob os quais as aproximações polinomiais são isoladamente impostas, utilizando o método separadamente em cada um destes elementos. A formulação do MEF pode ser obtida pela minimização dos funcionais de energia, ou pela integração por partes da função resíduo ponderada pela função peso, resultando nas abordagens de métodos de Raleigh-Ritz e Galerkin, respectivamente. A utilização do MEF permite a resolução simples, e com adequada aproximação, de uma ampla gama de problemas matemáticos, físicos e de engenharia descritos pelo PVC, como: modelagem da deformação de meios contínuos, do processo de condução de calor, escoamento de fluídos e eletrostática. 
Outro método numérico de destaque é o Método dos Elementos de Contorno (MEC), que tem como característica a discretização em elementos somente do contorno, sendo realizada aproximação e integração somente nestes. Isso resulta em redução da dimensionalidade da malha, e, frequentemente, redução do tempo de processamento. Por possuir aproximações somente no contorno, no MEC os resultados para o domínio são obtidos por meio de pósprocessamento, satisfazendo a equação governante de forma exata. Pelo fato de a solução para o domínio ser exata, o uso deste método se torna muito vantajoso em casos onde se tem grandes gradientes de tensão, como em problemas da mecânica da fratura. O método se destaca também pela facilidade de modelagem de meios infinitos, sendo realizada de forma mais eficiente que por métodos que envolvem integração no domínio.

No caso específico da modelagem de domínios enrijecidos utilizando o MEC, uma vez que somente o contorno é discretizado, para que seja analisada a presença de enrijecedores dentro do domínio se torna necessário o uso de um acoplamento auxiliar. Tradicionalmente os enrijecedores são modelados por meio do MEF, entretanto também é possível modelá-los por meio de outros métodos, sendo utilizado para isto neste trabalho o próprio MEC na sua forma unidimensional (MEC 1D). Nessa forma, o contorno passa a ser os nós extremos do elemento, sendo encontrada então primeiramente a solução para esses nós para em seguida obter-se por pós-processamento o resultado para os nós internos do elemento, sem aproximações.

\subsection{Objetivos}

O objetivo do presente trabalho foi o desenvolvimento de modelos numéricos baseados no MEC para a análise mecânica de domínios enrijecidos. Na modelagem dos enrijecedores, imersos em meio definido pelo MEC, buscou-se utilizar tanto o MEF, já presente na literatura, quanto o MEC 1D, tratando-se de nova formulação.

Foi foco do trabalho o desenvolvimento e implementação da formulação do MEC 1D. Objetivou-se realizar o acoplamento do MEC com o MEF e o MEC 1D para elementos de grau de aproximação qualquer, avaliando-se tanto para meio isotrópico quanto anisotrópico. Além disso, um objetivo complementar foi verificar os efeitos da adoção de diferentes discretizações e graus de aproximação nos enrijecedores.

\subsection{Justificativas}

Dada uma estrutura qualquer, busca-se encontrar a solução de seu problema mecânico, da forma mais precisa e eficiente possível. Dentro dessa condição o MEC se mostra robusto e seu desenvolvimento promissor, se destacando na análise de casos com ocorrência de grandes 
gradientes de tensão, como em problemas da mecânica da fratura. Além disso, no MEC a modelagem de meios infinitos é realizada de forma natural, sem a utilização de aproximações. No caso de métodos que envolvam integração no domínio, como o MEF, isto não é possível, sendo normalmente adotados modelos com elevado número de elementos e consideradas suas extremidades como apoios flexíveis.

Diante do exposto, ressalta-se a relevância do MEC na análise numérica de estruturas. Contudo, como no MEC é discretizado apenas o contorno, a solução de problemas de domínio não homogêneo, por exemplo o caso de enrijecedores, necessita de atenção especial na modelagem. Por outro lado, a análise de domínios enrijecidos possui relevância internacional, uma vez que suas aplicações envolvem uma ampla gama de áreas da engenharia, como aeronáutica, naval, geotécnica e estruturas civis.

O desenvolvimento um modelo numérico preciso e computacionalmente eficiente para análise de domínios enrijecidos permite prever adequadamente o comportamento de estruturas que utilizam tais materiais. Adicionalmente, tais modelos também possibilitam o dimensionamento racional da quantidade de enrijecedores necessárias, além de ser possível determinar cargas de colapso da estrutura com maior realismo. Tudo isso gera tanto a redução de custos, como também a viabilidade do projeto de estruturas complexas. Destaca-se que na análise desse tipo de problemas não se observa a existência de diretrizes normativas detalhando o tratamento a ser dado.

No caso específico da análise de domínios enrijecidos pelo MEC, é necessário que o enrijecedor presente no interior do domínio também seja modelado. Usualmente tal modelagem é efetuada com o acoplamento MEC/MEF (o primeiro aproximando o domínio, e o segundo discretizando o enrijecedor). No entanto, outra alternativa é a utilização do MEC 1D para a modelagem do enrijecedor. Tal estratégia resulta em um modelo inovador, simples e com resultados muitas vezes superiores ao acoplamento MEC/MEF, uma vez que o acoplamento MEC/MEC 1D tem por vantagem utilizar a mesma base matemática, ocorrendo de forma mais natural.

Por fim, o desenvolvimento desse trabalho se justifica pela contribuição na continuação da linha de pesquisa sobre desenvolvimento do Métodos Elementos de Contorno no Departamento de Estruturas da USP São Carlos (SET). Diversas outras abordagens e formulações do MEC já estão implementadas e validadas em código FORTRAN, sendo desenvolvidas e utilizadas de forma cooperativa pelo grupo de pesquisa. Os códigos desenvolvidos são então agregados ao código do grupo, provendo novas funcionalidades e possibilitando seu uso em pesquisas futuras. Além disso, os conceitos aprendidos no 
desenvolvimento do trabalho resultam em grande contribuição para formação do aluno em um tema de grande relevância na engenharia, observando-se carência de profissionais nesta área de estudo.

\subsection{Materiais e Métodos}

Em primeiro lugar, foi realizada extensa revisão bibliográfica, sendo facilitada pelas disciplinas cursadas pelo aluno no departamento de estruturas, principalmente a disciplina Introdução do Método dos Elementos de Contorno. Os métodos foram formulados partindo-se de suas bases matemáticas por meio do conceito de forma fraca do problema, foi possível notar dessa forma inclusive similaridades entre eles.

Foi considerada análise linear em regime de pequenos deslocamentos e deformações, no caso do estudo de meios enrijecidos estes foram avaliados tanto para caso de domínio isotrópico quanto anisotrópico. Foi avaliado o acoplamento para o caso de enrijecedores completamente inseridos em domínio modelado pelo MEC, considerando-os como barras de treliça, sem resistência a flexão. Mostrou-se que no acoplamento é indiferente o método a ser utilizado para o enrijecedor, sua modelagem é independente, sendo realizada superposição de efeitos.

Os enrijecedores podem ser modelados tanto por meio do MEF quanto no MEC 1D. De forma a tornar o acoplamento com o MEC 1D o mais compatível possível com o acoplamento com o MEF, buscou-se no desenvolvimento de sua formulação escrevê-lo de forma similar. Uma vez que a interface com o meio se dá por meio do acoplamento de deslocamentos e aproximação de forças distribuídas, buscou-se implementar elementos com possibilidade de aplicação de forças distribuídas de qualquer grau de aproximação.

As formulações são e foram implementadas em código FORTRAN 2003 em computador pessoal e do departamento de estruturas de forma a permitir o acoplamento da formulação junto ao restante do código, já desenvolvido pelo grupo da linha de pesquisa do MEC. A validação dos resultados da formulação do MEC 1D foi realizada analisando-se exemplos com diversos carregamentos, além de rotação e união de elementos. Foram comparados os resultados de deslocamentos, forças normais e reações de apoio com soluções analíticas e aquelas fornecidas pelo programa computacional FTOOL, de uso acadêmico. Foram analisados diversos casos de carregamentos, apoios, rotação e união de elementos.

Foi implementado o acoplamento do MEC com o MEF (MEC/MEF) e com o MEC 1D (MEC/MEC 1D) para elementos de grau de aproximação qualquer. Foi então realizada análise 
comparativa com modelos equivalentes construídos no ANSYS, programa computacional comercial consolidado onde é utilizado somente o MEF. Realizado o acoplamento de forma tradicional, ou seja, para o caso de domínio isotrópico, homogêneo e com análise linear em regime de pequenos deslocamentos e deformações, foi efetuada análise considerando-se meio anisotrópico. Foram avaliados diferentes modelos, buscou-se comparar os resultados entre os métodos, entre discretizações e grau de aproximação adotado, indicando possíveis pontos frágeis de cada uma das formulações e perturbações, objetivando-se verificar o que é mais indicado para as diferentes situações. 


\section{REVISÃO BIBLIOGRÁFICA}

\subsection{Breve histórico do desenvolvimento do MEC}

Em (CHENG; CHENG, 2005) é efetuado um levantamento histórico do desenvolvimento do MEC, que será descrito brevemente a seguir. Ao longo das últimas décadas se observa uma evolução do MEC, caracterizado por um grande aumento de publicações nessa área na década de 1990, seguida pela estabilização no começo dos anos 2000 com um número de 700 a 800 artigos por ano. Como medida de comparação, nesse período o número de artigos envolvendo o MEF girou em torno de 5000 e do Método das Diferenças Finitas em torno de 1400 , por ano.

O MEC possui como base a redução da dimensionalidade espacial da sua equação integral. Essa redução é decorrente do teorema de Gauss e previamente pelo teorema do divergente, cujo desenvolvimento pode ser encontrado em trabalhos de Lagrange ${ }^{6}$ e Laplace, em 1760. Em sequência, vale destacar também o trabalho de Green em 1828, que apresentou as chamadas três identidades de Green ${ }^{7}$. Usando a solução fundamental de Laplace, Green conseguiu obter uma formulação (terceira identidade de Green) até hoje utilizada para a solução de problemas potenciais via MEC.

Outros trabalhos de fundamental importância foram realizados por Fredholm, na direção de equações integrais. Em 1903 foi criado o teorema de Fredholm ${ }^{8}$, no qual foi provado que existe apenas uma solução para uma equação integral linear de funções contínuas. Tal solução é usada como base para resolver problemas de Dirichlet e de Neumann de forma analítica. Ainda mesmo no início do século XX, Fredholm já havia proposto um procedimento de solução baseado na discretização do domínio. Contudo, como ainda não existia computador, a ideia proposta era impraticável.

As equações analíticas para a solução do problema potencial apresentavam singularidades fracas e fortes (solução para problema de Dirichlet e Neumann,

\footnotetext{
${ }^{6}$ Lagrange J. Miscellanea Taurinasia, 1760.

${ }^{7}$ Green G. An essay on the application of mathematical analysis to the theories of electricity and magnetism, 1828.

${ }^{8}$ Fredholm I. Sur une classe d'équations fonctionelles. Acta Math, 1903.
} 
respectivamente). Nesse sentido, em 1814, Cauchy ${ }^{9}$ teve contribuição na resolução de integração de funções com singularidade, denotadas como sendo realizadas no sentido de Valor Principal de Cauchy (VPC). No caso de hipersingularidade a integração é realizada por meio da Parte Finita de Hadamart (PFH), introduzida por Jacques Salomon Hadamart ${ }^{10}$ em 1908.

O desenvolvimento de métodos numéricos como o MEF teve grande avanço por volta de 1960, coincidindo com o surgimento dos computadores, fator fundamental para sua difusão por tornar o uso de métodos numéricos altamente eficiente e muitas vezes simples. Quanto ao MEC, um grande avanço foi realizado em sua direção no ano de 1967, com o artigo publicado por Rizzo, chamado 'An integral equation approach to boundary value problems of classical elastostatics', nessa época o nome do método ainda não havia sido definido como é hoje conhecido. O termo MEC surge em 1977, como contraponto ao MEF, pelos trabalhos de Brebbia e Domingue $z^{11}$, Banerjee e Butterfield ${ }^{12}$.

\subsection{Estado da arte}

\subsubsection{Método dos Elementos de Contorno (MEC)}

(BREBBIA, 1978a) apresenta uma classificação para os diferentes métodos numéricos baseados na técnica dos Resíduos Ponderados e de acordo com o tipo de aproximações e funções peso utilizadas. Dentre os métodos numéricos encontra-se o MEC, sendo utilizada a equação de Laplace para ilustrar as comparações. Em (BREBBIA, 1978b) são apresentados os fundamentos dos métodos numéricos baseados no conceito de distribuição de erros (resíduos ponderados), o que resulta nas equações integrais. A partir dessa base, com o uso do teorema de Gauss, é mostrada a origem de métodos de domínio, de contorno e mistos. Deve-se a ele o nome "Método dos Elementos de Contorno", que a partir de então substituiu o que era conhecido como "Método das Equações Integrais".

\footnotetext{
${ }^{9}$ Cauchy, A. L. Mémoire sur les intégrales définies, Mémoires des divers savant, 1814.

${ }^{10}$ Hadamard J. Theorie des équations aux dérivées partielles linéaires hyperboliques et du problème de Cauchy. Acta Math 1908.

${ }^{11}$ Mais detalhes podem ser encontrados em: BREBBIA, C. A.; DOMINGUEZ, J. Boundary element methods for potential problems. Applied Mathematical Modelling, v. 1, n. 7, p. 372-378, 1977.

12 Mais detalhes podem ser encontrados em: BANERJEE, P.K.; BUTTERFIELD, R. Boundary element method in geomechanics. In: GUDEHUS G. (editor). Finite elements in geomechanics. New York: Wiley; 1977.
} 
A formulação do MEC para os problemas de elasticidade linear surge a partir da solução da equação governante para elasticidade, da equação de equilibrio de tensões com uso das relações constitutivas para o caso linear e de compatibilidade para pequenos deslocamentos e deformações. É utilizado o delta de Dirac para eliminar as integrais no domínio, permitindo solução de problemas com integração somente no seu contorno.

$\mathrm{Na}$ análise de materiais compósitos por meio do MEC, (CRUSE; SWEDLOW, 1971) desenvolveram soluções fundamentais para o problema elástico bidimensional anisotrópico. As soluções para o caso tridimensional anisotrópico foram desenvolvidas posteriormente por (WILSON; CRUSE, 1978). Para o caso de análise dinâmica, observa-se este uso em (STAMOS; BESKOS, 1995) onde o MEC foi utilizado para análise dinâmica de estruturas subterrâneas tridimensionais.

Por envolver aproximações somente no contorno dos problemas, o MEC oferece adequadas soluções para mecânica da fratura. Em (LE VAN; ROYER, 1996) é estudado o caso de fratura em meio tridimensional anisotrópico para o caso finito e infinito. Já em (LEONEL, 2006) o MEC é utilizado na análise de corpos multi-fraturados, posteriormente (LEONEL, 2009) apresenta modelos representando o processo de crescimento de fissuras em domínios planos constituídos de materiais frágeis, quase-frágeis e dúcteis, sendo que nos modelos de fratura é utilizada a formulação MEC dual. No trabalho ainda são apresentadas as expressões dos operadores tangente, utilizados em formulações não lineares em problemas de fratura elástico linear e coesiva, problemas de contato e problemas de domínios enrijecidos.

A formulação do MEC dual também é apresentada em (KZAM, 2009) e utilizada em problemas da Mecânica da Fratura. É descrito o Método de Subtração de Singularidade (MSS) e os conceitos de VPC e PFH a serem utilizados no MEC dual. Em (OLIVEIRA; LEONEL, 2013) e (OLIVEIRA, 2013) é estudada a propagação de fratura em materiais quase-frágeis por meio de uma formulação alternativa do MEC, onde é utilizado um campo de tensões iniciais para a representação da zona coesiva. A fim de acelerar a convergência da solução se faz uso do operador tangente. Os resultados são comparados com dados experimentais e com o MEC dual.

Em (CORDEIRO, 2015) é considerada a técnica de multi-regiões para acoplar a interface de sólidos multifásicos. São analisadas fraturas em estruturas compostas com materiais isotrópicos e anisotrópico e o comportamento não linear é introduzido pelo modelo coesivo de fratura. Foram analisadas estruturas compostas em regime elástico, assim como testes experimentais de fratura em espécimes de concreto e madeira foram simulados. Também 
na linha de estudo da mecânica da fratura por meio do MEC encontra-se o trabalho de (GONZALEZ et al,, 2015), sendo implementada uma forma não convencional para o cálculo dos fatores de intensidade de tensão. (OLIVEIRA, 2017) também estudou problemas de mecânica da fratura via MEC, porém aplicado a materiais viscoelásticos. Tais modelos foram aplicados em modelagens probabilísticas por meio da confiabilidade de estruturas (utilizando o método de simulação de Monte Carlo e metamodelagem por superfície de resposta). Também foram realizadas aplicações em casos de otimização topológica por acoplamento do MEC com o método Level SET (MLS).

O MEC apresenta grandes vantagens para as análises mecânicas em meios homogêneos. No caso de meios heterogêneos, dependendo das hipóteses de análise, dificilmente conseguese evitar a discretização do domínio, de forma incluir no modelo as diferentes propriedades do material. No trabalho de (LEE; WANG; QIN, 2016) objetiva-se justamente evitar esta discretização, sendo utilizados para isso métodos de transformação de domínio. Já (ANDRADE, 2017) usou a técnica de sub-regiões para a modelagem de domínios nãohomogêneos. As principais aplicações consistiram na análise de materiais frágeis por mecânica da fratura elástico-linear (MFEL) aplicando em problemas como os de fraturamento hidráulico. Além disso, o autor estudou modelos de fissura não coesiva e fadiga de alto-ciclo.

\subsubsection{Acoplamento do MEC a outros métodos numéricos}

$\mathrm{O}$ acoplamento de métodos numéricos tem por vantagem tornar mais consistente a modelagem de problemas, uma vez que cada método pode ser utilizado onde apresenta melhores resultados. Um caso típico é a interação solo-estrutura, a estrutura usualmente é modelada por meio do MEF, com elementos de barra, já para a modelagem do solo a utilização do MEC é muito vantajosa, devido a facilidade em se modelar meios semi-infinitos.

Tipicamente o acoplamento MEC/MEF é realizado para sub-regiões adjacentes, onde é feito o acoplamento de sua interface. Para o caso de domínios reforçados o enrijecedor, apesar de ser modelado de forma diferente, se situa dentro de sub-região modelada pelo MEC. Serão apresentados nessa seção textos que se referem ao acoplamento entre sub-regiões adjacentes.

$\mathrm{O}$ acoplamento MEC/MEF na engenharia de estruturas foi proposto inicialmente por (ZIENKIEWICZ; KELLY; BETTESS, 1977) e (FALBY; SHAWT, 1977). No trabalho de (BREBBIA; GEORGIOU, 1979) foram avaliados problemas bidimensionais por meio deste acoplamento. Foram adotadas duas abordagens, estruturando-se a região de elementos de contorno no formato de elementos finitos e o contrário, ou seja, estruturando-se a região de 
elementos finitos na forma de elementos de contorno. A primeira abordagem mostrou-se interessante por permitir acoplamento mais direto com códigos computacionais já existentes em elementos finitos. Foram considerados elementos de contorno constantes e elementos finitos quadráticos.

A utilidade do acoplamento é evidenciada no trabalho de (WEARING; BURSTOW, 1994) sendo utilizado para a análise de problemas elastoplásticos e de mecânica da fratura elastoplástica convencional. Em (CODA; VENTURINI; ALIABADI, 1999) e (CODA; VENTURINI, 1999) é estudado o acoplamento para o caso tridimensional elástico estático e dinâmico. Em (ELLEITHY; TANAKA; GUZIK, 2004) é feito o acoplamento MEC/MEF, considerando análise elastoplástica. Em (GANGULY; LAYTON; BALAKRISHNA, 2000) o acoplamento MEC/MEF é realizado de forma simétrica, tornando a resolução dos sistemas lineares mais rápida. Em (BIALECKI et al., 2002) é feito o acoplamento MEC/MEF, MEC/MEC e o acoplamento com soluções analíticas do MEC e do MEF, comparando-se os resultados.

Em (AOUR; RAHMANI; NAIT-ABDELAZIZ, 2007) é desenvolvido um novo método de elementos de contorno para um acoplamento de forma rápida e efetiva com o MEF. Esse novo elemento é chamado de super-elemento de contorno, sendo baseado na princípio de minimização da energia potencial total utilizada no MEF. O método foi avaliado com a mecânica da fratura pelo cálculo dos fatores de intensidade de tensão.

Em (FERNANDES; PITUBA; DE SOUZA NETO, 2015) é realizada a modelagem de multi-escala para análise de deformação de placas de materiais heterogêneos. Na modelagem do macro-contínuo, no caso a placa, é utilizado o MEC. Já para o problema de micro-escala, nesse caso elemento representativo de volume, é utilizado o MEF.

Para o caso de análise de viscoelaticidade de materiais compósitos, (TROYANI; PÉREZ, 2014) compararam a modelagem por meio puramente do MEF com o acoplamento MEC/MEF. Ambos levando a bons resultados em comparação com resultados experimentais, mas com o primeiro levando a menos esforço computacional.

Para problemas elastoplásticos, (BOUMAIZA; AOUR, 2014) analisaram a eficiência do acoplamento MEC/MEF de forma iterativa em domínios planos. A região em que deformações plásticas são observadas é representada por meio do MEF, onde o comportamento mecânico é modelado por meio de abordagem numérica no domínio. O domínio complementar 
é modelado pelo MEC, este sendo eficiente na modelagem de materiais com grandes gradientes de tensão.

Em (BIRD; TREVELYAN; AUGARDE, 2010) o acoplamento do MEC com o scaled boundary finite element method (SBFEM) é aplicado em problemas da mecânica da fratura. São gerados exemplos e estimados os fatores de intensidade de tensão, comparando estes com a solução analítica. O método mostra adequada velocidade de convergência. O SBFEM é definido por (SONG; WOLF, 1999) como derivado da equação da difusão de forma que somente o contorno é discretizado, mas ao contrário do MEC, não surgem singularidades. O método é uma alternativa ao uso do MEC, sendo utilizado em problemas similares, como em (CHEN; DAI, 2017), para análise dinâmica de interação solo-estrutura com a presença de fratura. Já (RAHNEMA; MOHASSEB; JAVIDSHARIFI, 2016) utiliza o método para a avaliação de interação solo-estrutura no domínio do tempo utilizando modelos não lineares para o solo, considerando-o como composto por areia com valores diversos de densidade.

A interação solo estrutura por meio do acoplamento MEC/MEF de sub-regiões adjacentes é explorada nos trabalhos de (RIZOS; WANG, 2002) e (ROMERO; GALVÍN; DOMÍNGUEZ, 2013), nos quais a estrutura é modelada por meio do MEF e o solo por meio do MEC. Em ambos é realizada análise de propagação de onda 3D e efeitos dinâmicos no domínio do tempo. No segundo é considerado o contato de forma não linear sendo utilizada a abordagem de velocidade constante para o MEC. No trabalho de (SANTANA et al., 2016) também é realizada análise dinâmica com o uso do MEC, a estrutura é modelada por meio do MEF e a fundação, considerada homogênea, isotrópica, elástica ou poroelástica, modelada por meio do MEC.

Da mesma forma, no trabalho de (SILVA; CODA, 2012) é realizado o acoplamento MEC/MEF, sendo utilizado uma formulação não-convencional para o MEF, de forma a considerar os efeitos não lineares da estrutura com cinemática exata. O solo é modelado por meio do MEC com múltiplas inclusões, sendo o acoplamento realizado por meio de uma estratégia algébrica. Tal estratégia realiza a inclusão da matriz de rigidez equivalente do solo na matriz hessiana da estrutura de forma a não serem levadas em consideração forças de superfície nas interfaces. A formulação analisa casos de fundações rasa e profunda com estacas em qualquer direção. Já o trabalho de (VASILEV et al., 2015) faz uso do programa computacional comercial ANSYS para avaliação de resposta sísmica de um sistema soloestrutura, e (SCHEPERS, 2017) propõe um chamado método rápido para solução de problemas deste tipo no domínio da frequência. 


\subsubsection{Acoplamento MEC-enrijecedor}

No caso de domínios enrijecidos, como dito anteriormente, o enrijecedor se situa dentro da sub-região modelada pelo MEC, sofrendo esforços a serem determinados. O uso de materiais reforçados possui inúmeras aplicações na indústria, no caso da indústria aeronáutica por exemplo a análise numérica do seu uso é realizada em (ARMENTANI; CITARELLA, 2006) utilizando tanto a formulação do MEC quanto do MEF. Por outro lado, em (CITARELLA, 2009) é utilizada somente a formulação do MEC.

Em (CODA, 2001) é desenvolvido o acoplamento MEC/MEF para meios reforçados visando tanto análise estática quanto dinâmica. A formulação do MEF é realizada de tal forma que as influências não lineares deles sejam consideradas como forças residuais na matriz do MEC. (LEITE; CODA; VENTURINI, 2003) e (FERNANDES; VENTURINI, 2002) aplicaram o acoplamento MEC-MEF para problemas de placas, analisando casos de lajes de concreto armado.

Em (LEITE; CODA; VENTURINI, 2003) é discutido o uso de dois algoritmos para simular a presença de enrijecedor. No primeiro é adaptada a técnica de multi-regiões para o caso de sub-região de pequena espessura, no segundo a sub-região é degenerada para simular a presença de enrijecedores no corpo. Foi efetuada a comparação com acoplamento via elementos finitos convencional, onde observou-se que ambos modelos fornecem adequados resultados quanto aos esforços de tração mesmo em regiões onde o acoplamento MEC/MEF normalmente falha, nas proximidades do fim dos elementos, onde costuma haver concentração de esforços.

(MESQUITA; CODA, 2007) estudaram o caso de meio enrijecido em problemas viscoelásticos. Em (BOTTA; VENTURINI, 2005) e (LEONEL, 2009) é realizado acoplamento MEC/MEF de enrijecedor com elemento finito com aproximação de deslocamentos por polinômios de terceiro grau e força de contato entre domínio e reforço aproximada de forma linear, sendo considerado o escorregamento entre o meio e o reforço. (LEONEL, 2009) realiza análises para o caso de comportamento elastoplástico dos elementos do enrijecedor, e de propagação de fissuras em domínio enrijecido. Já em (ROCHA et al., 2014), são consideradas a flexão e o escorregamento dos reforços. $\mathrm{O}$ acoplamento é realizado aproximando-se a força distribuída, chamada força de contato, como linear e deslocamentos e rotações como polinomial de terceiro grau.

Em diversos casos é utilizado o acoplamento MEC/MEF para análise da presença de estacas no solo, tal fato se deve à vantagem dos elementos de contorno na modelagem de 
domínios infinitos. Em (MENDONÇA; PAIVA, 2003) a estrutura é modelada por meio do MEF e o solo por meio do MEC, sendo analisado tanto o caso de fundação superficial (radier) quanto profunda (estacas). No caso das estacas, estas são modeladas como elemento único com aproximação quadrática, inseridas dentro do domínio do MEC e sendo acoplados os deslocamentos, considerando o esforço cortante na interface. Ainda é considerada a reação de apoio da ponta da estaca, considerada força distribuída. Em (RIBEIRO; DE PAIVA, 2014), também é estudada a interação com estacas, sendo estas modeladas com elementos finitos de aproximação polinomial até o quarto grau.

\subsubsection{MEC unidimensional (MEC 1D)}

Os estudos envolvendo o MEC tem tido maior foco para o caso de problemas bi e tridimensionais. São encontrados poucos estudos deste método envolvendo estruturas reticuladas, sendo em geral mais recentes. Somente a partir de 1980 soluções baseadas no MEC foram apresentadas por (BANERJEE; BUTTERFIELD, 1981), para o caso de flexão de vigas de Euler-Bernoulli nos problemas estáticos, e por (PROVIDASKIS; BESKOS, 1986), para o caso dos problemas dinâmicos.

Em (ANTES, 2003) é apresentada equação integral, por meio da técnica de resíduos ponderados, para o caso de vigas de Timoshenko. Desenvolve-se a formulação integral de contorno, com o uso de soluções fundamentais. Por fim, são gerados exemplos de pórticos planos, sendo comparados com a resposta de vigas de Euler-Bernoulli. Posteriormente em (ANTES; SCHANZ; ALVERMANN, 2004) é realizada, a partir da mesma formulação, análise dinâmica de vigas de Timoshenko.

(CARRER et al., 2014) apresenta as formulações para análise estática de vigas de EulerBernoulli e de Timoshenko por meio do MEC. Os resultados são comparados com a resposta analítica. Para o caso de vigas de Euler-Bernoulli a discretização não influencia no resultado. Isso não ocorre no caso de vigas de Timoshenko, onde é necessária a integração no domínio do elemento. Foram utilizados elementos de aproximação de forma linear, concluindo-se que com o aumento do grau de aproximação e do número de elementos o resultado converge para a resposta analítica.

Em (SEIXAS; MARQUES; FILGUEIRAS, 2010) é realizada análise de pórticos planos e espaciais pelo MEC. Em (DOS PASSOS, 2014) são propostas soluções, baseadas no MEC,

para os problemas de estabilidade estática e dinâmica de vigas de Euler-Bernoulli e Timoshenko. (CRUZ, 2012) também descreveu análises elásticas de pórticos utilizando o MEC, 
os efeitos de flexão são levados em conta segundo as teorias de Euler-Bernoulli e Timoshenko e de torção segundo hipóteses de Saint Venant. É dada atenção para a interação solo-estrutura em regime estático, o solo sendo considerado como um sólido elástico semi-infinito, modelado pelo MEC. Não foram encontrados trabalhos na literatura onde a análise mecânica de domínios enrijecidos é efetuada considerando o MEC 1D, o que justifica o desenvolvimento do presente trabalho 


\section{MÉTODOS NUMÉRICOS}

Os métodos numéricos são estratégias utilizadas para a construção de soluções aproximadas para um determinado problema mecânico. Tais estratégias são alternativas ao uso das soluções analíticas, que usualmente são limitadas a problemas específicos, as quais podem ser de complexa obtenção, ou mesmo não serem disponíveis. Com a criação dos computadores e seu respectivo aumento da capacidade computacional, houve grande incremento no uso dos métodos numéricos para a solução de problemas mecânicos, principalmente dos métodos MEC e MEF. Ambos métodos resolvem de forma eficiente as equações diferenciais oriundas do problema mecânico, que usualmente são da forma do PVC. Nos subtópicos em sequência, a formulação dos métodos MEF e MEC será descrita, ressaltando suas peculiaridades.

\subsection{Método dos Elementos Finitos}

O MEF está baseado na divisão do domínio em análise em um número finito de subdomínios, chamados de elementos finitos. O método constrói uma aproximação para a solução analítica utilizando a forma variacional da equação diferencial que rege o problema em análise. A forma variacional pode ser obtida de duas formas: método de Ritz, baseado na construção do funcional de energia; e método de Galerkin, que realiza a integração por partes da função resíduo, ponderada por uma função peso.

O presente trabalho irá apresentar a formulação do MEF pela abordagem de Galerkin, por ser mais geral e resolver uma maior variedade de problemas. Será demonstrada sua formulação para o caso bidimensional, na forma matricial, do mesmo modo que em (DE FREITAS; DE ALMEIDA; PEREIRA, 1996). A formulação será desenvolvida com base no problema de elasticidade dos meios contínuos, conforme definido no apêndice (item B.7 Estado Plano). Destaca-se que o método de Galerkin pode ser utilizado para uma variedade de outros problemas físicos, e para diferentes dimensões (1D e 3D por exemplo). No estudo da elasticidade linear dos meios contínuos, a equação governante do problema é dada por:

$$
[\mathrm{L}]\{\boldsymbol{\sigma}\}+\{\boldsymbol{b}\}=0
$$

onde $\{\boldsymbol{\sigma}\}$ é o vetor formado pelas componentes de tensão normal nas direções $x, y$ e pela parcela de tensão de cisalhamento $x y,\{\boldsymbol{b}\}$ é o vetor de forças de volume na direção $x$ e $y$, e [L] é uma matriz que representa o operador divergente.

Esta equação é a chamada forma forte de um problema mecânico, que consiste em uma equação diferencial ordinária linear. Admitindo que não se conheça sua solução, esta será 
satisfeita em termos de média ponderada através do conceito de minimização de erros (ou minimização da função resíduo):

$$
\int_{\Omega}([\mathrm{L}]\{\boldsymbol{\sigma}\}+\{\boldsymbol{b}\}) u^{*} d \Omega=0
$$

onde $u^{*}$ é a função peso (também chamada de função teste), $\Omega$ é o domínio do corpo, conforme apêndice B.

O formato da equação é chamado de forma fraca, ou forma variacional direta. O sistema resolvente é montado a partir da forma fraca do problema.

Integrando-se por partes o primeiro termo da integral anterior obtém-se:

$$
\int_{\Omega}[\mathrm{L}]\{\boldsymbol{\sigma}\} u^{*} d \Omega=\int_{\Gamma}[\mathrm{N}]\{\boldsymbol{\sigma}\} u^{*} d \Gamma-\int_{\Omega}\left([\mathrm{L}]^{T} u^{*}\right)^{T}\{\boldsymbol{\sigma}\} d \Omega
$$

onde [N] é a matriz contendo as componentes do vetor $\boldsymbol{n}$ normal ao contorno, definido no apêndice B.7 e $\Gamma$ é o contorno do corpo, conforme apêndice B.

Introduzindo a Eq. (3.3) na Eq. (3.2) obtém-se a Eq. (3.4):

$$
\int_{\Gamma}[\mathrm{N}]\{\boldsymbol{\sigma}\} u^{*} d \Gamma-\int_{\Omega}\left([\mathrm{L}]^{T} u^{*}\right)^{T}\{\boldsymbol{\sigma}\} d \Omega+\int_{\Omega}\{\boldsymbol{b}\} u^{*} d \Omega=0
$$

A condição de contorno de Neumann, também chamada de condição de contorno natural, é imposta em forma fraca da seguinte maneira:

$$
\int_{\Gamma_{\sigma}}([\mathrm{N}]\{\boldsymbol{\sigma}\}-\{\overline{\boldsymbol{t}}\}) u^{*} d \Gamma=0
$$

onde $\{\overline{\boldsymbol{t}}\}$ é o vetor de forças de superfícies prescritas.

Substituindo então a Eq. (3.5) na equação (3.4):

$$
\int_{\Omega}\left([\mathrm{L}]^{T} u^{*}\right)^{T}\{\boldsymbol{\sigma}\} d \Omega-\int_{\Omega}\{\boldsymbol{b}\} u^{*} d \Omega-\int_{\Gamma_{u}}[\mathrm{~N}]\{\boldsymbol{\sigma}\} u^{*} d \Gamma-\int_{\Gamma_{\sigma}}\{\overline{\boldsymbol{t}}\} u^{*} d \Gamma=0
$$

As condições de contorno de Dirichlet, também chamadas de condições de contorno essenciais, são impostas em forma forte sobre a aproximação adotada. Isso significa que é adotada uma função peso, $u^{*}$, homogênea nesse trecho:

$$
u^{*}=0 \text { em } \Gamma_{u}
$$




$$
\int_{\Gamma_{u}}[\mathrm{~N}]\{\boldsymbol{\sigma}\} u^{*} d \Gamma=0
$$

As relações constitutiva e de compatibilidade são descritas em forma forte, conforme Eq. (3.8), e substituídas na forma fraca . Assim:

$$
\begin{gathered}
\{\boldsymbol{\sigma}\}=k[\mathrm{~L}]^{T}\{\boldsymbol{u}\} \\
\int_{\Omega}\left([\mathrm{L}]^{T} u^{*}\right)^{T} k[\mathrm{~L}]^{T}\{\boldsymbol{u}\} d \Omega-\int_{\Omega}\{\boldsymbol{b}\} u^{*} d \Omega=\int_{\Gamma_{\sigma}}\{\overline{\boldsymbol{t}}\} u^{*} d \Gamma
\end{gathered}
$$

onde define-se $\{\boldsymbol{u}\}$ como sendo o vetor de deslocamentos relativo ao vetor de tensões aplicado, e $k$ um coeficiente de rigidez do elemento.

A Técnica dos Elementos Finitos ${ }^{13}$ é a estratégia utilizada para a determinação da função de solução aproximada dos problemas formulados em forma fraca. Essa técnica consiste na realização de aproximações efetuadas a partir da combinação linear de funções polinomiais com propriedade de partição da unidade - chamados de polinômios de Lagrange. Como exemplo, utilizando a técnica para o caso de um problema unidimensional onde se busca aproximação para deslocamentos, obtém-se a equação a seguir, definida em nota.

$$
\tilde{u}(x)=\alpha_{i} \phi_{i}(x)
$$

Sendo $\tilde{u}$ a solução aproximada, as funções base $\phi_{i}$ são escolhidas de forma que os coeficientes $\alpha_{i}$ sejam iguais ao valor da função incógnita de cada nó:

$$
\alpha_{i}=\tilde{u}\left(x_{i}\right)=\tilde{u}_{i}
$$

Portanto, para um nó j tem-se:

$$
\phi_{i}=\left\{\begin{array}{l}
1, \text { para } i=j \\
0, \text { para } i \neq j
\end{array}\right.
$$

Ou seja, os coeficientes $\alpha_{i}$ podem ser definidos da seguinte forma:

\footnotetext{
13 Apesar de técnica e método serem palavras frequentemente usadas como sinônimos, a técnica dos elementos finitos se distingue do método dos elementos finitos em si. Enquanto o primeiro apenas define uma função de aproximação baseada na partição de unidade, o segundo consiste em um método de solução do problema de valor de contorno descrito em forma variacional direta, baseado na divisão do domínio em um número finito de subdomínios.
} 


$$
\alpha_{j}=\tilde{u}\left(x_{j}\right)=\tilde{u}_{i} \phi_{i}\left(x_{j}\right)=\tilde{u}_{j}
$$

As funções $\phi_{i}$ são chamadas então de funções de forma. Normalmente são utilizadas funções polinomiais, variando-se o número de coeficientes de acordo com grau de aproximação adotado. Conforme mostrado na Figura 6, para a função linear há apenas dois coeficientes (relativos aos dois nós -1 e 2), enquanto para a função quadrática há três coeficientes $\alpha_{\mathrm{j}}$.

Figura 6. Funçoes de forma linear (à esquerda) e quadrática (à direita).
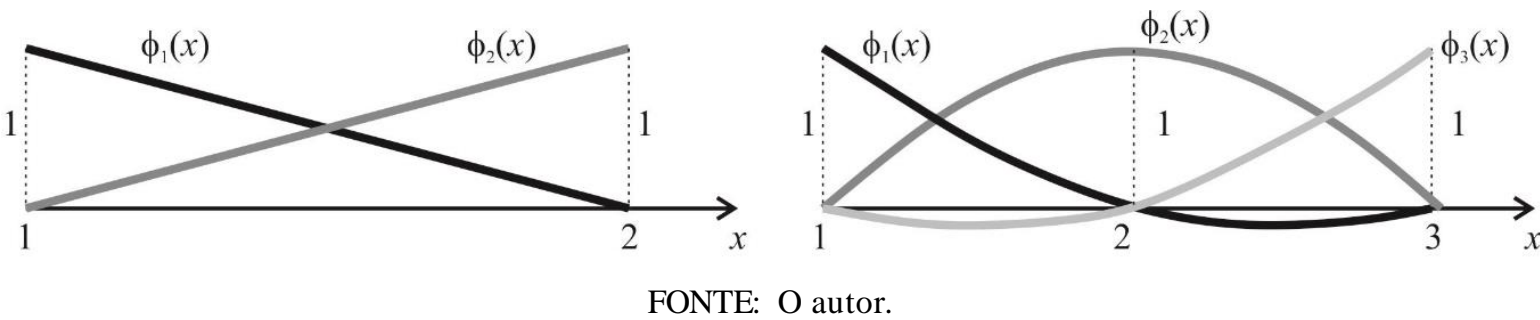

Os coeficientes da equação $\left(\alpha_{\mathrm{i}}\right)$ tem o significado de valores nodais da função incógnita e podem ser calculados pelo método de Galerkin. Esse método de solução impõe que a função peso utilizada, $u^{*}$, possua a mesma base da função aproximativa da solução $\tilde{u}(x)$. Introduzindo a aproximação para a função peso, sendo $\delta u$ seus coeficientes obtém-se:

$$
u^{*}=\phi_{\Omega} \delta u
$$

A resposta deve ser a mesma para quaisquer $\delta u_{\mathrm{i}}$, logo, introduzindo a aproximação para deslocamentos no domínio na forma fraca já apresentada na Eq. (3.9), obtém-se a equação do MEF em termos de deslocamentos:

$$
\begin{gathered}
u=\left\{\boldsymbol{\phi}_{\Omega}\right\}^{T}\left\{\boldsymbol{u}_{\Omega}\right\} \\
{[\mathrm{K}]\left\{\boldsymbol{u}_{\Omega}\right\}=\{\boldsymbol{F}\}}
\end{gathered}
$$

onde $[\mathrm{K}]$ é a matriz de rigidez e $\{\boldsymbol{F}\}$ é o vetor de forças, calculados, respectivamente, pelas equações a seguir:

$$
\begin{gathered}
{[K]=\int_{\Omega}\left([\mathrm{L}]^{T}\left\{\boldsymbol{\phi}_{\Omega}\right\}\right)^{T} k\left([\mathrm{~L}]^{T}\left\{\boldsymbol{\phi}_{\Omega}\right\}\right) d \Omega} \\
\{\boldsymbol{F}\}=\int_{\Gamma_{\sigma}}\left\{\boldsymbol{\phi}_{\Omega}\right\}^{T}\{\boldsymbol{t}\} d \Gamma+\int_{\Omega}\left\{\boldsymbol{\phi}_{\Omega}\right\}^{T}\{\boldsymbol{b}\} d \Omega
\end{gathered}
$$

Uma observação importante é que as condições de contorno de Dirichlet não precisam ser impostas previamente. Elas podem ser impostas sobre o sistema resolvente final, tornando o método bastante prático de ser implementado. Além disso, a matriz de rigidez definida na Eq. 
(3.17) é simétrica, reduzindo o custo computacional da solução do sistema. Posteriormente, a partir das relações de compatibilidade e constitutiva, é possível se obter os resultados para deformações e tensões.

Na forma clássica, o MEF apresenta limitações - deformações e tensões possuem ordem de aproximação reduzida, sua obtenção envolve derivação. Pela aproximação depender de funções de forma polinomiais há dificuldade para obtenção de respostas precisas em regiões com grande gradiente de deformações, exigindo grande refinamento da malha.

\subsection{Método dos Elementos de Contorno}

Será detalhada a seguir a obtenção da formulação do MEC para os problemas elastostásticos planos. Da mesma forma que no MEF se parte da equação diferencial de equilibrio infinitesimal, escrita na forma indicial da seguinte maneira:

$$
\sigma_{k j, j}+b_{k}=0
$$

Esta equação é a chamada forma forte do problema mecânico. Procura-se minimizar seu erro, encontrando-se então a sua forma fraca, ou variacional direta. Assim:

$$
\int_{\Omega}\left(\sigma_{k j, j}+b_{k}\right) w_{k} d \Omega=0
$$

A função peso $w$ será considerada como campo de deslocamentos no chamado problema fundamental, possuindo relações de compatibilidade e constitutivas escritas da seguinte maneira:

$$
\begin{gathered}
w_{k}=u_{k}^{*} \\
\sigma_{i j}^{*}=2 G \varepsilon_{i j}^{*}+\frac{2 G v}{1-2 v} \varepsilon_{k k}^{*} \delta_{i j} \\
\varepsilon_{i j}^{*}=\frac{1}{2}\left(u_{i, j}^{*}+u_{j, i}^{*}\right)
\end{gathered}
$$

onde $G$ é o módulo de elasticidade transversal, $v$ é o coeficiente de Poisson e $\varepsilon$ representa o tensor de deformações.

No contorno se observa também o equilibrio de forças de superfície:

$$
p_{i}^{*}=\sigma_{i j}^{*} n_{j}
$$


onde $p_{i}$ representa as forças de superfície e $n_{j}$ é o vetor normal ao contorno.

A forma variacional direta, equação (3.20), assume o seguinte formato:

$$
\int_{\Omega}\left(\sigma_{k j, j}+b_{k}\right) u_{k}^{*} d \Omega=0
$$

Integrando por partes a primeira parcela obtém-se a seguinte relação:

$$
\int_{\Omega} \sigma_{k j, j} u_{k}^{*} d \Omega=\int_{\Gamma} p_{k} u_{k}^{*} d \Gamma-\int_{\Omega} \sigma_{\mathrm{kj}} \varepsilon_{\mathrm{kj}}^{*} d \Omega
$$

Substituindo essa relação na equação (3.25) obtém-se:

$$
\int_{\Gamma} p_{k} u_{k}^{*} d \Gamma-\int_{\Omega} \sigma_{\mathrm{kj}} \varepsilon_{\mathrm{kj}}^{*} d \Omega+\int_{\Omega} b_{k} u_{k}^{*} d \Omega=0
$$

Esta equação é similar à Eq. (3.4) utilizada no MEF, à exceção da notação adotada. No entanto, a partir desse momento o MEC adota outra abordagem, onde se procura evitar termos de integração no domínio. Então é realizada nova integração por partes, nesse caso no segundo termo, conforme a relação (B.25), surgindo novo termo de integral no contorno:

$$
\int_{\Omega} \sigma_{\mathrm{kj}} \varepsilon_{\mathrm{kj}}^{*} d \Omega=\int_{\Gamma} p_{k}^{*} u_{k} d \Gamma-\int_{\Omega} \sigma_{k j, j}^{*} u_{k} d \Omega
$$

Substituindo na equação (3.27) obtém-se a seguinte equação, chamada de Teorema de Reciprocidade de Betti:

$$
\int_{\Omega} \sigma_{k j, j}^{*} u_{k} d \Omega+\int_{\Omega} b_{k} u_{k}^{*} d \Omega=-\int_{\Gamma} p_{k} u_{k}^{*} d \Gamma+\int_{\Gamma} p_{k}^{*} u_{k} d \Gamma
$$

Nesta equação há dois termos de integral no domínio e dois termos de integral no contorno. O MEC objetiva evitar a integração do campo de deslocamentos $\left(u_{k}\right)$ no domínio, (primeiro termo da equação anterior), pois para isso é necessário o uso de aproximações de domínio. Dessa forma, na definição da função peso $\sigma_{k j, j}^{*}$ é utilizada a função delta de Dirac $\Delta$ :

$$
\sigma_{l k j, j}^{*}+\Delta^{i} \delta_{l k}=0
$$

Como nesse caso o campo de deslocamentos possui mais de uma dimensão, a função delta de Dirac é aplicada separadamente para cada direção, representada pela letra $l . \delta_{l k}$ representa o delta de Kronecker e o ponto de aplicação, ou ponto fonte, da função delta de Dirac 
é representado pela letra $i$. Esta equação é chamada Problema Fundamental, e sua solução é a Solução Fundamental.

Exemplificando para um problema bidimensional:

1. Delta de Dirac aplicado na direção 1:

$$
\begin{gathered}
l=1 \\
\left\{\begin{array}{l}
\sigma_{11 j, j}^{*}+\Delta^{i} \delta_{11}=0 \\
\sigma_{12 j, j}^{*}+\Delta^{i} \delta_{12}=0
\end{array}\right.
\end{gathered}
$$

Ou seja:

$$
\left\{\begin{array}{c}
\sigma_{11 j, j}^{*}+\Delta^{i}=0 \\
\sigma_{12 j, j}^{*}=0
\end{array}\right.
$$

2. Delta de Dirac aplicado na direção 2:

$$
\begin{gathered}
l=2 \\
\left\{\begin{array}{l}
\sigma_{21 j, j}^{*}+\Delta^{i} \delta_{21}=0 \\
\sigma_{22 j, j}^{*}+\Delta^{i} \delta_{22}=0
\end{array}\right.
\end{gathered}
$$

Ou seja:

$$
\left\{\begin{array}{c}
\sigma_{21 j, j}^{*}=0 \\
\sigma_{22 j, j}^{*}+\Delta^{i}=0
\end{array}\right.
$$

Com o uso da função Delta de Dirac não é mais necessária integração de deslocamentos no domínio. Assim:

$$
\int_{\Omega} \sigma_{l k j, j}^{*} u_{k} d \Omega=\int_{\Omega}\left(-\Delta^{i} \delta_{l k}\right) u_{k} d \Omega=-\int_{\Omega} \Delta^{i} u_{l} d \Omega=-u_{l}^{i}
$$

Com isso obtém-se a equação conhecida como Identidade Somigliana:

$$
c u_{k}+\int_{\Gamma} p_{l k}^{*} u_{k} d \Gamma=\int_{\Gamma} p_{k} u_{l k}^{*} d \Gamma+\int_{\Omega} b_{k} u_{l k}^{*} d \Omega
$$

A variável $c$ possui valor dependente da localização do ponto fonte do Delta de Dirac:

$$
\begin{aligned}
& c=0 \rightarrow \text { Para pontos externos ao domínio } \Omega \\
& c=1 \rightarrow \text { Para pontos internos ao domínio } \Omega
\end{aligned}
$$


Conforme (BREBBIA, 1978b), para a obtenção do termo $c$ no caso de pontos fonte sobre o contorno procede-se análise limite do ponto fonte pertencente ao domínio, transportando-o para sobre o contorno. No caso de contorno $\Gamma$ suave obtém-se:

$$
c=0,5 \rightarrow \text { Para pontos sobre o contorno } \Gamma
$$

Utilizando-se a equação (3.36), com a solução fundamental, escolhendo-se ponto fonte externo ou sobre o contorno se obtém a equação para a solução do PVC. Com as respostas para o contorno, pode-se obter as respostas para os pontos internos, bastando para isto escolhê-los como pontos fonte.

Considerando que não há forças de domínio e introduzindo as aproximações sobre a geometria e os campos mecânicos obtém-se:

$$
\begin{gathered}
b_{k}=0 \\
u_{k}=\phi_{i} u_{k i} \\
p_{k}=\phi_{i} p_{k i}
\end{gathered}
$$

Para o ponto fonte $j$, a identidade Somigliana toma a forma:

$$
c u_{k j}+\int_{\Gamma} p_{l k j}^{*} \phi_{i} u_{k i} d \Gamma=\int_{\Gamma} u_{l k j}^{*} \phi_{i} p_{k i} d \Gamma
$$

Utilizando o delta de Kronecker e mudando para coordenadas adimensionais, reescrevese a equação anterior:

$$
c \delta_{j i} u_{k i}+\int_{-1}^{+1} p_{l k j}^{*} \phi_{i} u_{k i} J(\xi) d \xi=\int_{-1}^{+1} u_{l k j}^{*} \phi_{i} p_{k i} J(\xi) d \xi
$$

Logo, a equação anterior pode ser apresentada na forma compacta a seguir:

$$
H_{l k j i} u_{k i}=G_{l k j i} p_{k i}
$$

onde $H_{l k j i}$ e $G_{l k j i}$ são calculados pelas equações a seguir, respectivamente.

$$
\begin{gathered}
H_{l k j i}=c \delta_{j i}+\int_{-1}^{+1} p_{l k j}^{*} \phi_{i} J(\xi) d \xi \\
G_{l k j i}=\int_{-1}^{+1} u_{l k j}^{*} \phi_{i} J(\xi) d \xi
\end{gathered}
$$


Para o caso bidimensional a equação (3.41) resulta no seguinte sistema:

$$
\left[\begin{array}{ll}
H_{11 j i} & H_{12 j i} \\
H_{21 j i} & H_{22 j i}
\end{array}\right]\left\{\begin{array}{l}
u_{1 i} \\
u_{2 i}
\end{array}\right\}=\left[\begin{array}{ll}
G_{11 j i} & G_{12 j i} \\
H_{21 j i} & G_{22 j i}
\end{array}\right]\left\{\begin{array}{l}
p_{1 i} \\
p_{2 i}
\end{array}\right\}
$$

Por meio do sistema anterior obtém-se os resultados para o contorno do problema. Já para o caso de tensões internas, deriva-se a Identidade Somigliana, Eq. (3.36), em relação aos eixos, considerando-se forças de domínio nulas e por meio das relações de compatibilidade e constitutiva obtém-se equação para sua determinação:

$$
c \sigma_{i j}+\int_{\Gamma} S_{k i j}^{*} u_{j} d \Gamma=\int_{\Gamma} D_{k i j}^{*} p_{j} d \Gamma
$$

Os termos $D_{k i j}^{*}$ e $S_{k i j}^{*}$ são obtidos derivando-se os núcleos $u^{*}$ e $p^{*}$ respectivamente. Para a sua obtenção é necessário o uso da Solução Fundamental. A formulação acima é interessante pois dela se deriva a chamada Formulação Hipersingular, de grande importância para análise de problemas de Mecânica da Fratura.

\subsubsection{Solução Fundamental de Kelvin - Meio Isotrópico}

A solução da Eq. (3.30) é chamada de solução fundamental. Ela é determinada considerando um corpo de dimensão infinita submetido a uma força pontual, representada pelo delta de Dirac. A seguir apresenta-se a solução para o caso isotrópico obtida por Kelvin, chamada de Solução Fundamental de Kelvin:

Para deslocamentos:

$$
u_{l k}^{*}=\frac{1}{8 \pi G(1-v)}\left[(3-4 v) \ln \left(\frac{1}{r}\right) \delta_{l k}+r_{, l} r_{, k}\right]
$$

sendo $r$ a distância ao ponto fonte.

Utilizando-se da relação de compatibilidade, Eq. (B.9), obtém-se a solução em termos de deformações:

$$
\varepsilon_{i j k}^{*}=-\frac{1}{8 \pi G r(1-v)}\left\{(1-2 v)\left[\delta_{i j} r_{{ }_{k}}+\delta_{i k} r_{{ }_{j}}\right]+2 r_{, i} r_{, j} r_{{ }_{k}}-\delta_{k j} r_{,_{i}}\right\}
$$

Por meio da relação constitutiva, Eq. (B.7), nesse caso a lei de Hooke generalizada, obtém-se a solução em termos de tensões: 


$$
\sigma_{i j k}^{*}=-\frac{1}{4 \pi r(1-v)}\left\{(1-2 v)\left[\delta_{i j} r_{r_{k}}+\delta_{i k} r_{{ }_{j}}-\delta_{k j} r_{, i}\right]+2 r_{, i} r_{{ }_{j}} r_{,_{k}}\right\}
$$

Aplicando-se a equação de equilibrio de Cauchy, Eq. (B.3), obtém-se em termos de forças de superfície:

$$
p_{l k}^{*}=-\frac{1}{4 \pi r(1-v)}\left\{\frac{\partial \mathrm{r}}{\partial \mathrm{n}}\left[(1-2 v) \delta_{i k}+2 r_{l} r_{,_{k}}\right]+(1-2 v)\left(n_{l} r_{,_{k}}-n_{k} r_{l_{l}}\right)\right\}
$$

sendo que $n_{j}$ representa o versor normal da superfície, orientado para fora do corpo.

Para a obtenção das tensões internas, Eq. (3.45), é necessário o cálculo dos termos $D_{k i j}^{*}$ e $S_{k i j}^{*}$, obtidos derivando-se os núcleos $u^{*}$ e $p^{*}$ respectivamente, resultando em:

$$
\begin{aligned}
& D_{k i j}^{*}=\frac{1}{4 \pi r(1-v) r}\left\{(1-2 v)\left[\delta_{k i} r_{, j}+\delta_{k j} r_{, i}-\delta_{i j} r_{, k}\right]+2 r_{, i} r_{, j} r_{{ }_{k}}\right\} \\
& S_{k i j}^{*}=\frac{G}{2 \pi(1-v) r^{2}}\left\{2 \frac{\partial \mathrm{r}}{\partial \mathrm{n}}\left[(1-2 v) \delta_{i j} r_{{ }_{k}}+v\left(\delta_{i k} r_{j}+\delta_{j k} r, i\right)-4 r_{,} r_{{ }_{j}} r_{{ }_{k}}\right]\right. \\
& +2 v\left(n_{i} r_{, j} r_{,_{k}}+n_{j} r_{, i} r_{,_{k}}\right) \\
& \left.+(1-2 v)\left(2 n_{k} r_{, i} r_{, j}+n_{j} \delta_{i k}+n_{i} \delta_{j k}\right)-(1-4 v) n_{k} \delta_{i j}\right\}
\end{aligned}
$$

Observa-se que a solução fundamental de Kelvin para deslocamentos e forças de superfície possuem singularidade da ordem de $\ln (r)$ e $1 / r$ no ponto fonte. Surge então a necessidade de tratar essa singularidade, o que será feito por meio de Método de Subtração de Singularidade (MSS). No caso de núcleos hipersingulares da ordem de $1 / r^{2}$ como $S_{k i j}^{*}$ não será possível a solução analítica por meio do VPC, sendo necessário o uso do conceito de Parte Finita de Hadamart (PFH). Esses núcleos ocorrerão na formulação chamada Hipersingular.

\subsubsection{Método de Subtração de Singularidade (MSS) - Meio Isotrópico}

Segundo (ALIABADI, 2002 apud OLIVEIRA, 2013) uma maneira de tratar núcleos de integração singulares consiste em subtrair o ponto de singularidade dando origem a um novo núcleo regular e uma nova integral, ainda singular:

Figura 7. Separação de núcleo singular

\begin{tabular}{|l|l|}
\hline Singular & Singular \\
\hline
\end{tabular}




$$
\int_{-1}^{1} F(x) d x=\int_{-1}^{1}\left[F(x)-F^{*}(x)\right] d x+\int_{-1}^{1} F^{*}(x) d x
$$

FONTE: O autor.

Para que o segundo núcleo seja regular basta que $F^{*}(x)$ possua o mesmo grau de singularidade de $F(x)$, sendo então possível realizar a integração numericamente. A função $F^{*}(x)$ deve ser tal que o terceiro núcleo possa ser integrado analiticamente.

O procedimento de subtração de singularidade das soluções fundamentais foi realizado por (KZAM, 2009), tanto para núcleos singulares, no caso de ordem $\ln (r)$ e $1 / r$, quanto para hipersingulares, no caso de ordem de $1 / r^{2}$. As integrais singulares são avaliadas em um elemento tangente ao contorno no ponto fonte.

Figura 8. Configuração do elemento reto auxiliar - coordenadas adimensionais

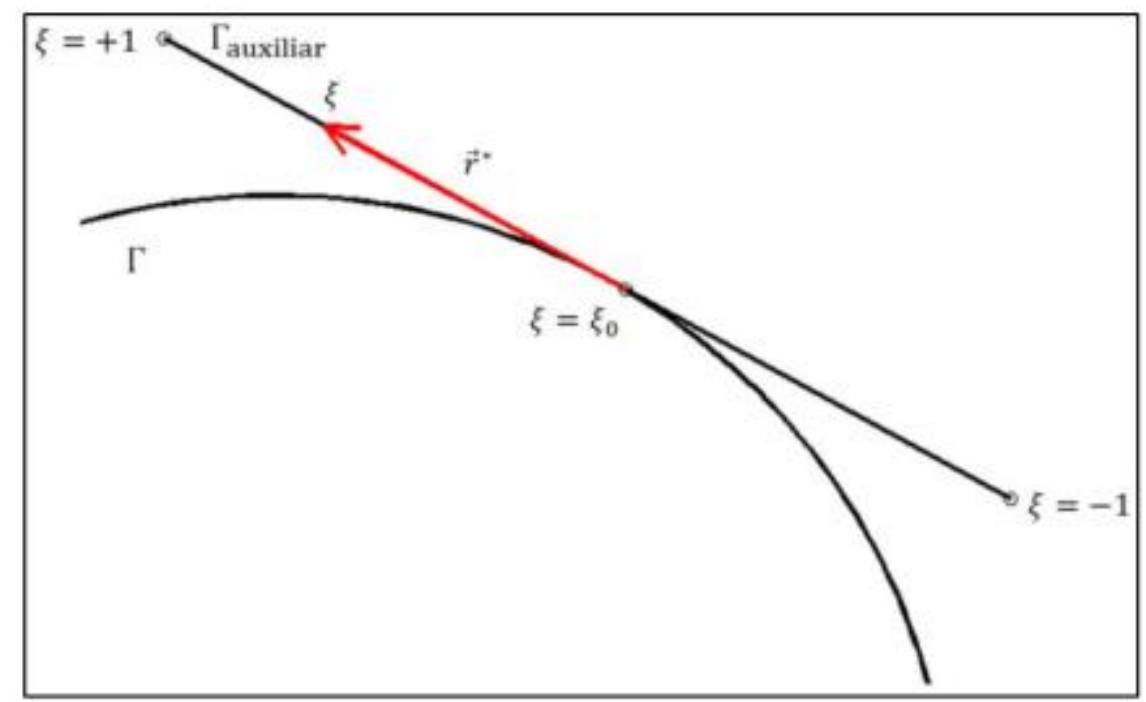

FONTE: (OLIVEIRA, 2013)

A coordenada adimensional será designada como sendo $\xi$, sendo a do ponto fonte $\xi_{0}$. A diferença será dada por $\epsilon$ :

$$
\epsilon=\xi-\xi_{0}
$$

A geometria do elemento de contorno curvo é dada por meio do uso das funções de forma. Ou seja:

$$
x_{i}(\xi)=\phi_{i}(\xi) x_{i}^{l}
$$

Sua derivada é dada então por:

$$
x_{i, j}(\xi)=\phi_{l, j}(\xi) x_{i}^{l}
$$


Expandindo-se por série de Taylor as coordenadas do ponto campo nas proximidades do ponto fonte e eliminando-se os termos de ordem superior:

$$
x_{i}(\xi)=x_{i}\left(\xi_{0}\right)+x_{i, \xi}\left(\xi_{0}\right) \epsilon
$$

A distância no elemento auxiliar do ponto de coordenada $\xi$ ao ponto fonte será dada pelo vetor $\vec{r}^{*}$ :

$$
r_{i}^{*}(\xi)=x(\xi)-x\left(\xi_{0}\right)=x_{i, \xi}\left(\xi_{0}\right) \epsilon
$$

A distância entre os pontos será então representada por $r^{*}$ :

$$
\begin{gathered}
r^{*}=\left|\vec{r}^{*}\right|=\sqrt{r_{i}^{*}(\xi) r_{i}^{*}(\xi)}=\sqrt{x_{i, \xi}\left(\xi_{0}\right) \epsilon x_{i, \xi}\left(\xi_{0}\right) \epsilon} \\
r^{*}=J\left(\xi_{0}\right)|\epsilon|
\end{gathered}
$$

Dada a Identidade Somigliana, equação (3.36), substituindo-se a solução fundamental (3.46) no termo referente a $u_{l k}^{*}$ obtém-se:

$$
\begin{gathered}
\int_{\Gamma} p_{k} u_{l k}^{*} d \Gamma=\int_{\Gamma}\left(u_{1} \ln (r) \delta_{l k}+u_{2} r_{,_{l}} r_{{ }_{k}}\right) p_{k} d \Gamma \\
u_{1}=\frac{-(3-4 v)}{8 \pi G(1-v)} \text { e } u_{2}=\frac{1}{8 \pi G(1-v)}
\end{gathered}
$$

Observa-se que a singularidade está em $\ln (r)$, logo procura-se remover a singularidade dessa parte da integral. Realizando a transformação de coordenadas e utilizando a aproximação de forças de superfície, sendo que $\phi_{m}$ representa as funções de forma, obtém-se:

$$
\begin{gathered}
p_{k}(\xi)=\phi_{m}(\xi) p_{k}^{m} \\
\int_{\Gamma} u_{1} \ln (r) \delta_{l k} p_{k} d \Gamma=\left[\int_{-1}^{1} u_{1} \ln (r) \delta_{l k} \phi_{m}(\xi) J_{j}(\xi) d \xi\right] p_{k}^{m j}
\end{gathered}
$$

É efetuada então a redução de singularidade. Sendo subtraída e somada integral sobre o elemento reto auxiliar obtém-se: 


$$
\begin{aligned}
\int_{-1}^{1} \ln (r) \phi_{m}(\xi) & J_{j}(\xi) d \xi \\
& =\int_{-1}^{1} \ln (r) \phi_{m}(\xi) J_{j}(\xi) d \xi-\int_{-1}^{1} \ln \left(r^{*}\right) \phi_{m}^{*}\left(\xi_{0}\right) J_{j}\left(\xi_{0}\right) d \xi \\
& +\int_{-1}^{1} \ln \left(r^{*}\right) \phi_{m}^{*}\left(\xi_{0}\right) J_{j}\left(\xi_{0}\right) d \xi
\end{aligned}
$$

A última integral poderá ser resolvida por meio do uso das integrais no sentido do Valor Principal de Cauchy (VPC).

Quanto às outras duas integrais pode-se escrever:

$$
\begin{array}{r}
\int_{-1}^{1} \ln (r) \phi_{m}(\xi) J_{j}(\xi) d \xi-\int_{-1}^{1} \ln \left(r^{*}\right) \phi_{m}^{*}\left(\xi_{0}\right) J_{j}\left(\xi_{0}\right) d \xi \\
=\int_{-1}^{1}\left[\ln (r) \phi_{m}(\xi) J_{j}(\xi)-\ln \left(r^{*}\right) \phi_{m}^{*}\left(\xi_{0}\right) J_{j}\left(\xi_{0}\right)\right] d \xi
\end{array}
$$

Observa-se que no ponto fonte as equações terão o mesmo valor, dessa forma ocorrerá a efetiva subtração da singularidade. A integral poderá então ser resolvida numericamente.

Figura 9. Configuração de elemento reto auxiliar, setas indicam o sentido de integração.

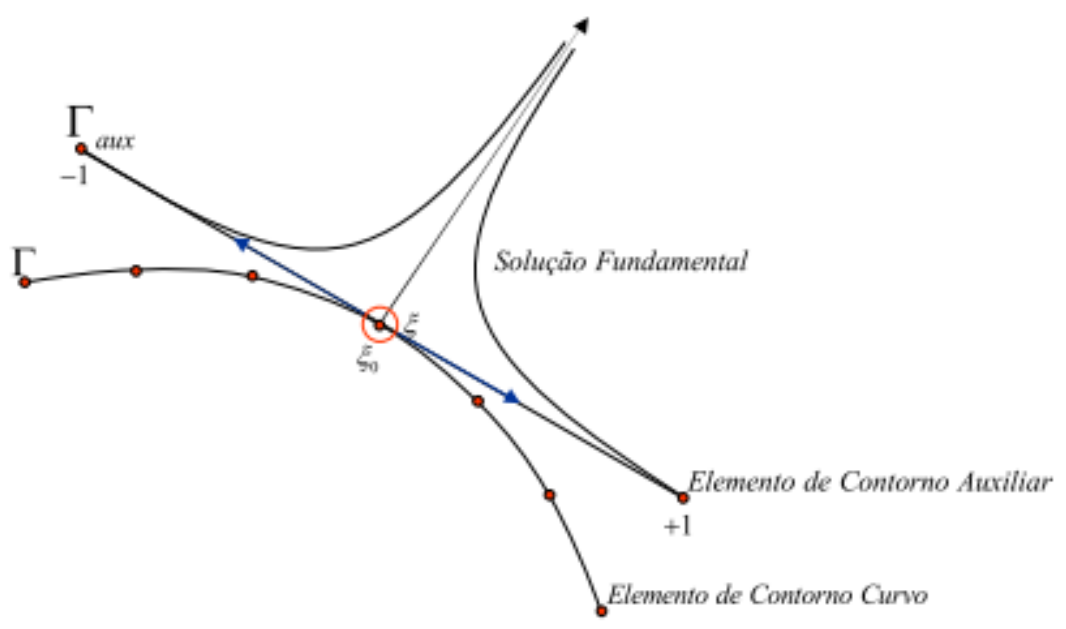

FONTE: (KZAM, 2009)

Quanto ao termo da identidade Somigliana referente a $p_{l k}^{*}$, procede-se da mesma forma, resolvendo-se a integral singular por meio do Valor Principal de Cauchy. 


\subsubsection{Solução Fundamental - Meio Anisotrópico}

Para o caso de material anisotrópico, a grande diferença em relação ao isotrópico se dá na Solução Fundamental, apresentada por (CRUZE \& SWEDLOW, 1971 apud CORDEIRO, 2015), desenvolvida com uso da teoria das funções complexas.

Primeiramente, é necessária a obtenção das raízes $\mu_{1}, \mu_{2}, \overline{\mu_{1}}$ e $\overline{\mu_{2}}$ da seguinte equação:

$$
C_{11} \mu^{4}-2 C_{16} \mu^{3}+\left(2 C_{12}+C_{66}\right) \mu^{2}-2 C_{26} \mu+C_{22}=0
$$

sendo que $\overline{\mu_{1}}$ é a raiz complexa conjugada de $\mu_{1}$, o mesmo valendo para $\overline{\mu_{2}}$.

Em seguida calcula-se a matriz de parâmetros complexos $q_{k m}$ :

$$
\left\{\begin{array}{l}
q_{k 1} \\
q_{k 2}
\end{array}\right\}=\left\{\begin{array}{l}
C_{11} \mu_{k}^{2}+C_{12}-C_{16} \mu_{k} \\
C_{12} \mu_{k}^{2}+C_{22}-C_{26} \mu_{k}
\end{array}\right\}
$$

Deve-se então encontrar as soluções do seguinte sistema complexo:

$$
\left[\begin{array}{cccc}
1 & -1 & 1 & -1 \\
\mu_{1} & -\overline{\mu_{1}} & \mu_{2} & -\overline{\mu_{2}} \\
q_{11} & -\overline{q_{11}} & q_{12} & -\overline{q_{12}} \\
q_{21} & -\overline{q_{21}} & q_{22} & -\overline{q_{22}}
\end{array}\right]\left\{\begin{array}{l}
A_{l 1} \\
\overline{A_{l 1}} \\
A_{l 2} \\
\overline{A_{l 2}}
\end{array}\right\}=\left\{\begin{array}{c}
-\delta_{l 2} / 2 \pi i \\
-\delta_{l 1} / 2 \pi i \\
0 \\
0
\end{array}\right\}
$$

Ao final, a solução em deslocamentos fica escrita da seguinte forma:

$$
u_{l k}^{*}=2 \operatorname{Re}\left[q_{k 1} A_{l 1} \ln \left(z_{1}-z_{1}^{0}\right)+q_{k 2} A_{l 2} \ln \left(z_{2}-z_{2}^{0}\right)\right]
$$

E, no caso de forças de superfície, o resultado é o seguinte:

$$
p_{l k}^{*}=2 R e\left[\frac{1}{z_{1}-z_{1}^{0}} g_{k 1}\left(\mu_{1} \eta_{1}-\eta_{2}\right) A_{l 1}+\frac{1}{z_{2}-z_{2}^{0}} g_{k 2}\left(\mu_{2} \eta_{1}-\eta_{2}\right) A_{l 2}\right]
$$

sendo que $\eta_{p}$ representa o versor normal ao exterior do corpo e $g_{k m}$ é dado por:

$$
g_{k m}=\left[\begin{array}{cc}
\mu_{1} & \mu_{2} \\
-1 & -1
\end{array}\right]
$$

Similarmente ao caso isotrópico, a Solução Fundamental Anisotrópica também apresenta singularidades, procedendo sua integração com uso de MSS, com uso do conceito do VPC e PFH. 


\subsection{Acoplamento MEC - enrijecedor}

Será realizada a diferenciação entre o acoplamento MEC/MEF para sub-regiões adjacentes e o acoplamento MEC com enrijecedores.

No caso do acoplamento MEC/MEF para sub-regiões adjacentes haverá acoplamento somente da interface entre os métodos. É imposta a compatibilidade de deslocamentos, ou seja, para o contorno das duas sub-regiões o deslocamento será o mesmo. Além disso, é imposto o equilibrio, que nesse caso significa que as forças de superfície para as duas sub-regiões são de mesmo valor absoluto e opostas, ou seja, se anulam.

De outra forma, no acoplamento MEC com enrijecedores estes estão presentes em qualquer direção dentro do domínio do MEC, que será chamado de Domínio. Na formulação do MEC o meio é considerado homogêneo. Para se levar em conta a existência de enrijecedores é utilizada então a superposição de efeitos, sendo o acoplamento realizado através da aplicação das condições de compatibilidade e equilibrio sobre os nós das fibras.

Foram adotados enrijecedores, também chamados de fibras, lineares com rigidez somente na direção axial, ou seja, elementos de treliça. Da mesma forma que realizado por (LEONEL, 2009) para o acoplamento MEC/MEF, os dois métodos são utilizados separadamente para então ser realizada a superposição de efeitos:

Figura 10. Acoplamento MEC/MEF.

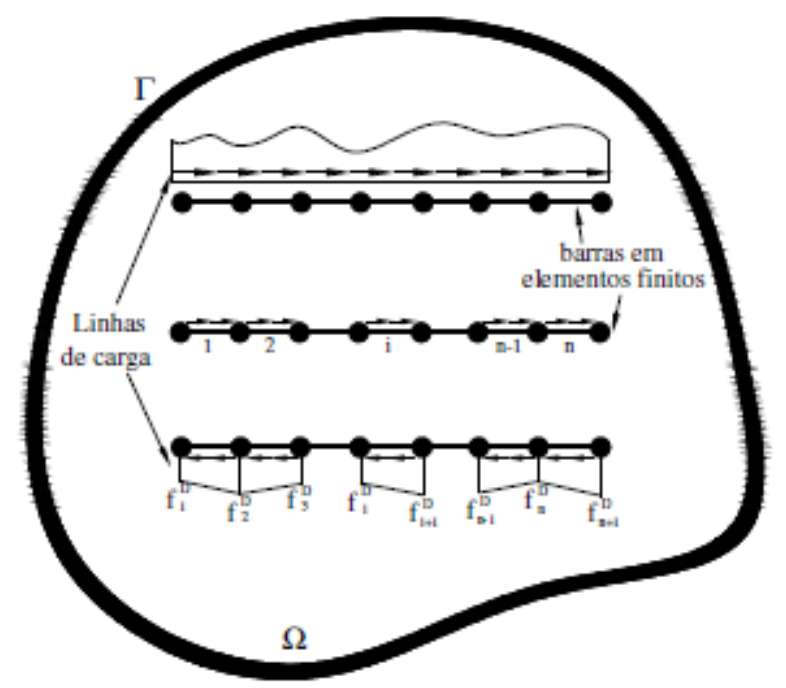

FONTE: (LEONEL, 2009)

A aderência entre os enrijecedores e o Domínio causa o surgimento de forças distribuídas, estas são chamadas de linhas de carga ou forças de aderência. Por equilíbrio, a força aplicada sobre a fibra deve ser oposta à carga aplicada sobre o Domínio, ou seja: 


$$
f^{D}=-f^{F}
$$

onde $f^{D}$ e $f^{F}$ são forças sobre o Domínio e sobre a fibra respectivamente.

Desconsiderando-se o escorregamento das fibras, o deslocamento nos pontos delas deve ser igual para os dois métodos, ou seja:

$$
u^{D}=u^{F}
$$

Utilizando-se a formulação do MEC para o contorno, a partir da Identidade Somiglia na, Eq. (3.36), obtêm-se a seguinte equação:

$$
H_{C C} u_{C}=G_{C C} p_{C}+G_{C F} f^{D}
$$

onde o primeiro índice indica a localização do ponto fonte e o segundo a localização dos elementos por ele integrados, ou seja:

$H_{C C}$ é a matriz $H$ obtida pelo MEC para os pontos do contorno integrados no contorno.

$G_{C C}$ é a matriz $G$ obtida pelo MEC para os pontos do contorno integrados no contorno.

$G_{C F}$ é a matriz $G$ obtida pelo MEC para os pontos do contorno integrados na fibra.

Utilizando-se a formulação do MEC para o enrijecedor obtêm-se a seguinte equação:

$$
u_{F}+H_{F C} u_{C}=G_{F C} p_{C}+G_{F F} f^{D}
$$

$H_{F C}$ é a matriz $H$ obtida pelo MEC para os pontos da fibra integrados no contorno.

$G_{F C}$ é a matriz $G$ obtida pelo MEC para os pontos da fibra integrados no contorno.

$G_{F F}$ é a matriz $G$ obtida pelo MEC para os pontos da fibra integrados na fibra.

Para concluir o acoplamento fica faltando a equação algébrica do próprio enrijecedor, esta pode ser escrita da seguinte forma:

$$
K_{F} u_{F}=G_{F} f^{F}
$$

A diferença entre os métodos utilizados para modelar o enrijecedor só ocorrem na obtenção dessa última equação, sendo indiferente se o meio é isotrópico ou anisotrópico. Para o caso do acoplamento MEC/MEF é necessária aproximação tanto para deslocamentos quanto para a força distribuída. Com o uso do acoplamento MEC/MEC 1D é necessária aproximação somente da força distribuída. 
Unindo as equações (3.71), (3.72) e (3.73) obtêm-se:

$$
\left[\begin{array}{ccc}
H_{C C} & 0 & -G_{C F} \\
H_{F C} & I & -G_{F F} \\
0 & K_{F} & G_{F}
\end{array}\right]\left\{\begin{array}{l}
u_{c} \\
u_{F} \\
f^{D}
\end{array}\right\}=\left\{\begin{array}{c}
G_{C C} \\
G_{F C} \\
0
\end{array}\right\} p_{c}
$$

Dessa forma é possível finalmente obter-se a solução do problema efetuando o processo de troca de colunas.

Observa-se que as linhas de cargas são incógnitas do problema, para sua obtenção é necessário o uso de funções aproximativas. É adotada a técnica dos Elementos Finitos para realizar a sua aproximação, de forma que são obtidos então seus valores nodais. No caso do acoplamento com o MEF, é adotado o mesmo grau de aproximação, desta forma para todos os nós do problema são obtidos resultados de deslocamentos e de força de aderência. Além disso, foi adotada formulação do MEF onde podem ser utilizados elementos de qualquer grau de aproximação, sendo então construídas as matrizes por meio de integração numérica.

\subsection{Método dos Elementos de Contorno Unidimensional (MEC 1D)}

Em (CRUZ, 2012) é apresentada a solução fundamental para o MEC 1D. Por meio dessa solução é possível o desenvolvimento da formulação para o caso de barras de treliça com forças distribuídas, necessária para a representação do enrijecedor em uma malha de elementos de contorno.

O equilibrio de uma barra de treliça é dado pela seguinte equação:

$$
\frac{d N(x)}{d x}=-p(x)
$$

sendo que $N(x)$ é a força normal no elemento, $p(x)$ é a força distribuída sobre o elemento e $x$ é o eixo longitudinal.

Aplicando-se a relação constitutiva e a relação de compatibilidade obtém-se a relação:

$$
N(x)=E A \frac{d u(x)}{d x}
$$

onde $E$ é o módulo de elasticidade longitudinal, ou módulo de Young, $A$ é a área da seção transversal.

Substituindo-se a Eq. (3.76) na Eq. (3.75) é obtida a equação governante do problema de barra de treliça em termos de deslocamento: 


$$
E A \frac{d^{2} u(x)}{d x^{2}}=-p(x)
$$

Seja $u^{*}$ a função peso, a forma variacional direta é dada por:

$$
\int_{0}^{L}\left(E A \frac{d^{2} u(x)}{d x^{2}}+p(x)\right) u^{*} d x=0
$$

Integrando por partes:

$$
\left[E A \frac{d u(x)}{d x} u^{*}\right]_{0}^{L}-\int_{0}^{L}\left[\frac{d u}{d x} E A \frac{d u^{*}}{d x}-p(x)\right] u^{*} d x=0
$$

Integrando o segundo termo por partes novamente:

$$
\left[E A \frac{d u(x)}{d x} u^{*}\right]_{0}^{L}+\int_{0}^{L}\left[u(x) E A \frac{d^{2} u^{*}}{d x^{2}}+p(x) u^{*}\right] d x=0
$$

A função peso $u^{*}$ é escolhida de forma que as relações (3.76) e (3.77) sejam válidas. Substituindo-se estas relações na Eq. (3.80) obtém-se:

$$
\left[N(x) u^{*}\right]_{0}^{L}-\left[u(x) N^{*}\right]_{0}^{L}=\int_{0}^{L} u(x) p^{*} d x-\int_{0}^{L} p(x) u^{*} d x
$$

O diferencial do MEC 1D se trata da escolha da função peso $p^{*}$. Da mesma forma que para o MEC ela é escolhida de forma a evitar integração no domínio, sendo utilizado para isto o Delta de Dirac. Assim:

$$
p^{*}(x, \hat{x})=\Delta(x, \hat{x})
$$

$\Delta(x, \hat{x})$ é o Delta de Dirac;

$x$ é o ponto a ser avaliado, chamado Ponto Campo;

$\hat{x}$ é o ponto de aplicação do Delta de Dirac, chamado Ponto Fonte.

A solução da equação anterior é chamada Solução Fundamental do MEC 1D.

Desta forma, não é mais necessária a integração de deslocamentos no domínio:

$$
\int_{0}^{L} u(x) p^{*}(x, \hat{x}) d x=u(\hat{x})
$$


A Eq. (3.81) assume então a seguinte forma:

$$
u(\hat{x})+\left[u(x) N^{*}(x, \hat{x})\right]_{0}^{L}=\left[N(x) u^{*}(x, \hat{x})\right]_{0}^{L}+\int_{0}^{L} p(x) u^{*}(x, \hat{x}) d x
$$

Por meio desta equação e com uso da solução fundamental encontra-se a resposta para o contorno do elemento de treliça, ou seja, suas extremidades. A Solução Fundamental é encontrada em (CRUZ, 2012):

$$
\begin{gathered}
u^{*}(x, \hat{x})=-\frac{|x-\hat{x}|}{2 E A} \\
N^{*}(x, \hat{x})=E A \frac{d u^{*}(x, \hat{x})}{d x}=-\frac{1}{2} \operatorname{sign}(x-\hat{x})
\end{gathered}
$$

Será adotada a seguinte nomenclatura:

$$
N_{i j}^{*} \quad i \rightarrow \text { Ponto Fonte } j \rightarrow \text { Ponto avaliado }
$$

Para uma barra com $n$ nós, são avaliados os nós extremos:

$$
\left\{\begin{array}{l}
u_{1} \\
u_{n}
\end{array}\right\}_{L}+\left[\begin{array}{ll}
-N_{11}^{*} & N_{1 n}^{*} \\
-N_{n 1}^{*} & N_{n n}^{*}
\end{array}\right]\left\{\begin{array}{l}
u_{1} \\
u_{n}
\end{array}\right\}_{L}=\left[\begin{array}{ll}
-u_{11}^{*} & u_{1 n}^{*} \\
-u_{n 1}^{*} & u_{n n}^{*}
\end{array}\right]\left\{\begin{array}{l}
N_{1} \\
N_{n}
\end{array}\right\}+\left\{\begin{array}{l}
q_{1} \\
q_{n}
\end{array}\right\}
$$

A primeira linha refere-se ao ponto fonte 1 e a segunda ao ponto fonte $n$. Além disso foi definido o seguinte vetor de integrais da força distribuída:

$$
q_{i}=\int_{0}^{L} p(x) u^{*}\left(x, \hat{x}_{i}\right) d x
$$

Mas as forças normais na equação não estão nos eixos locais, o valor positivo está indicando força de tração e negativo de compressão. Para deixá-las no eixo local tem-se:

$$
\left\{\begin{array}{l}
N_{1} \\
N_{n}
\end{array}\right\}=\left\{\begin{array}{c}
-N_{1} \\
N_{n}
\end{array}\right\}_{L}
$$

Ou seja:

$$
\left[\begin{array}{cc}
1-N_{11}^{*} & N_{1 n}^{*} \\
-N_{n 1}^{*} & 1+N_{n n}^{*}
\end{array}\right]\left\{\begin{array}{l}
u_{1} \\
u_{n}
\end{array}\right\}=\left[\begin{array}{ll}
u_{11}^{*} & u_{1 n}^{*} \\
u_{n 1}^{*} & u_{n n}^{*}
\end{array}\right]\left\{\begin{array}{l}
N_{1} \\
N_{n}
\end{array}\right\}_{L}+\left\{\begin{array}{l}
q_{1} \\
q_{n}
\end{array}\right\}
$$

De outra forma, nomeando as matrizes:

$$
[A]\{u\}_{L}=[B]\{N\}_{L}+\{q\}
$$


A equação anterior também pode ser escrita da forma:

$$
[B]^{-1}[A]\{u\}_{L}=\{N\}_{L}+[B]^{-1}\{q\}
$$

Busca-se realizar o cálculo das integrais da força distribuída $q_{i}$. Fazendo mudança de espaço obtêm-se:

$$
q_{i}=\int_{-1}^{1} p(\xi) u^{*}\left(\xi, \hat{\xi}_{i}\right) J d \xi
$$

sendo que $J$ é o Jacobiano da função.

Observa-se que até o momento não foram introduzidas aproximações. Entretanto, no acoplamento do MEC/MEC 1D é necessário aproximar a forças distribuídas sobre o enrijecedor, as quais são as forças transmitidas para ele pelo meio em que ele está inserido, o Domínio. Para fazer a aproximação será feito o uso da técnica dos elementos finitos, por meio das funções de forma, com $b_{i}$ sendo os valores nodais da força distribuída:

$$
p(\xi)=\phi_{i}(\xi) b_{i}
$$

Como as forças distribuídas são definidas pelos valores nodais, mantém-se o conceito de elementos lineares, quadráticos, etc., entretanto isto somente significará que as forças distribuídas são aproximadas por este grau de aproximação dentro do elemento.

Introduzindo-se a equação (3.94) na equação (3.93) obtém-se:

$$
q_{i}=\int_{-1}^{1} \phi_{j}(\xi) u^{*}\left(\xi, \hat{\xi}_{i}\right) J d \xi b_{j}
$$

Pode se escrever então:

$$
\{q\}=[C]\{b\}_{L}
$$

Sendo que [C] é dado por:

$$
C_{i j}=\int_{-1}^{1} u^{*}\left(\xi, \hat{\xi}_{i}\right) \phi_{j}(\xi) J d \xi
$$

Substituindo-se a Eq. (3.96) em (3.92):

$$
[B]^{-1}[A]\{u\}_{L}=\{N\}_{L}+[B]^{-1}[C]\{b\}_{L}
$$


Esse formato de equações é similar ao utilizado no $\mathrm{MEF}$, entretanto só é válido para o contorno dos elementos. Para que o formato se torne o mesmo se faz necessário que sejam incluídos na equação anterior os pontos internos dos elementos.

\subsubsection{Pontos Internos}

No acoplamento de métodos é de interesse que seja possível que o elemento possua qualquer número de nós. Isso proporcionará que a força distribuída possua aproximação de polinômio de qualquer ordem. Busca-se então incluir na equação os pontos internos. Para o caso de ponto interno $j$ a equação seria a seguinte:

$$
u_{j}-N_{j 1}^{*} u_{1}+N_{j n}^{*} u_{n}=-u_{j 1}^{*} N_{1}+u_{j n}^{*} N_{n}+q_{j}
$$

Acrescentando-se às matrizes dos pontos extremos:

$$
\left\{\begin{array}{l}
u_{1} \\
u_{j} \\
u_{n}
\end{array}\right\}_{L}+\left[\begin{array}{lll}
-N_{11}^{*} & 0 & N_{n 1}^{*} \\
-N_{j 1}^{*} & 0 & N_{j n}^{*} \\
-N_{n 1}^{*} & 0 & N_{n n}^{*}
\end{array}\right]\left\{\begin{array}{l}
u_{1} \\
u_{j} \\
u_{n}
\end{array}\right\}_{L}=\left[\begin{array}{ccc}
u_{11}^{*} & 0 & u_{n 1}^{*} \\
u_{j 1}^{*} & 0 & u_{j n}^{*} \\
u_{n 1}^{*} & 0 & u_{n n}^{*}
\end{array}\right]\left\{\begin{array}{l}
N_{1} \\
N_{j} \\
N_{n}
\end{array}\right\}_{L}+\left\{\begin{array}{l}
q_{1} \\
q_{j} \\
q_{n}
\end{array}\right\}_{L}
$$

Observa-se que nesse caso:

$$
B=\left[\begin{array}{lll}
u_{11}^{*} & 0 & u_{n 1}^{*} \\
u_{j 1}^{*} & 0 & u_{j n}^{*} \\
u_{n 1}^{*} & 0 & u_{n n}^{*}
\end{array}\right]
$$

A matriz $B$ obtida não é inversível. Entretanto, observando que $N_{j}=0$, pode-se adotar então $B_{j j}=E A / L$ sem prejuízo para o produto $[B]\{N\}$.

Incorporando-se o ponto interno à Eq. (3.98) conforme (3.100) e (3.101) e agrupando as matrizes obtêm-se a equação:

$$
\begin{gathered}
{[K]_{L}\{u\}_{L}=\{N\}_{L}+[G]_{L}\{b\}_{L}} \\
{[K]_{L}=[B]^{-1}[A] e[G]_{L}=[B]^{-1}[C]}
\end{gathered}
$$

Esse formato de equações é o mesmo utilizado no Método dos Elementos Finitos. É interessante para que seja realizado o acoplamento de métodos, ou mesmo para que seja efetuada a rotação e união de elementos, como será explicado adiante.

Após a solução do problema, com obtenção de $u_{G}$, e $b_{G}$, procura-se encontrar os valores dos esforços normais dos elementos, para isto é utilizada a equação (3.75) na seguinte forma: 


$$
\{N\}_{L}=[K]_{L}\{u\}_{L}-[G]_{L}\{b\}_{L}
$$

Entretanto, a equação anterior fornece somente os valores dos esforços normais nos nós extremos do elemento, procura-se também os valores nos nós internos. Uma vez que está sendo utilizado o MEC 1D, somente a força distribuída é definida ao longo do elemento. Com base nisso, para a obtenção dos esforços normais pode ser utilizada a Eq (3.75), já apresentada anteriormente.

Integrando-se até o ponto de interesse $j$, sendo 1 o primeiro ponto do elemento:

$$
N_{j}=N_{1}-\int_{0}^{L_{j}} p(x) d x=N_{1}-\left(\int_{0}^{L_{j}} \phi_{i} d x\right) b_{i}
$$

Foi adotada a estratégia de se realizar a mudança de espaço em 2 etapas, sendo a primeira em relação ao elemento inteiro e a segunda em relação à parte do elemento que deve realmente ser integrada. Desta forma, realizando mudança de espaço em relação ao elemento inteiro obtém-se:

$$
N_{J}=N_{1}-\left(\int_{-1}^{\xi_{j}} \phi_{i}(\xi) J d \xi\right) b_{i}
$$

O Jacobiano $J$ é calculado da forma usual. Em seguida é realizada nova mudança de espaço, em relação ao intervalo entre -1 e $\xi_{j}$, com o cálculo do Jacobiano Equivalente $J_{E}$ :

$$
\begin{gathered}
N_{J}=N_{1}-\left(\int_{-1}^{1} \phi_{i}(\xi) J J_{E} d \xi_{E}\right) b_{i} \\
J_{E}=\frac{\xi_{j}+1}{2} \\
\xi=\left(\xi_{E}+1\right) * \frac{\xi_{j}+1}{2}-1
\end{gathered}
$$

Desta forma pode-se integrar numericamente para obtenção dos esforços normais, tanto para o MEC 1D quanto para o MEF.

\subsubsection{Rotação e União de Elementos}

Tanto para o acoplamento quanto para a união de elementos é necessário que os eixos adotados sejam os mesmos, ou seja, globais. Para isso então efetua-se a rotação dos eixos dos 
elementos da mesma forma que para elementos finitos, similarmente ao que se encontra em (PROENÇA, 2010).

A rotação dos elementos é efetuada por meio do uso da matriz de rotação $R$, ortogonal própria, de forma que:

$$
\begin{gathered}
{[R]^{-1}=[R]^{T}} \\
\{u\}_{G}=[R]\{u\}_{L} \\
\{N\}_{G}=[R]\{N\}_{L} \\
\{b\}_{G}=[R]\{b\}_{L}
\end{gathered}
$$

Substituindo-se na Eq. (3.75):

$$
[K]_{L}[R]^{T}\{u\}_{G}=[R]^{T}\{N\}_{G}+[G]_{L}[R]^{T}\{b\}_{G}
$$

Logo:

$$
[R][K]_{L}[R]^{T}\{u\}_{G}=\{N\}_{G}+[R][G]_{L}[R]^{T}\{b\}_{G}
$$

Portanto, pode-se escrever as matrizes rotacionadas da seguinte forma:

$$
\begin{aligned}
{[K]_{G} } & =[R][K]_{L}[R]^{T} \\
{[G]_{G} } & =[R][G]_{L}[R]^{T}
\end{aligned}
$$

Já para a união de elementos é imposta a compatibilidade de deslocamentos e equilíbrio do nó comum $i$, traduzindo-se nas seguintes equações:

$$
\begin{gathered}
u_{i}^{(1)}=u_{i}^{(2)} \\
N_{i}^{(1)}+N_{i}^{(2)}=0
\end{gathered}
$$

onde:

$u_{i}^{(1)}$ é o deslocamento do nó $i$ para o elemento 1

$u_{i}^{(2)}$ é o deslocamento do nó $i$ para o elemento 2

$N_{i}^{(1)}$ é a força normal aplicada sobre o nó $i$ para o elemento 1

$N_{i}^{(2)}$ é a força normal aplicada sobre o nó $i$ para o elemento 2 
Da mesma forma que em (PROENÇA, 2010) é feito para elementos finitos pode-se unir as equações dos elementos em somente uma equação global, da seguinte forma:

$$
[K]_{G}\{u\}_{G}=\{N\}_{G}+[G]_{G}\{b\}_{G}
$$




\section{MEC 1D - VALIDAÇÃO E APLICAÇÃO}

De forma a validar a formulação implementada, serão analisadas estruturas cujas respostas mecânicas sejam conhecidas. Primeiramente será testada a formulação do MEC 1D com elementos na mesma direção para em seguida se testar com rotação de elementos.

\subsection{MEC 1D - Exemplo 1: Elemento com força distribuída linear}

Será, inicialmente, avaliado o caso de um elemento isolado com força normal distribuída de forma linear, conforme ilustra a Figura 11:

Figura 11. Elemento com força normal distribuída de forma linear

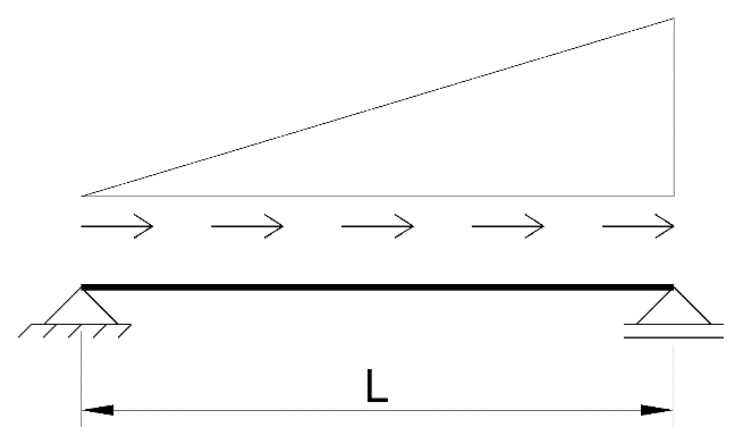

FONTE: O autor.

Nesse caso, foi adotado $L$ como sendo o comprimento do elemento e a força distribuída foi definida pela seguinte fórmula, sendo $a$ um valor constante:

$$
p(x)=a \cdot x
$$

As relações (3.75), (3.76) e (3.77) são válidas:

$$
\begin{aligned}
& N(x)=u^{\prime}(x) E A \\
& u^{\prime \prime}(x)=-\frac{p(x)}{E A}
\end{aligned}
$$

Ou seja:

$$
u^{\prime \prime}(x)=-\frac{a \cdot x}{E A}
$$

Como condições de contorno foi adotado:

$$
\begin{gathered}
u(0)=0 \\
N(\quad)=0
\end{gathered}
$$


Dessa forma:

$$
u^{\prime}(L)=0
$$

Integrando-se (4.3):

$$
u^{\prime}(x)=-\frac{a \cdot x^{2}}{2 E A}+C_{1}
$$

Aplicando as condições de contorno:

$$
\begin{gathered}
C_{1}=\frac{a \cdot L^{2}}{2 E A} \\
u^{\prime}(x)=-\frac{a \cdot x^{2}}{2 E A}+\frac{a \cdot L^{2}}{2 E A} \\
N(x)=-\frac{a \cdot x^{2}}{2}+\frac{a \cdot L^{2}}{2}
\end{gathered}
$$

Integrando-se (4.9) e aplicando-se a condição de contorno essencial obtêm-se a solução analítica:

$$
u(x)=-\frac{a \cdot x^{3}}{6 E A}+\frac{a \cdot L^{2} \cdot x}{2 E A}
$$

Quanto à reação de apoio $\mathrm{R}$, pode ser obtida pela equação (4.10):

$$
R=-N(0)=-\frac{a \cdot L^{2}}{2}
$$

Dado que a resposta analítica é conhecida, foi efetuada a comparação com o resultado da formulação do MEC 1D. Adotou-se:

$$
\begin{aligned}
& a=1 \\
& L=6
\end{aligned}
$$


A barra foi discretizada com 5 nós. Foram utilizados primeiramente 4 elementos lineares, em seguida 2 elementos quadráticos e ao final 1 elemento do quarto grau. O resultado pode se observar na figura a seguir:

Figura 12. Resposta do MEC 1D - Força distribuída de forma linear

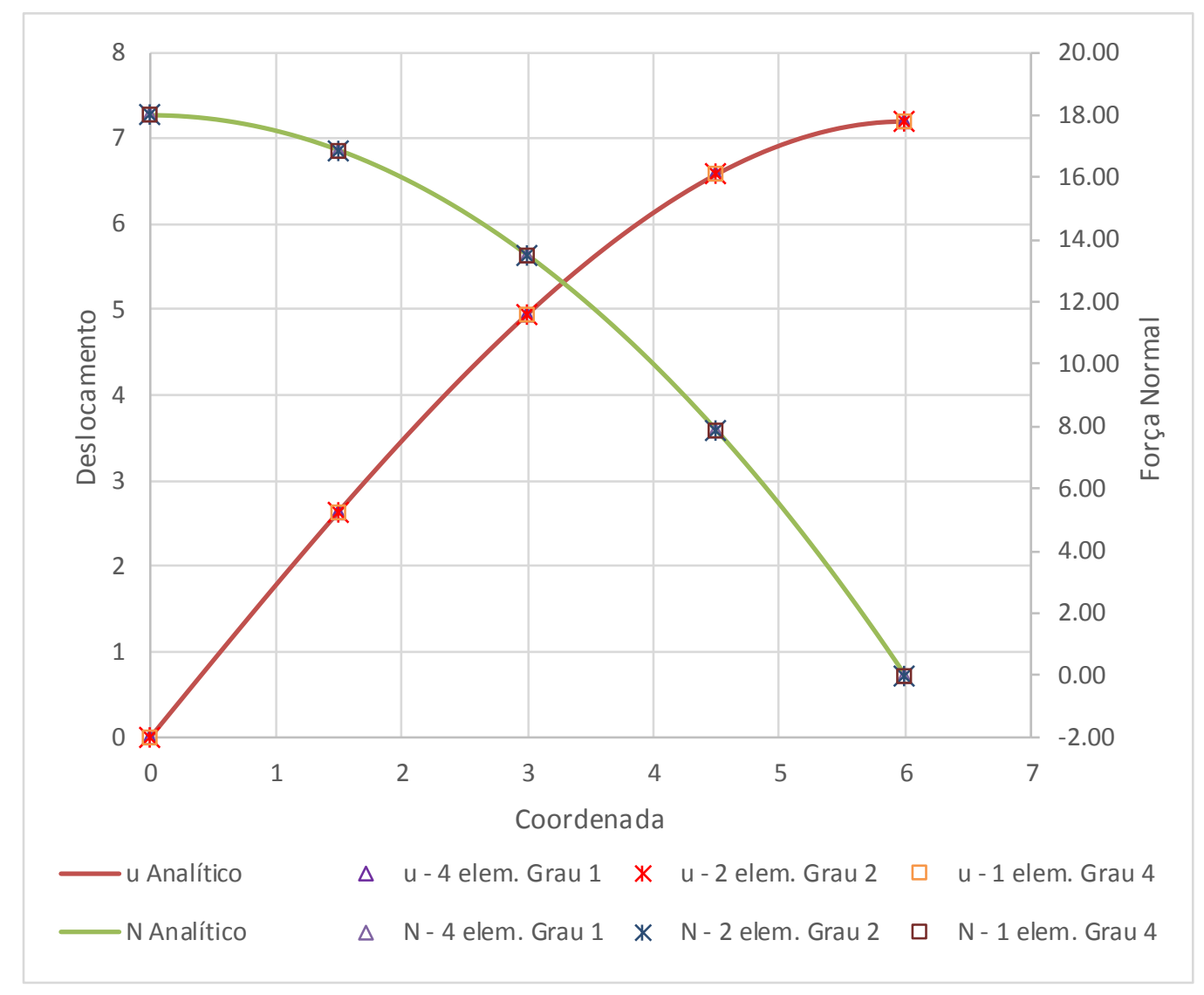

FONTE: O autor

Foi realizado o cálculo do erro dos resultados, para isso foi utilizada a seguinte fórmula:

$$
\text { Erro }=\left|\frac{x_{M E C 1 D}-x_{F T O O L}}{x_{F T O O L}}\right|
$$

onde $x$ é a variável sendo avaliada.

Nesse caso, o erro máximo tanto para deslocamento dos pontos quanto para a reação de apoio foi de 4,44E-15. Portanto, não se tratou de erro propriamente, e sim de truncamento próprio do computado. Ou seja, pode ser considerado que a resposta numérica coincide com a resposta analítica. 


\subsection{MEC 1D - Exemplo 2: Elemento com força distribuída quadrática}

Será avaliado agora o caso de um elemento com força distribuída, regida de forma quadrática, da seguinte equação:

$$
p(x)=a \cdot x^{2}
$$

Tem-se então que:

$$
u^{\prime \prime}(x)=-\frac{a \cdot x^{2}}{E A}
$$

Condições de contorno:

$$
\begin{aligned}
& u(0)=0 \\
& N(L)=0
\end{aligned}
$$

Integrando-se (4.16):

$$
u^{\prime}(x)=-\frac{a \cdot x^{3}}{3 E A}+C_{1}
$$

Mas, utilizando a relação (3.76) em (4.17) observa-se condição de contorno em termos de derivada de deslocamentos:

$$
u^{\prime}(L)=0
$$

Logo:

$$
\begin{gathered}
C_{1}=\frac{a \cdot L^{3}}{3 E A} \\
u^{\prime}(x)=-\frac{a \cdot x^{3}}{3 E A}+\frac{a \cdot L^{3}}{3 E A} \\
N(x)=-\frac{a \cdot x^{3}}{3}+\frac{a \cdot L^{3}}{3}
\end{gathered}
$$

Integrando-se novamente e aplicando-se a condição de contorno em deslocamentos obtém-se:

$$
u(x)=-\frac{a \cdot x^{4}}{12 E A}+\frac{a \cdot L^{3} \cdot x}{3 E A}
$$


A reação de apoio $R$ é dada então por:

$$
R=-N(0)=-\frac{a \cdot L^{3}}{3}
$$

Foi efetuada novamente comparação do resultado da formulação do MEC $1 \mathrm{D}$ com 5 nós, sendo utilizados 4 elementos lineares, 2 elementos quadráticos ou 1 elemento do quarto grau. Adotou-se:

$$
\begin{aligned}
& a=1 \\
& L=6
\end{aligned}
$$

O resultado pode ser observado na figura a seguir:

Figura 13. Resposta do MEC 1D - Força distribuída de forma quadrática

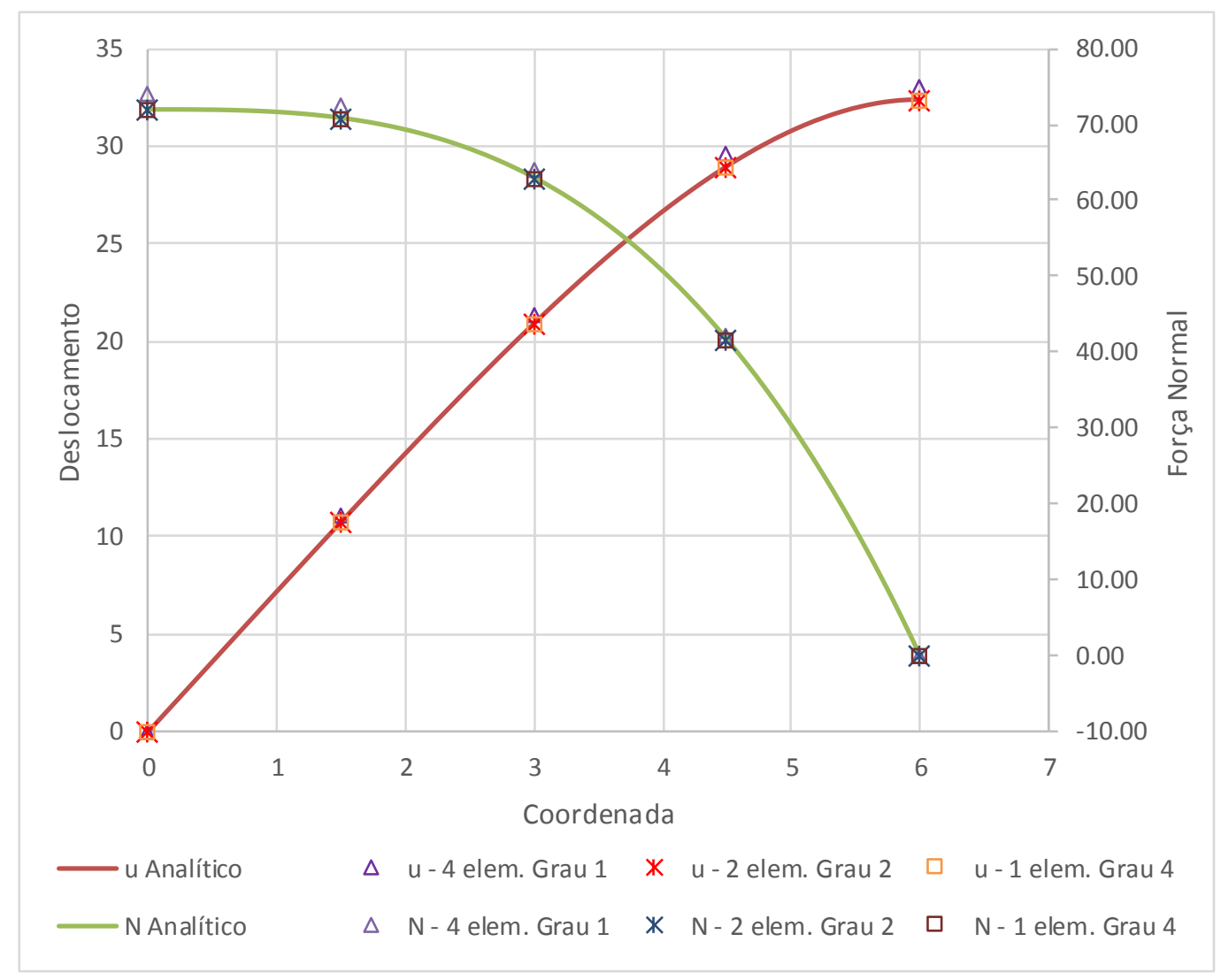

FONTE: O autor.

Novamente calculou-se o erro dos resultados, conforme equação (4.14). No caso de uso de elementos quadráticos e do quarto grau o erro máximo foi de 2,39E-15, podendo ser considerado que coincidem com a resposta analítica. Entretanto, no caso de uso de elementos lineares foi obtido erro relevante, 3,13E-02. O erro é justificável pelo fato da força distribuída 
ser descrita através da Técnica dos Elementos Finitos, conforme a equação (3.94). Ou seja, como ela é definida através dos valores nodais, com o uso de elementos lineares ela também está sendo considerada linear dentro dos elementos. Como foi adotada força distribuída quadrática, ao considera-la linear dentro dos elementos ocorre erro. $\mathrm{O}$ aumento da discretização da barra é uma opção para redução deste erro.

A última configuração foi reanalisada utilizando-se elemento com 41 nós. Utilizandose o MEC 1D a quantidade de nós possui menor influência sobre o resultado, uma vez que na prática a solução se dá por meio dos nós do contorno. A resposta para os nós internos é obtida por pós-processamento:

Figura 14. Resposta do MEC 1D, 41 nós - Força distribuída de forma quadrática

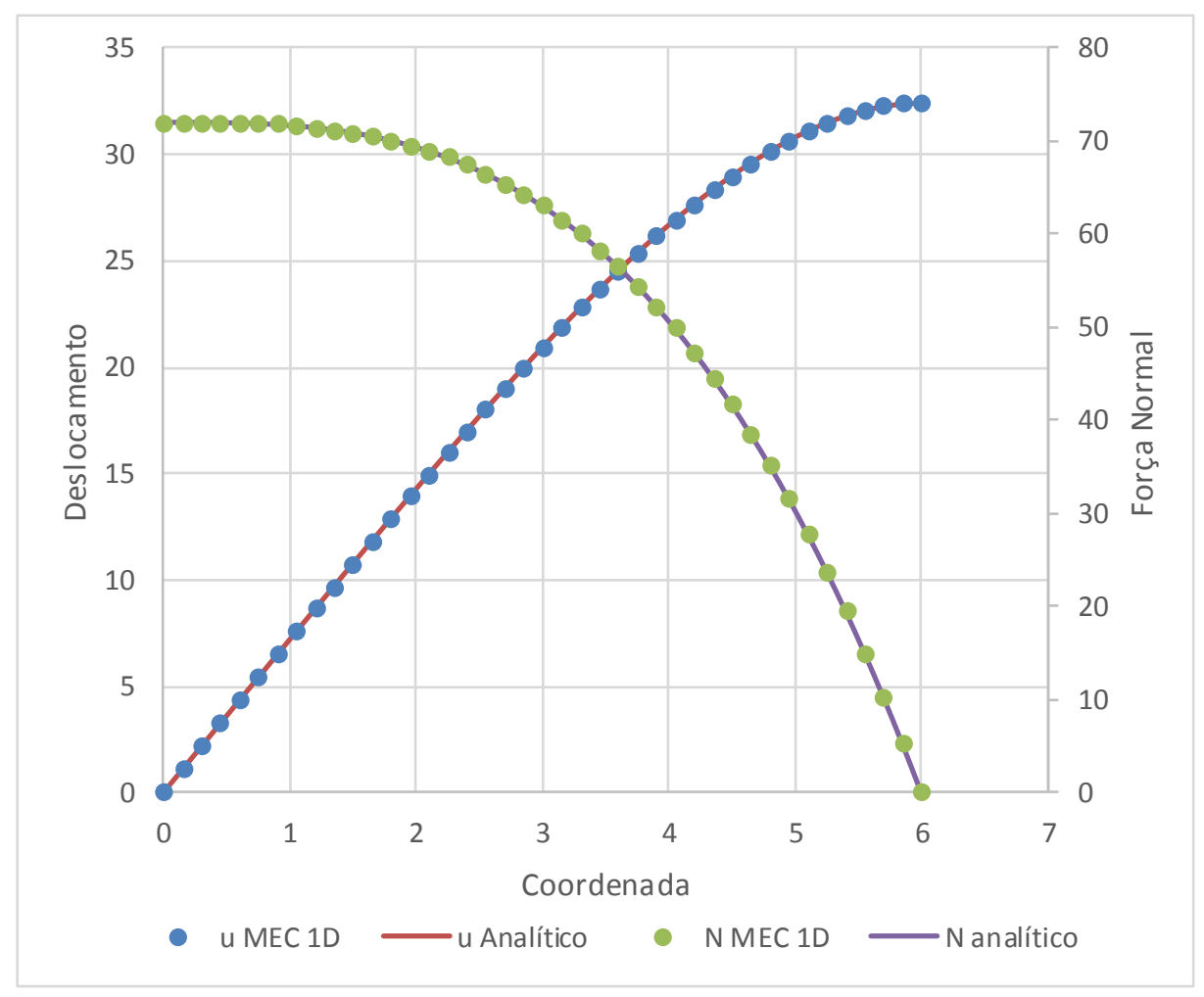

FONTE: O autor.

O ponto negativo de se utilizar grande quantidade de nós em um elemento se deve ao fato da força distribuída ser aproximada pela Técnica dos Elementos Finitos. Como a aproximação é definida pelos valores nodais, sendo neste caso de grau 40, possivelmente ocorre grande oscilação. Outro fator relevante é a necessidade de, pela formulação adotada, se inverter matriz não-simétrica com tamanho proporcional ao número de nós, podendo resultar em maiores erros numéricos. Provavelmente por estes motivos os erros foram maiores do que com o uso de elementos quadráticos ou do quarto grau, possuindo valor máximo de 4,95E-4. 


\subsection{MEC 1D - Exemplo 3: União e Rotação de elementos}

Nesse caso será validada a rotação e a união de elementos por meio de exemplo com união de 3 elementos formando a treliça apresentada na Figura 15:

Figura 15. Treliça formada por 3 elementos

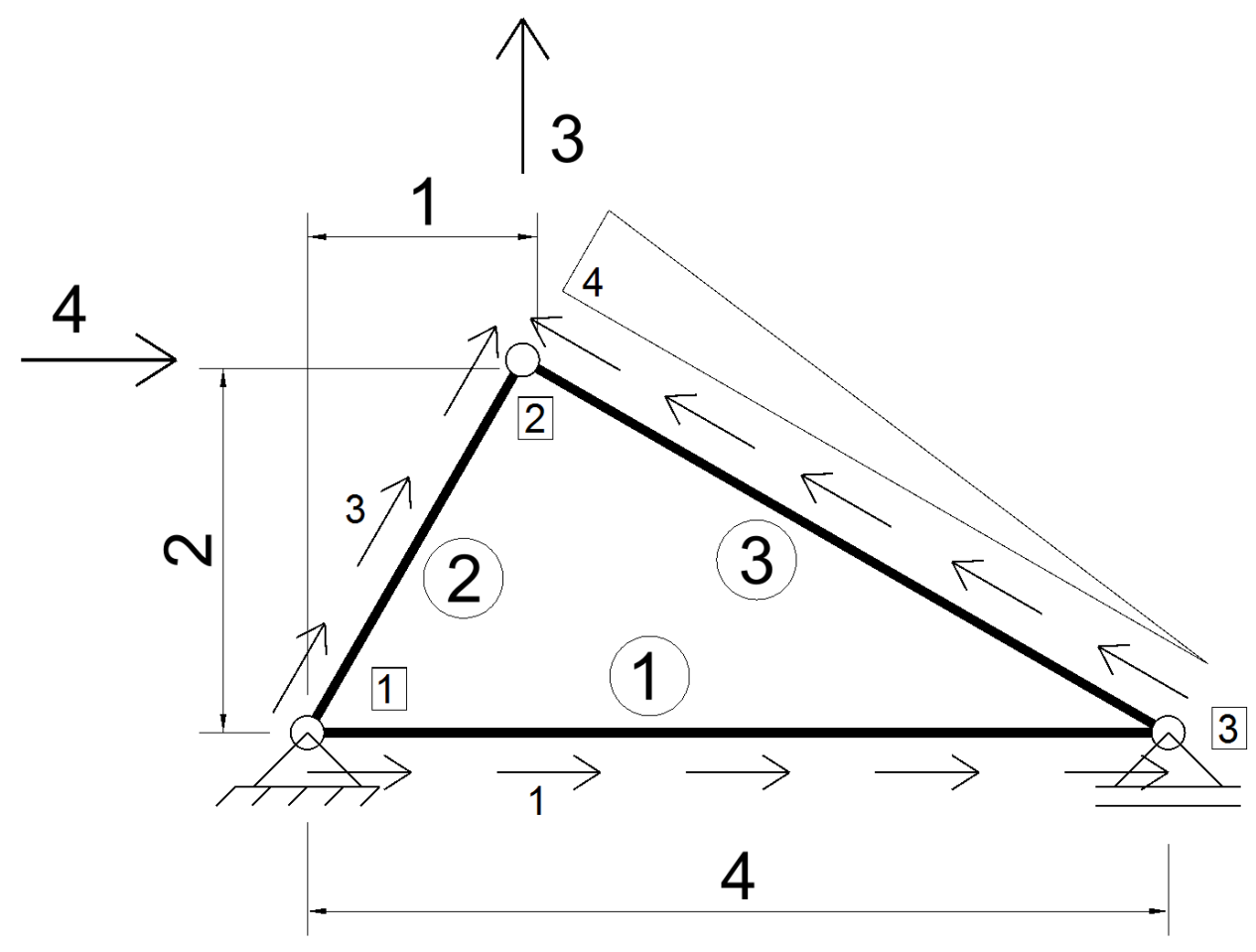

FONTE: O autor.

O número dos elementos está dentro de círculo e número do nó dentro de retângulo. Pode-se observar que foi aplicada carga concentrada sobre o nó de número 2. Os dados dos elementos podem ser verificados na Tabela 1 . Por se tratar de exemplo didático apenas com o objetivo de validar o programa desenvolvido, não são apresentadas unidades.

Tabela 1 - Dados dos elementos

\begin{tabular}{cccc}
\hline Elemento & $\boldsymbol{E} \boldsymbol{A}$ & $\boldsymbol{p}$ & $\boldsymbol{N}_{\text {nós }}$ \\
\hline $\mathbf{1}$ & 10 & 1 & 2 \\
\hline $\mathbf{2}$ & 15 & 3 & 2 \\
\hline $\mathbf{3}$ & 5 & $0-4$ & 5 \\
\hline \multicolumn{4}{c}{ FONTE: O autor. }
\end{tabular}

$E A$ representa a rigidez do elemento, $p$ a força distribuída e $N_{\text {nós }}$ o número de nós utilizado na modelagem do MEC 1D.

Foi utilizado o programa computacional de uso acadêmico Ftool, desenvolvido pela PUC-RIO, para a verificação dos resultados por meio da comparação da configuração 
deformada, conforme mostra a Figura 16 e Tabela 2, e entre os esforços normais, de acordo com a Figura 17 e Tabela 3.

Figura 16. Modelo e sua deformada gerados no programa computacional Ftool.

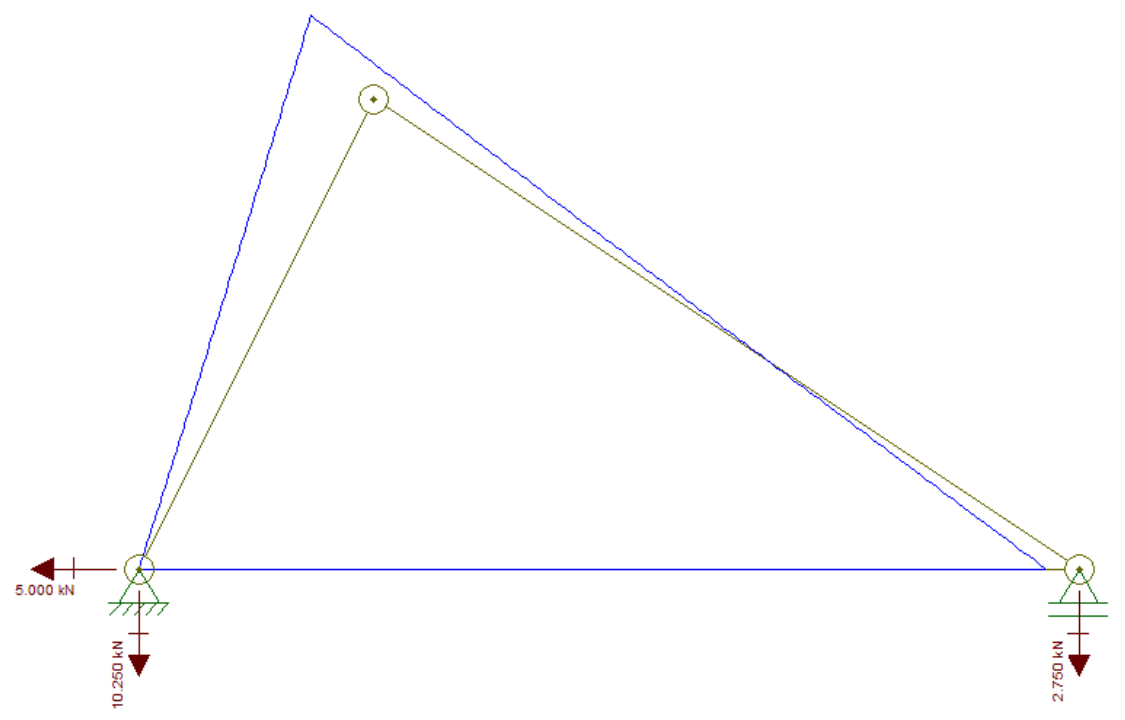

FONTE: O autor.

Foi realizada a comparação de resultados calculando-se o erro entre eles, através da equação (4.14):

Tabela 2 - Comparação de resultados de deslocamentos e reações de apoio do método como Ftool.

Erro

\begin{tabular}{ccccc} 
& \multicolumn{2}{c}{ Deslocamentos } & \multicolumn{2}{c}{ Reações de apoio } \\
\hline Direção & $\mathbf{1}$ & $\mathbf{2}$ & $\mathbf{1}$ & $\mathbf{2}$ \\
\hline Nó 1 & $0,00 \mathrm{E}+00$ & $0,00 \mathrm{E}+00$ & $2,84 \mathrm{E}-10$ & $6,72 \mathrm{E}-12$ \\
\hline Nó 2 & $4,75 \mathrm{E}-05$ & $1,73 \mathrm{E}-06$ & $0,00 \mathrm{E}+00$ & $0,00 \mathrm{E}+00$ \\
\hline Nó 3 & $6,51 \mathrm{E}-10$ & $0,00 \mathrm{E}+00$ & $2,14 \mathrm{E}-18$ & $3,07 \mathrm{E}-10$ \\
\hline \multicolumn{3}{c}{ FONTE: O autor. }
\end{tabular}


Figura 17. Modelo e Forças Normais gerados no programa computacional Ftool

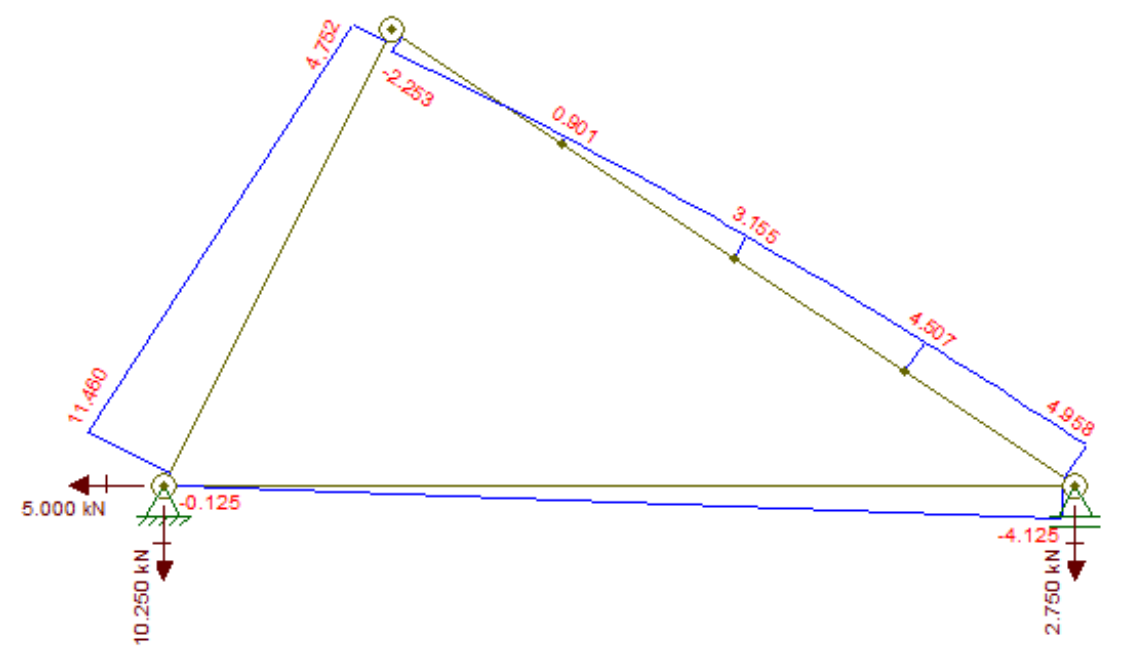

FONTE: O autor.

Para a comparação de forças normais, foram numerados os nós de cada elemento:

Tabela 3 - Comparação de resultado de Forças Normais do método com o Ftool.

\begin{tabular}{cccc}
\hline \multicolumn{5}{c}{ Forças Normais - Erro } \\
\hline Elemento & $\mathbf{1}$ & $\mathbf{2}$ & $\mathbf{3}$ \\
\hline Nó 1 & $1.11 \mathrm{E}-08$ & $1.32 \mathrm{E}-05$ & $7.40 \mathrm{E}-05$ \\
\hline Nó 2 & $3.35 \mathrm{E}-10$ & $7.48 \mathrm{E}-05$ & $1.35 \mathrm{E}-05$ \\
\hline Nó 3 & - & - & $4.52 \mathrm{E}-05$ \\
\hline Nó 4 & - & - & $4.30 \mathrm{E}-04$ \\
\hline Nó 5 & - & - & $2.08 \mathrm{E}-04$ \\
\hline
\end{tabular}

FONTE: O autor.

Observa-se que a resposta da formulação do MEC 1D tanto para deslocamento dos pontos quanto para a reação de apoio e forças normais em comparação com o Ftool resulta em erro máximo de 4,30E-04. Levando-se em conta que as formulações adotadas são diferentes, o próprio Ftool possui erros, e que nesse caso a diferença de resultados se deve principalmente ao truncamento da resposta do Ftool pode-se avaliar como satisfatório esse valor de erro.

\subsection{Conclusões Parciais - MEC 1D}

Foram obtidos bons resultados com o uso do método em diversos casos, com diferentes condições de carregamento. Ficou clara a influência do grau de aproximação adotado para força distribuída, o uso de aproximação de grau inferior ao aplicado leva a aumento do erro. Neste caso, aumentando-se a discretização do elemento ocorreria redução deste erro. 


\section{ACOPLAMENTO MEC/FIBRA - VALIDAÇÃO E APLICAÇÃO}

Serão avaliados neste item diferentes exemplos envolvendo acoplamento do MEC com enrijecedores, os quais são modelados tanto pelo MEF quanto pelo MEC 1D. Serão considerados meios isotrópico e anisotrópico, diferentes propriedades de materiais, discretização e grau de aproximação de enrijecedores, não foram consideradas nãolinearidades.

A modelagem dos enrijecedores no acoplamento com o MEC é realizada definindo-se primeiramente seus nós. Em seguida é definido o grau de aproximação e a conectividade dos elementos. Todos os nós dos elementos devem ter sido previamente definidos, ou seja, ao se variar o seu grau de aproximação não estão sendo criados novos nós e graus de liberdade, simplesmente está sendo modificada sua conectividade de forma a abranger número maior de nós. É realizada integração numérica tanto no contorno quanto nos enrijecedores. A integração no contorno é realizada com uso de 400 pontos de Gauss, sendo definida por análise de convergência realizada anteriormente pelo grupo de pesquisa.

Os resultados obtidos pela formulação proposta foram comparados com as respostas fornecidas por modelos equivalentes construídos no programa computacional comercial ANSYS, utilizando-se o MEF. No modelo gerado no ANSYS o meio é modelado por meio de elementos de chapa e os enrijecedores por barras de treliça, o acoplamento é realizado vinculando-se os graus de liberdade dos nós do meio com os nós dos enrijecedores, sendo sobrepostas as matrizes de rigidez. Ou seja, não é necessária a aproximação de força de aderência.

\subsection{Acoplamento - Exemplo 1}

Primeiramente, foi simulada no ANSYS e por meio do MEC com acoplamento com o MEF e MEC 1D um painel em EPT com 3 enrijecedores. Como condição de apoio foi engastado o seu lado esquerdo, foram aplicadas forças distribuídas tanto no contorno superior quanto no contorno direito, gerando esforços de flexão e tração respectivamente: 
Figura 18. Modelo de painel com enrijecedores (medidas em $\mathrm{cm}$, carregamentos em $\mathrm{kN} / \mathrm{m}$ ) - Exemplo 1

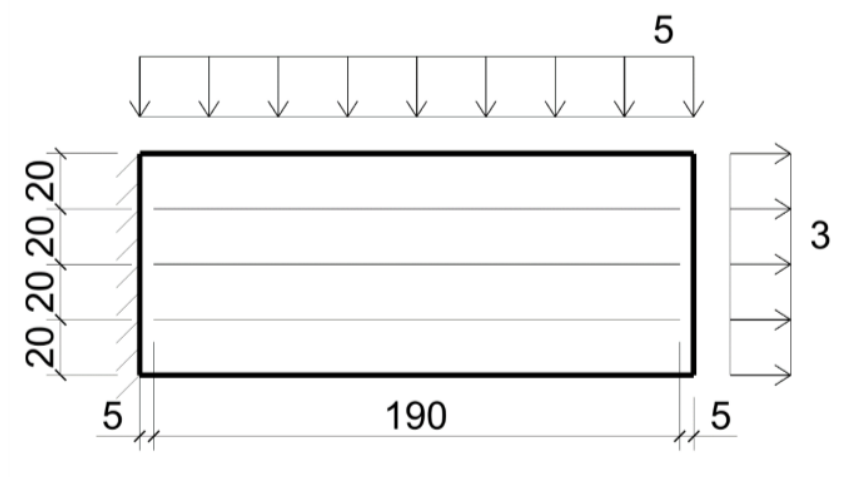

FONTE: O autor

O concreto foi considerado como meio isotrópico linear. Foram adotadas as seguintes propriedades mecânicas para o domínio (subscrito C) e os enrijecedores (subscrito $\mathrm{S}$ ):

$$
\begin{gathered}
E_{s}=200 \mathrm{GPa} \\
E_{c}=25 \mathrm{GPa} \\
v_{C}=0,25 \\
A_{s}=10 \mathrm{~cm}^{2} \text { (por enrijecedor) }
\end{gathered}
$$

Por meio do ANSYS o meio foi modelado com uso de elementos de chapa quadrados de aproximação quadrática, do tipo "PLANE 42". Enrijecedores foram modelados por meio de elementos de treliça de aproximação linear, do tipo "LINK 1". Ao total foram adotados 16000 elementos no meio e 190 elementos para cada enrijecedor, definidos com base em estudo prévio de convergência de malha, resultando em bom comportamento da resposta. A malha utilizada para a análise via ANSYS está apresentada na figura a seguir:

Figura 19. Modelo no ANSYS - Exemplo 1

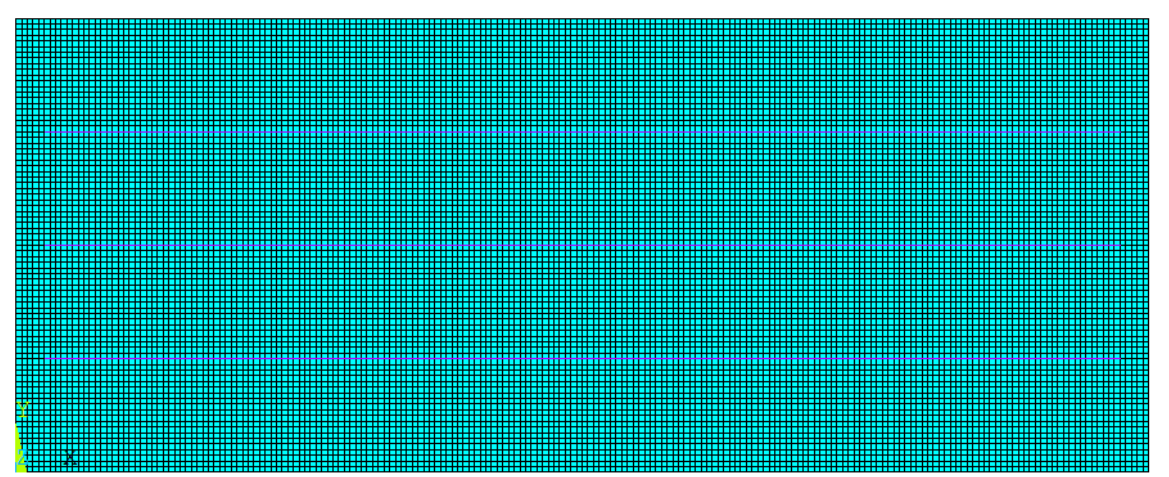

FONTE: O autor

No caso da análise de acoplamento do MEC com enrijecedores, o meio foi modelado por meio do MEC, sendo utilizados 16 elementos de contorno de aproximação quadrática. Para 
análise de deslocamentos e reações de apoio o contorno foi linearizado em sentido anti-horário partindo-se do vértice inferior esquerdo, a posição sendo identificada como $\mathrm{S}$ nos gráficos. É importante ressaltar que não é utilizada a consideração de valores positivos ou negativos para tração ou compressão, resultados serão positivos quando o seu sentido coincidir com o sentido do eixo.

Quanto aos enrijecedores, modelados por meio do MEF e MEC 1D primeiramente, será realizada análise comparativa em relação à sua discretização, avaliando-se resultados para 23, 51 e 111 nós com elementos de aproximação quadrática, com respectivamente 11,25 e 55 elementos, resultados apresentados no item 5.1.1. Em seguida será avaliado o efeito de mudança do grau de aproximação dos elementos dos enrijecedores, sendo apresentados os resultados no item 5.1.2. Para avaliação de resultados foram discutidos efeitos da flexão e da tração do painel separadamente. Foram apresentados resultados de deslocamentos, forças normais e força de aderência. De forma a auxiliar na interpretação, o gráfico do último foi apresentado ao lado direito do gráfico de forças normais. Além disso, dentro de cada item procurou-se utilizar os mesmos limites de eixos, possibilitando comparação mais direta entre gráficos.

Uma vez que na ponta dos enrijecedores era esperada concentração de força, foram utilizados menores elementos nestas áreas. Ao se variar a discretização e grau de aproximação, foi observado que a criação de elementos irregulares nestas áreas levava a maior aumento do erro, evitou-se então esta situação.

\subsubsection{Mudança de Discretização}

Primeiramente foram avaliadas diferentes discretizações das fibras, verificando os efeitos mecânicos no contorno do problema e nos próprios enrijecedores.

\subsubsection{Resultados no contorno}

No caso do contorno, a variação de discretização de enrijecedores não influenciou no resultado. Observa-se que o lado inferior do painel possuiu deslocamento negativo em x e o lado superior deslocamento positivo, maior em módulo, os resultados obtidos são o esperado uma vez que se trata de um painel sujeito a flexo-tração: 
Figura 20. Deslocamentos na direção $\mathrm{x}$ - Acoplamento Ex. 1, discretização

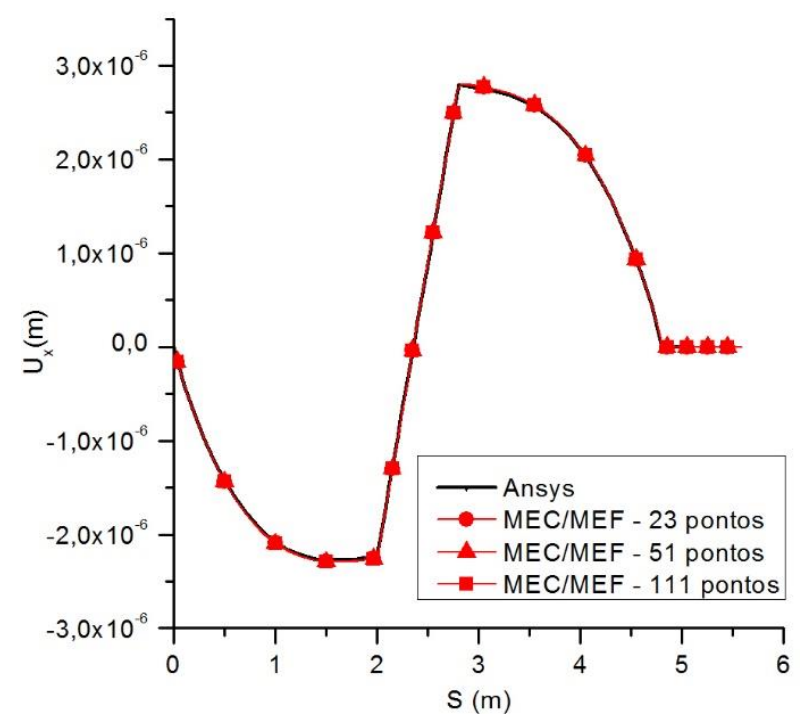

(a)

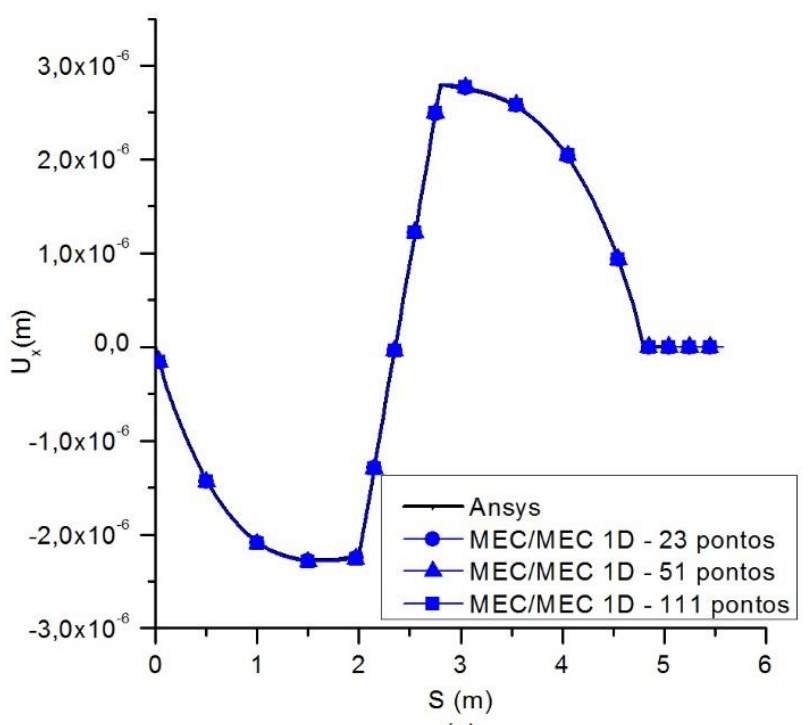

(a)

FONTE: O autor.

Nas duas direções os deslocamentos foram de pequeno valor, garantindo desta forma a validade do regime de pequenos deslocamentos e deformações. No caso de deslocamentos em y, todo o contorno possuiu resultado negativo. Resultado esperado devido aos efeitos da flexão aplicada:

Figura 21. Deslocamentos na direção y - Acoplamento Ex. 1, discretização

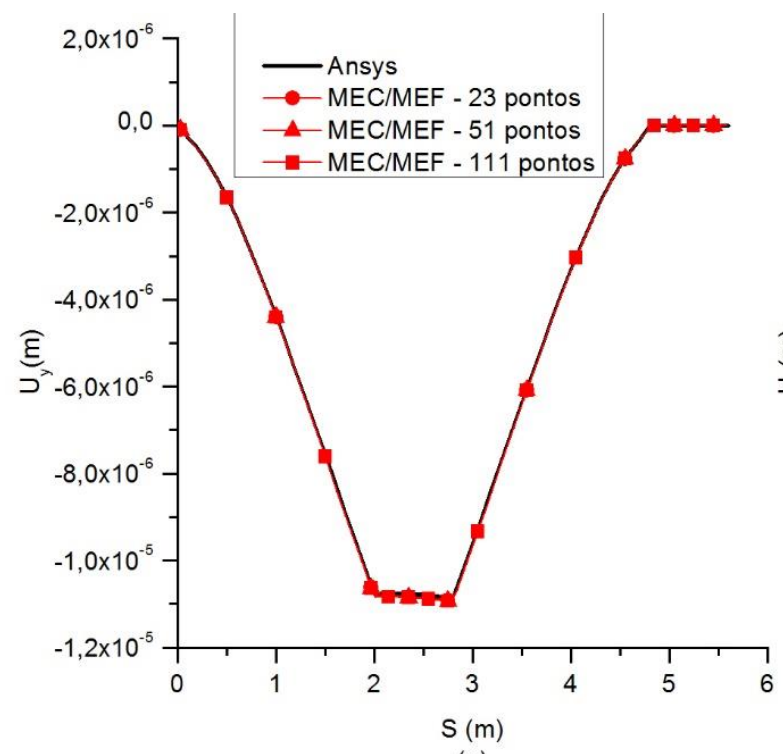

(a)

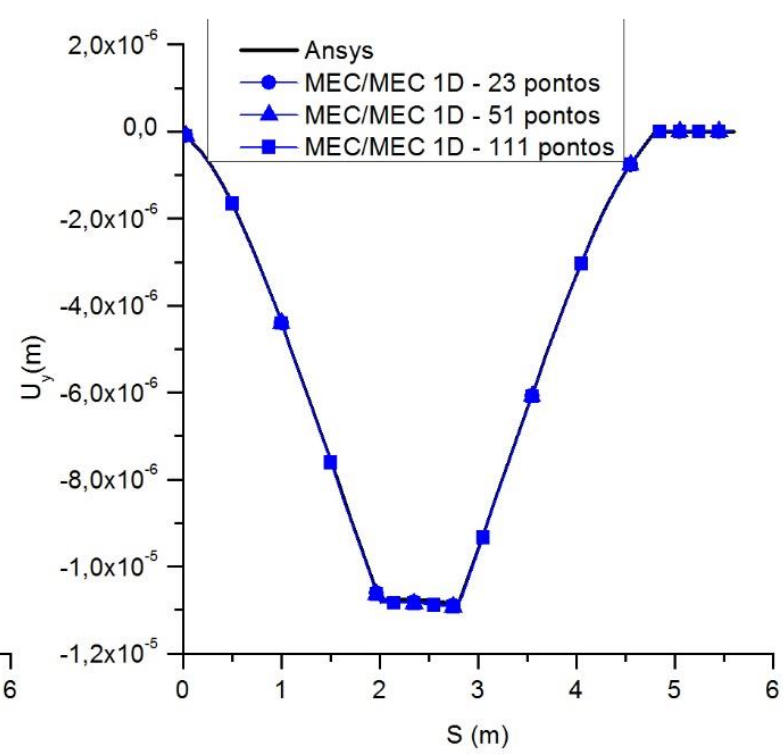

(b)

FONTE: O autor.

Quanto às reações de apoio, observou-se maior concentração nas extremidades, com valores crescentes. O engaste se localiza no lado esquerdo do painel, valores inicialmente negativos indicam que as reações estão no sentido contrário ao eixo x, sendo portanto tração. Valores positivos indicam compressão. Valores de tração superam a compressão, sendo 
condizentes com um painel sujeita à flexo-tração. Observa-se que através do ANSYS são obtidas maiores concentrações de tensão próximo às extremidades do contorno onde o deslocamento é nulo. Isso é esperado devido à discretização de domínio requerida pelo MEF:

Figura 22. Reações de apoio na direção x - Acoplamento Ex. 1, discretização

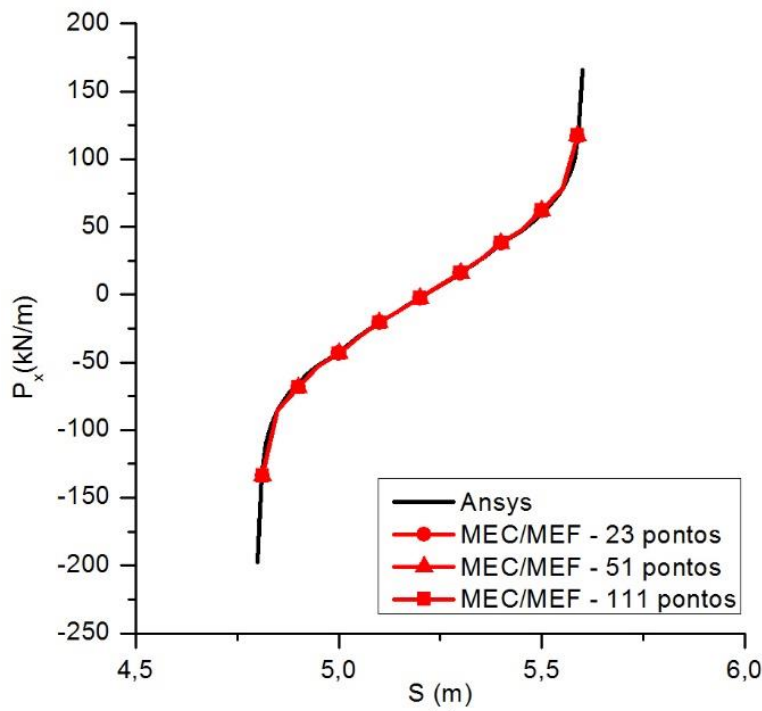

(a)

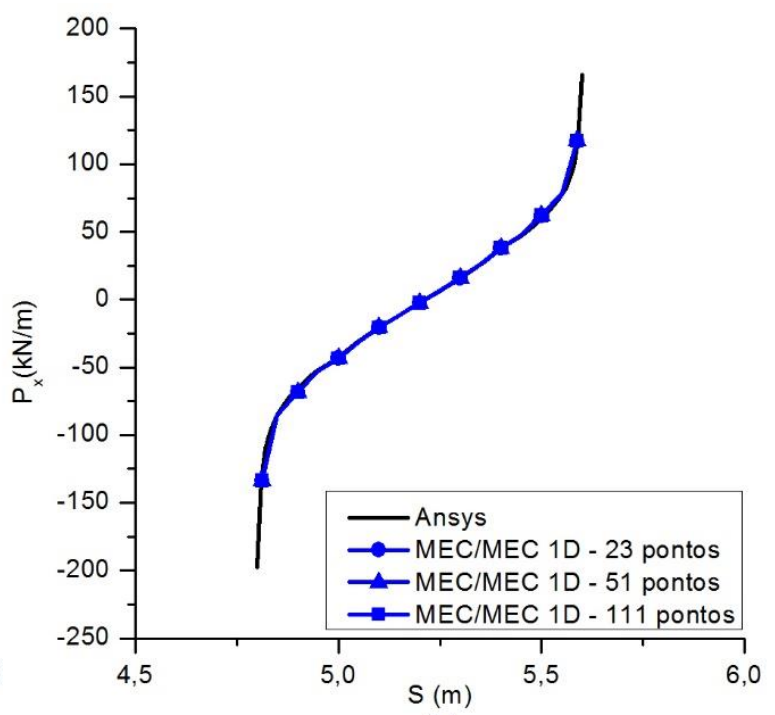

(b)

FONTE: O autor

As reações de apoio na direção y são devidas ao esforço cortante gerado no painel, observa-se que há concentração de tensão nas extremidades do engaste:

Figura 23. Reações de apoio na direção y - Acoplamento Ex. 1, discretização

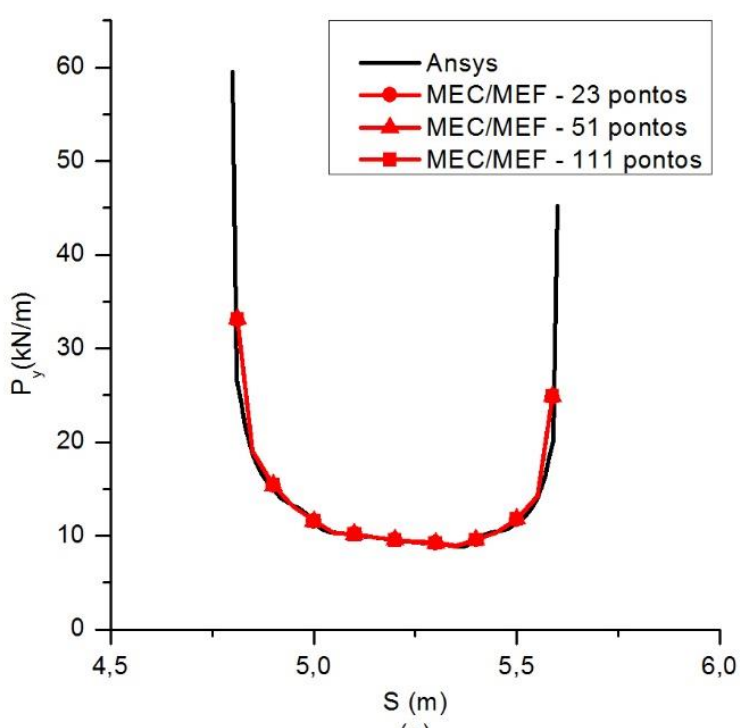

(a)

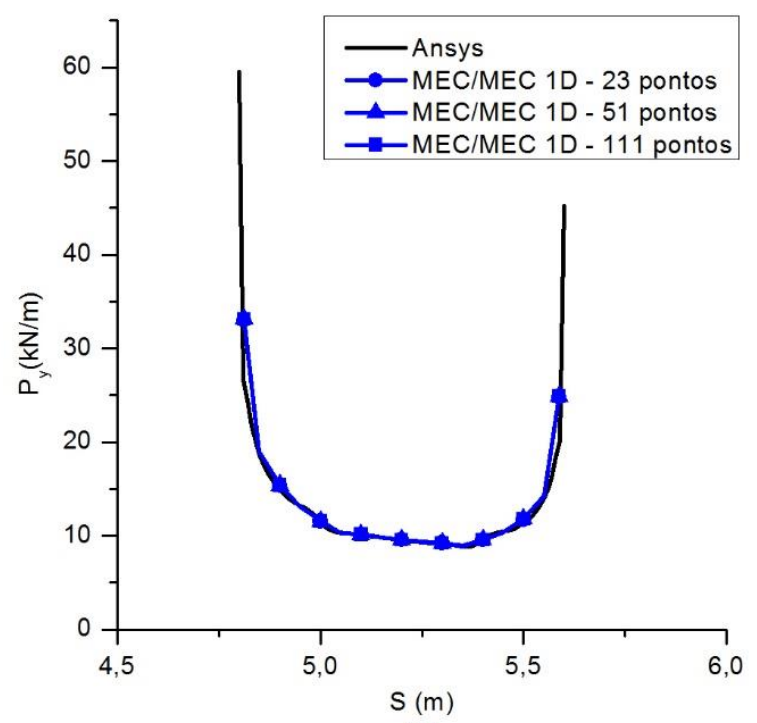

(b)

FONTE: O autor.

\subsubsection{Fibra Inferior}

No caso da fibra inferior, foram próximos também os resultados em deslocamentos. A discretização dos enrijecedores gerou pouca ou nenhuma influência sobre estes resultados: 
Figura 24. Deslocamentos em x na fibra inferior - Acoplamento Ex. 1, discretização

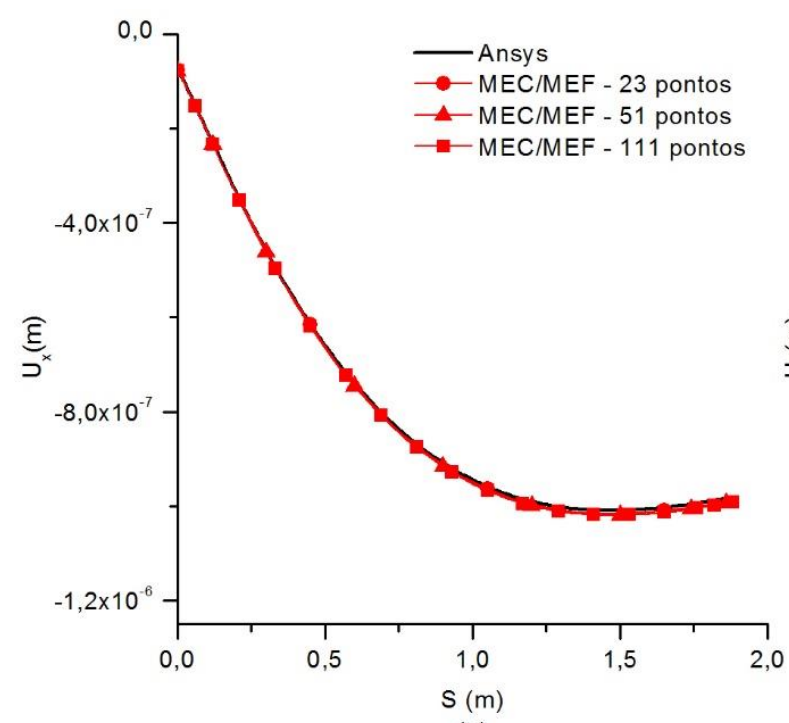

(a)

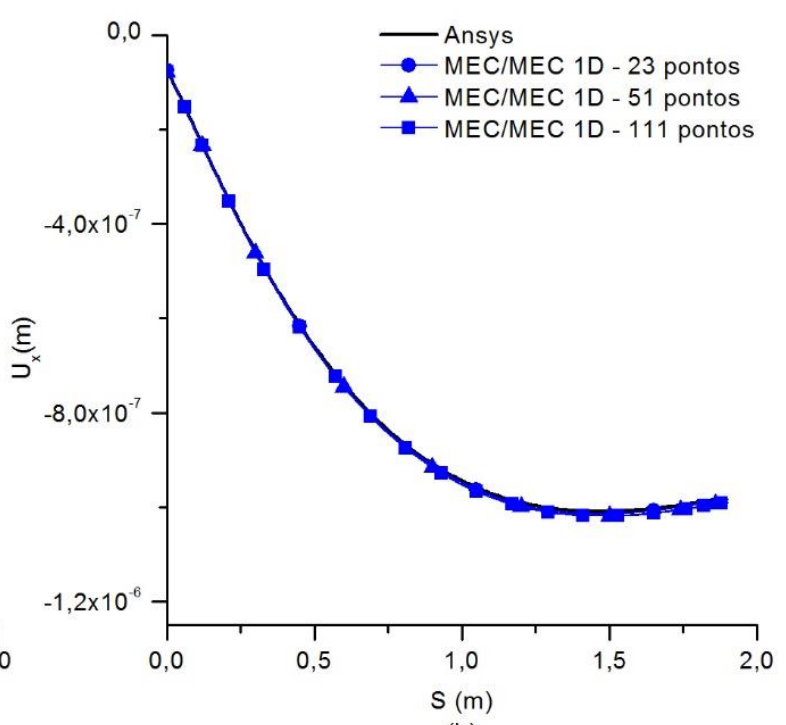

(b)

FONTE: O autor

Figura 25. Deslocamentos em y na fibra inferior - Acoplamento Ex. 1, discretização

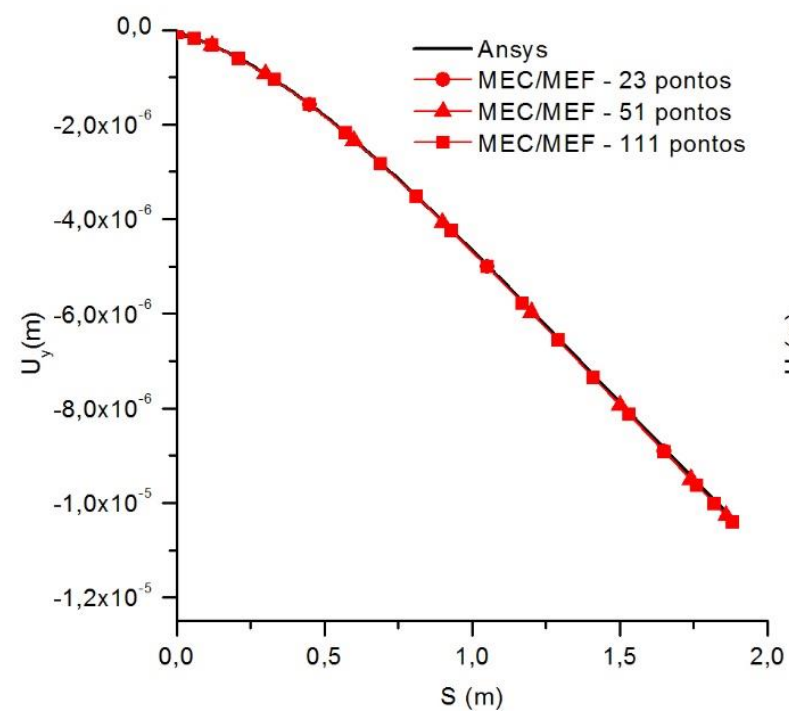

(a)

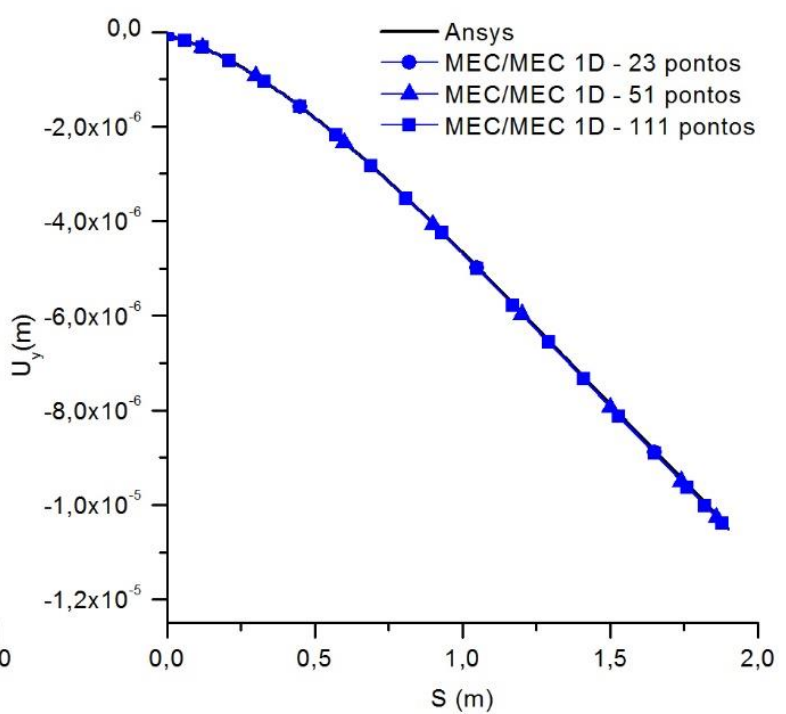

(b)

FONTE: O autor

Foram obtidos deslocamentos negativos em x e y e forças normais negativas, indicando compressão, ou seja, os efeitos da flexão do painel superaram os de tração nesta fibra.

No caso de forças normais e forças de aderência, observa-se relevante perturbação nos resultados do acoplamento MEC/MEF em comparação com o MEC/MEC 1D para fibras menos discretizadas, com 23 nós. Também fica clara concentração de tensões na ponta esquerda da fibra: 
Figura 26. Forças normais na fibra inferior - 23 nós - Acoplamento Ex. 1, discretização
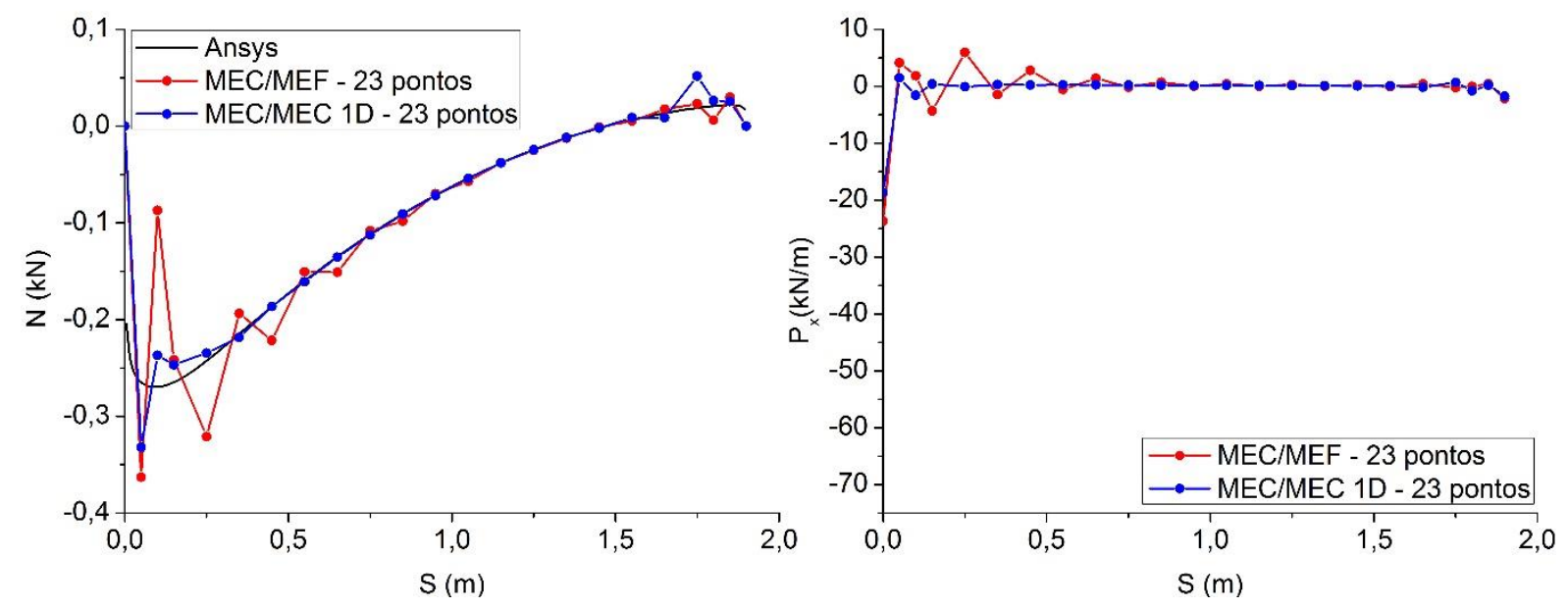

FONTE: O autor

Com o aumento da discretização os resultados se aproximam, mas com ainda alguma perturbação do acoplamento MEC/MEF. O resultado de força de aderência na ponta da fibra aumenta com o aumento da discretização, como pode ser observado nas figuras a seguir:

Figura 27. Forças normais na fibra inferior - 51 nós - Acoplamento Ex. 1, discretização
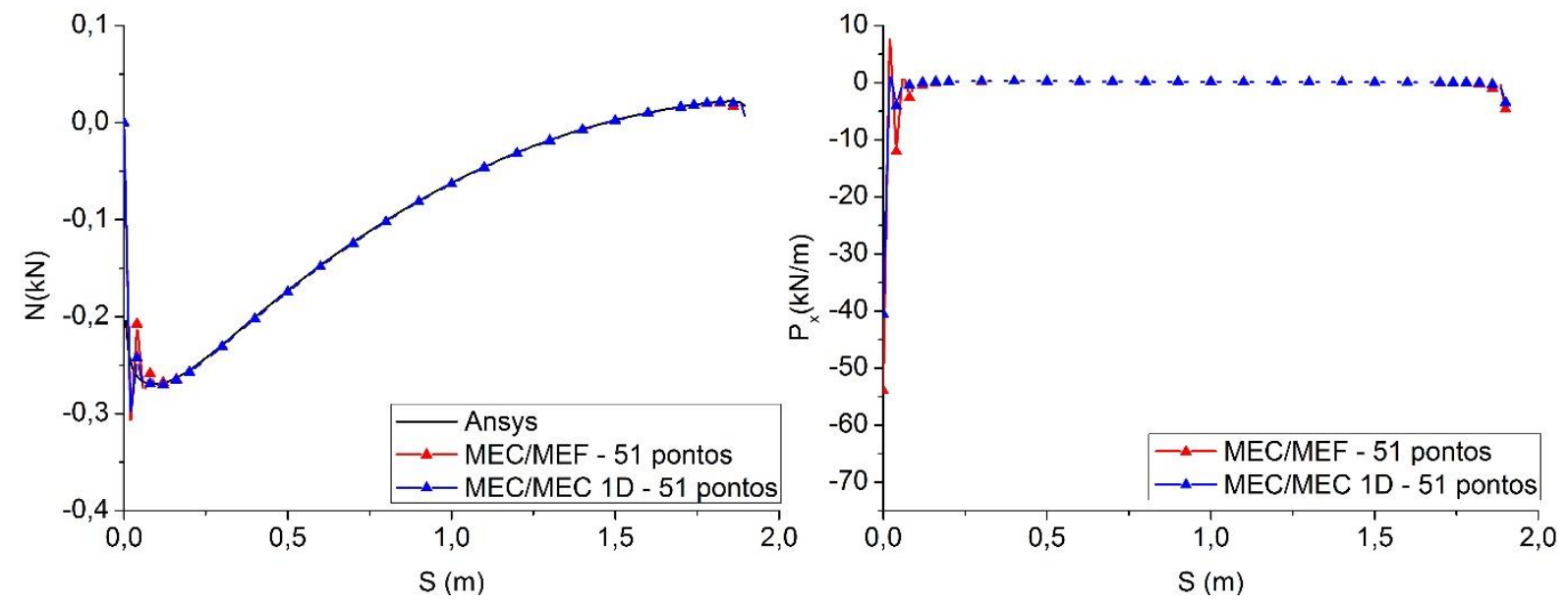

FONTE: O autor 
Figura 28. Forças normais na fibra inferior - 111 nós - Acoplamento Ex. 1, discretização
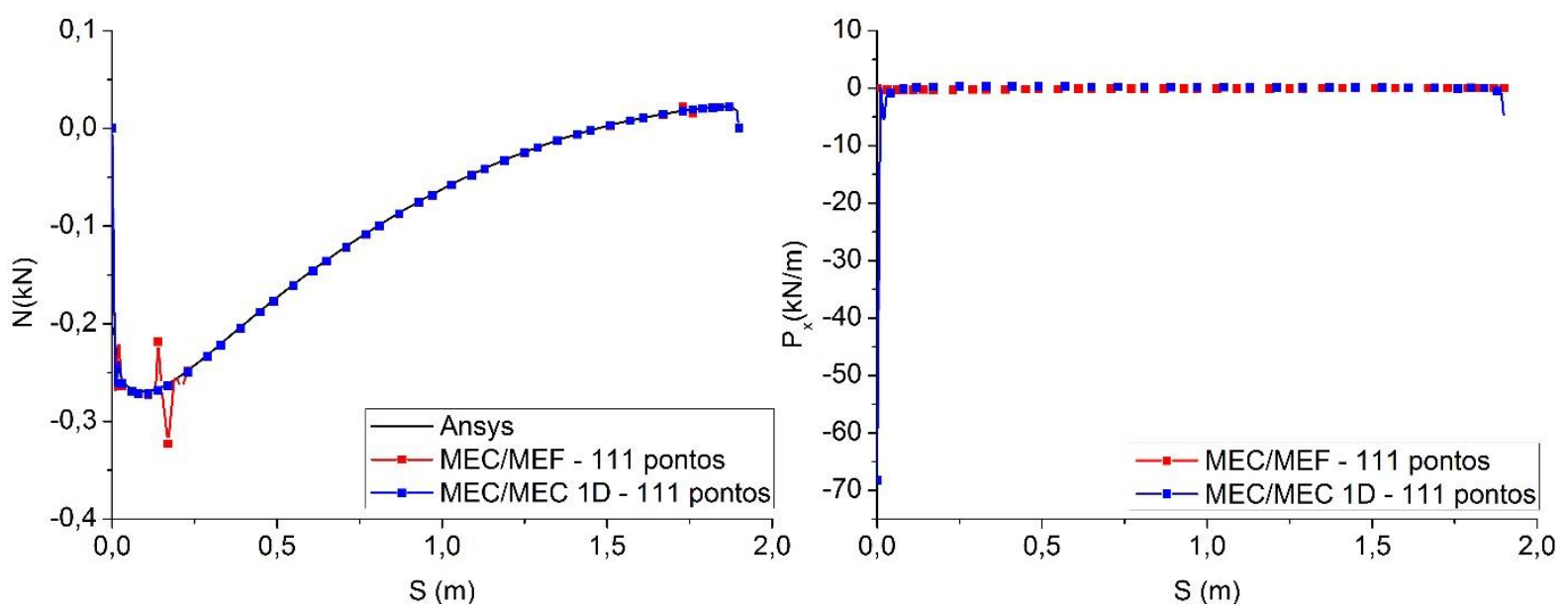

FONTE: O autor

\subsubsection{Fibra Intermediária}

Quanto à fibra intermediária, novamente os resultados em deslocamentos foram próximos. Observa-se que na direção x estes foram positivos. Como a fibra se localiza a meia altura do painel, avaliando-se somente flexão do painel nesta posição estaria a linha neutra, ou seja, não haveriam esforços normais ou deslocamentos em x. Entretanto, como também há esforços de tração, existem deslocamentos nesta direção:

Figura 29. Deslocamentos em x na fibra intermediária - Acoplamento Ex. 1, discretização

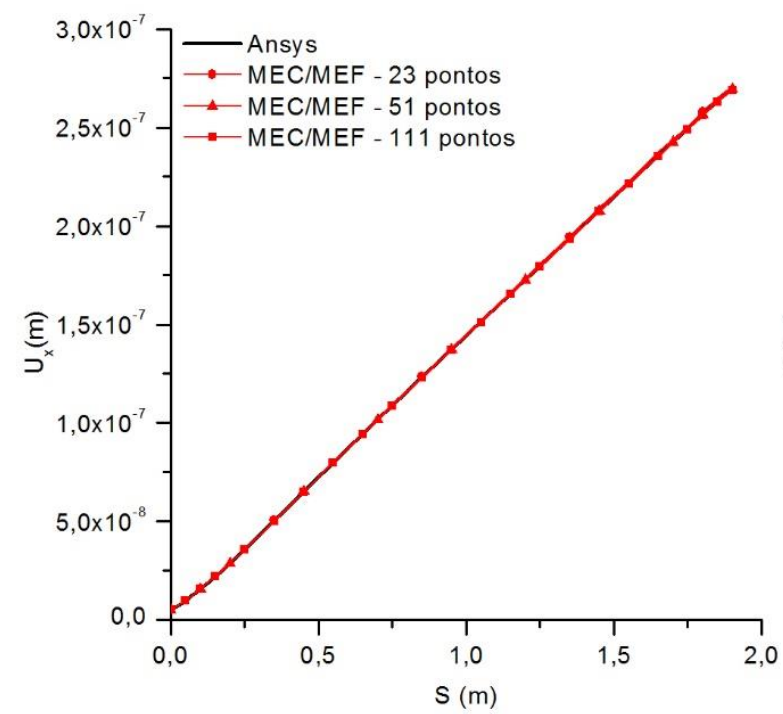

(a)

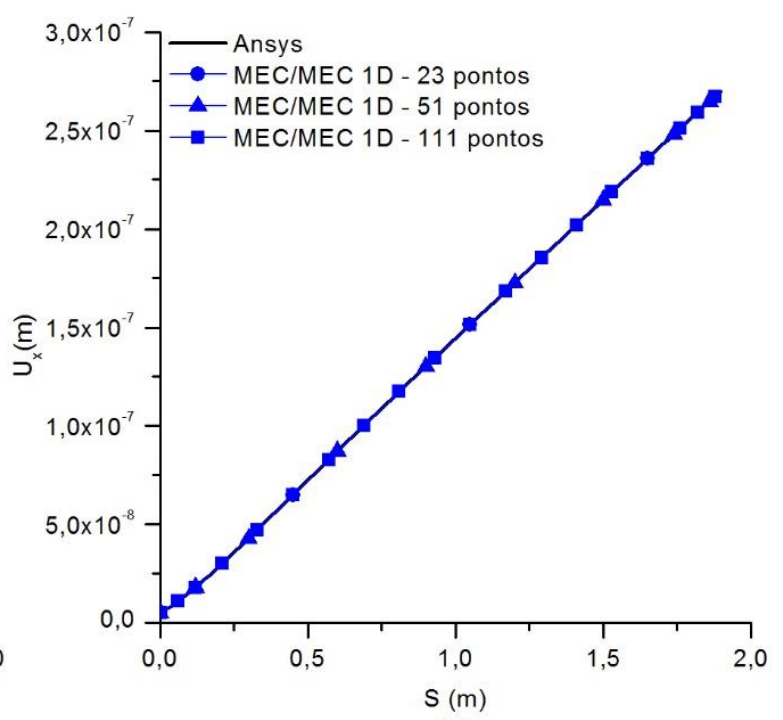

(b)

FONTE: O autor

Já na direção y não há efeitos da tração, somente deslocamento negativo devido à flexão do painel: 
Figura 30. Deslocamentos em y na fibra intermediária - Acoplamento Ex. 1, discretização

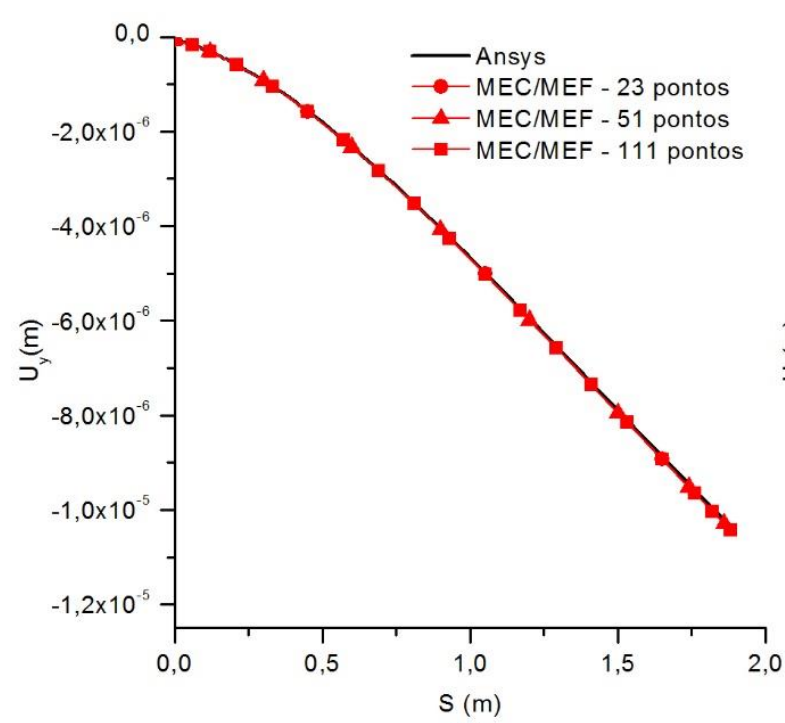

(a)

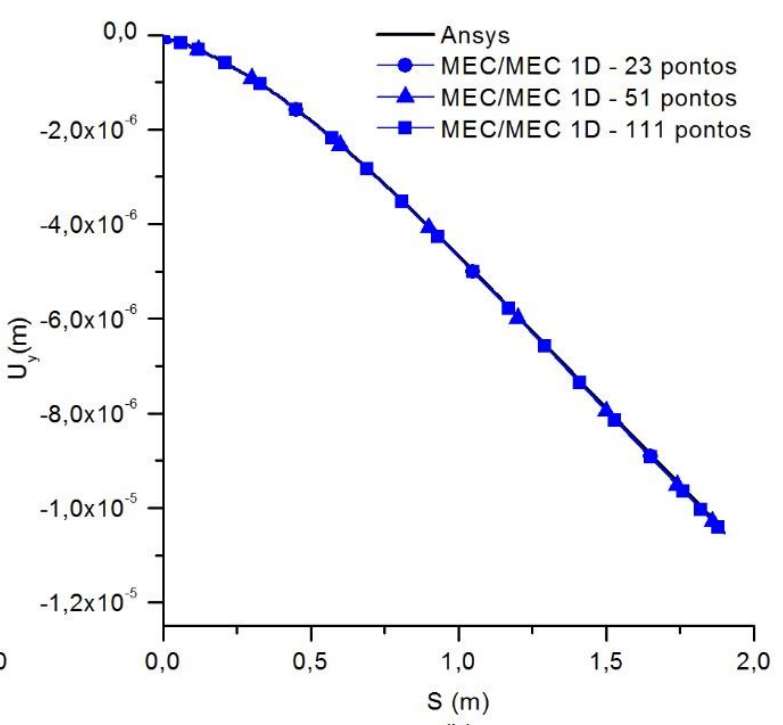

(b)

FONTE: O autor

Da mesma forma que para deslocamentos na direção $\mathrm{x}$, forças normais nesta fibra podem ser entendidas como devido à tração do painel. O resultado de força de aderência apresenta concentração de tensão nas pontas. No caso da lateral onde é aplicada força isto mostra que a fibra promove reação contrária sobre o meio, próximo à lateral onde se encontra o engaste a fibra transmite novamente a carga para o meio. Ao longo da fibra a transmissão de forças se deve principalmente pela diferença de rigidez, sendo os valores ligeiramente negativos.

Para forças normais, da mesma forma que no Exemplo 1, observou-se maior perturbação do acoplamento MEC/MEF, claramente causada pela perturbação do resultado de força de aderência. Ocorre relevante perturbação nos resultados do acoplamento MEC/MEF em comparação com o MEC/MEC 1D para fibras menos discretizadas, com 23 nós:

Figura 31. Forças normais na fibra intermediária - 23 nós - Acoplamento Ex. 1, discretização
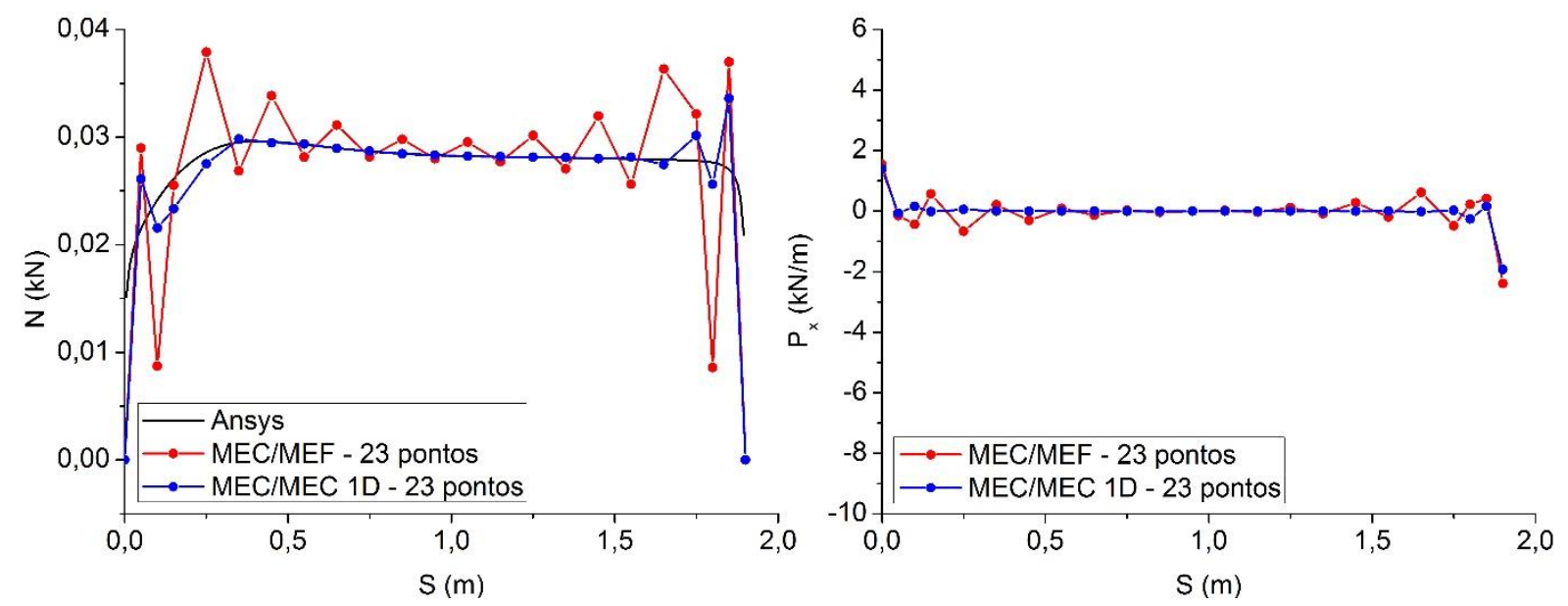

FONTE: O autor 
Novamente, com o aumento da discretização os resultados se aproximam, mas com ainda alguma perturbação do acoplamento MEC/MEF:

Figura 32. Forças normais na fibra intermediária - 51 nós - Acoplamento Ex. 1, discretização
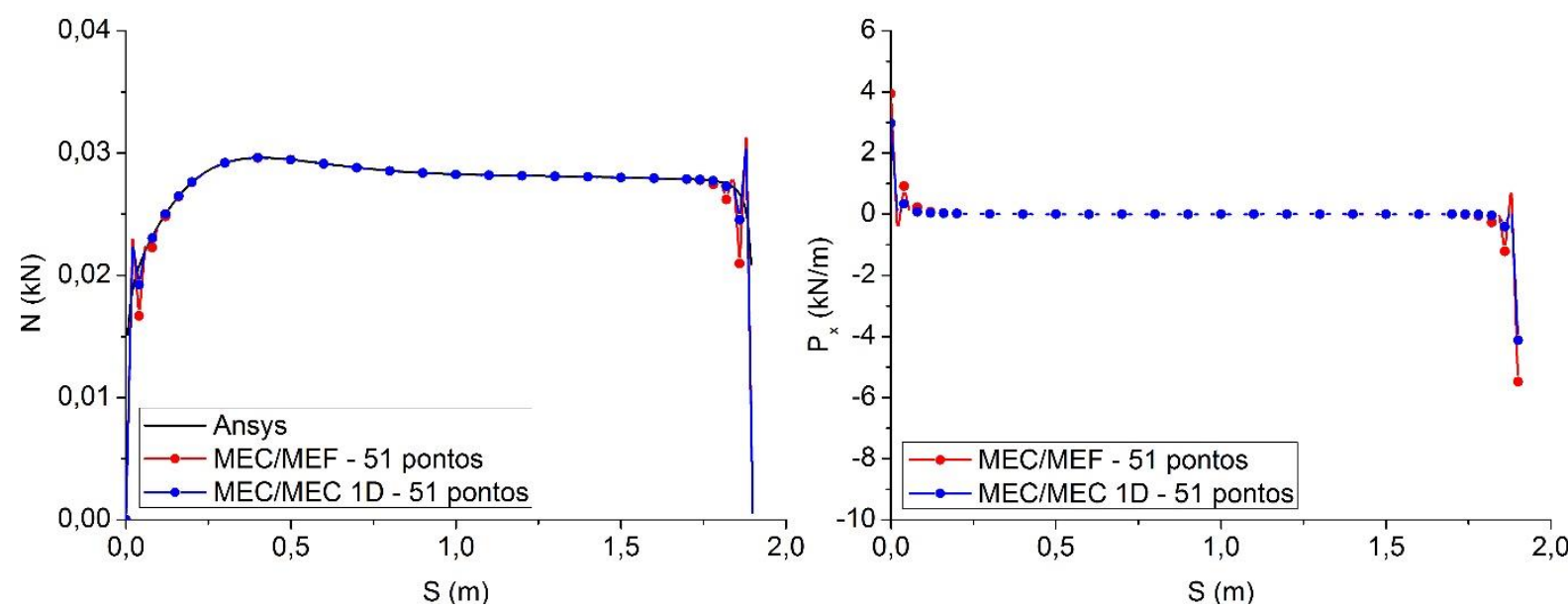

FONTE: O autor

Figura 33. Forças normais na fibra intermediária - 111 nós - Acoplamento Ex. 1, discretização
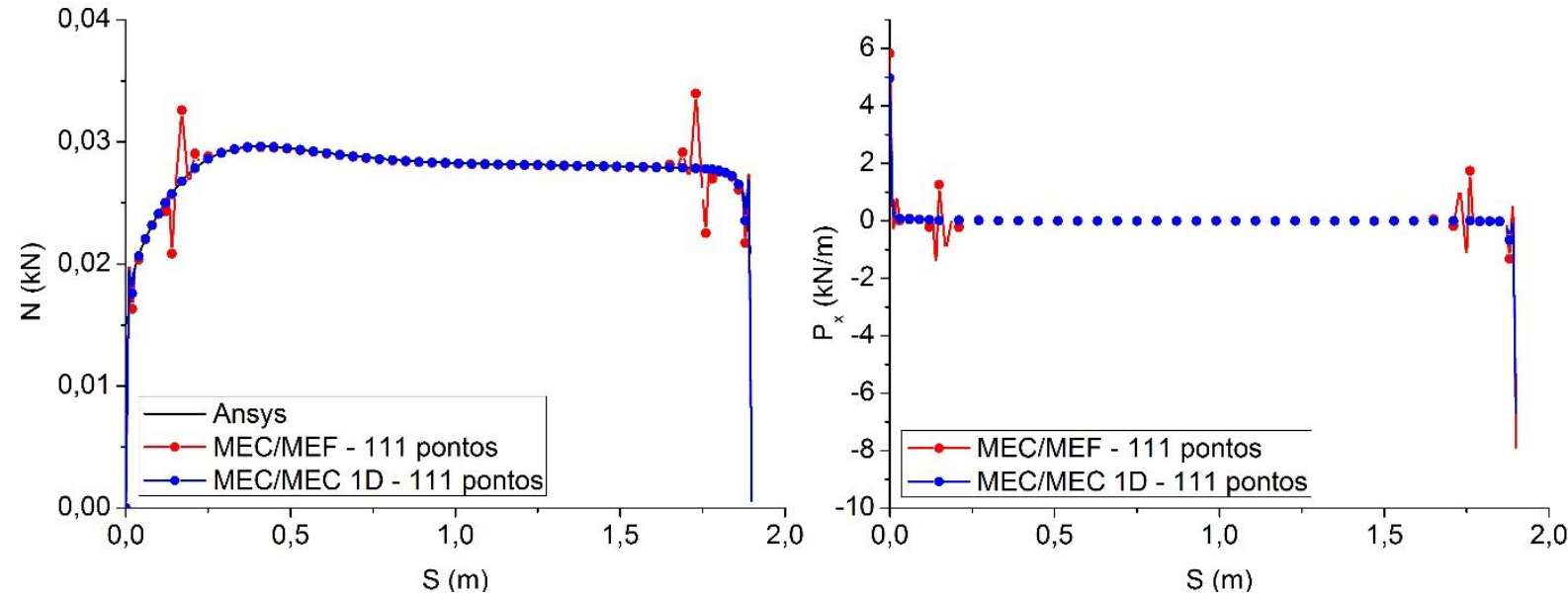

FONTE: O autor

\subsubsection{Fibra Superior}

No caso da fibra superior, resultados em deslocamentos também foram próximos. Quanto a deslocamentos na direção $x$, esforços de flexão e de tração possuem efeito complementar: 
Figura 34. Deslocamentos em x na fibra superior - Acoplamento Ex. 1, discretização

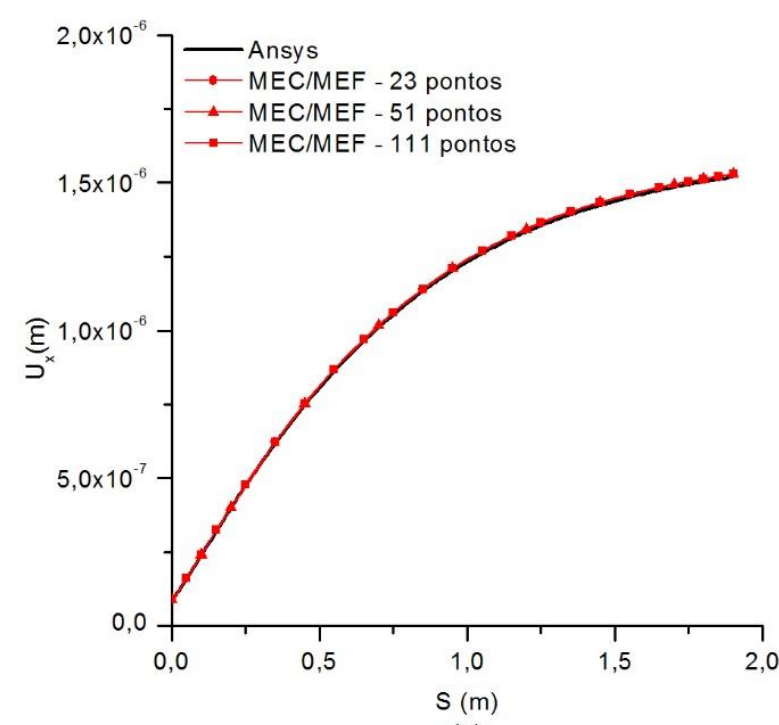

(a)

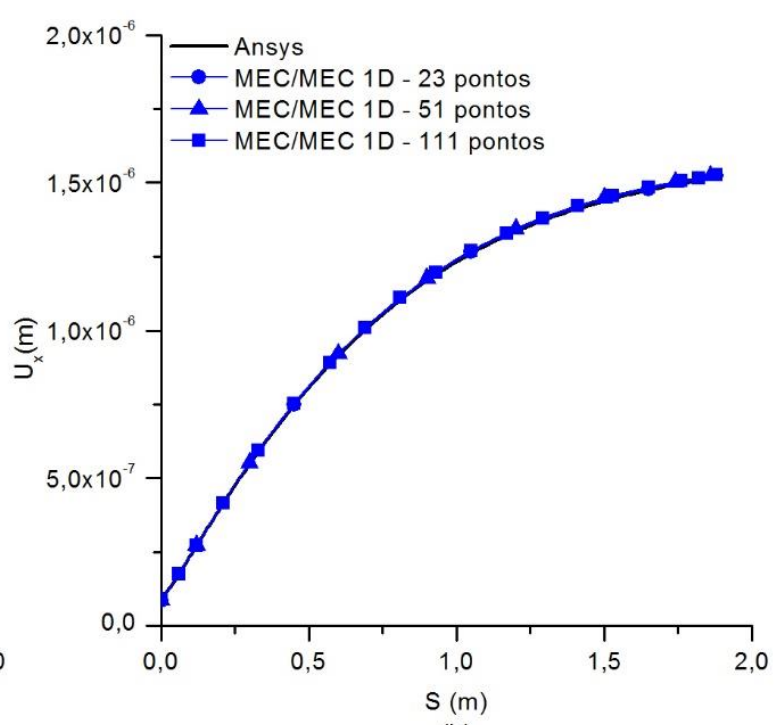

(b)

FONTE: O autor

Resultados na direção y se devem principalmente à flexão:

Figura 35. Deslocamentos em y na fibra superior - Acoplamento Ex. 1, discretização

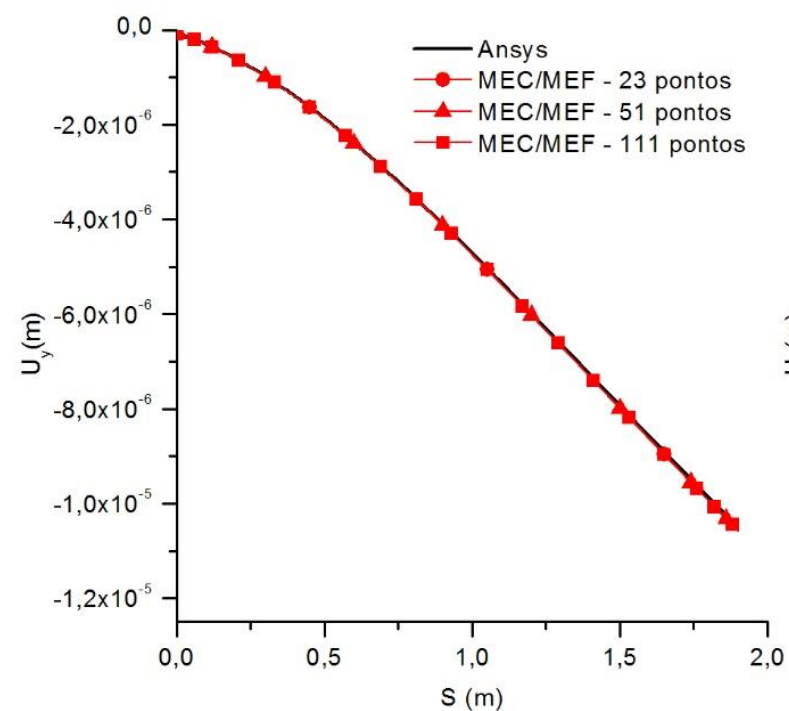

(a)

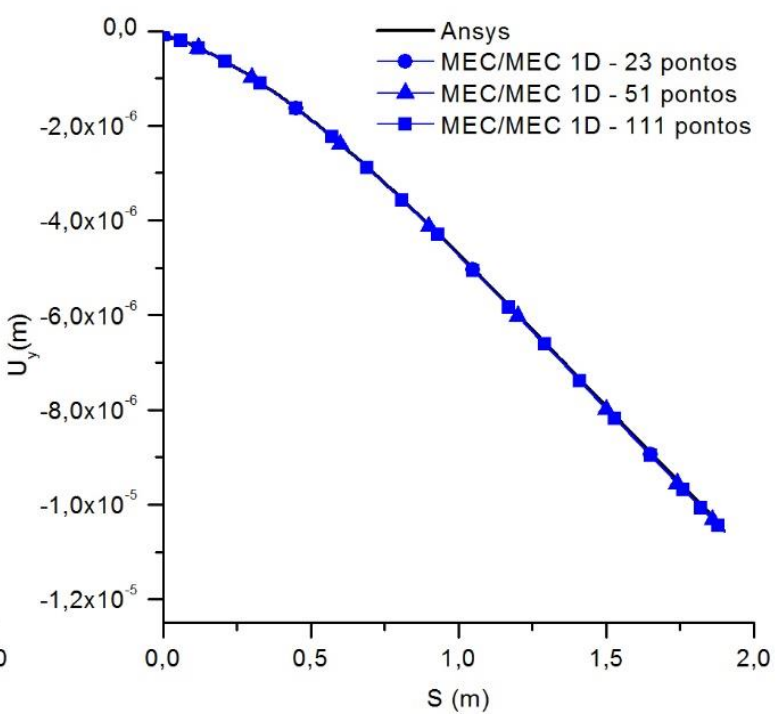

(b)

FONTE: O autor

Quanto a forças normais, também se observa relevante perturbação nos resultados do acoplamento MEC/MEF em comparação com o MEC/MEC 1D para fibras menos discretizadas, com 23 nós: 
Figura 36. Forças normais na fibra superior - 23 nós - Acoplamento Ex. 1, discretização
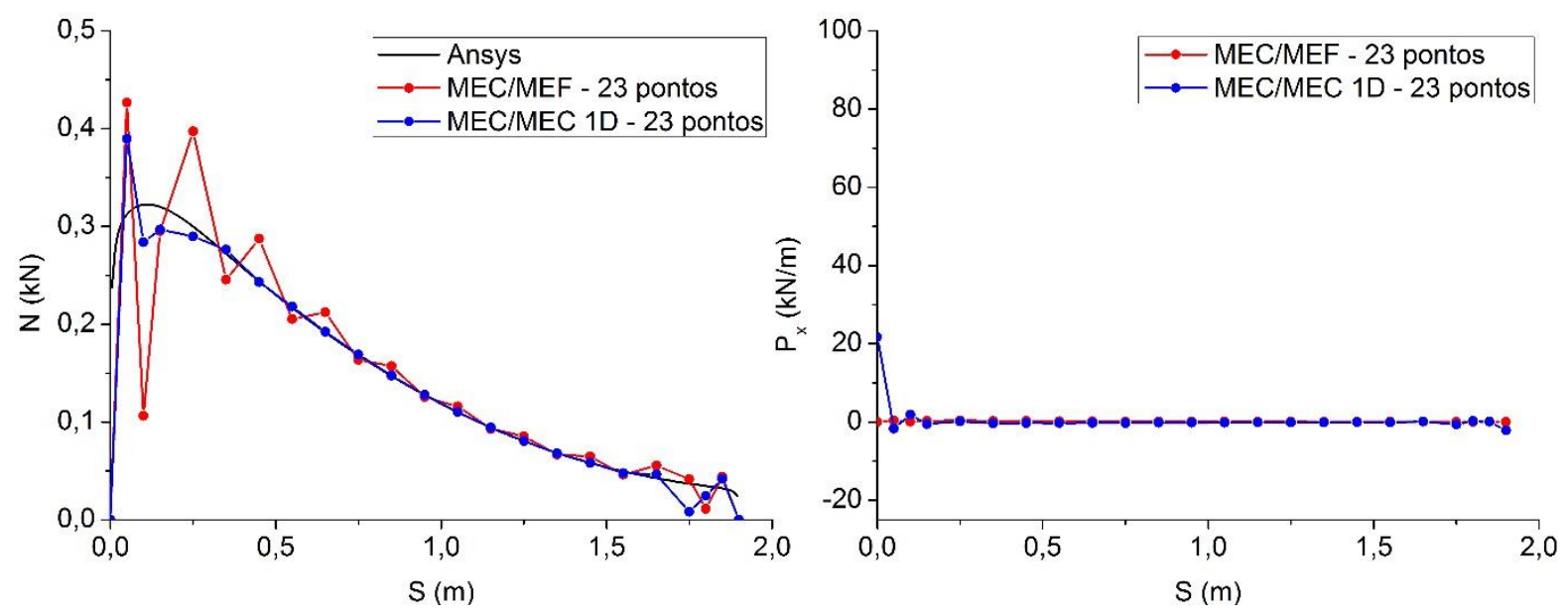

FONTE: O autor.

Da mesma forma que para as outras fibras, com o aumento da discretização os resultados se aproximam, mas com ainda alguma perturbação do acoplamento MEC/MEF:

Figura 37. Forças normais na fibra superior - 51 nós - Acoplamento Ex. 1, discretização
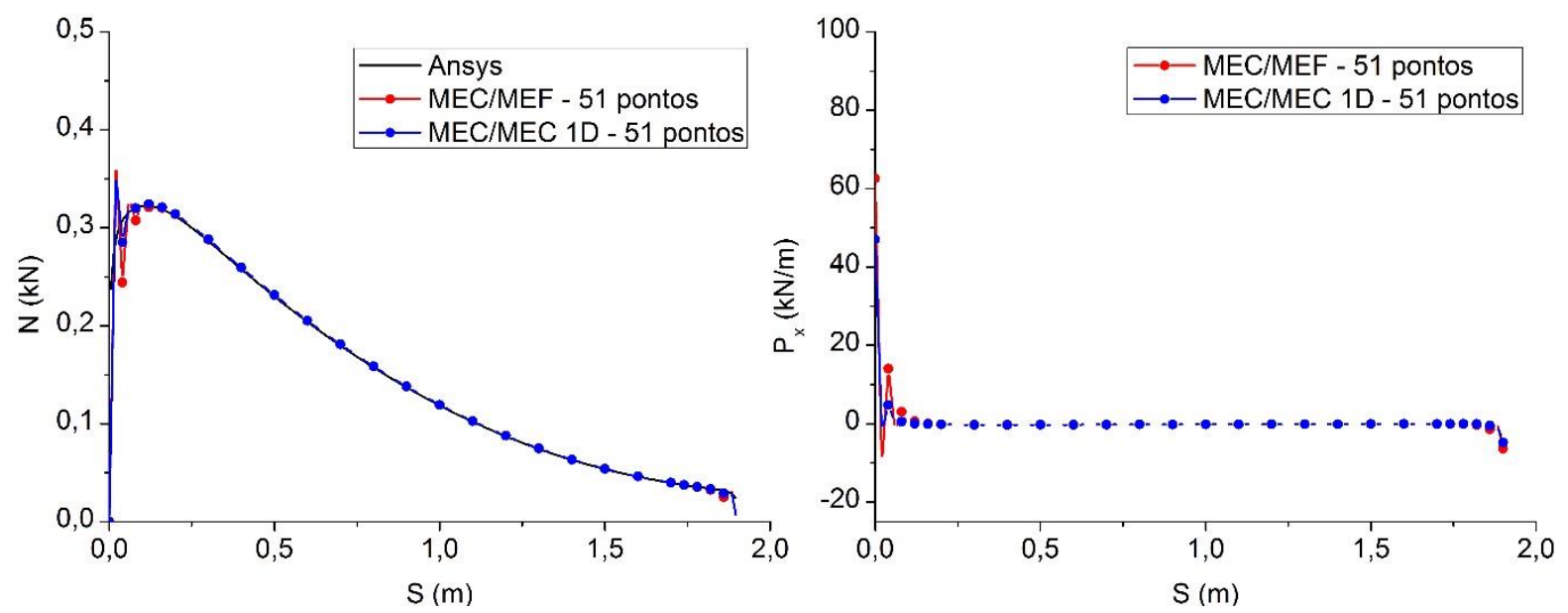

FONTE: O autor

Figura 38. Forças normais na fibra superior - 111 nós - Acoplamento Ex. 1, discretização
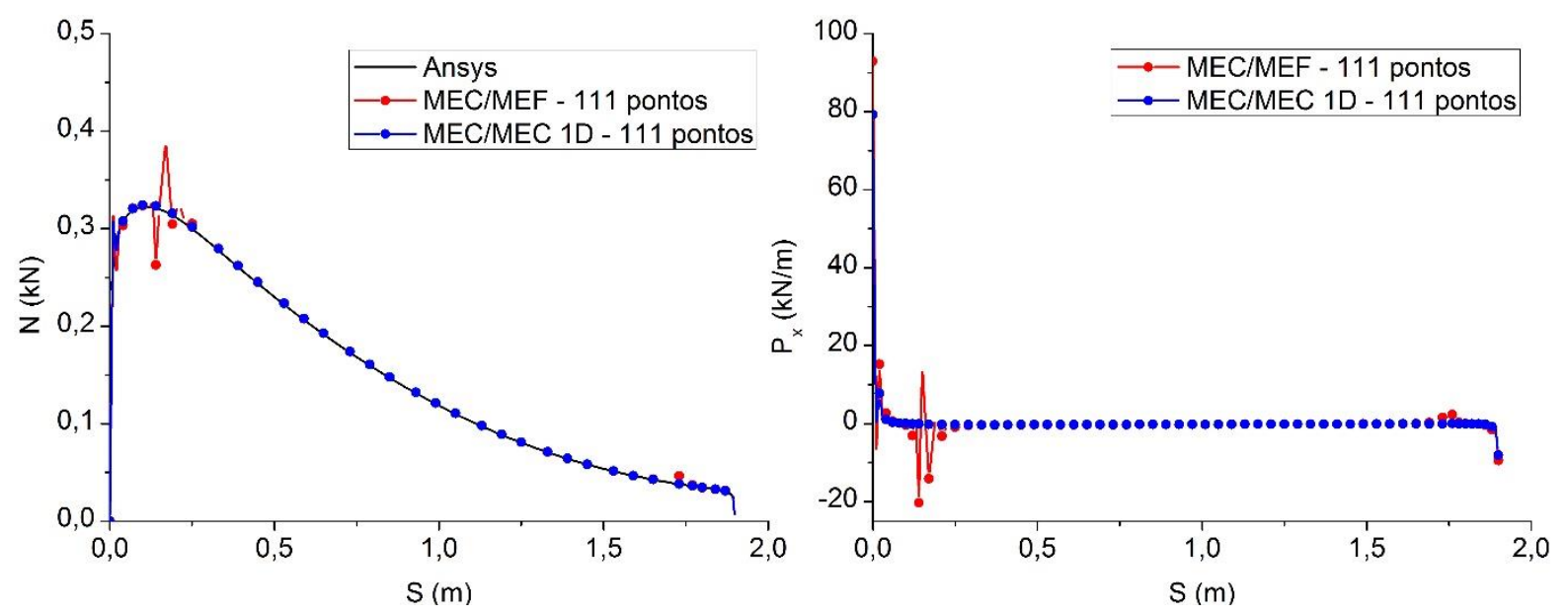

FONTE: O autor 


\subsubsection{Mudança Grau de Aproximação}

Foi verificada maior diferença entre os métodos ao se discretizar com 23 nós. É de interesse verificar se o grau de aproximação adotado para os elementos das fibras possui efeito relevante. Entretanto, para este número de nós não é possível utilizar somente elementos de grau 3 ou 4, mas observa-se que as perturbações surgem próximo às pontas dos enrijecedores. Nestas áreas ocorre concentração de forças e maior variação de resultados. Por este motivo é possível avaliar o efeito do uso de elementos de grau mais elevado adotando-os somente nelas, utilizando elementos de menor grau em outras. O exemplo foi avaliado então com as seguintes discretizações de fibras no MEC/MEF e MEC/MEC 1D:

- Grau 2 - 11 elementos de grau 2;

- Grau 3-6 elementos de grau 3, 2 elementos de grau 2;

- Grau 4-4 elementos de grau 4, 3 elementos de grau 2.

\subsubsection{Resultados no contorno}

Quanto aos resultados no contorno, não houve influência da mudança de grau de aproximação dos enrijecedores:

Figura 39. Deslocamentos na direção x - Acoplamento Ex. 1, grau de aproximação

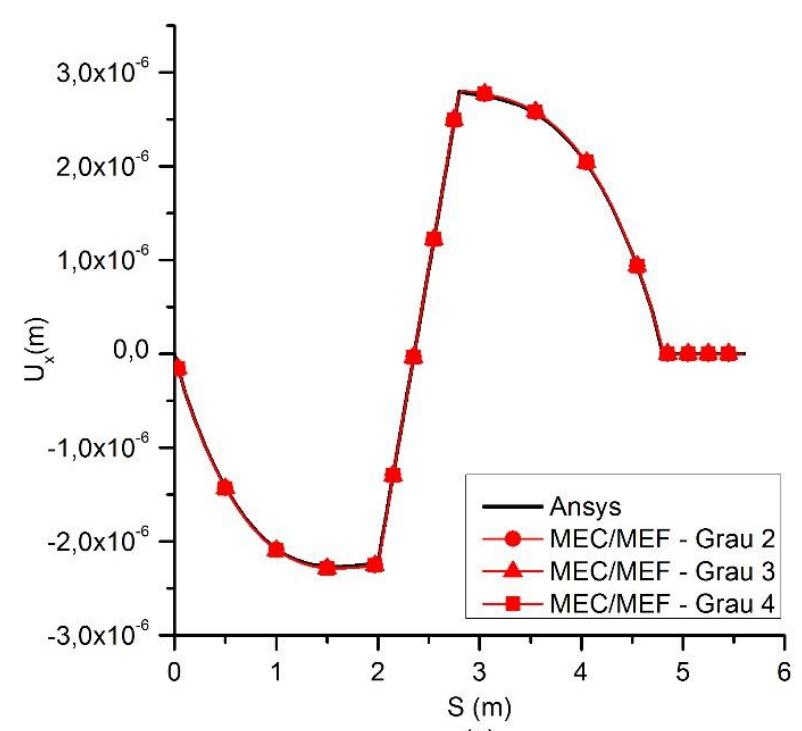

(a)

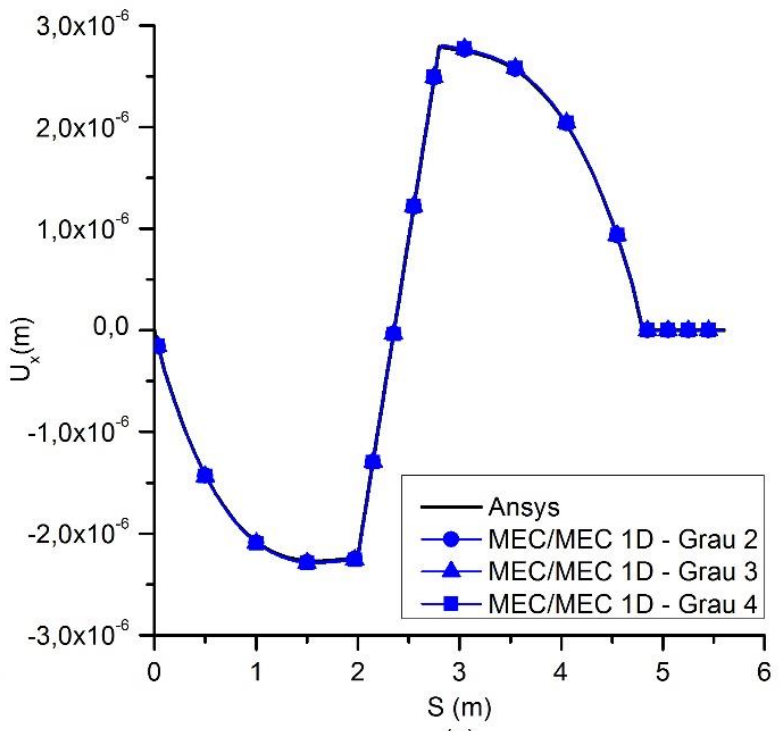

(a)

FONTE: O autor 
Figura 40. Des locamentos na direção y - Acoplamento Ex. 1, grau de aproximação

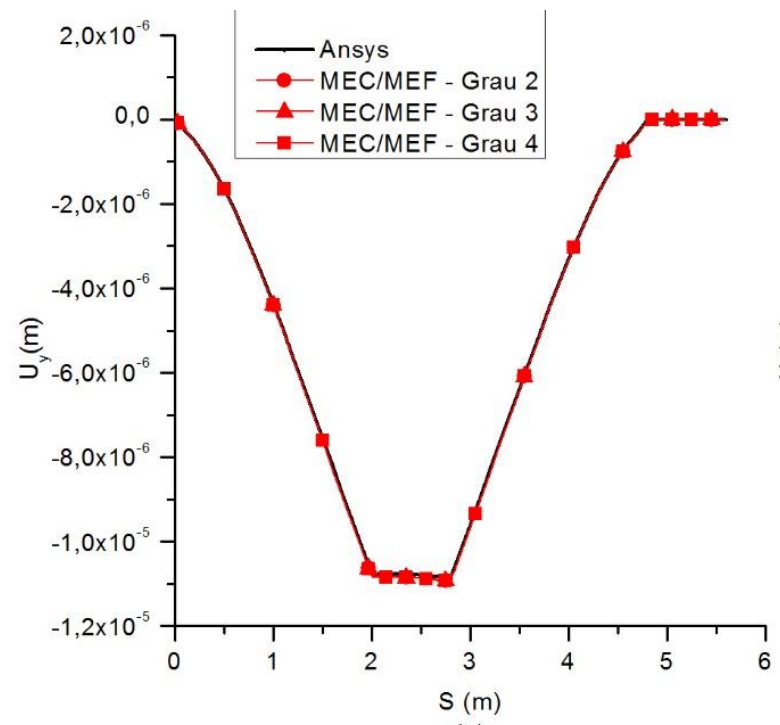

(a)

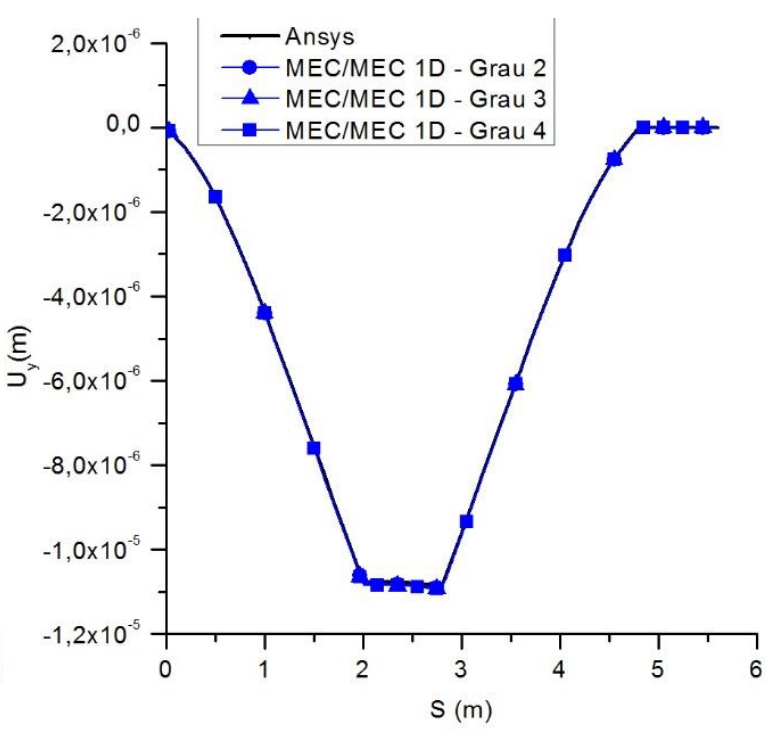

(a)

FONTE: O autor

Figura 41. Reações de apoio na direção x - Acoplamento Ex. 1, grau de aproximação

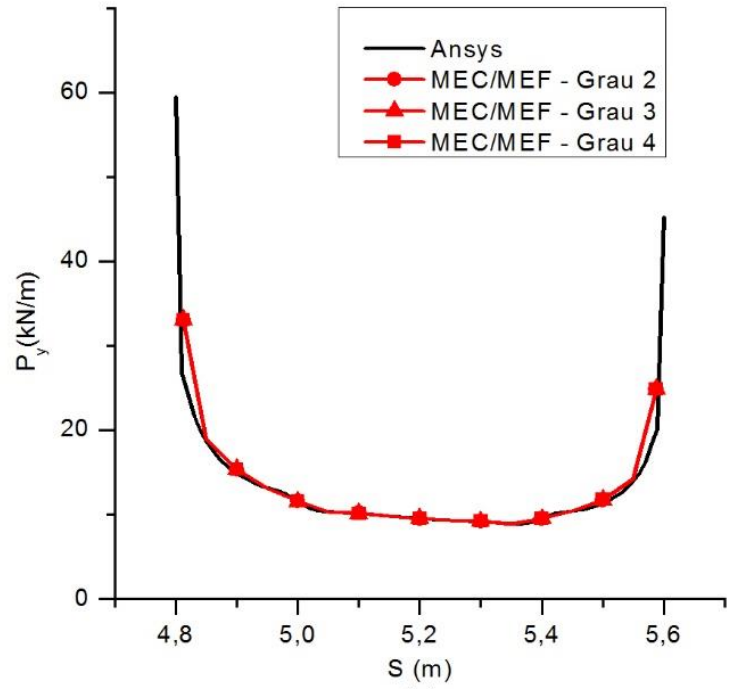

(a)

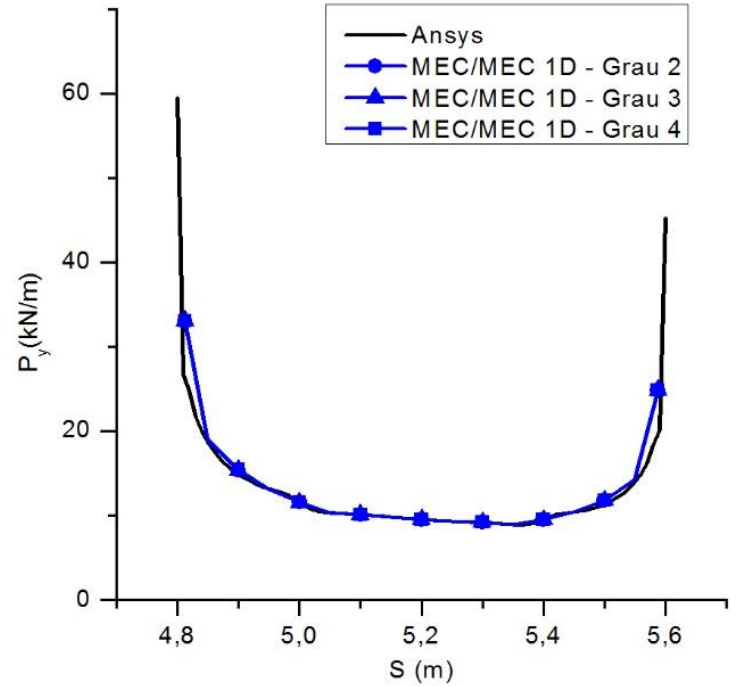

(b)

FONTE: O autor 
Figura 42. Reações de apoio na direção y - Acoplamento Ex. 1, grau de aproximação

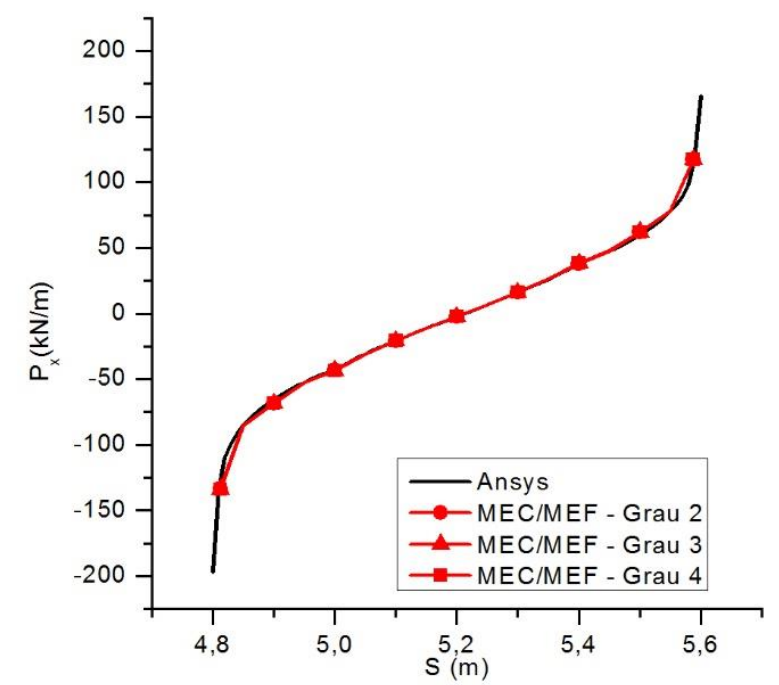

(a)

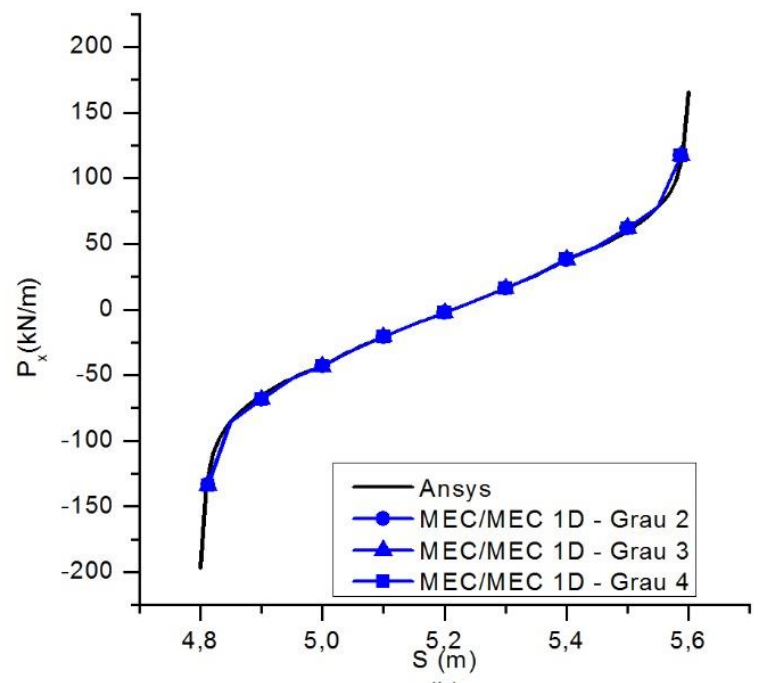

(b)

FONTE: O autor

\subsubsection{Fibra Inferior}

Quanto à Fibra Inferior, para todos os cenários os resultados em deslocamentos continuaram com precisão adequada:

Figura 43. Deslocamentos em x na fibra inferior - Acoplamento Ex. 1, grau de aproximação

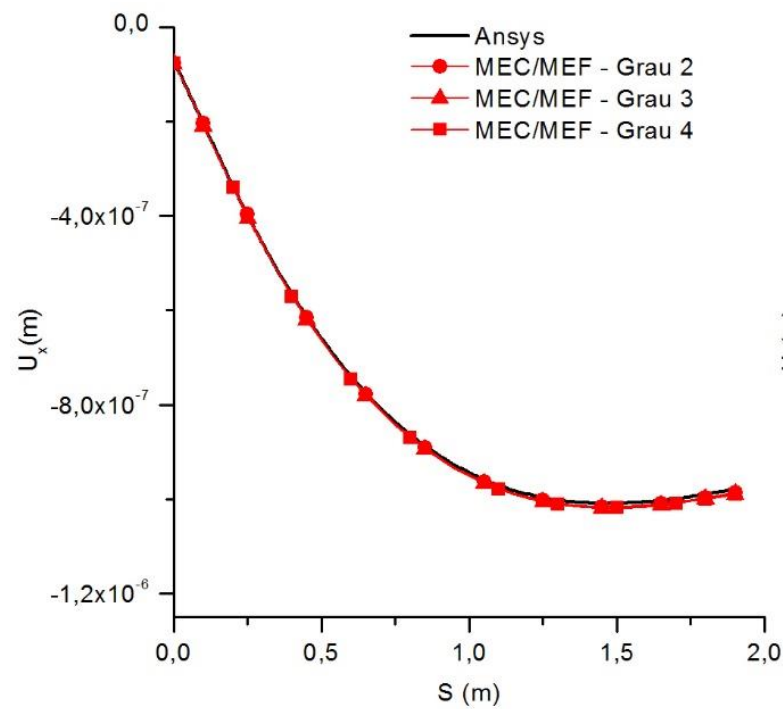

(a)

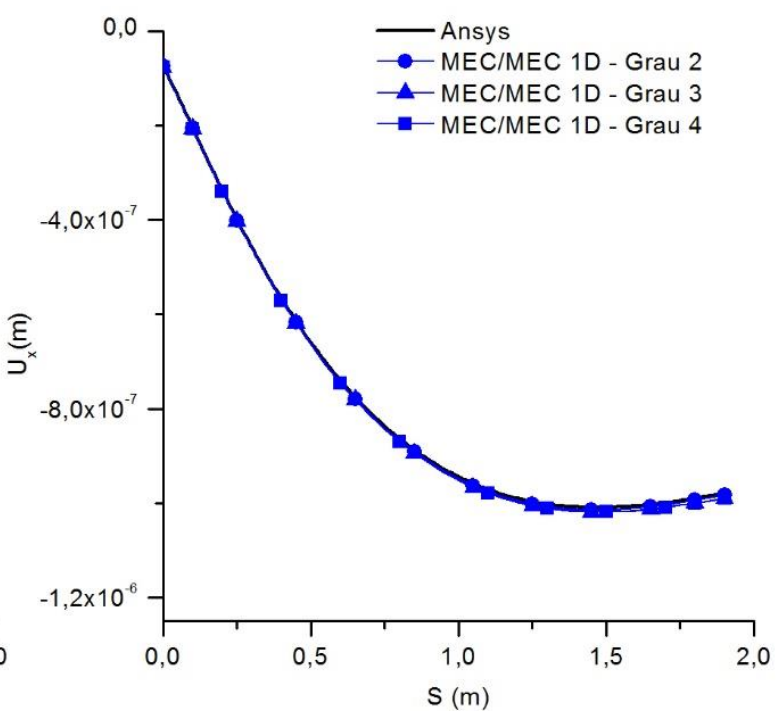

(b)

FONTE: O autor 
Figura 44. Deslocamentos em y na fibra inferior - Acoplamento Ex. 1, grau de aproximação

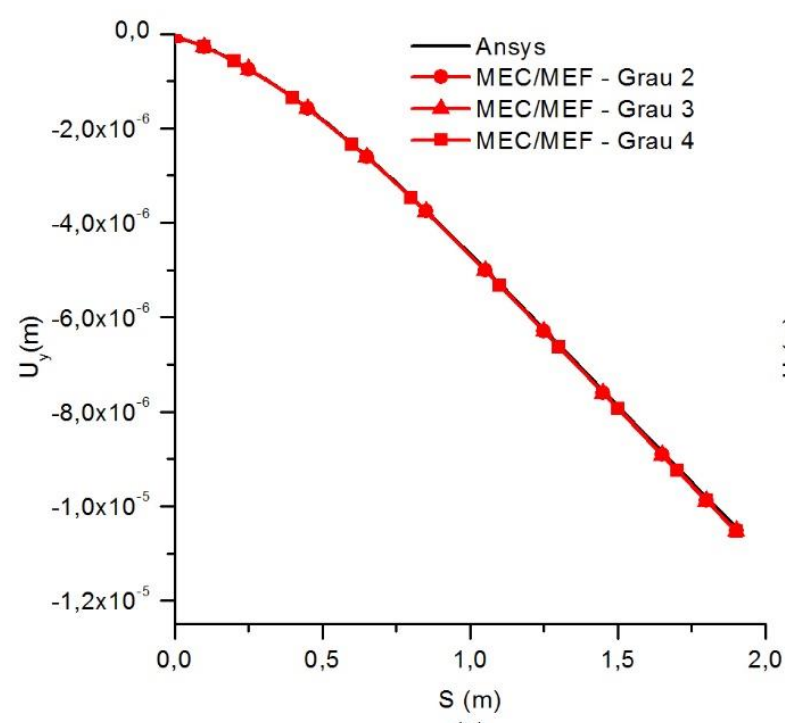

(a)

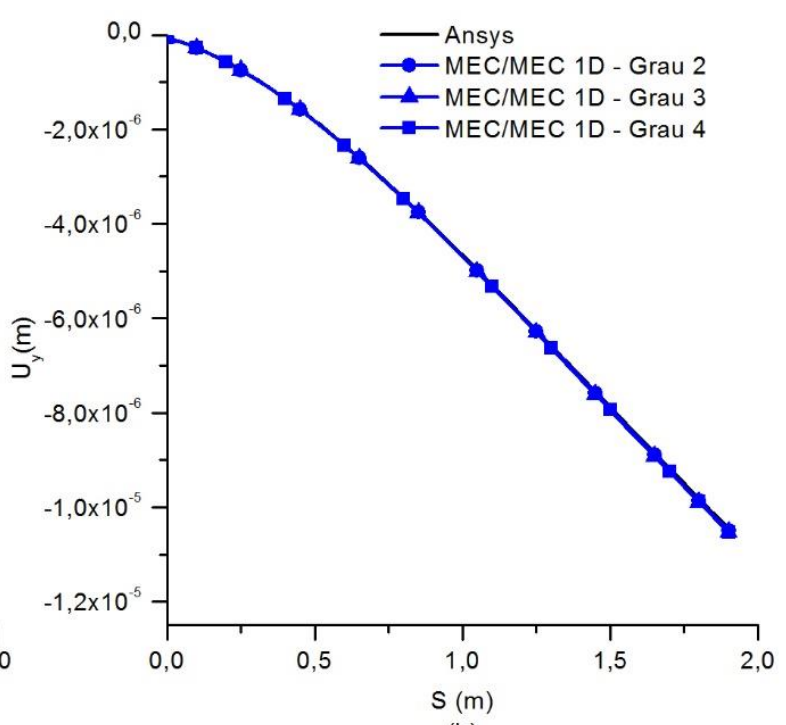

(b)

FONTE: O autor

Em relação a forças normais, verifica-se que o aumento do grau de aproximação possuiu efeito positivo principalmente para o acoplamento MEC/MEF. Entretanto em todos os casos o acoplamento MEC/MEC 1D apresentou comportamento mais estável:

Figura 45. Forças normais na fibra inferior - Grau 2 - Acoplamento Ex. 1, grau de aproximação
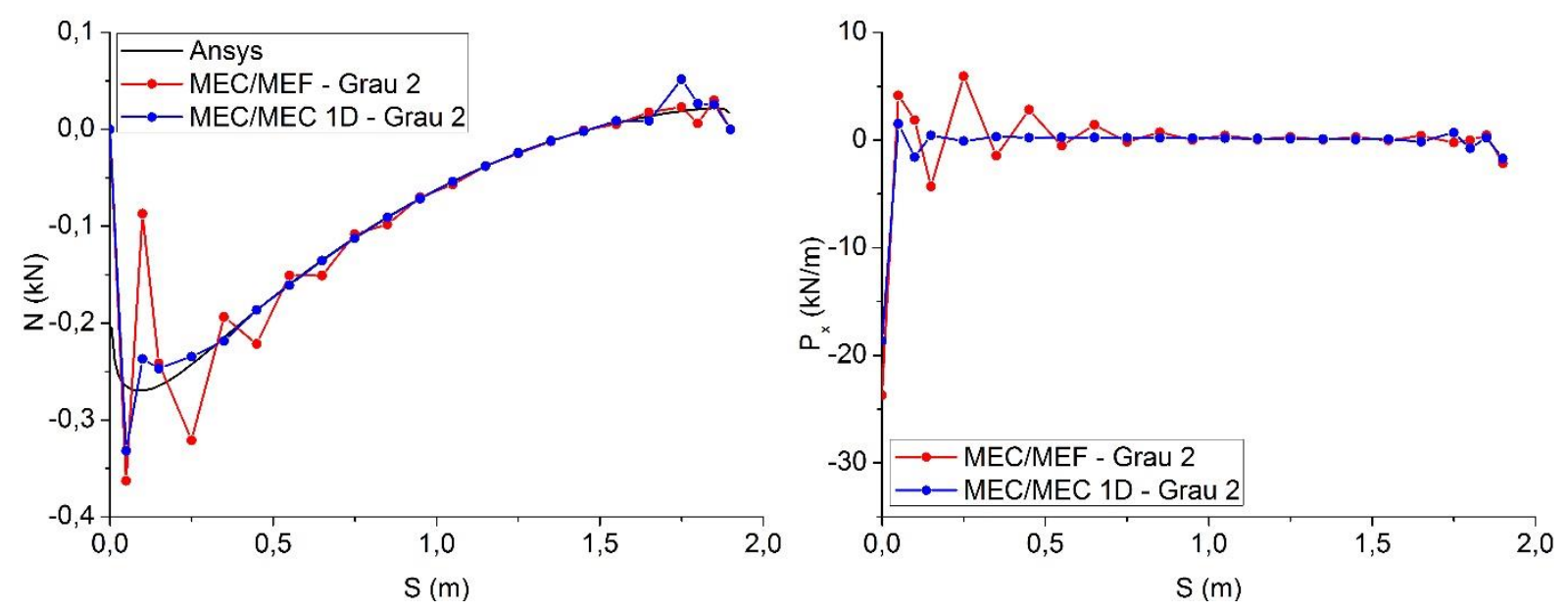

FONTE: O autor 
Figura 46. Forças normais na fibra inferior - Grau 3 - Acoplamento Ex. 1, grau de aproximação
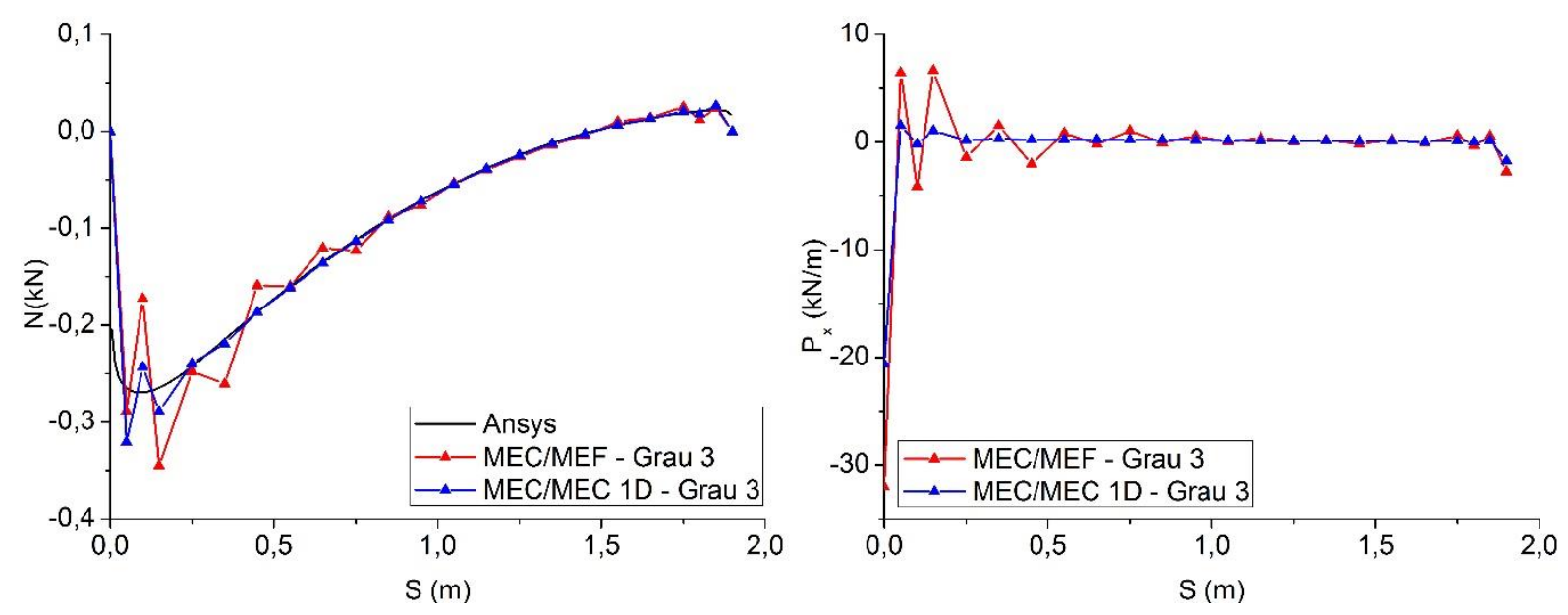

FONTE: O autor

Observa-se relevante melhora no resultado do MEC/MEF com o uso de elementos com aproximação do quarto grau, obtendo resultado muito próximo ao MEC/MEC 1D:

Figura 47. Forças normais na fibra inferior - Grau 4-Acoplamento Ex. 1, grau de aproximação
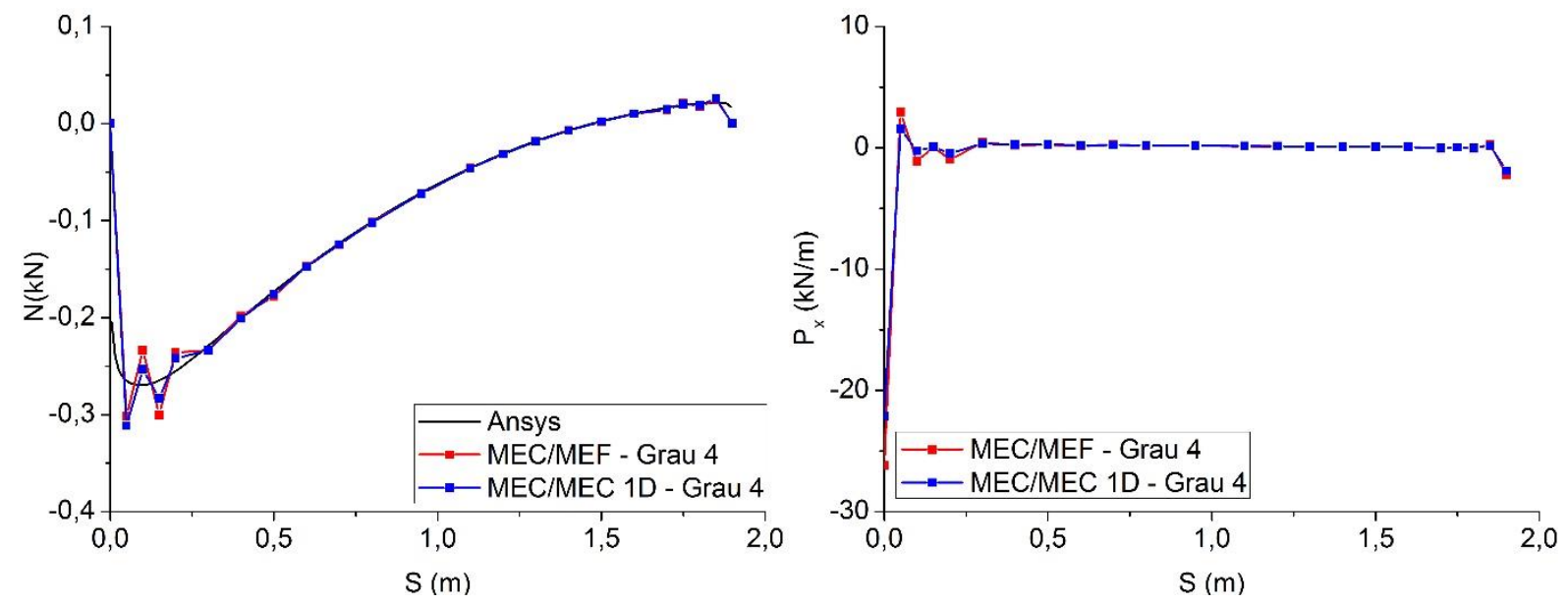

FONTE: O autor

\subsubsection{Fibra Intermediária}

No caso da fibra intermediária, da mesma forma que para a fibra inferior, não houve influência no resultado de deslocamentos: 
Figura 48. Deslocamentos em x na fibra intermediária - Acoplamento Ex. 1, grau de aproximação

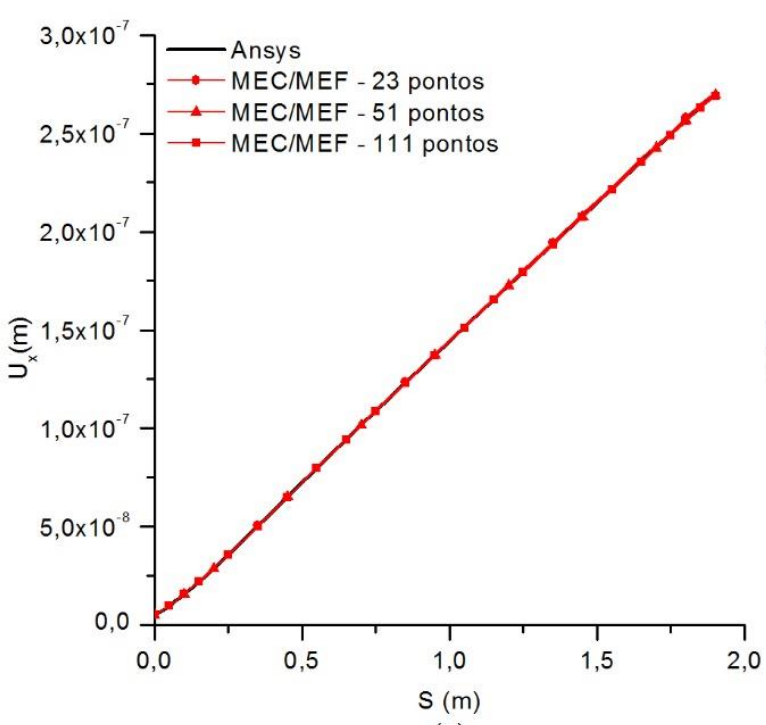

(a)

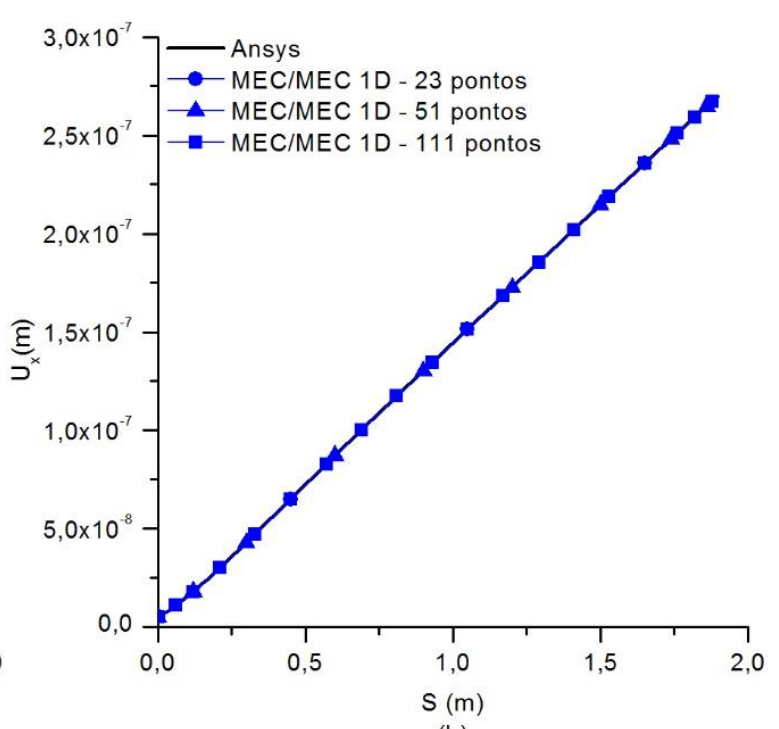

(b)

FONTE: O autor

Figura 49. Deslocamentos em y na fibra intermediária - Acoplamento Ex. 1, grau de aproximação

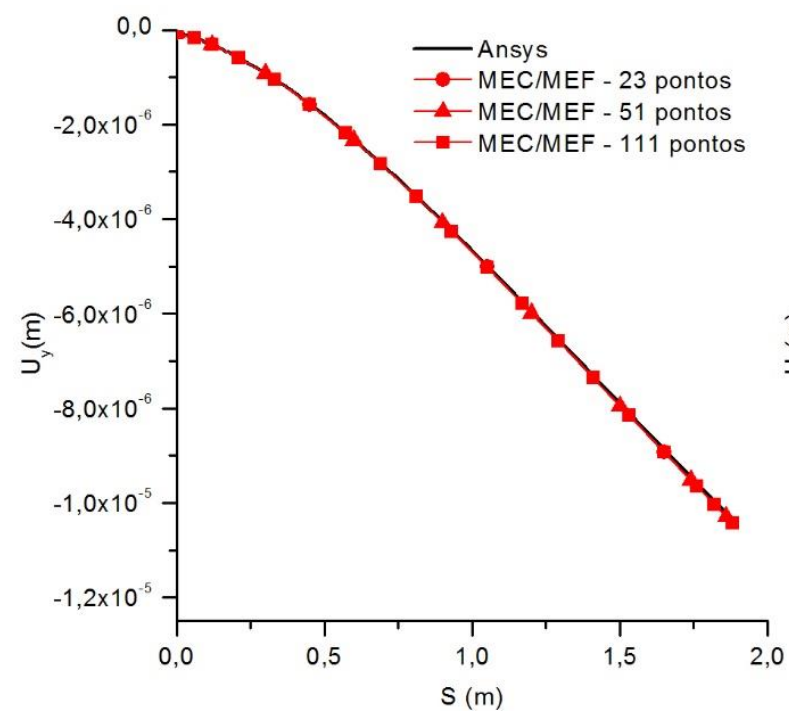

(a)

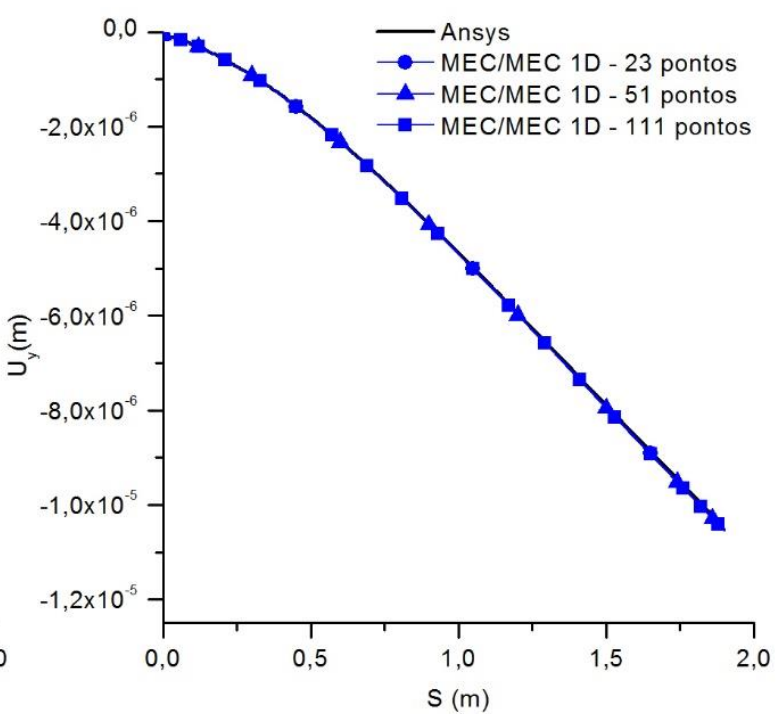

(b)

FONTE: O autor

Quanto às forças normais, o aumento do grau de aproximação possuiu efeito positivo, conforme pode ser observado nas figuras seguintes: 
Figura 50. Forças normais na fibra intermediária - Grau 2 - Acoplamento Ex. 1, grau de aproximação
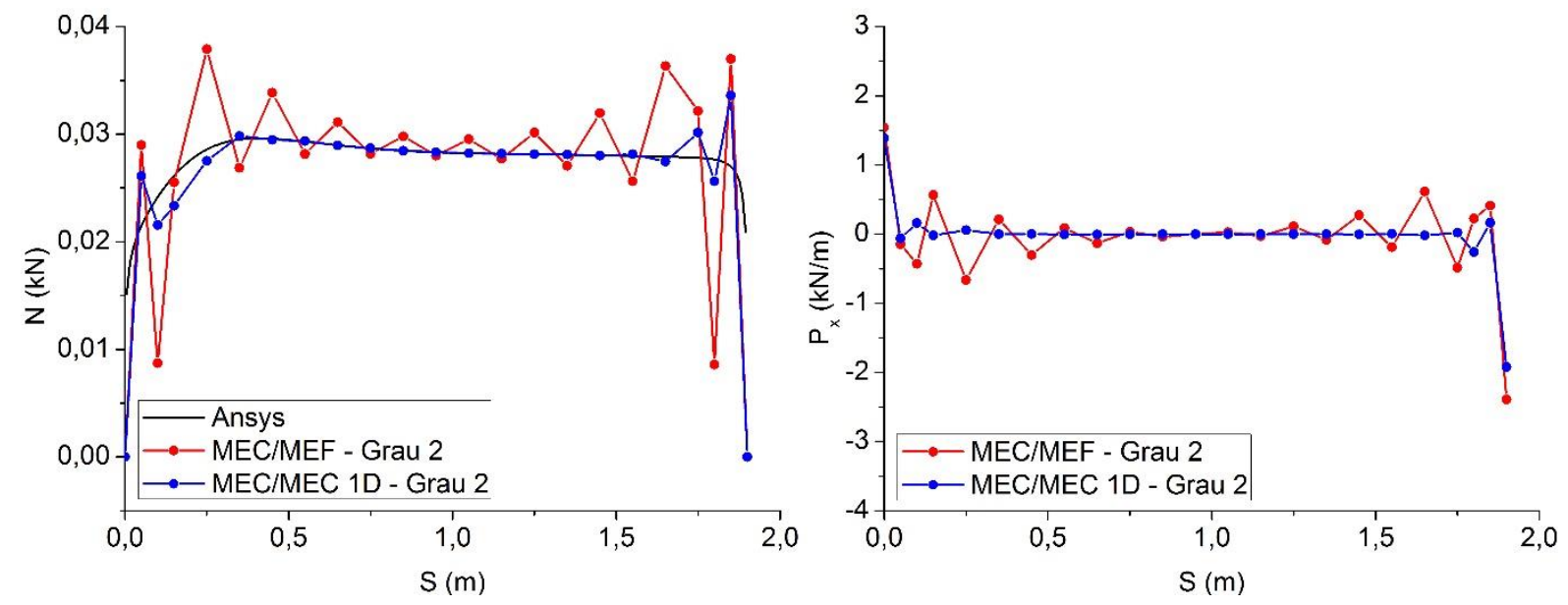

FONTE: O autor

Figura 51. Forças normais na fibra intermediária - Grau 3 - Acoplamento Ex. 1, grau de aproximação
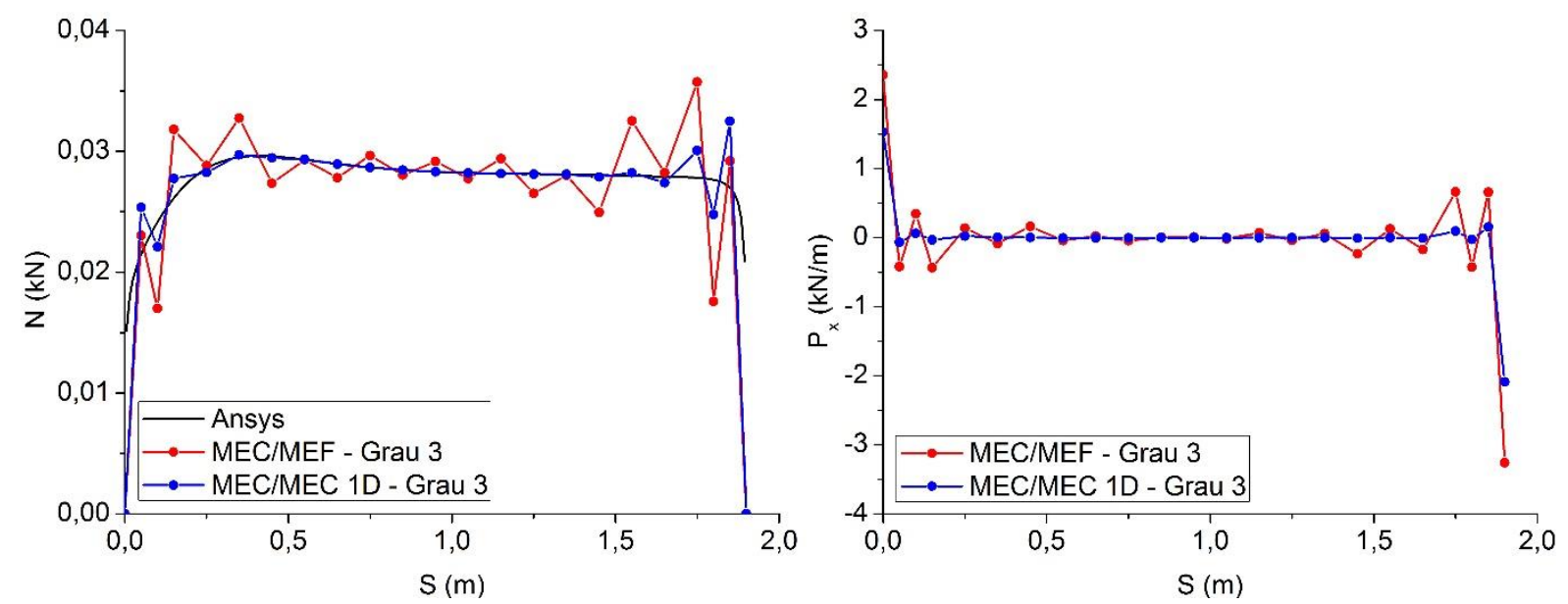

FONTE: O autor

Com o uso de elementos com aproximação do quarto grau, o resultado do MEC/MEF é muito próximo do MEC/MEC 1D:

Figura 52. Forças normais na fibra intermediária - Grau 4 - Acoplamento Ex. 1, grau de aproximação
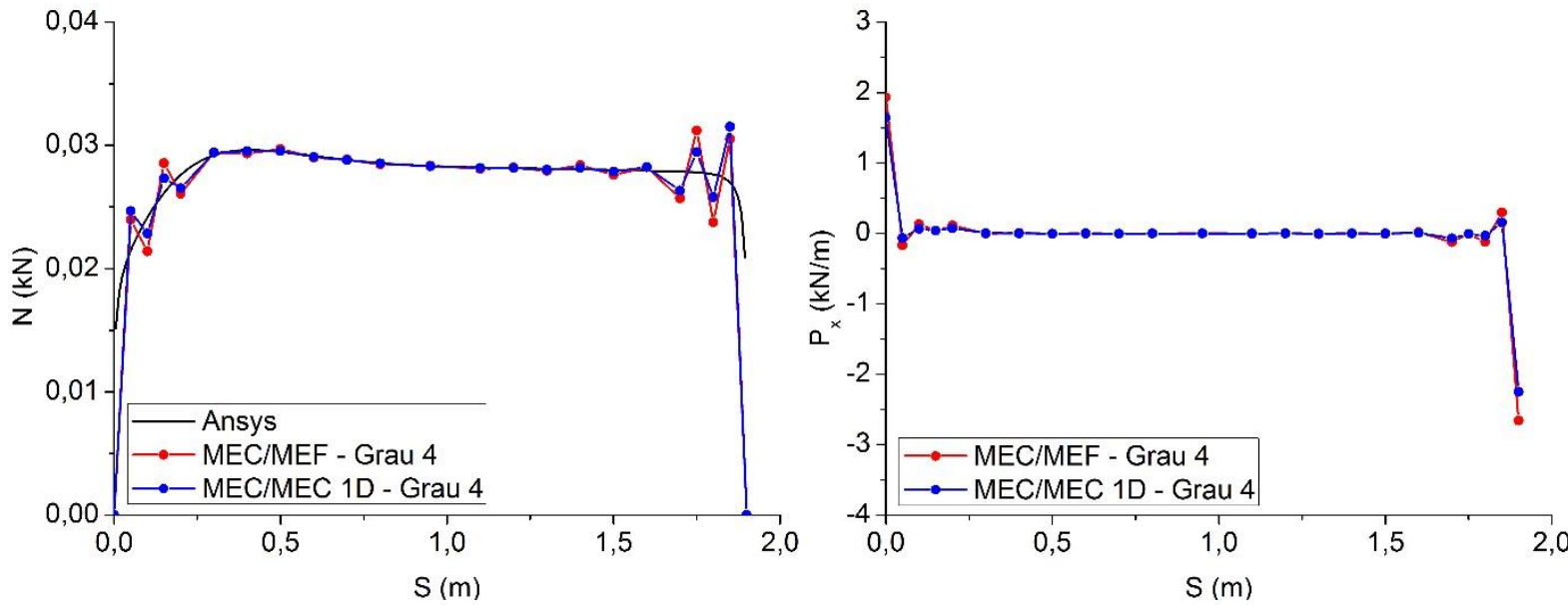

FONTE: O autor 


\subsubsection{Fibra Superior}

Em relação à fibra superior, novamente resultados em deslocamentos se mantiveram próximos e o aumento do grau de aproximação possuiu efeito positivo sobre forças normais: Com o uso de aproximação do quarto grau os métodos possuem resultados muito próximos:

Figura 53. Deslocamentos em x na fibra superior - Acoplamento Ex. 1, grau de aproximação

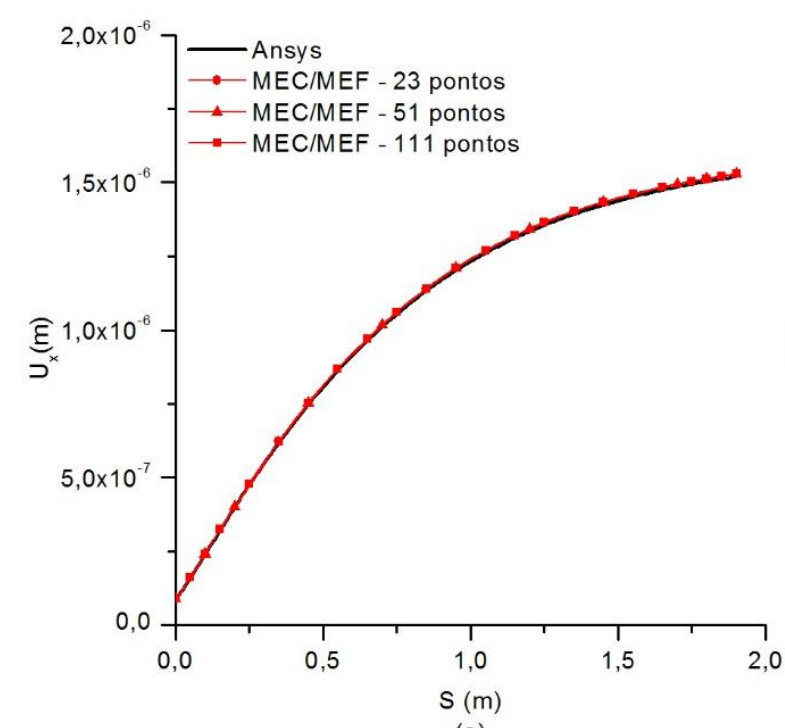

(a)

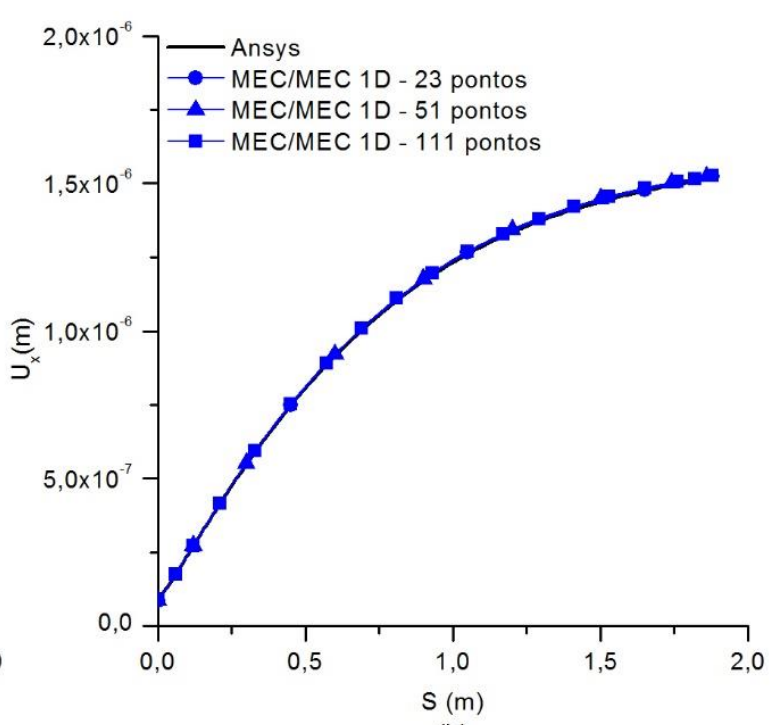

(b)

FONTE: O autor

Figura 54. Deslocamentos em y na fibra superior - Acoplamento Ex. 1, grau de aproximação

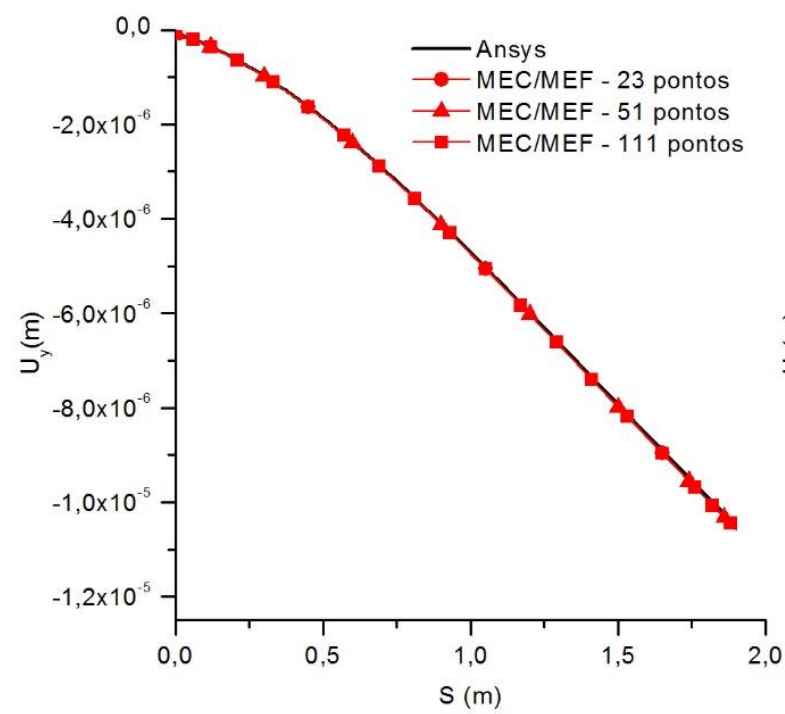

(a)

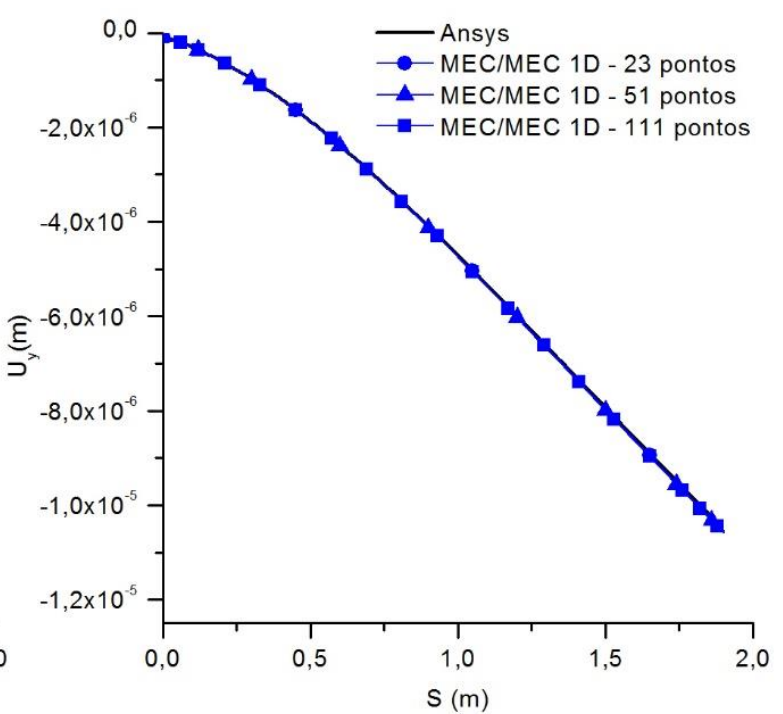

(b)

FONTE: O autor 
Figura 55. Forças normais na fibra superior - Grau 2 - Acoplamento Ex. 1, grau de aproximação
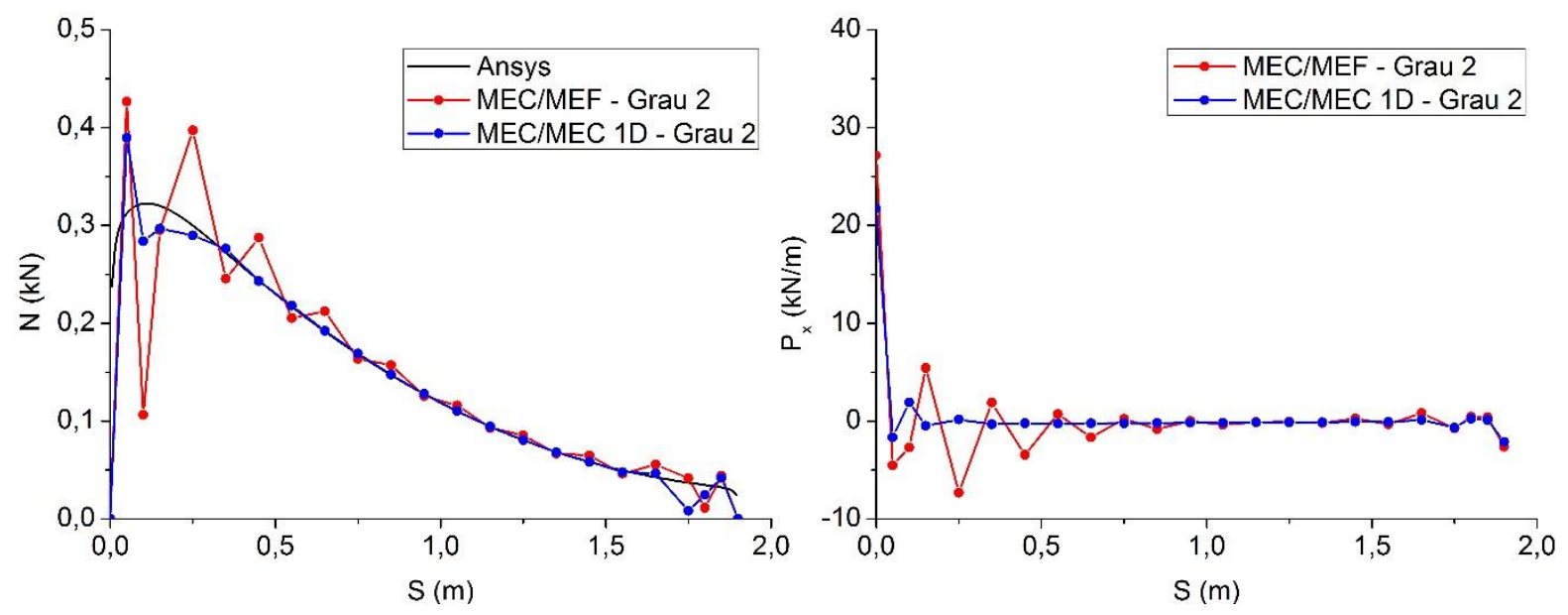

FONTE: O autor

Figura 56. Forças normais na fibra superior - Grau 3 - Acoplamento Ex. 1, grau de aproximação
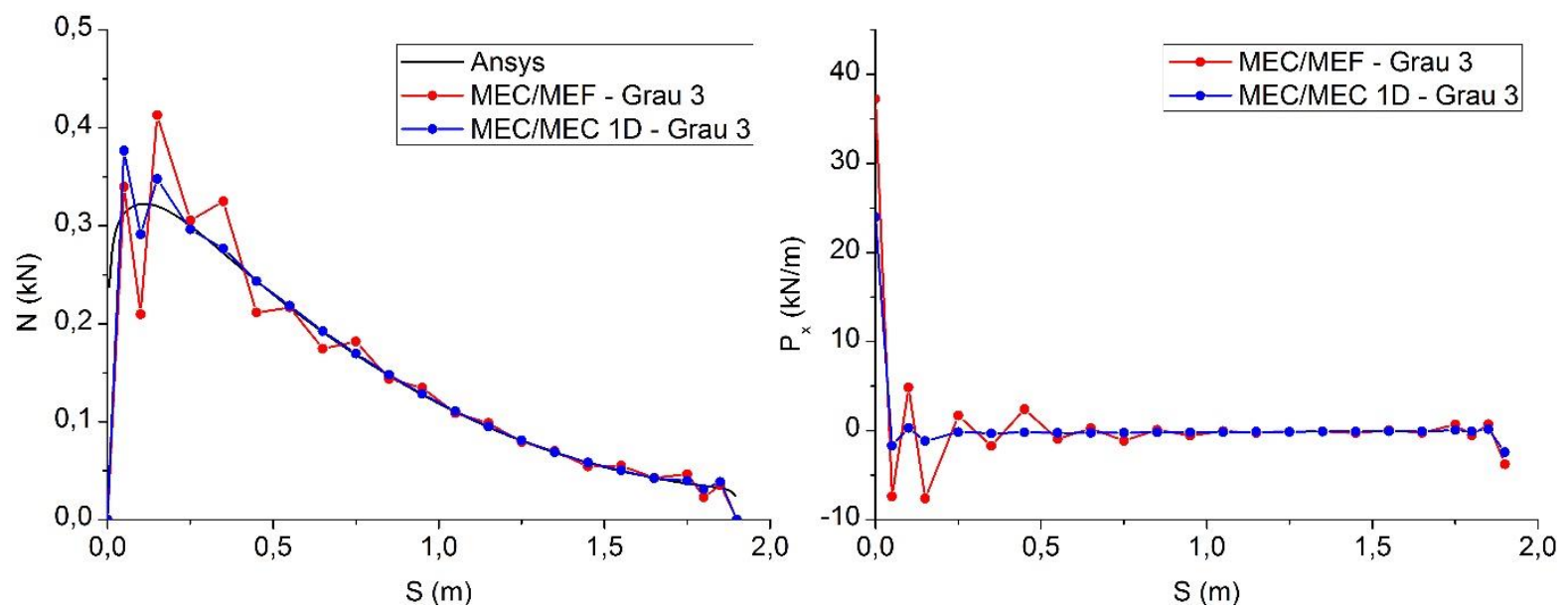

FONTE: O autor

Figura 57. Forças normais na fibra superior - Grau 4 - Acoplamento Ex. 1, grau de aproximação
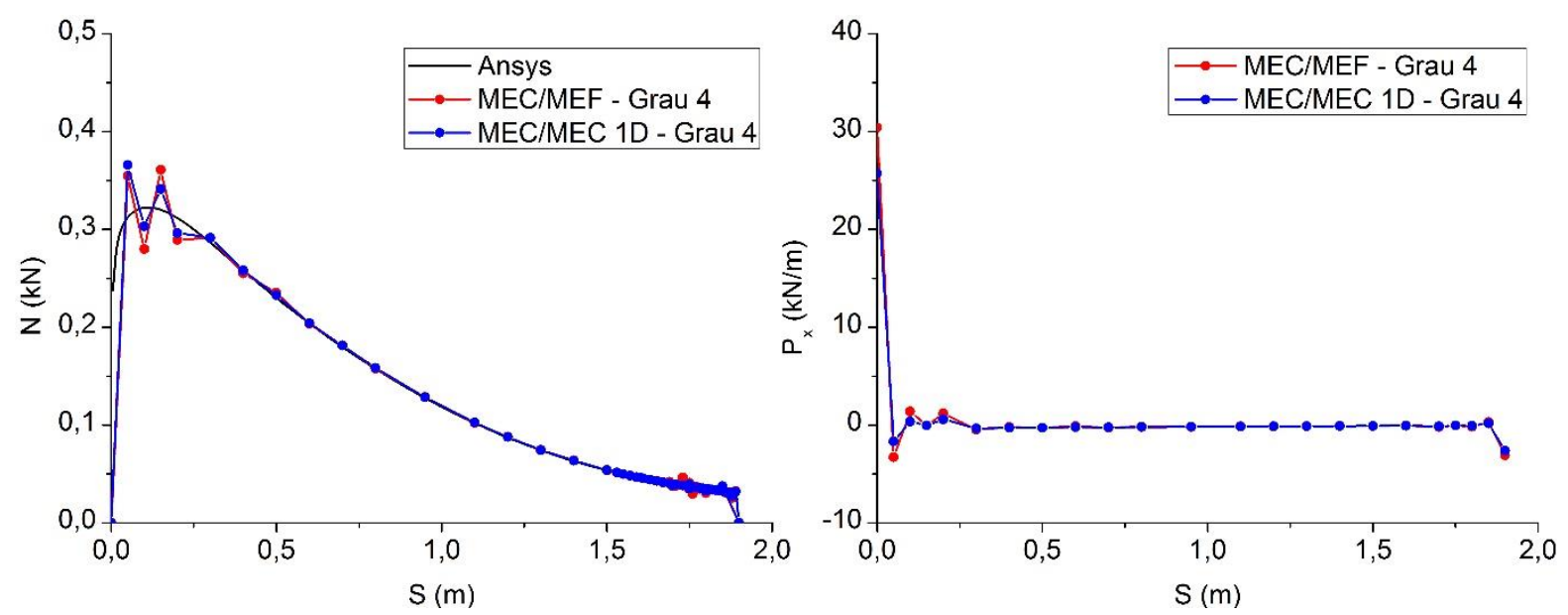

FONTE: O autor 


\subsubsection{Conclusões Parciais}

O exemplo foi estudado primeiramente com elementos de aproximação quadrática e diversas discretizações dos enrijecedores, 23, 51 e 111 nós. Em todos os casos foram obtidos bons resultados para o contorno e para os deslocamentos das fibras. Com o aumento da discretização obteve-se a usual melhoria de resultados e claramente pôde-se perceber que ocorre concentração de tensões nas extremidades das fibras. O acoplamento MEC/MEC 1D possuiu resultado superior em todas análises realizadas, principalmente no caso de discretização das fibras com 23 nós, havendo relevante perturbação do resultado em forças de aderência e força normal no acoplamento com o MEF.

Com base no resultado anterior, o exemplo foi reavaliado variando-se o grau de aproximação, mantendo-se o número de nós das fibras em 23. Foi verificado que o aumento do grau de aproximação possui efeito positivo, principalmente para resultados de forças normais . $\mathrm{O}$ acoplamento MEC/MEC 1D possuiu novamente resultado superior, entretanto no caso de aproximação do quarto grau os resultados do MEC/MEF se tornaram próximos.

\subsection{Acoplamento - Exemplo 2}

A estrutura apresentada no Exemplo 1 (item 5.1) foi novamente analisada considerando outros valores para as propriedades mecânicas. Foi considerado meio com rigidez muito inferior à do enrijecedor, de forma que este governe o comportamento mecânico do problema. Buscouse verificar se a solução se torna mais estável:

$$
\begin{gathered}
E_{s}=200 \mathrm{GPa} \\
E_{c}=0,025 \mathrm{GPa} \\
v_{C}=0,25 \\
A_{s}=10 \mathrm{~cm}^{2} \text { (por enrijecedor) }
\end{gathered}
$$

No Exemplo 1 verificou-se que a mudança de discretização possui efeito mais relevante em relação à mudança de grau de aproximação, além disso, verificou-se maior perturbação para enrijecedores com 23 nós com aproximação quadrática.

Uma vez que o objetivo é avaliar a influência da rigidez do meio, será verificado o caso mais instável apresentado no Exemplo 1, enrijecedores com 23 nós, sendo avaliados os efeitos do uso de elementos de grau 2,3 e 4 . 


\subsubsection{Resultados no contorno}

Observa-se que no caso de deslocamentos do contorno, nas duas direções, os deslocamentos foram de pequeno valor, garantindo desta forma a validade do regime de pequenos deslocamentos e deformações. O resultado para enrijecedores com aproximação quadrática diverge dos demais. Além disso, nesse caso o acoplamento MEC/MEF obteve respostas melhores que o MEC/MEC 1D. Mesmo o meio possuindo menor rigidez, nas duas direções os deslocamentos foram de pequeno valor, garantindo desta forma a validade do regime de pequenos deslocamentos e deformações:

Figura 58. Deslocamentos na direção $\mathrm{x}$ - Acoplamento Ex.2

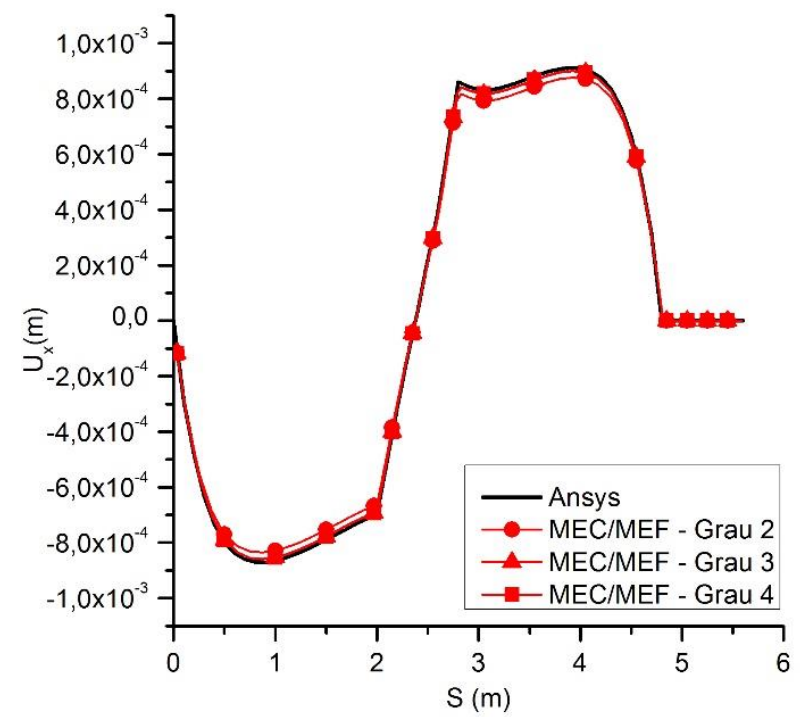

(a)

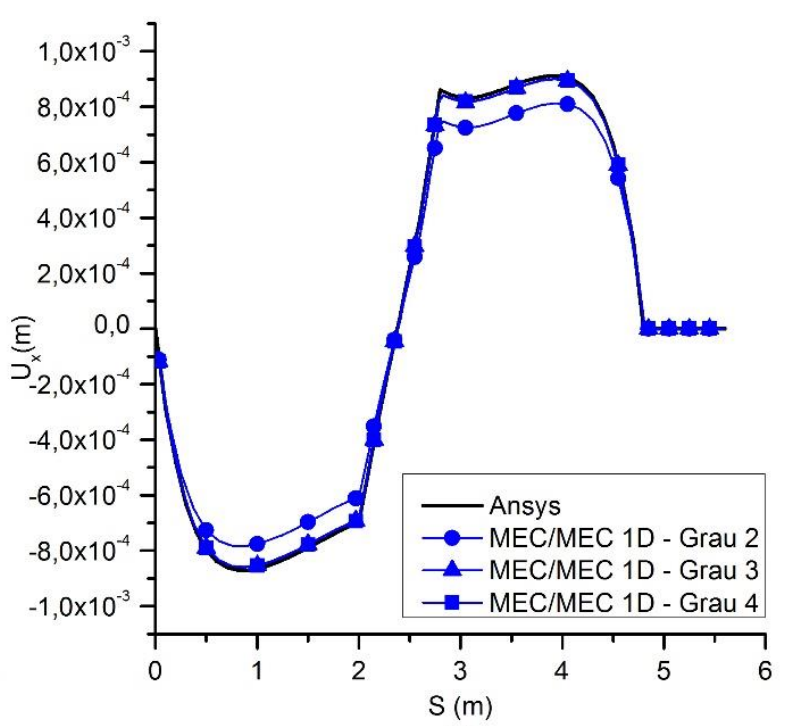

(a)

FONTE: O autor

Figura 59. Deslocamentos na direção y - Acoplamento Ex.2

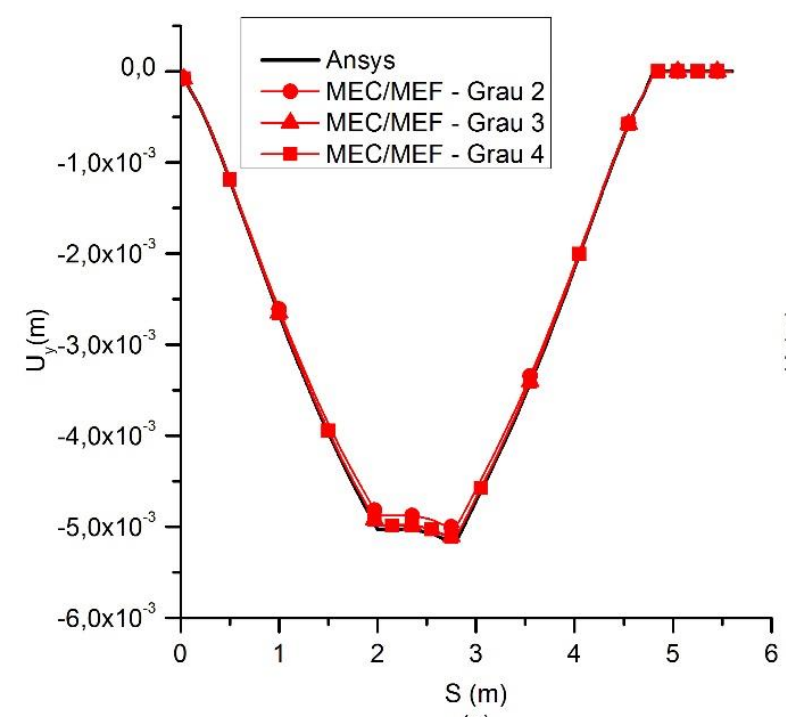

(a)

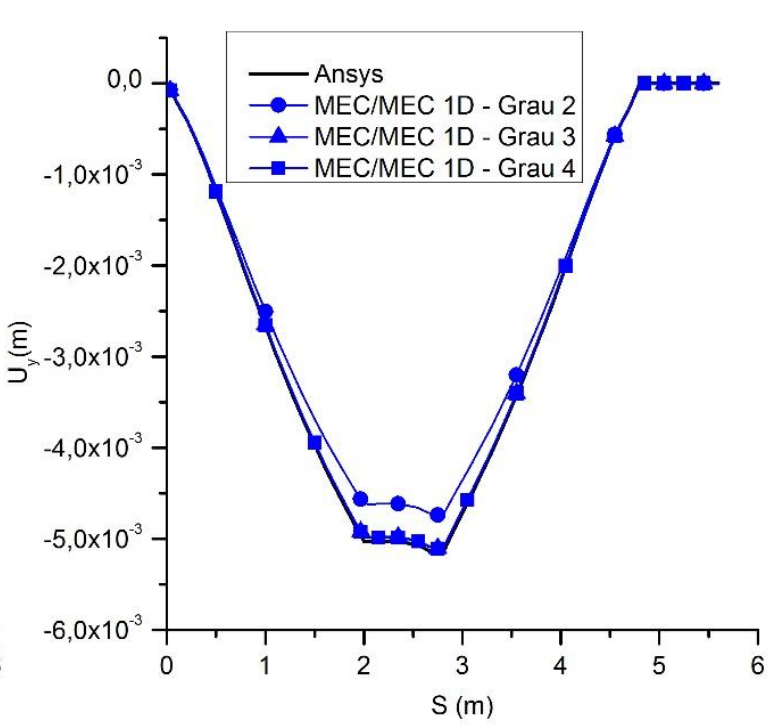

(a)

FONTE: O autor 
No caso de reações de apoio, se observa que há concentração de tensões nos trechos próximos aos enrijecedores, indicando que eles possuem influência direta no resultado do contorno:

Figura 60. Reações de apoio na direção $\mathrm{x}$ - Acoplamento Ex.2

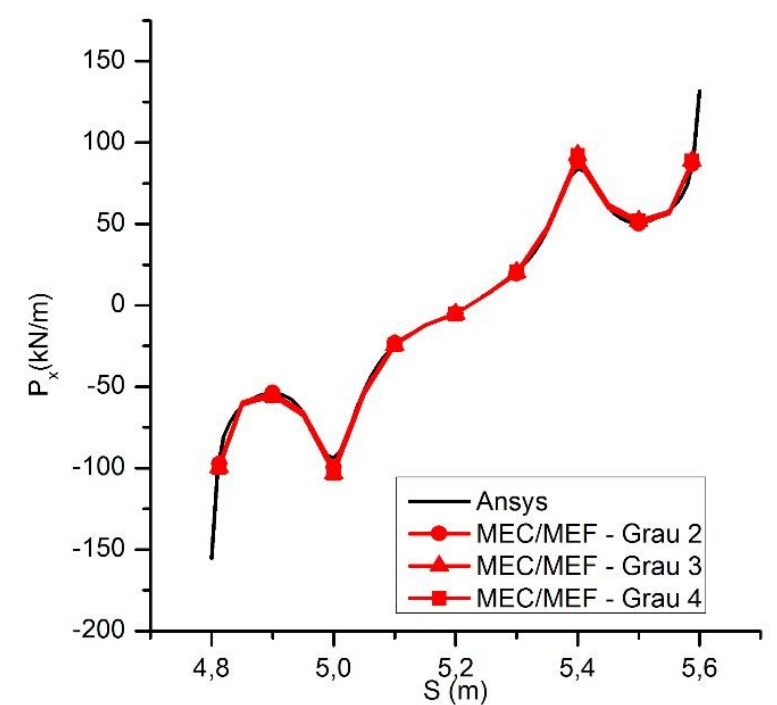

(a)

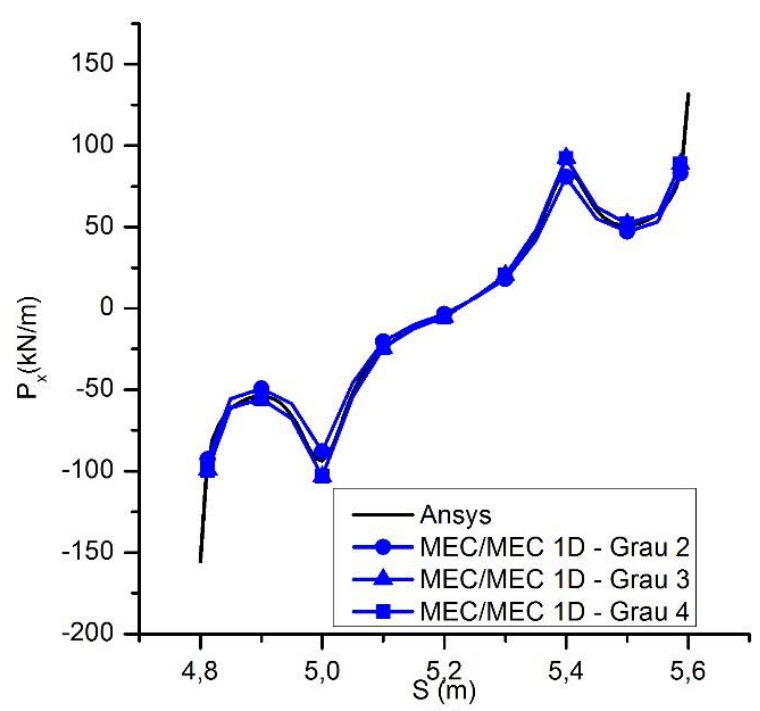

(b)

FONTE: O autor

Figura 61. Reações de apoio na direção y - Acoplamento Ex.2

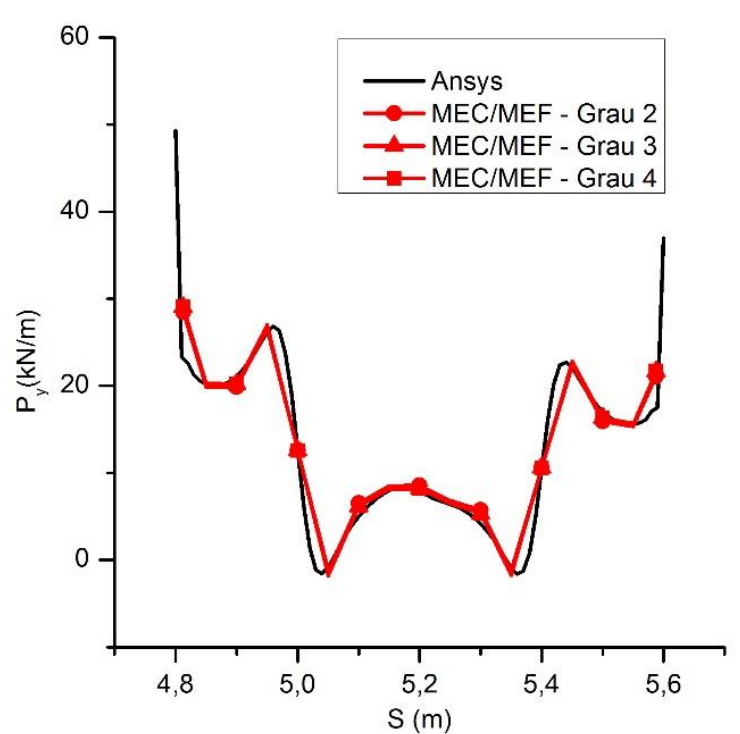

(a)

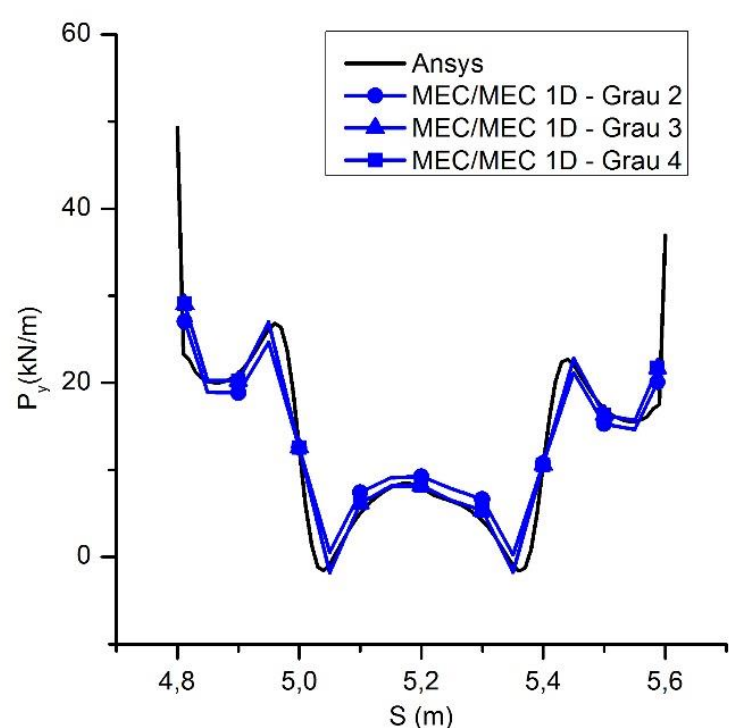

(b)

FONTE: O autor

\subsubsection{Fibra Inferior}

A mesma divergência de resultados do contorno se replica em certo grau na fibra inferior. Principalmente no caso de deslocamentos na direção x, há relevante influência do grau de aproximação no resultado. Entretanto, mesmo com o aumento do grau de aproximação ainda 
ocorre certa divergência com o resultado do ANSYS, apesar de haver convergência entre resultados de acoplamento com MEC:

Figura 62. Deslocamentos em x na fibra inferior - Acoplamento Ex.2

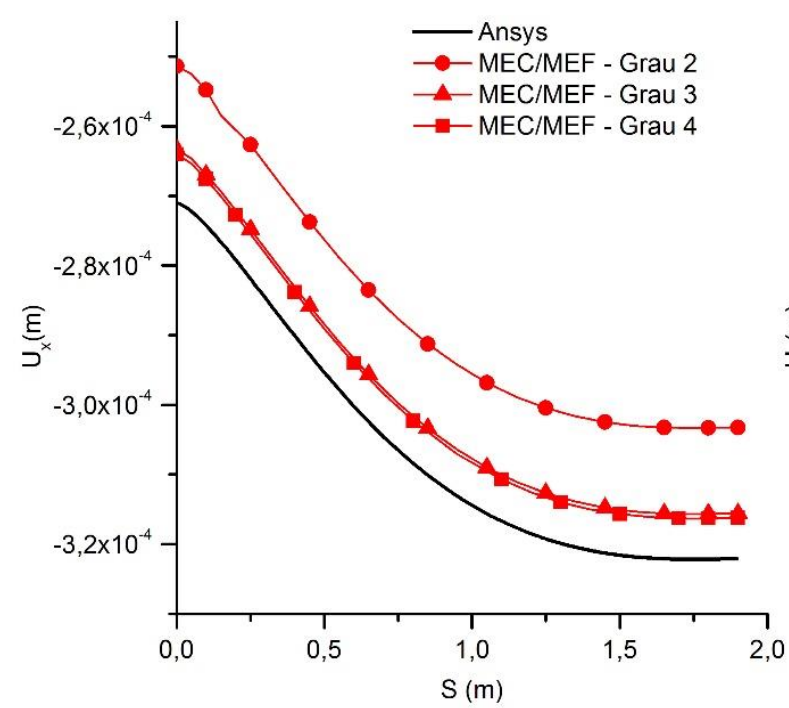

(a)

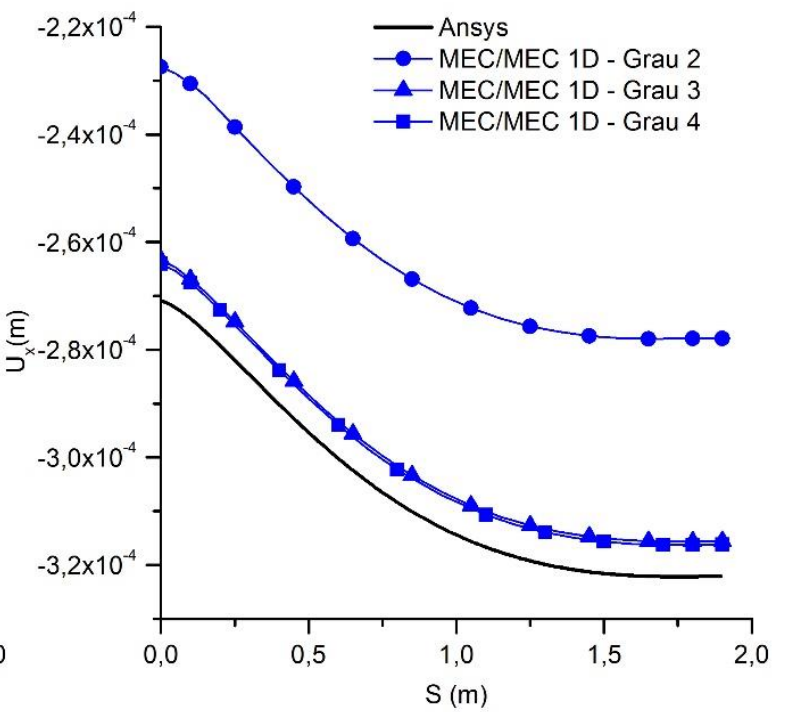

(b)

FONTE: O autor

Na direção y não se espera grande efeito da mudança de discretização dos enrijecedores uma vez que eles não possuem rigidez nesta direção:

Figura 63. Deslocamentos em y na fibra inferior - Acoplamento Ex.2

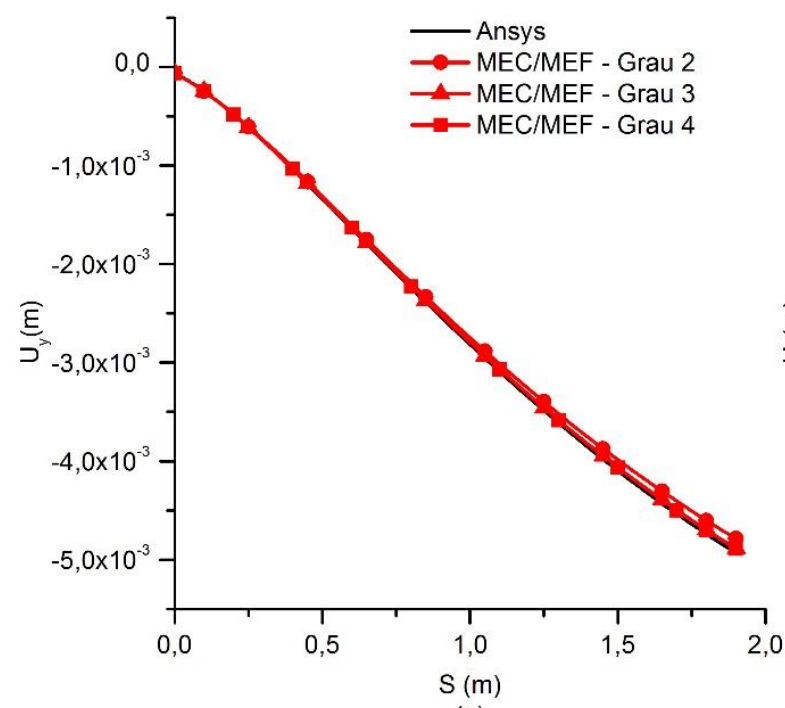

(a)

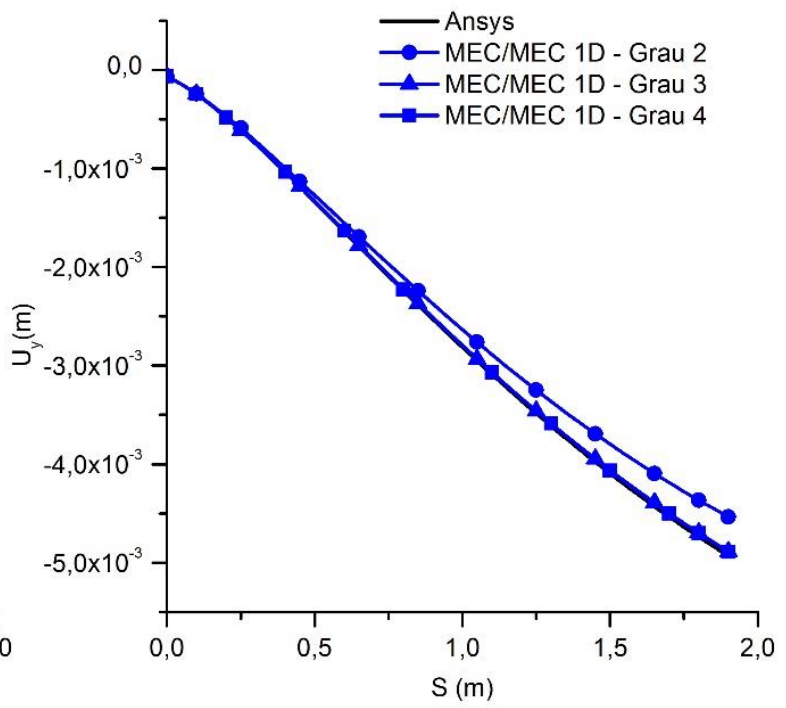

(b)

FONTE: O autor

Apesar da divergência de resultados no contorno e em deslocamentos, no caso de forças normais há maior convergência. Em todos os casos há grande concentração de tensão na ponta da fibra, o efeito disto na escala leva os resultados em termos de força de aderência a ficarem muito próximos: 
Figura 64. Forças normais na fibra inferior - Grau 2 - Acoplamento Ex.2
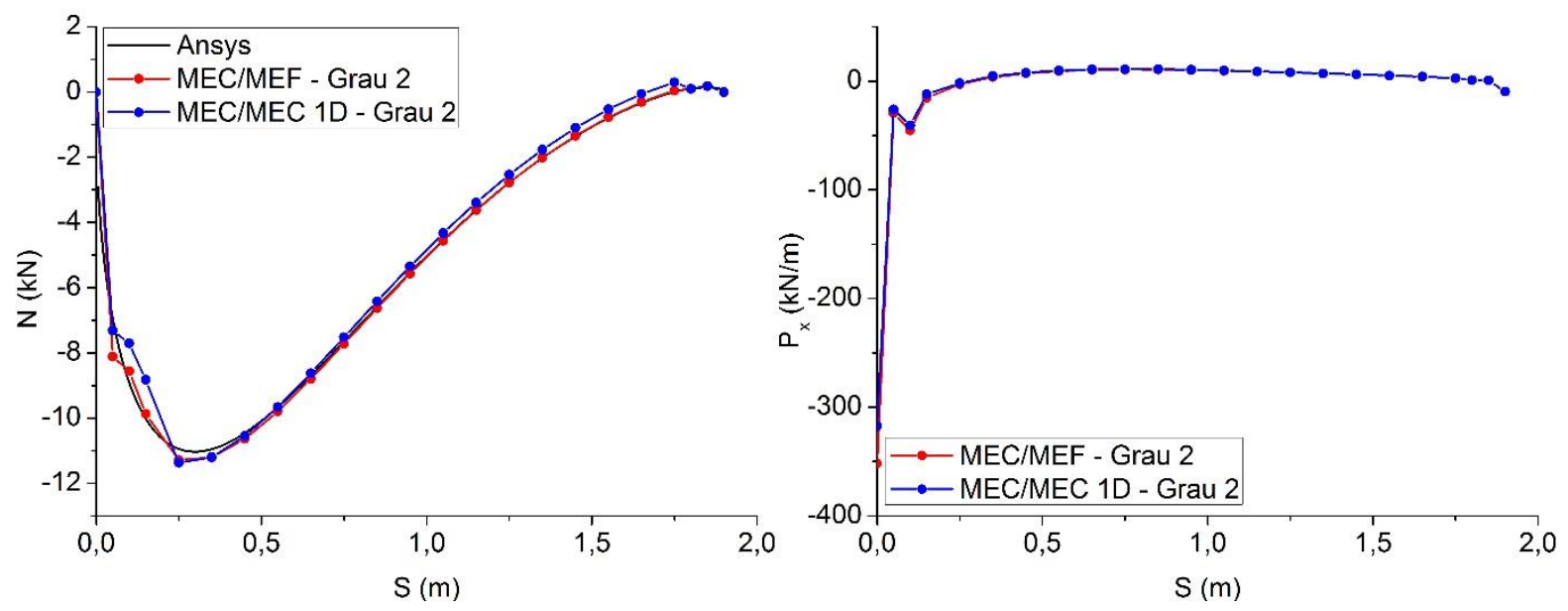

FONTE: O autor

Em relação ao Exemplo 1, percebe-se que com o uso de aproximação cúbica já há convergência, o mesmo ocorrendo com aproximação do quarto grau. O resultado do MEC/MEF de fato se mostrou mais estável que no Exemplo 1:

Figura 65. Forças normais na fibra inferior - Grau 3 - Acoplamento Ex.2
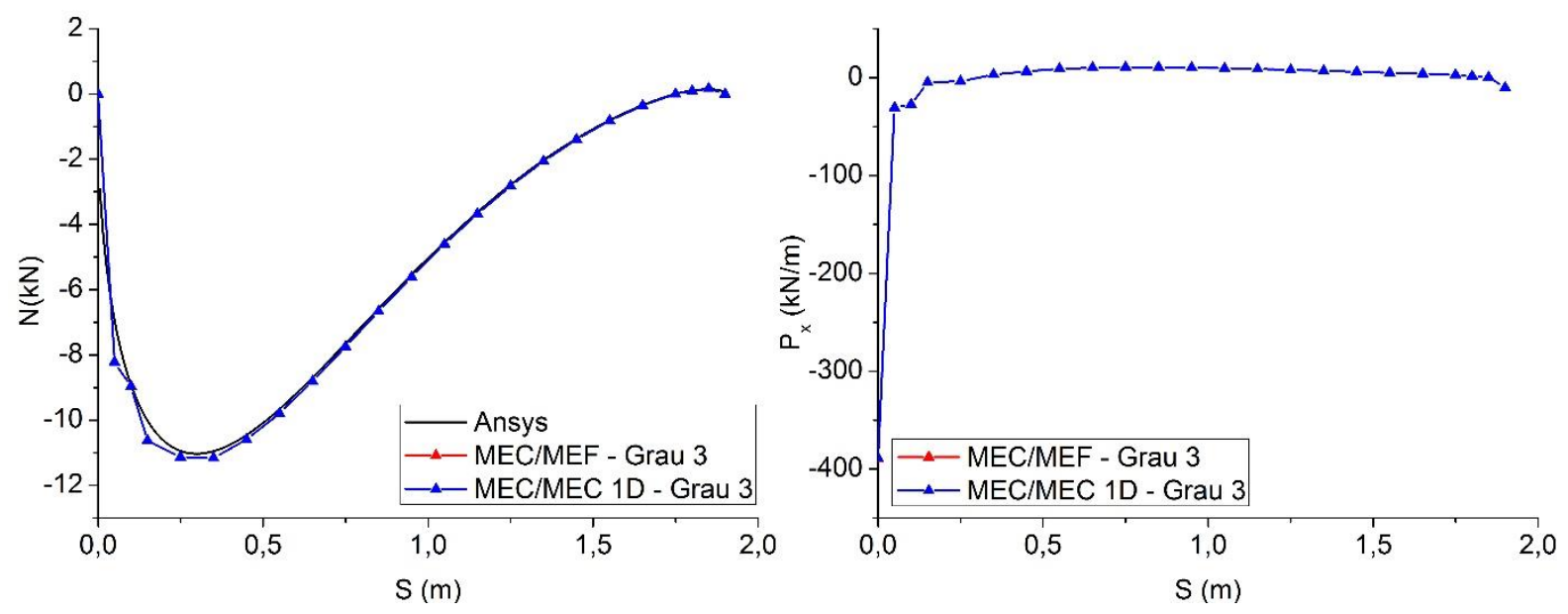

FONTE: O autor 
Figura 66. Forças normais na fibra inferior - Grau 4 - Acoplamento Ex.2
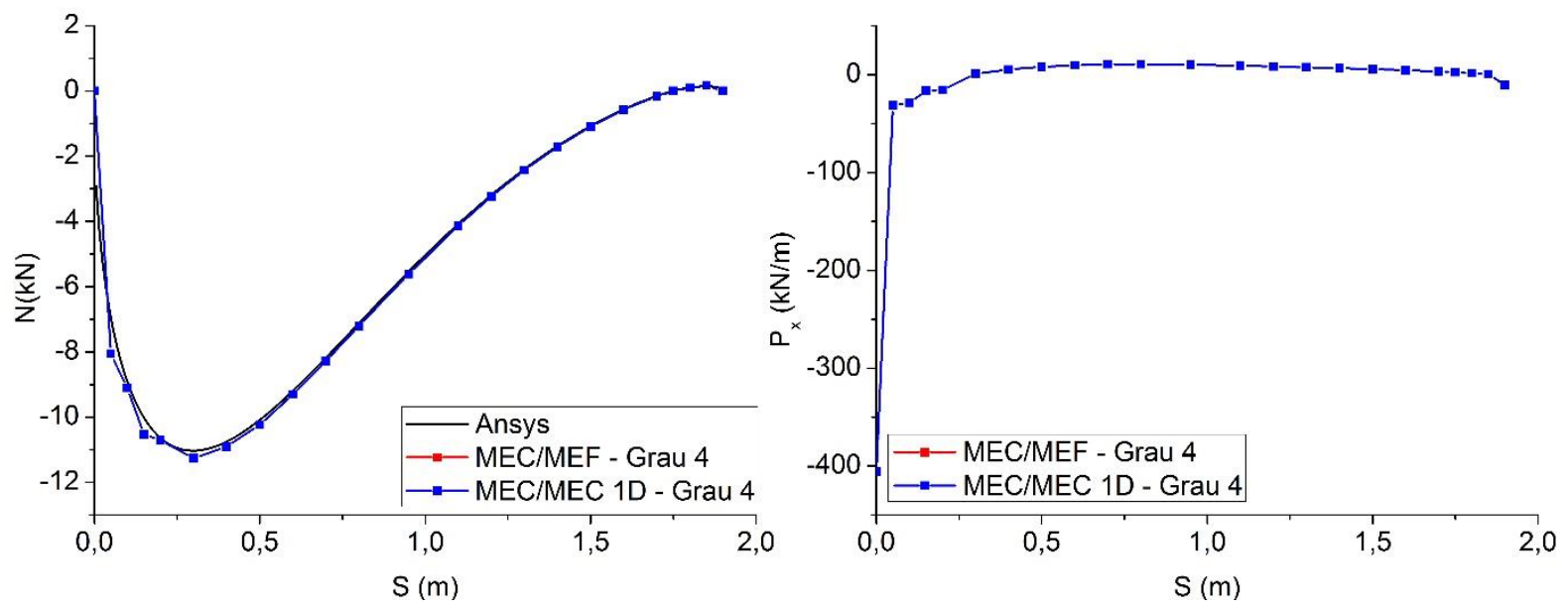

FONTE: O autor

\subsubsection{Fibra Intermediária}

No caso da fibra intermediária, semelhantemente à fibra inferior, a mesma divergência de resultados do contorno se replica em certo grau e há certa divergência com o resultado do ANSYS:

Figura 67. Deslocamentos em x na fibra intermediária - Acoplamento Ex.2

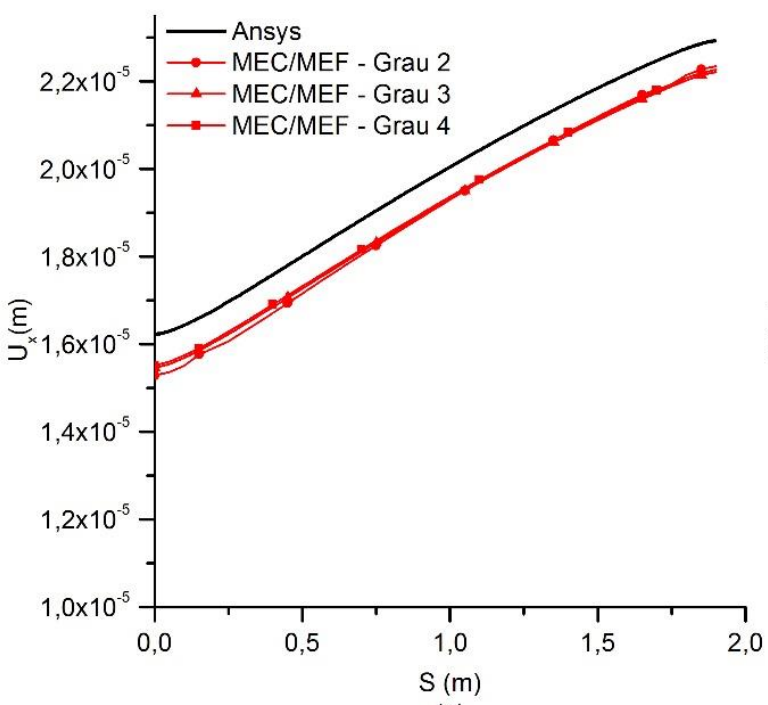

(a)

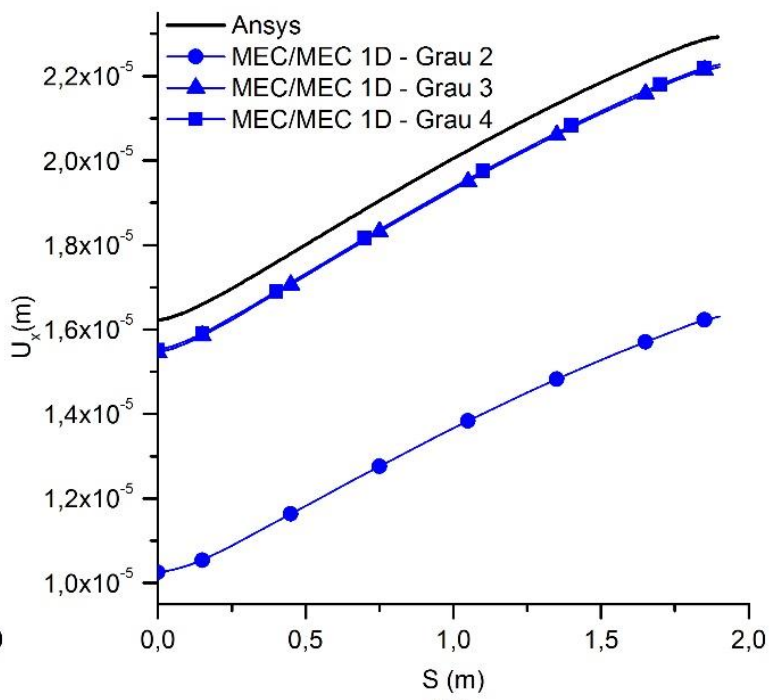

(b)

FONTE: O autor

$\mathrm{Na}$ direção y não há grande efeito da mudança do grau de aproximação dos enrijecedores: 
Figura 68. Deslocamentos em y na fibra intermediária - Acoplamento Ex.2

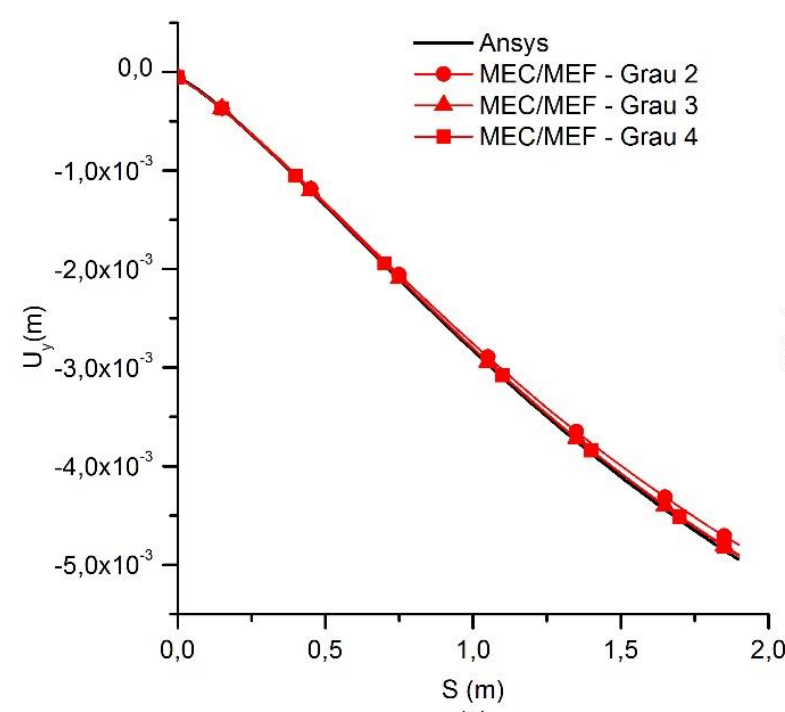

(a)

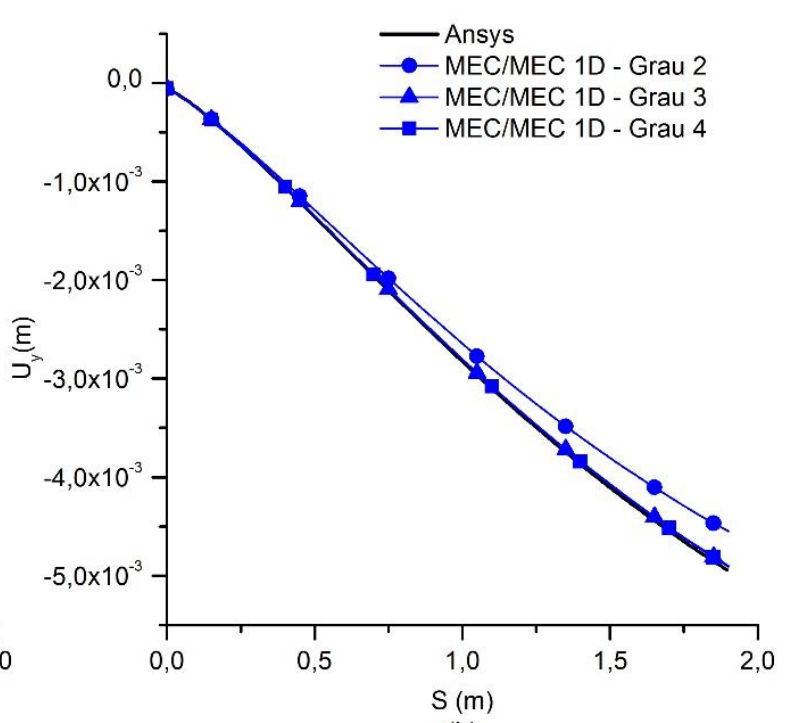

(b)

FONTE: O autor

Quanto às forças normais, o resultado do MEC/MEF foi ligeiramente superior:

Figura 69. Forças normais na fibra intermediária - Grau 2 - Acoplamento Ex.2
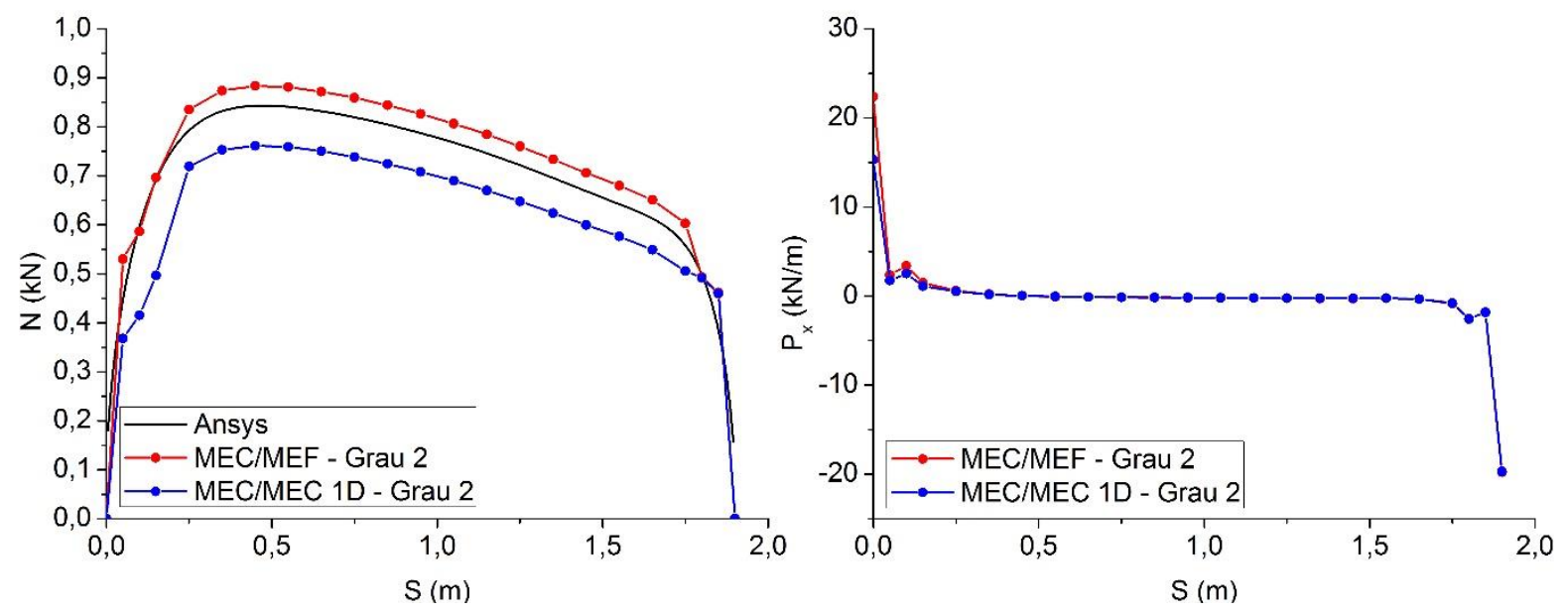

FONTE: O autor

O aumento do grau de aproximação possui relevante influência, havendo convergência já com aproximação cúbica: 
Figura 70. Forças normais na fibra intermediária - Grau 3 - Acoplamento Ex.2
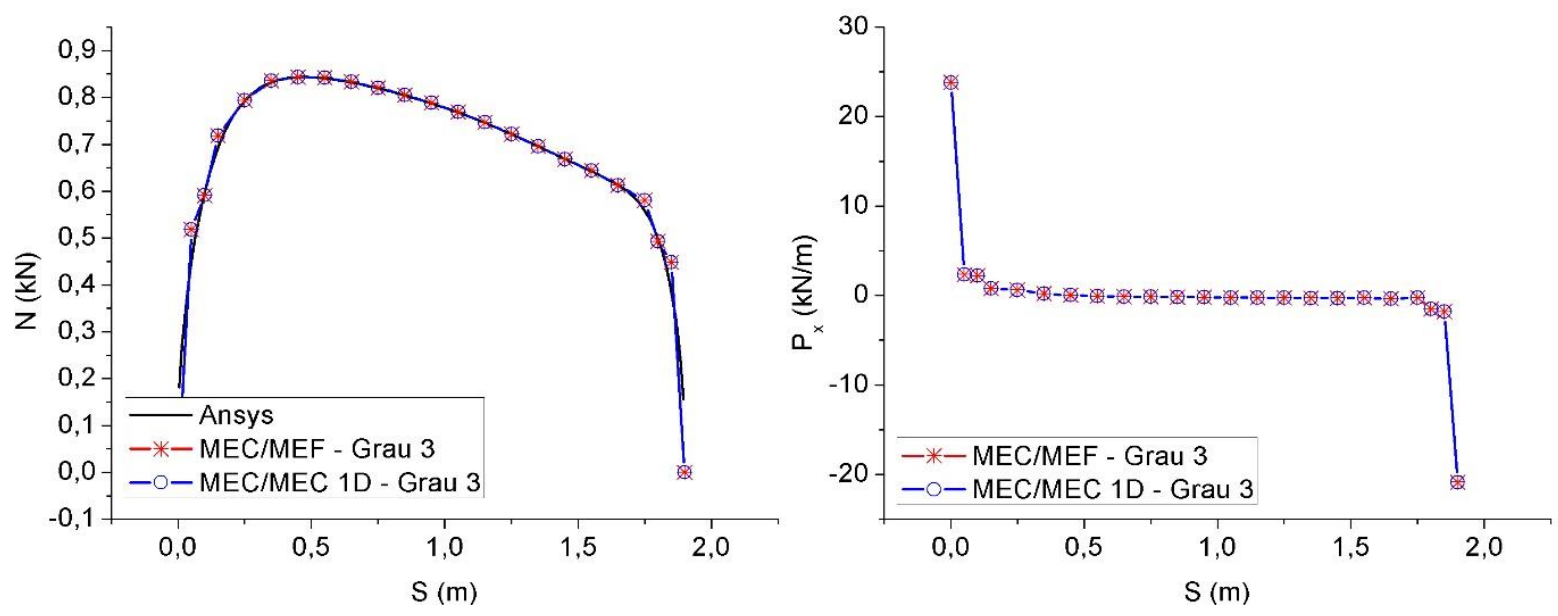

FONTE: O autor

Figura 71. Forças normais na fibra intermediária - Grau 4 - Acoplamento Ex.2
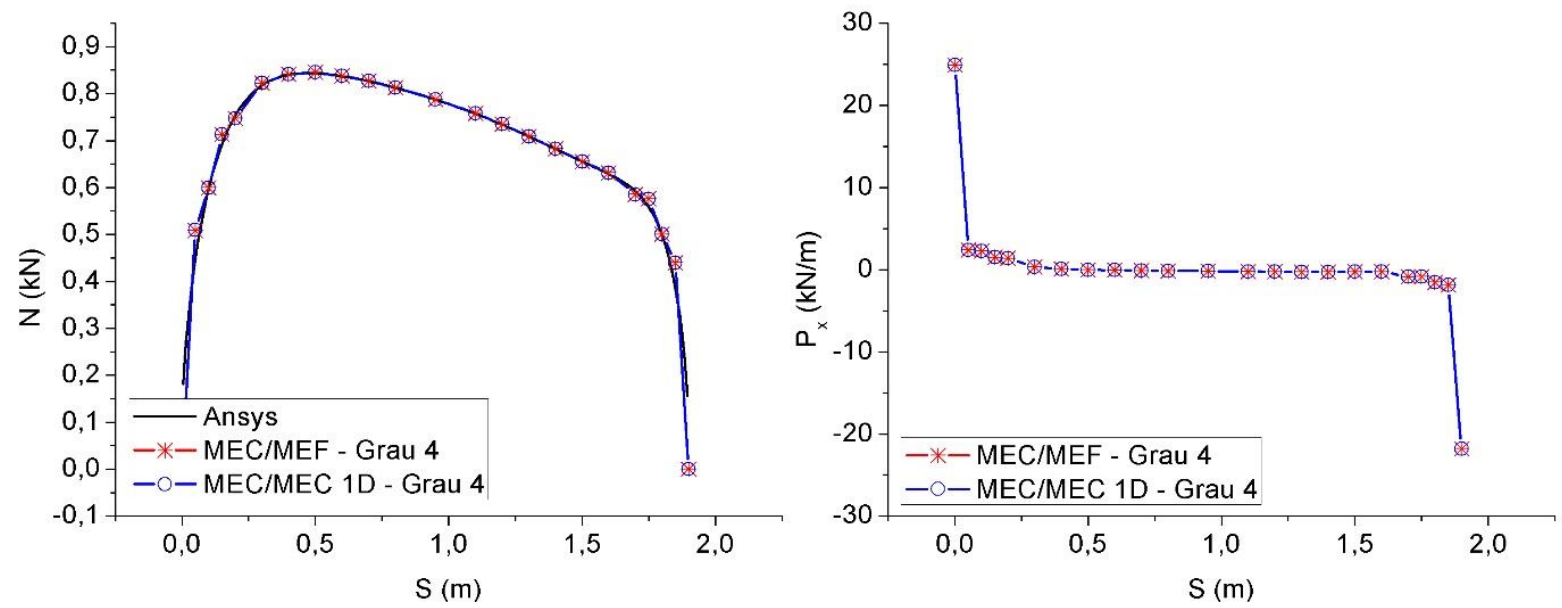

FONTE: O autor

\subsubsection{Fibra Superior}

Em relação à fibra superior, novamente houve maior divergência para o uso de aproximação quadrática 
Figura 72. Deslocamentos em x na fibra superior - Acoplamento Ex.2

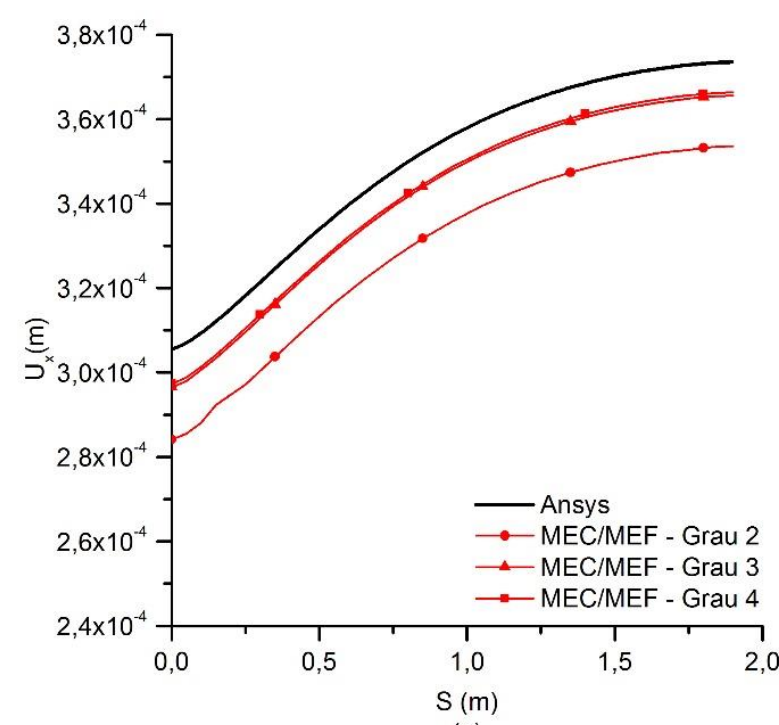

(a)

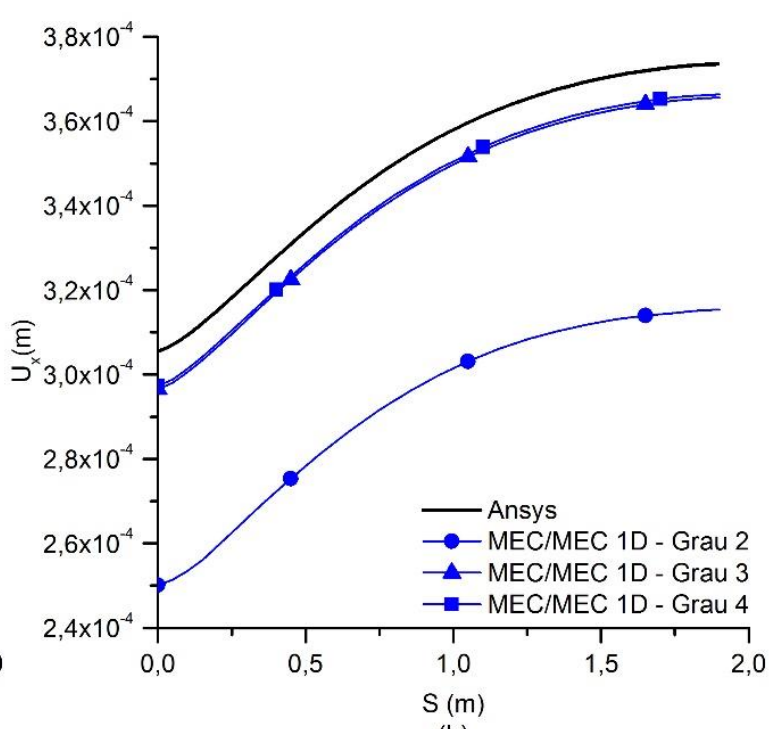

(b)

FONTE: O autor

Figura 73. Deslocamentos em y na fibra superior - Acoplamento Ex.2

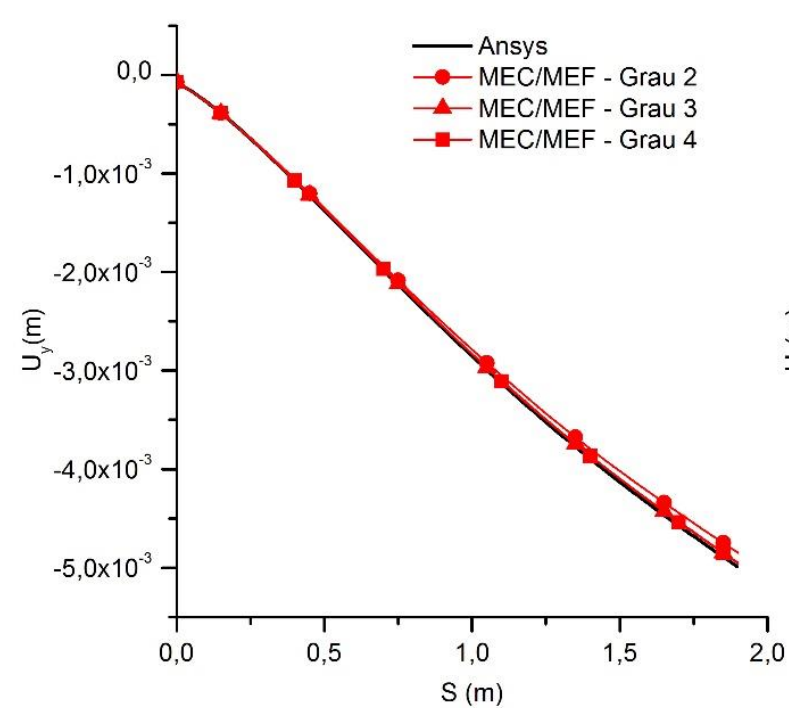

(a)

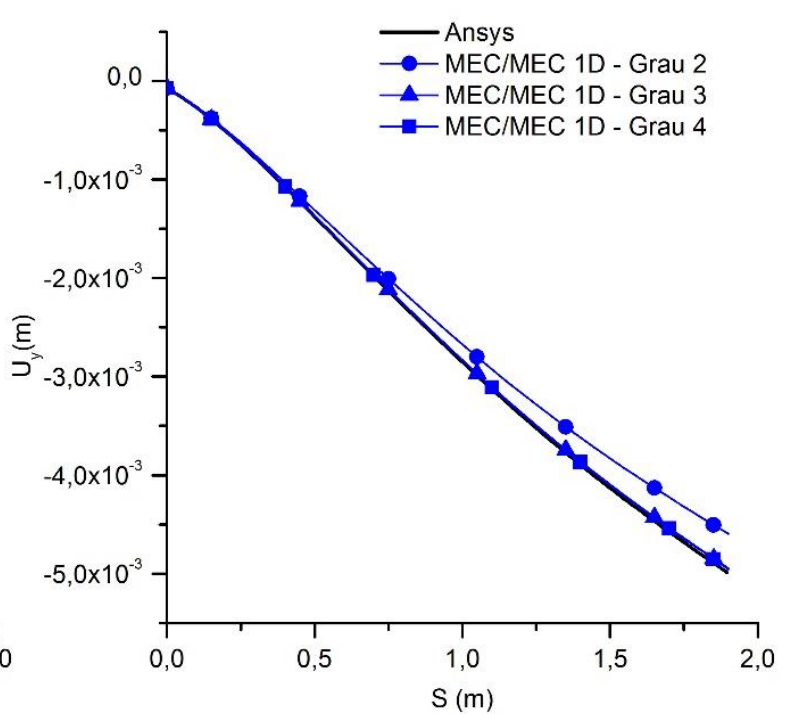

(b)

FONTE: O autor

Com aproximação quadrática o resultado do MEC/MEF foi ligeiramente superior ao MEC/MEC 1D: 
Figura 74. Forças normais na fibra superior - Grau 2 - Acoplamento Ex.2
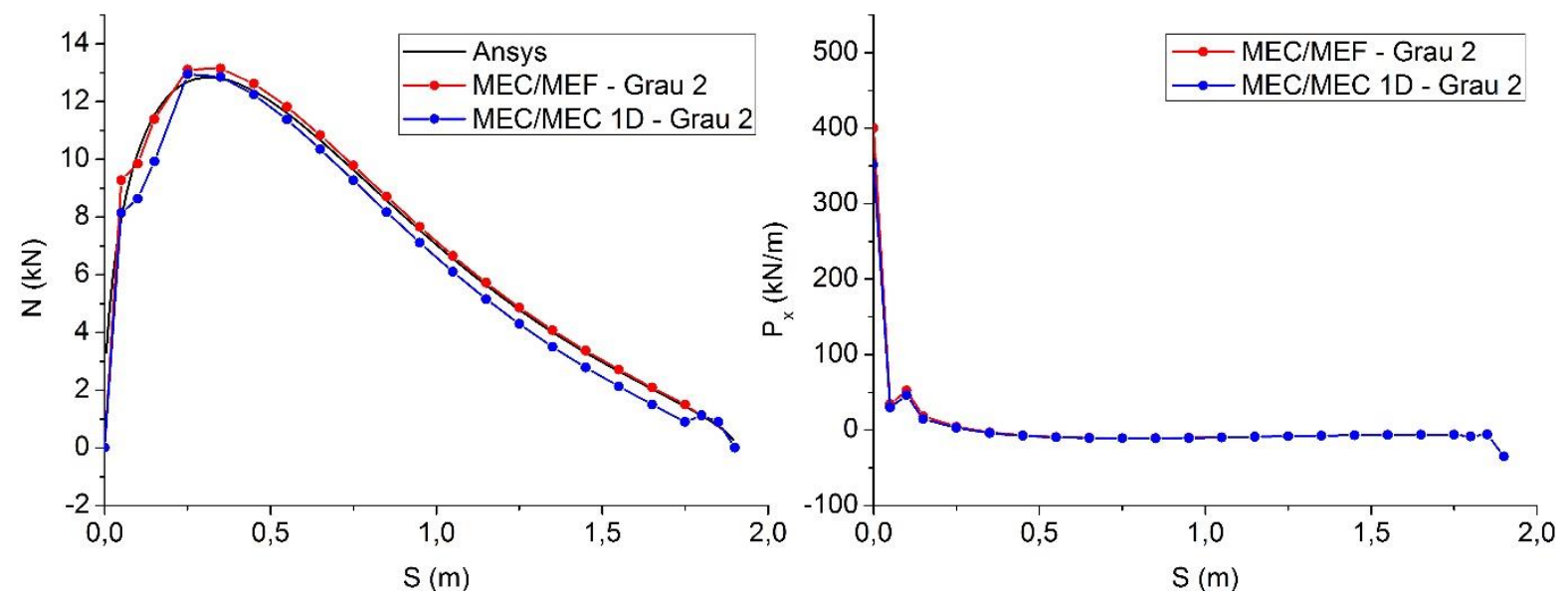

FONTE: O autor

O aumento do grau de aproximação possuiu efeito positivo, havendo convergência a partir de 51 nós:

Figura 75. Forças normais na fibra superior - Grau 3 - Acoplamento Ex.2
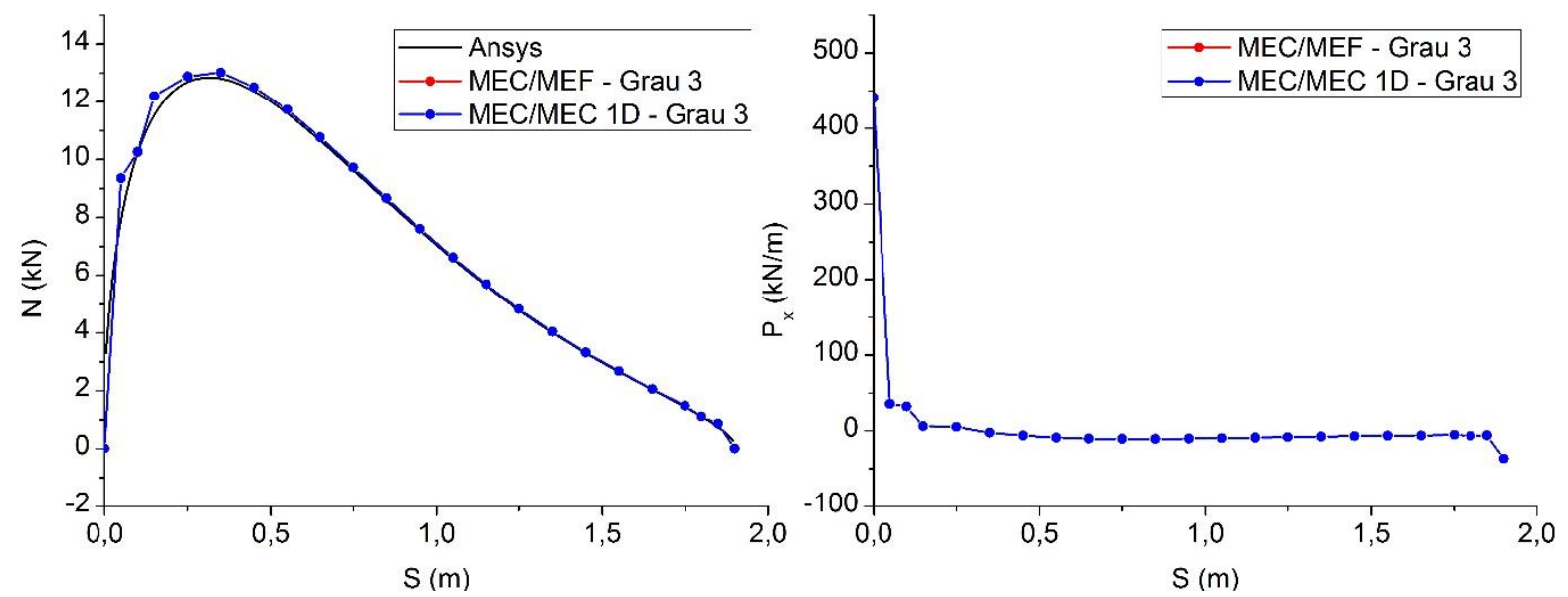

FONTE: O autor

Figura 76. Forças normais na fibra superior - Grau 4 - Acoplamento Ex.2
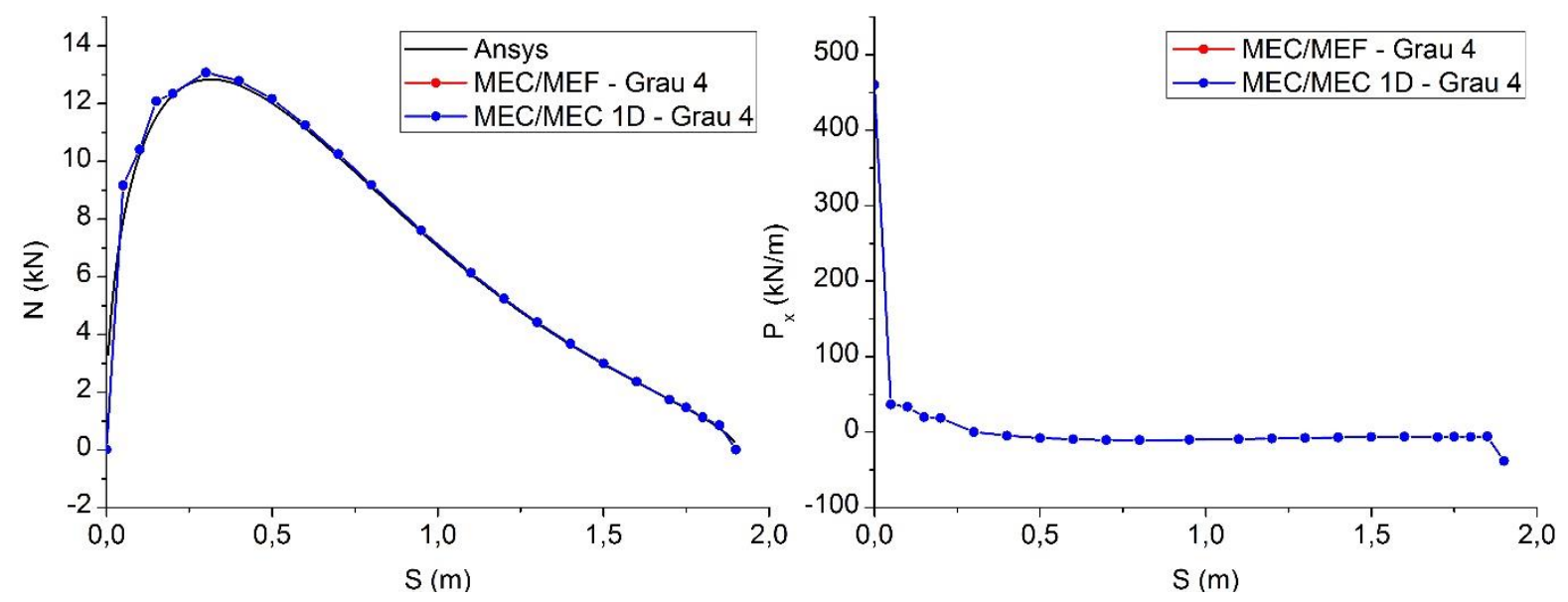

FONTE: O autor 


\subsubsection{Conclusões Parciais}

Diferentemente do Exemplo 1, neste caso a presença dos enrijecedores possui influência relevante no resultado. Pode-se notar nos gráficos de reações de apoio, Figura 60 e Figura 61, que as reações estão concentradas nas áreas mais próximas a eles. Ou seja, a modelagem dos enrijecedores influencia inclusive no resultado do contorno.

Como pode-se observar na Figura 58 e Figura 59, utilizando-se os enrijecedores com aproximação quadrática o resultado diverge em relação ao de outros graus de aproximação e ao ANSYS, além disso nessas condições o acoplamento MEC/MEF obteve respostas melhores do que o acoplamento MEC/MEC 1D. A mesma divergência se replica em certo grau nos resultados dos enrijecedores, principalmente no caso de deslocamentos na direção $\mathrm{x}$ e forças normais. Se observa que o resultado do MEC/MEF se mostrou inclusive mais estável em relação ao Exemplo 1.

No MEC o resultado para o contorno de um problema influencia diretamente no resultado do domínio. Desta forma, era esperado que no caso de erro no contorno este se replicasse. Supõe-se que nestas situações o motivo do resultado do MEC/MEF ter sido superior é o próprio fato de ser realizada aproximação adicional - uma vez havendo erro, este fica limitado pelas funções de aproximação, sendo de certa forma distribuído. Entretanto, com o aumento do grau de aproximação houve convergência dos resultados de ambos métodos.

Mesmo com o aumento do grau de aproximação ainda houve certa divergência de deslocamentos na direção $\mathrm{x}$ das fibras entre o uso do MEC e o ANSYS. Isto não indica necessariamente erro do MEC, pois, a princípio, não é possível afirmar qual representa melhor a realidade, ambos adotam aproximações. Entretanto, a divergência observada foi considerada aceitável, se esperando que reduzisse com o aumento da discretização.

\subsection{Acoplamento - Exemplo 3}

Foi simulada a existência de enrijecedor em um meio anisotrópico. Foi avaliada uma chapa com enrijecedor sofrendo esforços de tração, sendo o contorno esquerdo engastado: 
Figura 77. Modelo anis otrópico com enrijecedor (medidas em cm, carregamentos em kN/m) - Exemplo 3

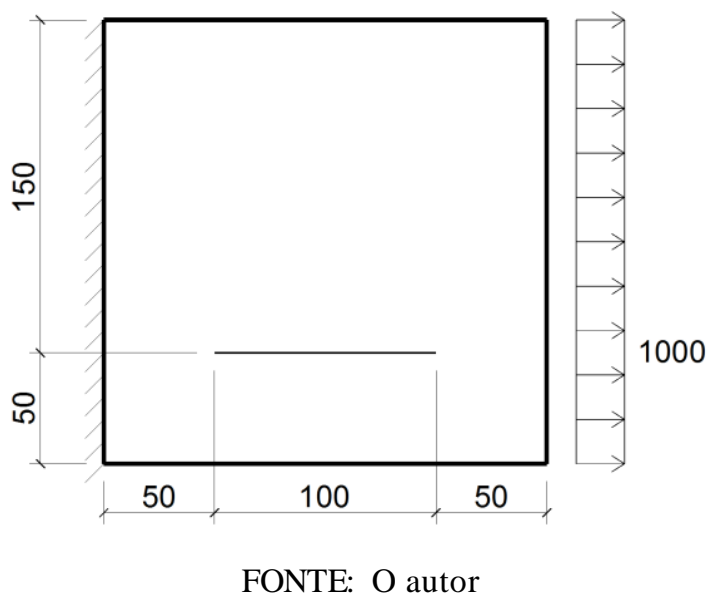

Por meio do ANSYS o meio foi modelado com uso de elementos de chapa quadrados de aproximação quadrática, do tipo "PLANE 182". Enrijecedores foram modelados por meio de elementos de treliça de aproximação linear, do tipo "LINK 1" O número de elementos foi definido com base em estudo prévio de convergência de malha, resultando em bom comportamento da resposta. Foram adotados 6400 elementos no meio e 40 elementos para o enrijecedor:

Figura 78. Modelo no ANSYS - Exemplo 3

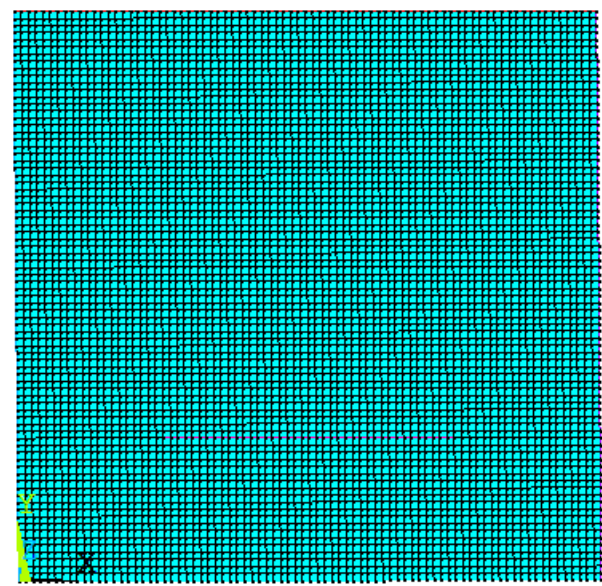

FONTE: O autor

Propriedades do enrijecedor:

$$
\begin{gathered}
E_{s}=210 \mathrm{GPa} \\
A_{s}=10 \mathrm{~cm}^{2}
\end{gathered}
$$

Propriedades do meio anisotrópico:

$$
E_{x}=20 \mathrm{GPa}
$$




$$
\begin{gathered}
E_{y}=10 \mathrm{GPa} \\
G_{x y}=6 \mathrm{GPa} \\
v_{C}=0,25 \\
\eta_{x y, x}=1,255 \\
\eta_{x y, y}=-0,031
\end{gathered}
$$

O meio foi modelado por meio do MEC com uso de 16 elementos de contorno de aproximação quadrática. Para análise de deslocamentos e reações de apoio o contorno foi linearizado em sentido anti-horário partindo-se do ponto inferior esquerdo.

Quanto ao enrijecedor, foi realizada análise comparativa utilizando-se enrijecedor com 21 e 41 nós, com aproximação de grau 2, 3 e 4 . No caso de 21 nós foram adotados:

- Grau 2: 10 elementos de grau 2;

- Grau 3: 6 elementos de grau 3, 1 elemento de grau 2;

- Grau 4: 5 elementos de grau 4.

No caso de enrijecedor com 41 nós foram adotados:

- Grau 2: 20 elementos de grau 2;

- Grau 3: 12 elementos de grau 3, 2 de grau 2;

- Grau 4: 10 elementos de grau 4.

\subsubsection{Resultados no contorno}

Quanto aos resultados do contorno, nas duas direções os deslocamentos foram de pequeno valor, garantindo desta forma a validade do regime de pequenos deslocamentos e deformações. Foram obtidos resultados muito próximos, principalmente para deslocamentos na direção $\mathrm{x}$ : 
Figura 79. Deslocamentos na direção x - Acoplamento Ex.3

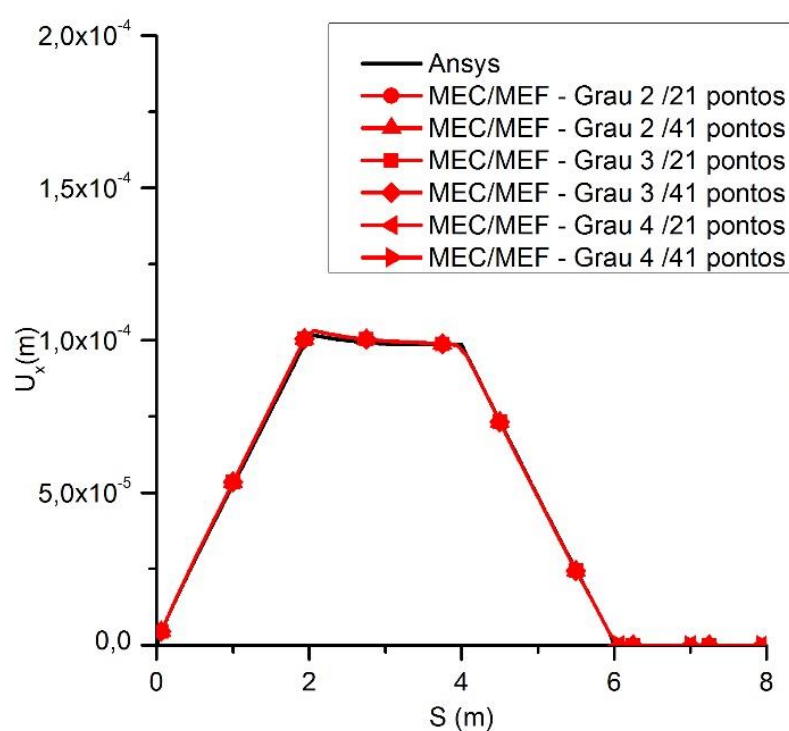

(a)

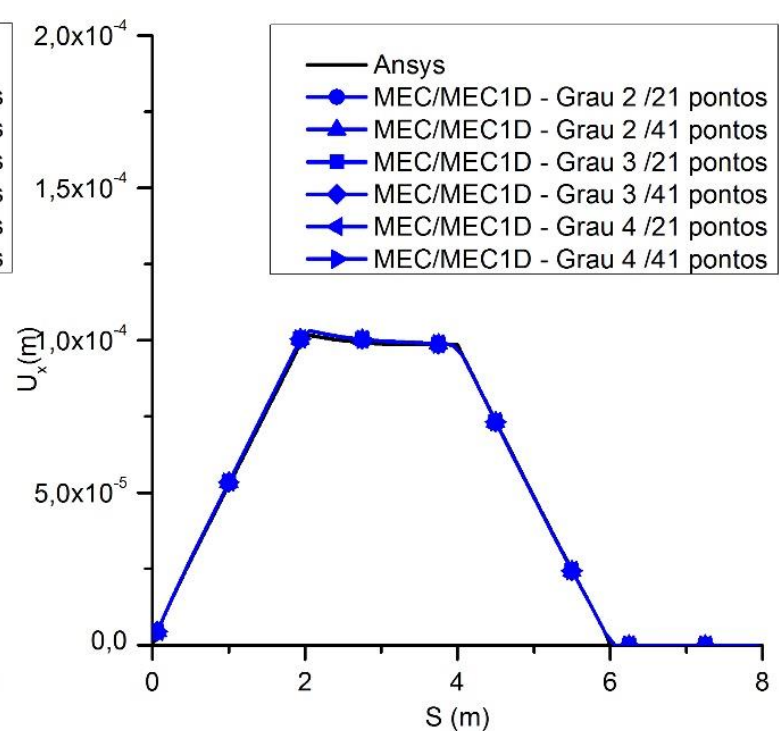

(b)

FONTE: O autor

Observa-se que os esforços de tração geram deslocamentos positivos e até mesmo superiores em valor na direção y, isto ocorre por se tratar de material anisotrópico, neste caso tensão normal gera distorção:

Figura 80. Deslocamentos na direção y - Acoplamento Ex.3

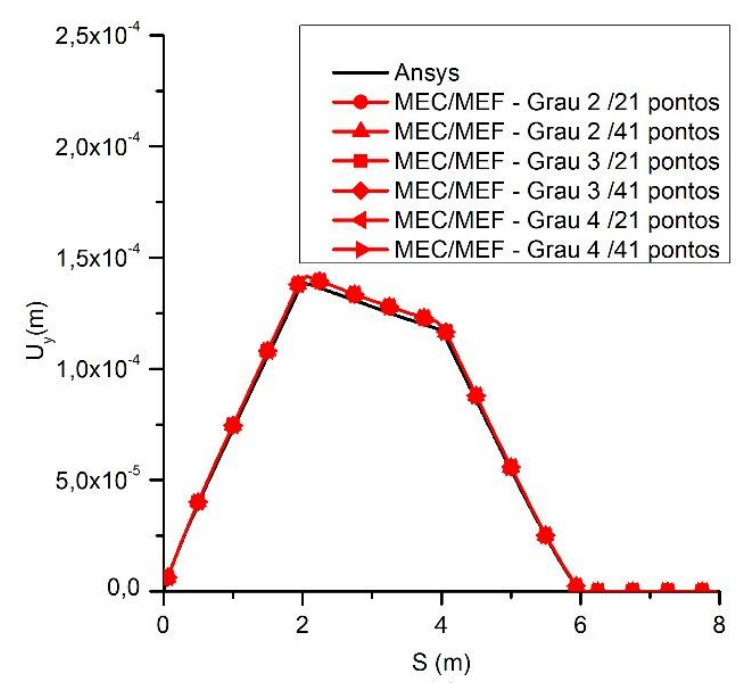

(a)

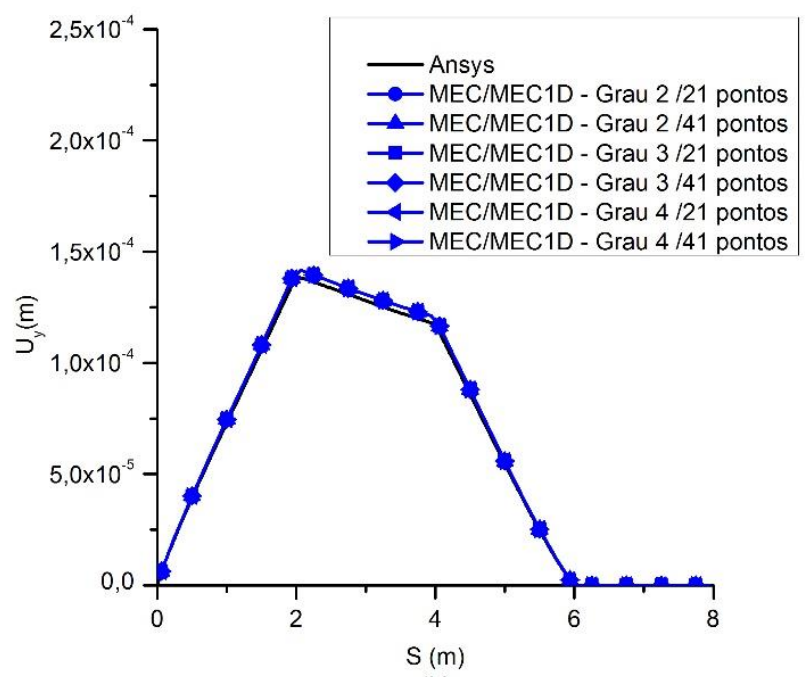

(b)

FONTE: O autor

Da mesma forma que no Exemplo 1, as reações de apoio se concentraram nas extremidades, indicando que o enrijecedor não possui grande influência na resposta do contorno: 
Figura 81. Reações de apoio na direção $\mathrm{x}$ - Acoplamento Ex.3

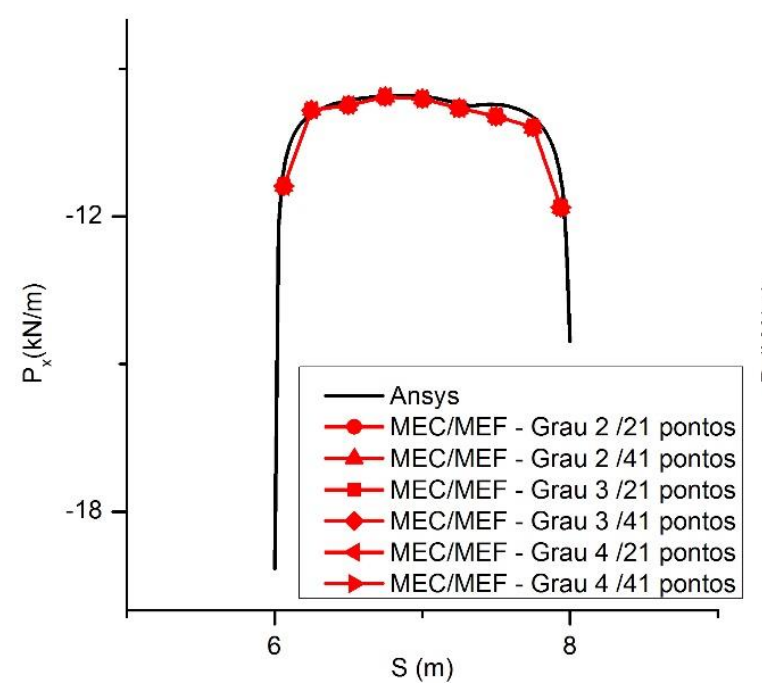

(a)

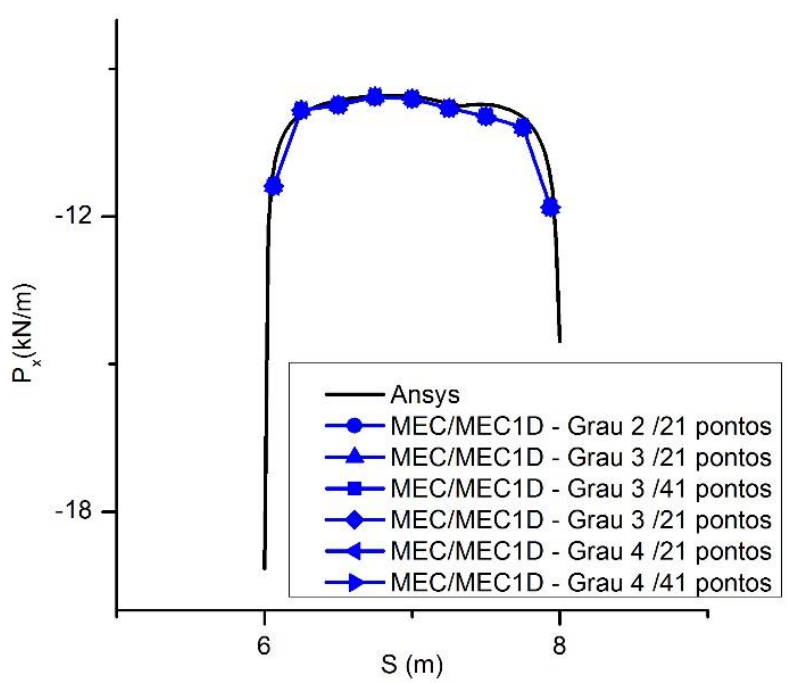

(b)

FONTE: O autor

$\mathrm{Na}$ direção y surgem reações em sentido contrário, devido à natureza do material. Uma vez que está sendo aplicado somente carregamento de tração, a reação resultante deve ser nula:

Figura 82. Reações de apoio na direção y - Acoplamento Ex.3

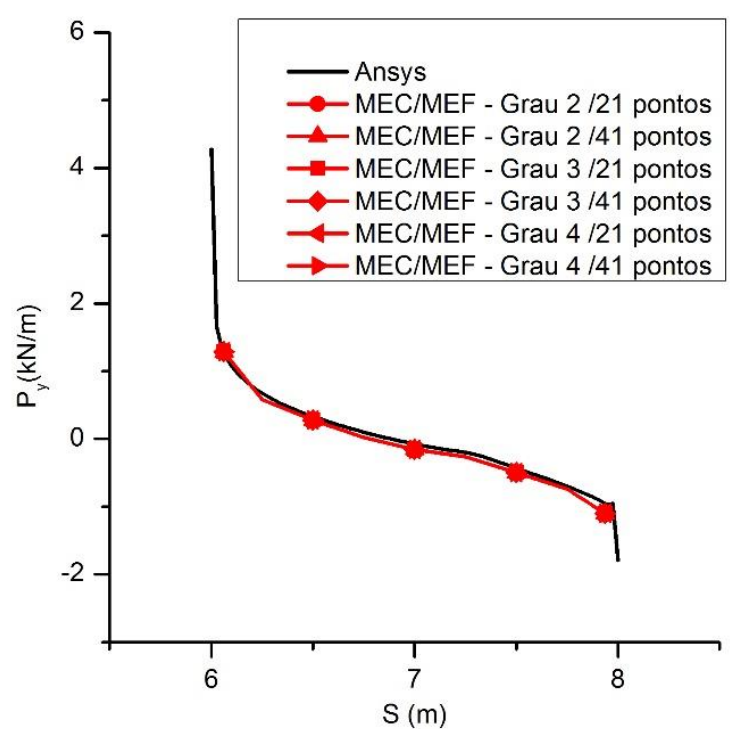

(a)

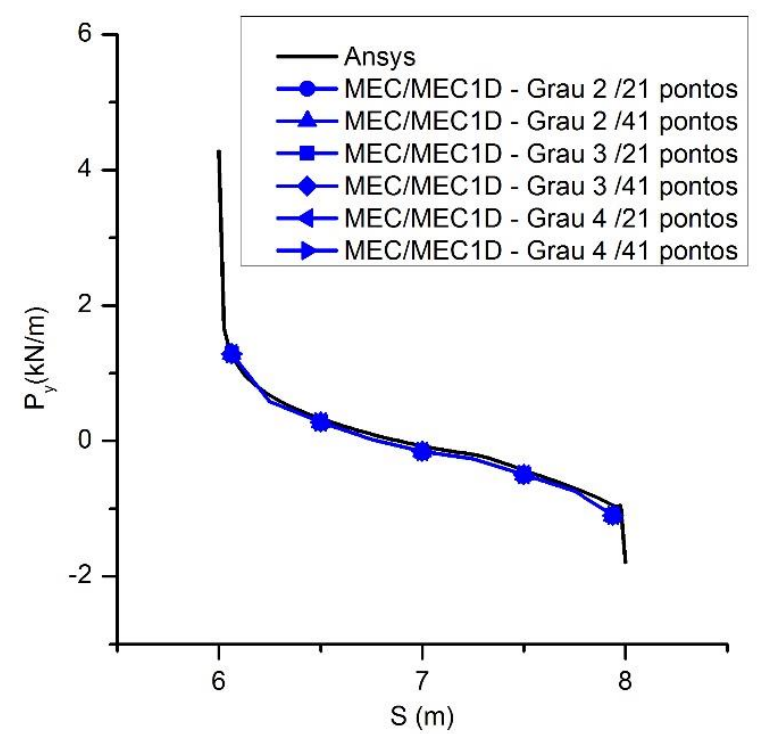

(b)

FONTE: O autor

\subsubsection{Fibra}

Também foram obtidos resultados muito próximos para deslocamentos da fibra, não sendo verificada influência da mudança de grau de discretização e grau de aproximação. Deslocamentos na direção x e y são positivos, similarmente à resposta do contorno: 
Figura 83. Deslocamentos em x na fibra - Acoplamento Ex.3

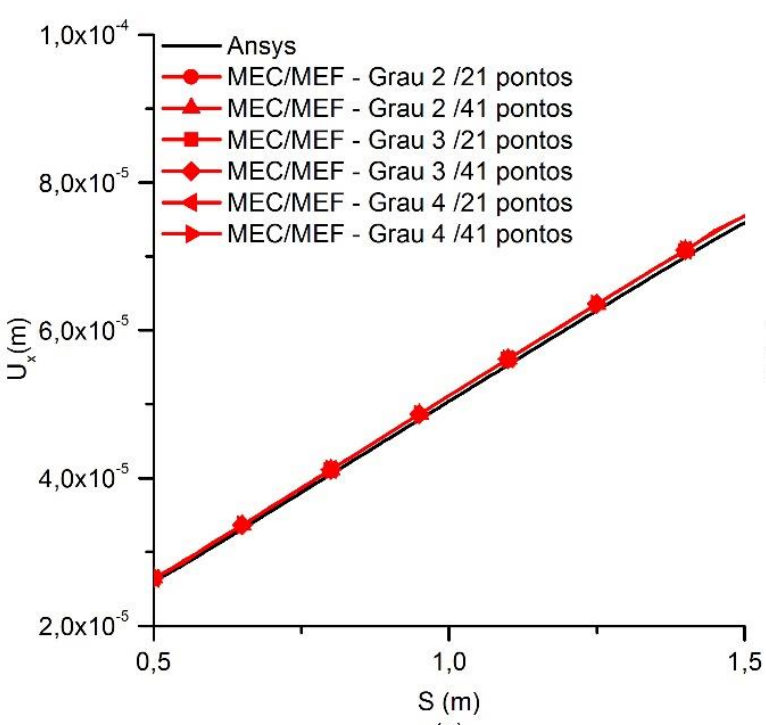

(a)

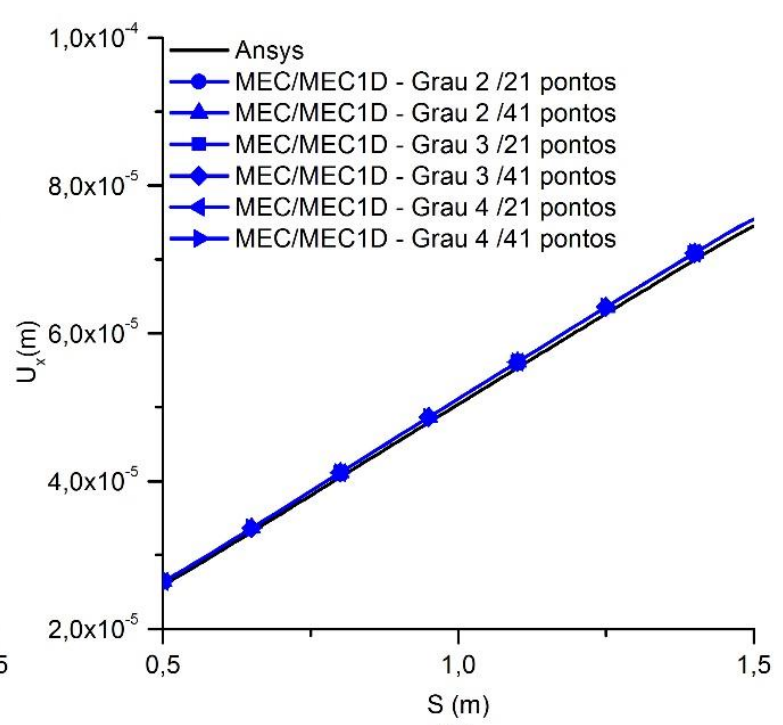

(b)

FONTE: O autor

Figura 84. Deslocamentos em y na fibra - Acoplamento Ex.3

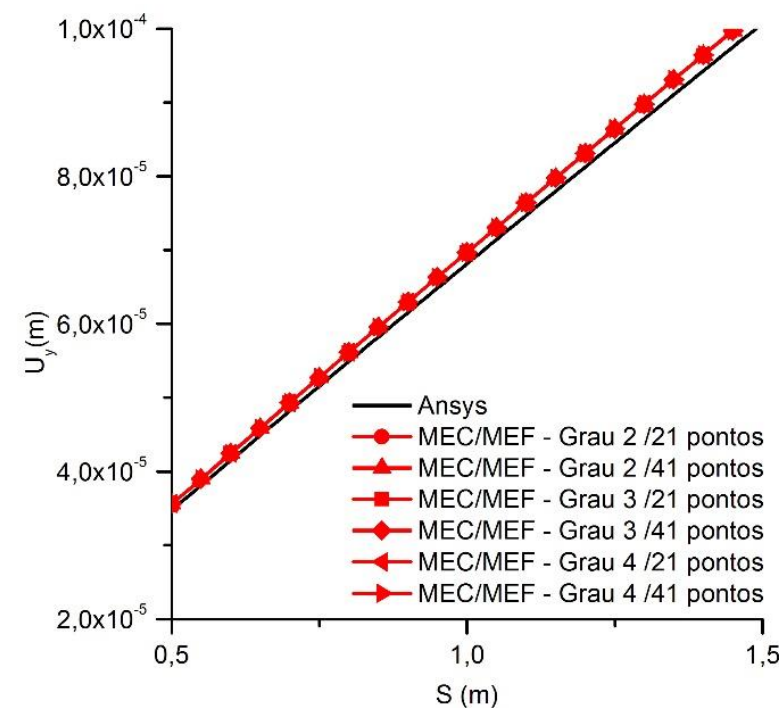

(a)

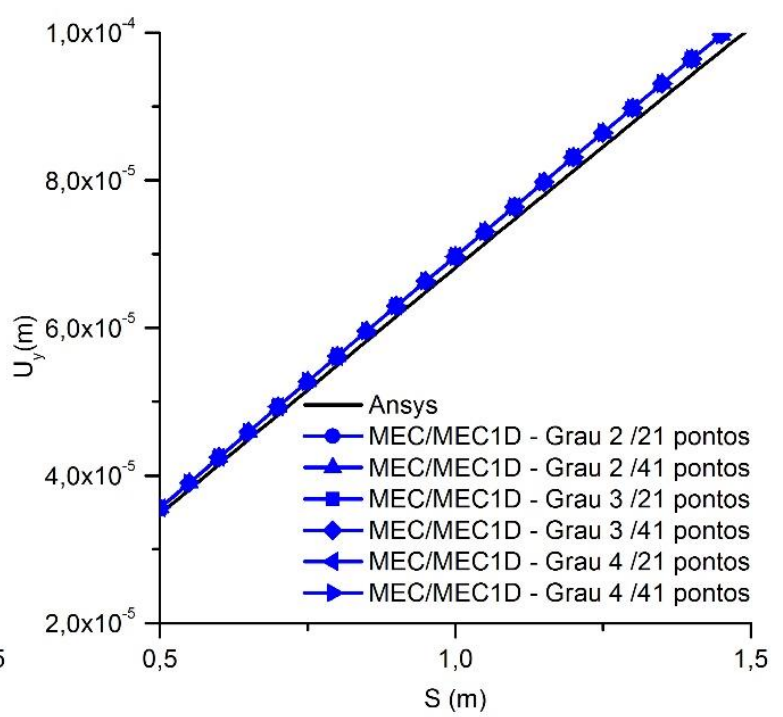

(b)

FONTE: O autor

O resultado de força de aderência apresenta concentração de tensões nas pontas e, da mesma forma que no Exemplo 1, observou-se maior perturbação do acoplamento MEC/MEF, resultando em perturbação do resultado de forças normais. Destaca-se que no ANSYS, por terem sido adotados elementos de aproximação linear, a resposta em força normal é constante dentro destes elementos: 
Figura 85. Forças normais na fibra - 21 nós / Grau 2 - Acoplamento Ex.3
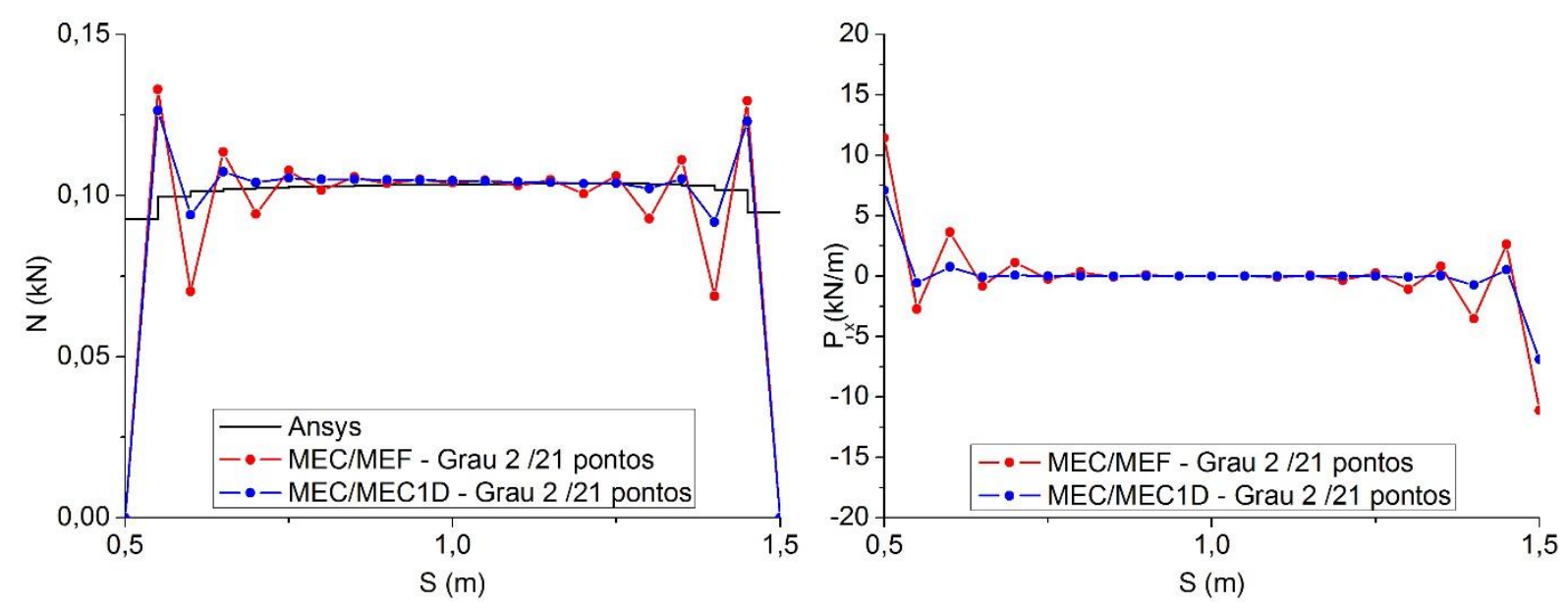

FONTE: O autor

Avaliou-se o efeito do aumento do grau de aproximação. No caso de aproximação cúbica ele não foi relevante:

Figura 86. Forças normais na fibra - 21 nós / Grau 3 - Acoplamento Ex.3
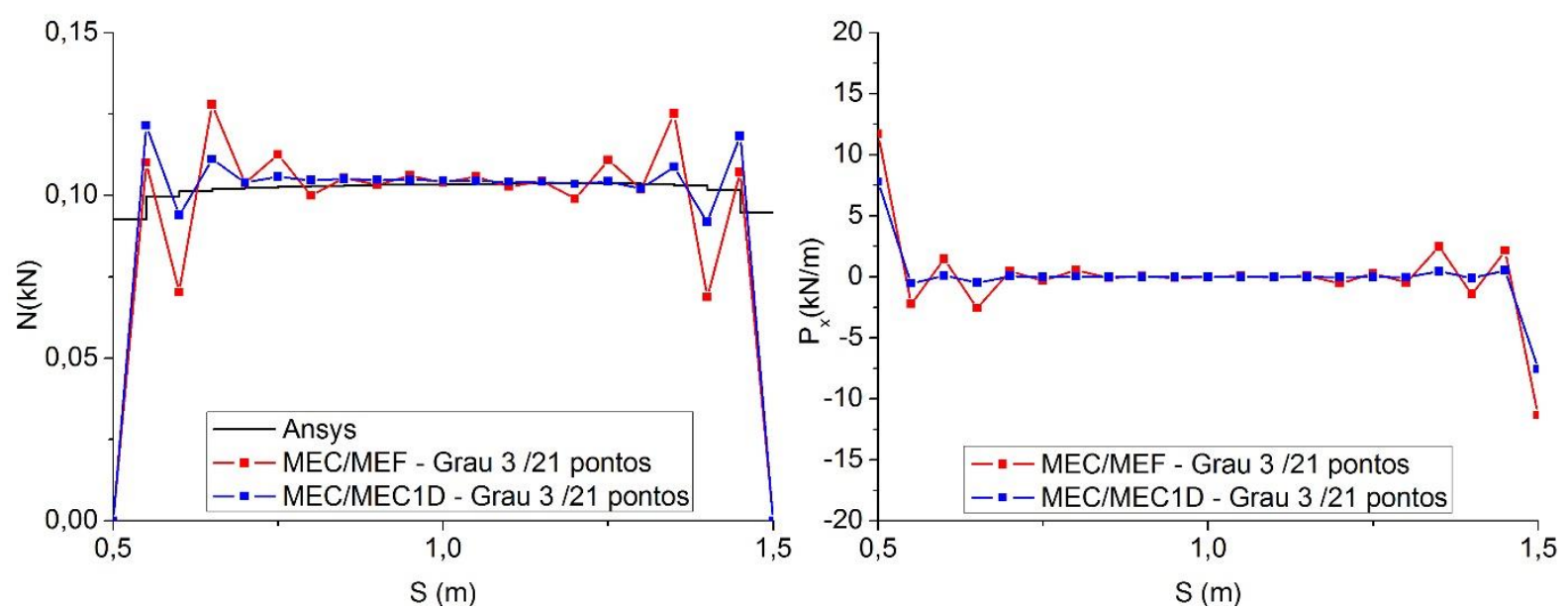

FONTE: O autor

Com o uso de aproximação do quarto grau, da mesma forma que nos exemplos anteriores, se observa convergência de resultados: 
Figura 87. Forças normais na fibra - 21 nós / Grau 4 - Acoplamento Ex.3
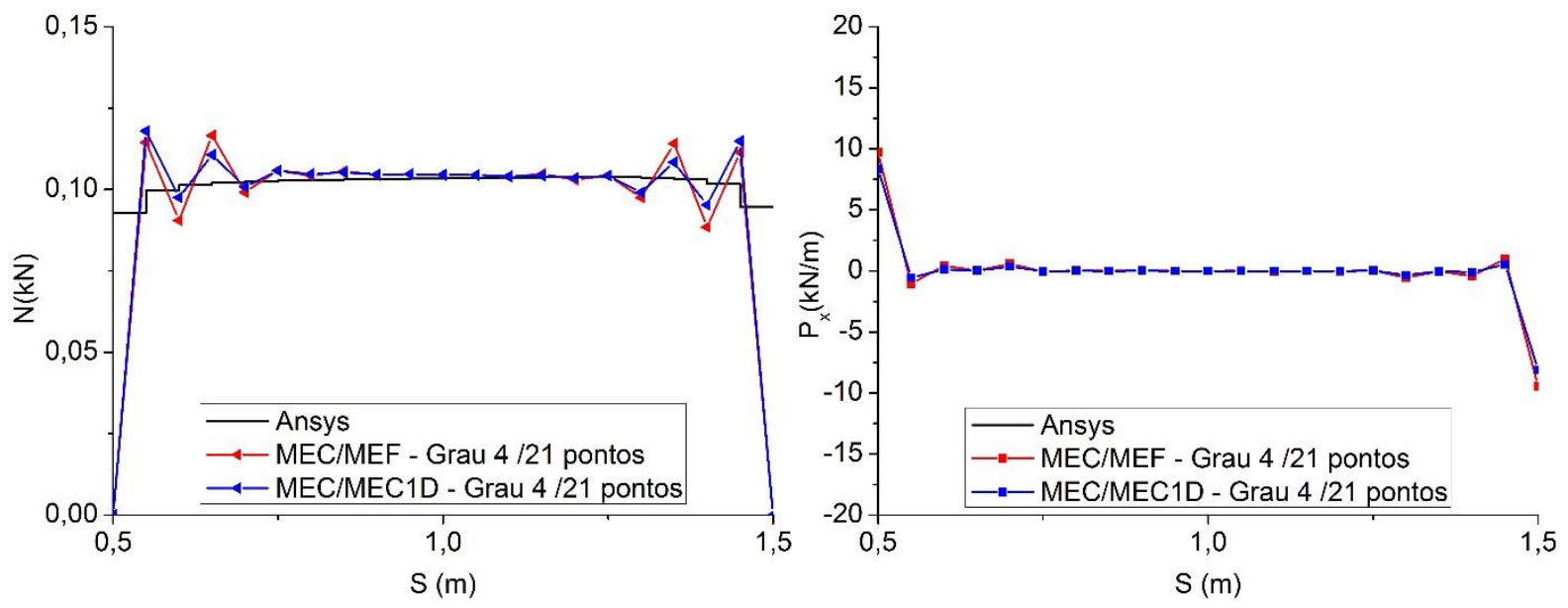

FONTE: O autor

Como é usual, verifica-se que o aumento da discretização também possui efeito positivo para ambos métodos de acoplamento. Uma vez que próximo às pontas do enrijecedor há concentração de tensão, a melhor discretização se mostrou mais capaz de captar esse efeito. Com isso a perturbação, mesmo com o uso de aproximação quadrática e cúbica, se concentra próximo às pontas, tanto em força normal quanto na força de aderência:

Figura 88. Forças normais na fibra - 41 nós / Grau 2 - Acoplamento Ex.3
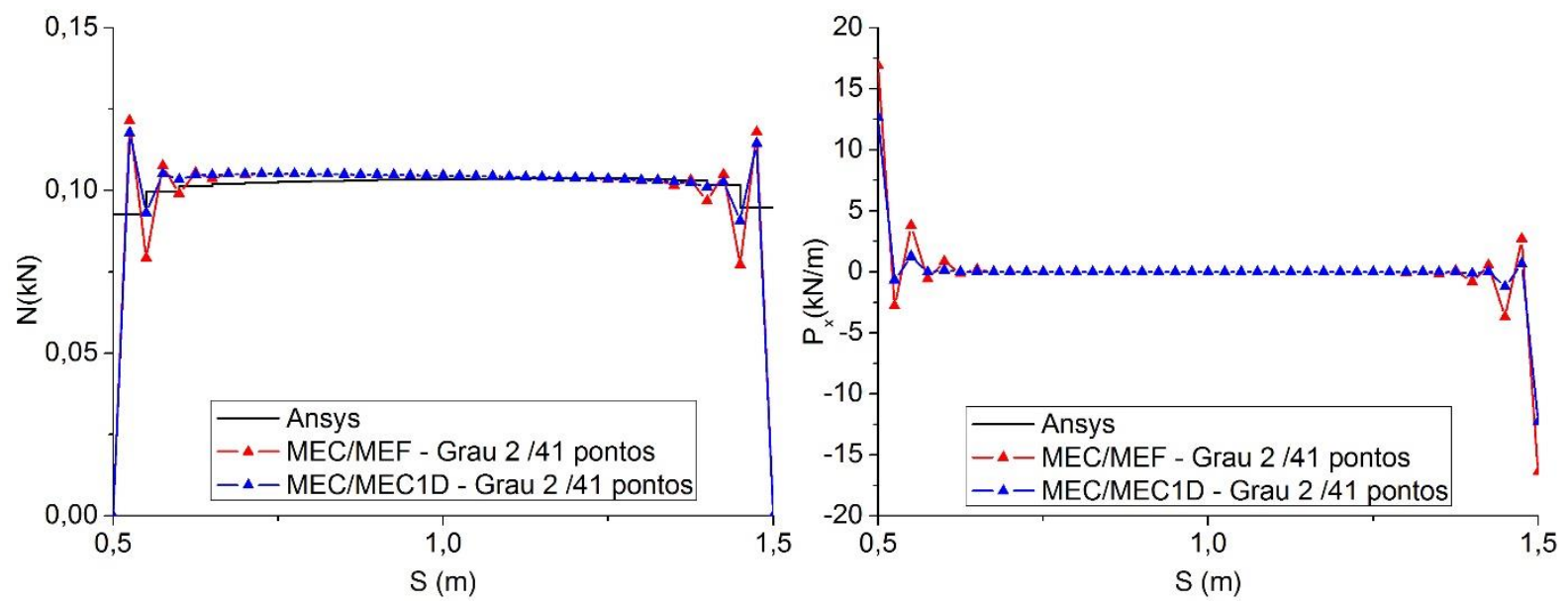

FONTE: O autor 
Figura 89. Forças normais na fibra - 41 nós / Grau 3 - Acoplamento Ex.3
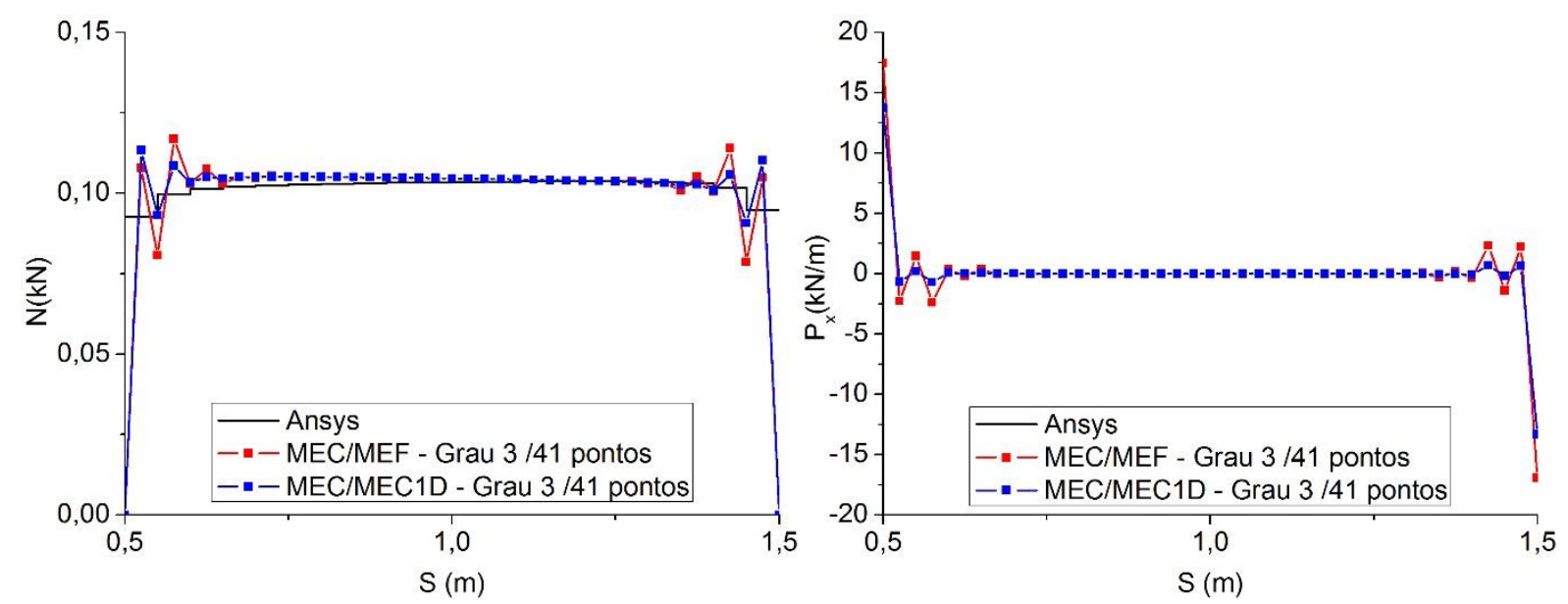

FONTE: O autor

Figura 90. Forças normais na fibra - 41 nós / Grau 4 - Acoplamento Ex.3
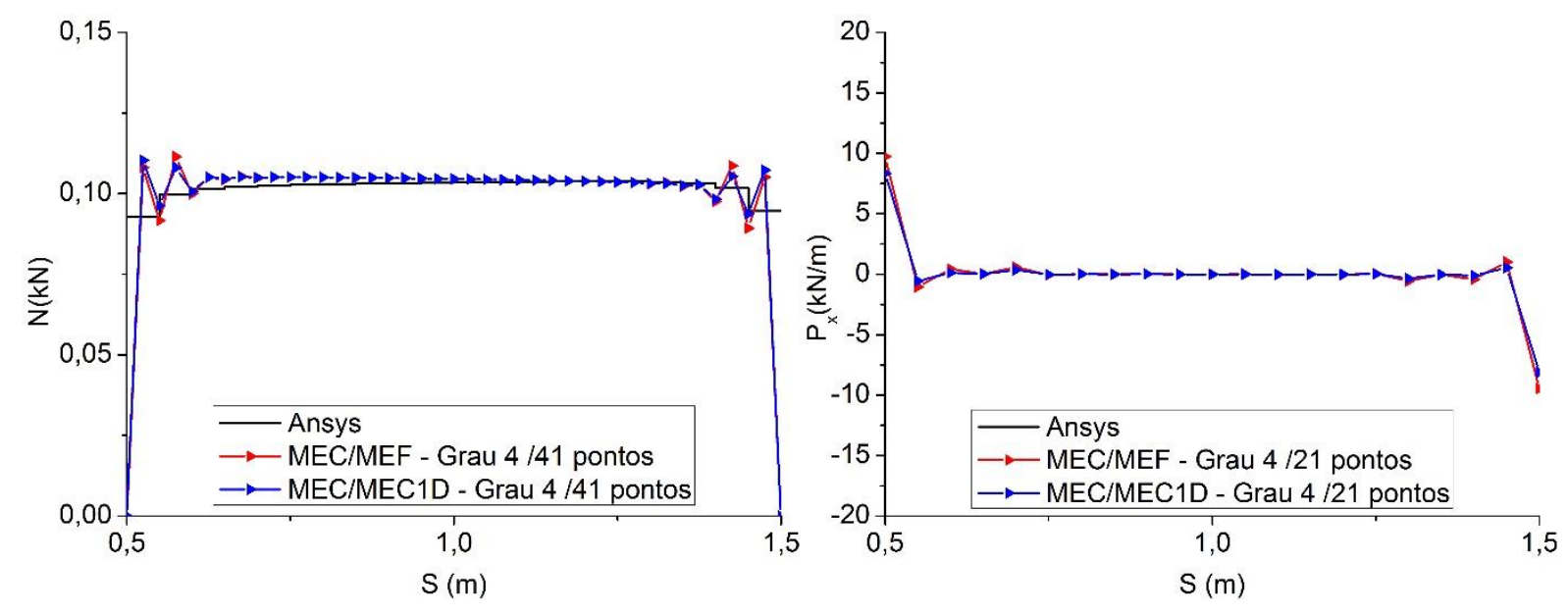

FONTE: O autor

\subsubsection{Conclusões Parciais}

Foram obtidos resultados similares ao Exemplo 1, isso se justifica por terem sido adotadas propriedades de mesma ordem de grandeza, tanto geometria quanto materiais. $\mathrm{O}$ resultado do contorno indicou pouca influência da fibra, sendo obtidos resultados muito próximos para o contorno e para deslocamentos da fibra.

Para forças normais, da mesma forma que no Exemplo 1, observou-se maior perturbação do acoplamento MEC/MEF, sendo minimizada com o uso de aproximação do quarto grau. Verifica-se que o aumento do grau de aproximação também possui efeito positivo para ambos métodos de acoplamento, sendo a concentração de tensão melhor captada. Com isso a perturbação se concentra próximo às pontas da fibra. 


\subsection{Acoplamento - Exemplo 4}

Com o objetivo de validar o acoplamento do MEC com enrijecedor para o caso anisotrópico, foi proposto modelo com o mesmo material anisotrópico do exemplo anterior, mas com inclusões de material isotrópico e condições mais adversas de carregamentos e vinculação:

Figura 91. Modelo anis otrópico com inclusões (hachuradas) e condições adversas (medidas em cm, carregamentos em $\mathrm{kN} / \mathrm{m}$ ) - Exemplo 4

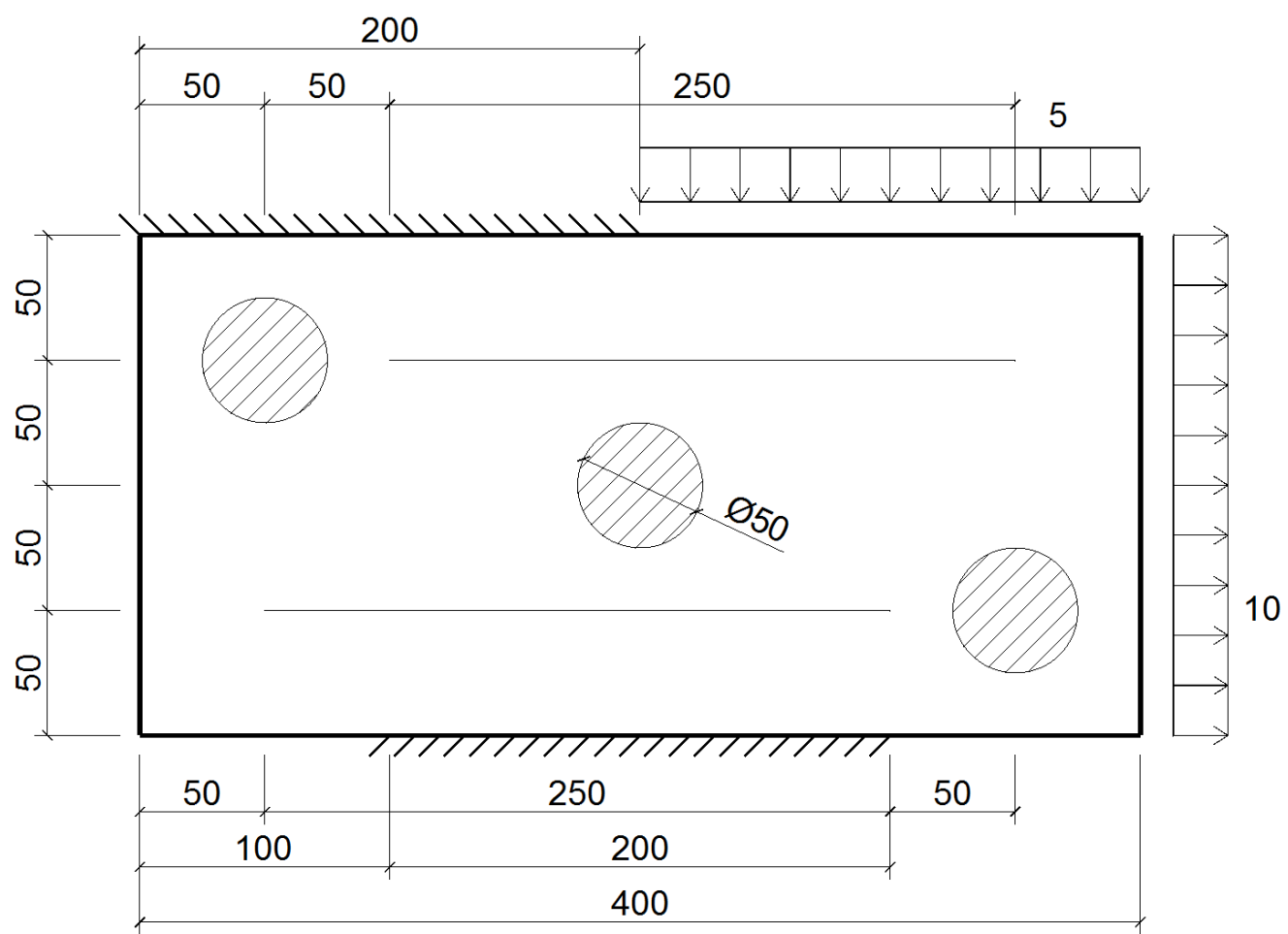

FONTE: O autor

Propriedades dos enrijecedores:

$$
\begin{gathered}
E_{S}=210 \mathrm{GPa} \\
A_{s}=10 \mathrm{~cm}^{2} \text { (por enrijecedor) }
\end{gathered}
$$

Propriedades das inclusões:

$$
\begin{gathered}
E_{c}=25 G P a \\
v_{C}=0,25
\end{gathered}
$$


O meio foi modelado por meio do MEC com uso de 24 elementos de contorno quadráticos. Para análise de deslocamentos e reações de apoio o contorno foi linearizado em sentido anti-horário partindo-se do ponto inferior esquerdo.

As inclusões foram modeladas com o uso de 12 elementos de contorno quadráticos cada, totalizando 36 elementos de contorno. Enrijecedores foram modelados com 51 nós, com elementos quadráticos e do quarto grau, da seguinte forma:

- Grau 2: 25 elementos de grau 2

- Grau 4: 12 elementos de grau 4, 1 elemento de grau 2

Quanto ao modelo no ANSYS, foi realizado estudo prévio de convergência da malha, o qual não foi mostrado aqui por simplicidade, chegando-se à seguinte configuração:

- 100 elementos nos enrijecedores - elementos de treliça (“Link1”)

- 2225 elementos nas inclusões isotrópicas - elementos de chapa quadráticos ("Plane183")

- 4316 elementos no meio anisotrópico - elementos de chapa lineares ("Plane182")

Figura 92. Modelo no ANSYS - Exemplo 4

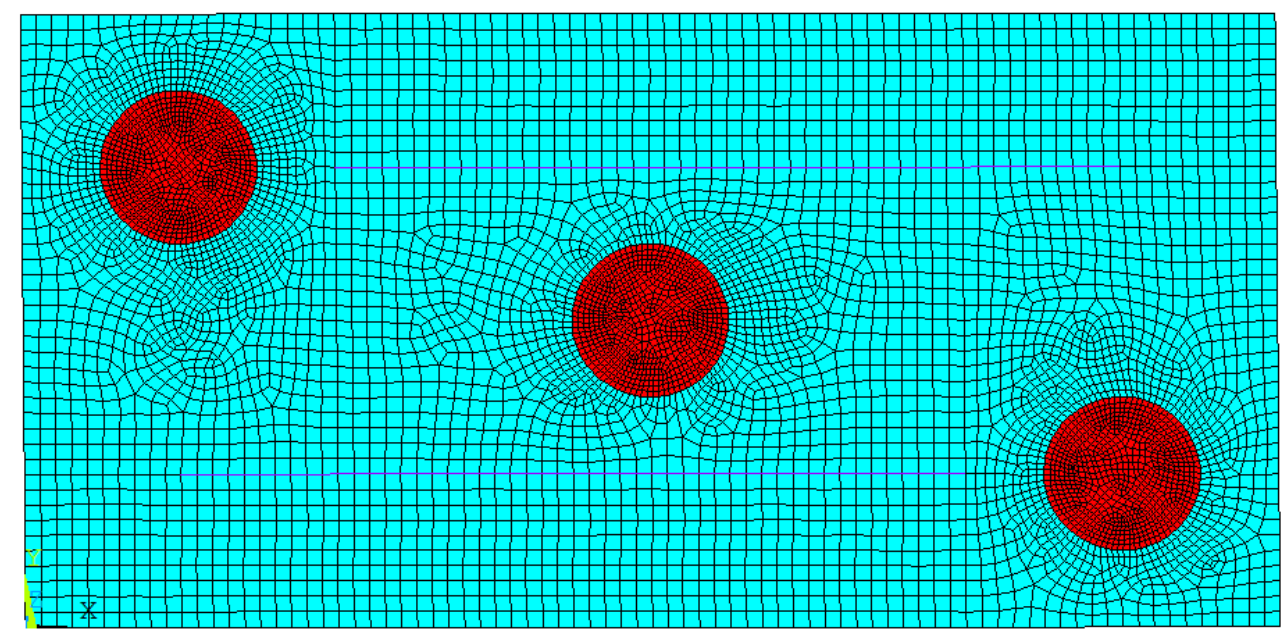

FONTE: O autor 
Detalhe da inclusão isotrópica:

Figura 93. Detalhe da inclusão isotrópica no ANSYS - Exemplo 4

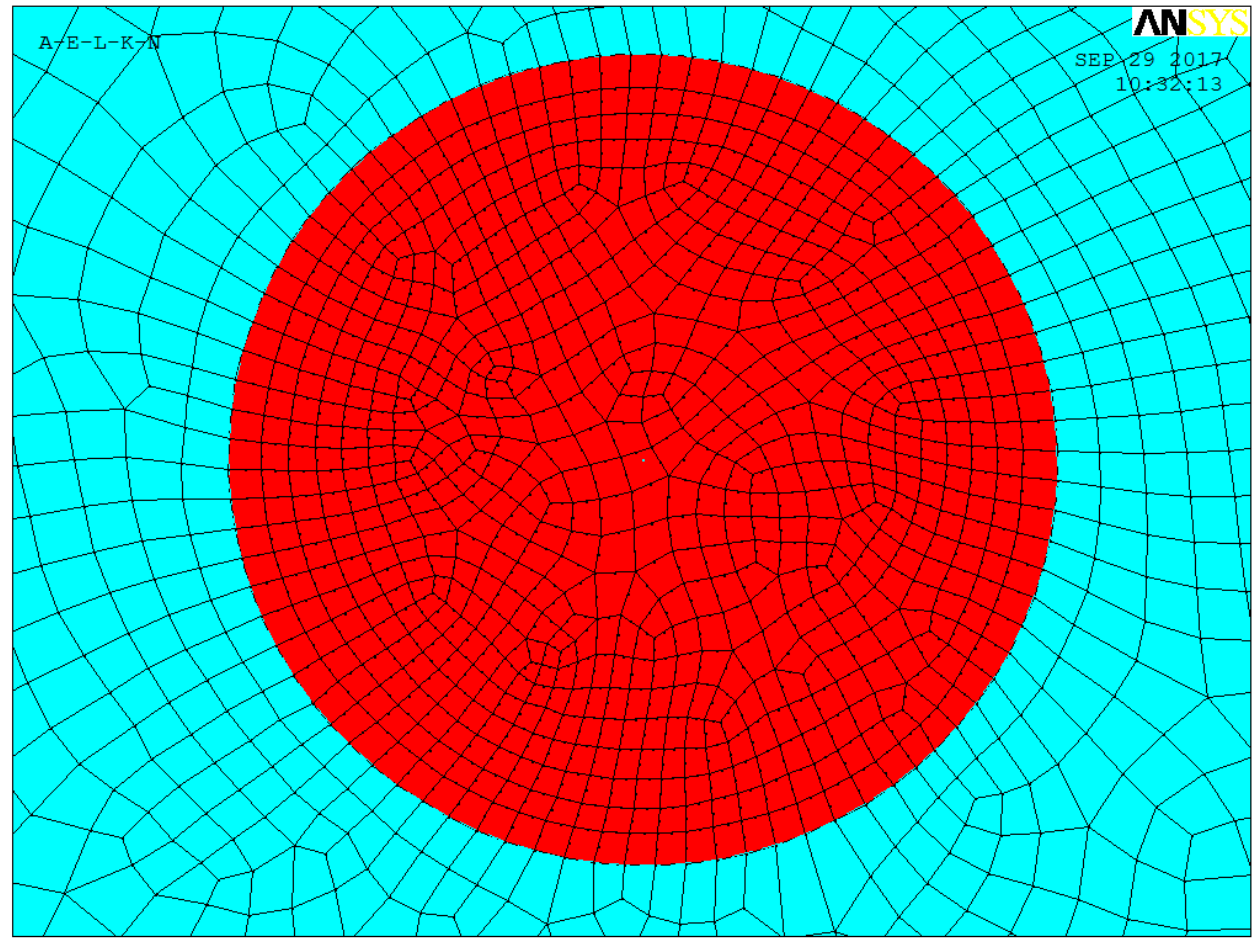

FONTE: O autor

\subsubsection{Resultados no contorno}

Novamente foram obtidos resultados próximos para deslocamentos no contorno, sendo indiferente o método utilizado para discretizá- lo:

Figura 94. Deslocamentos na direção x - Acoplamento Ex.4

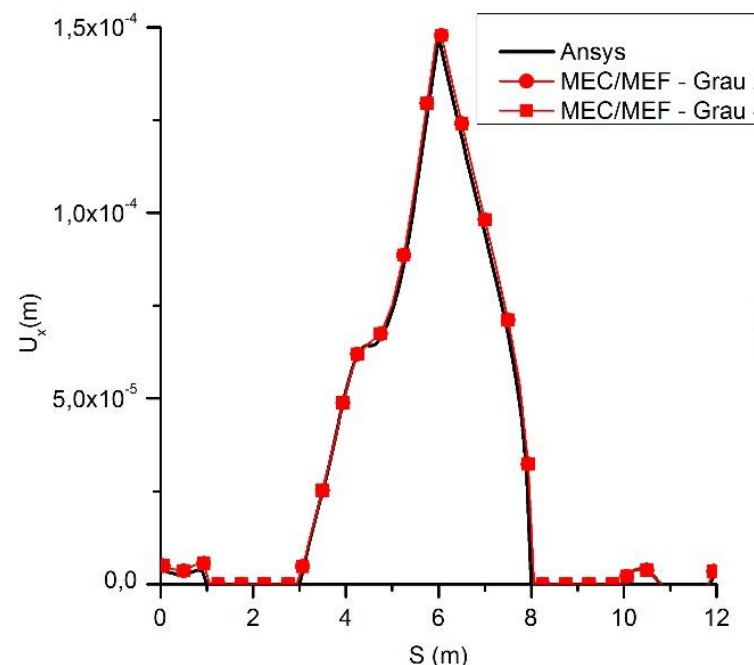

(a)

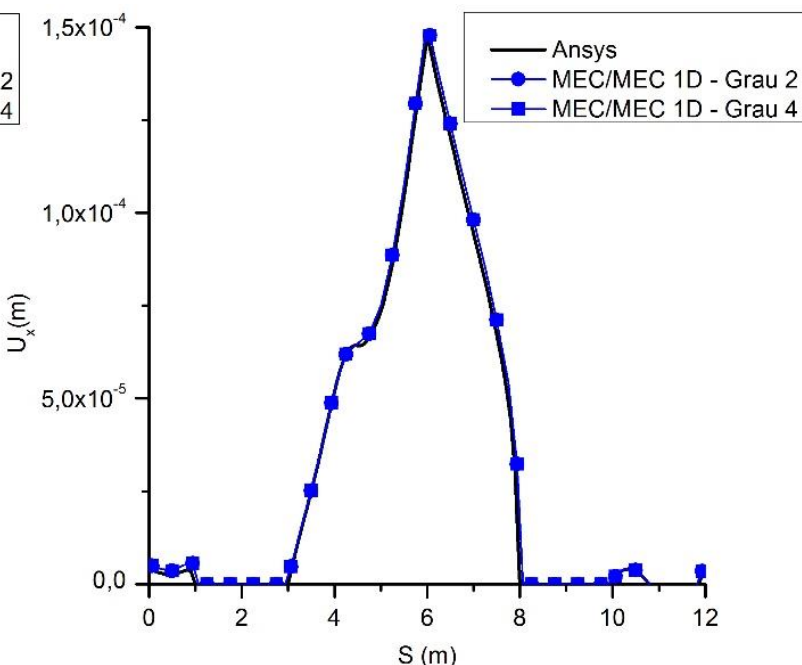

(b)

FONTE: O autor 
Figura 95. Deslocamentos na direção y - Acoplamento Ex.4

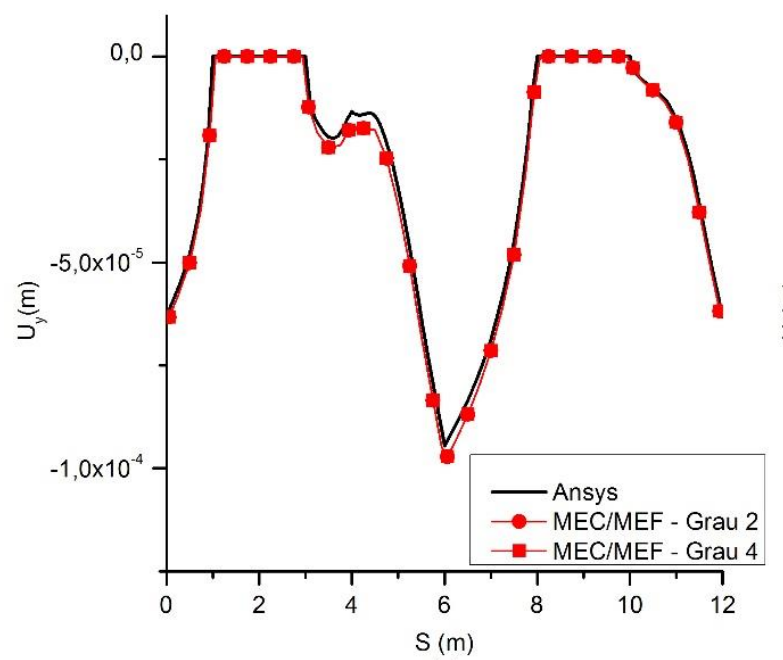

(a)

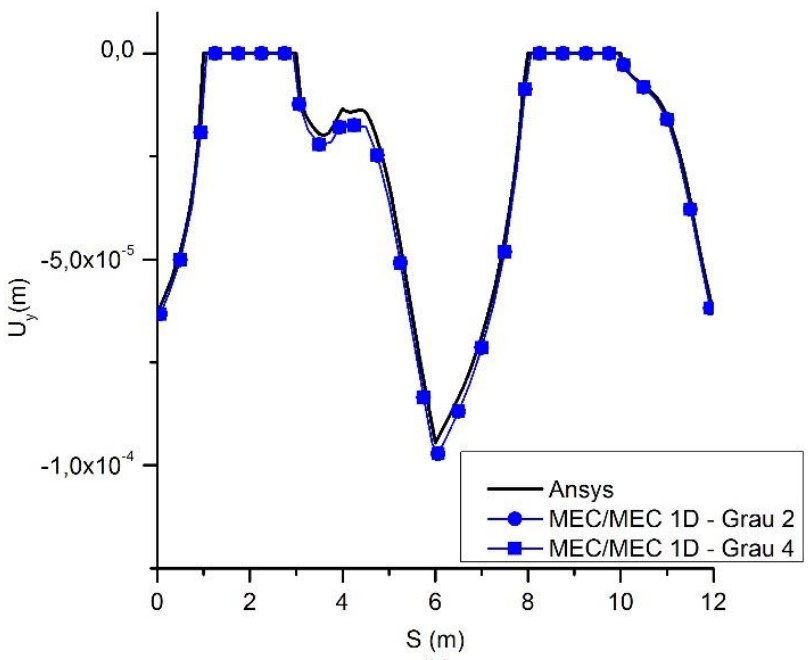

(b)

FONTE: O autor

Quanto a reações de apoio, há 2 trechos em que o modelo está engastado, apresentando concentração de tensão próximo às extremidades:

Figura 96. Reações de apoio na direção x - Acoplamento Ex.4

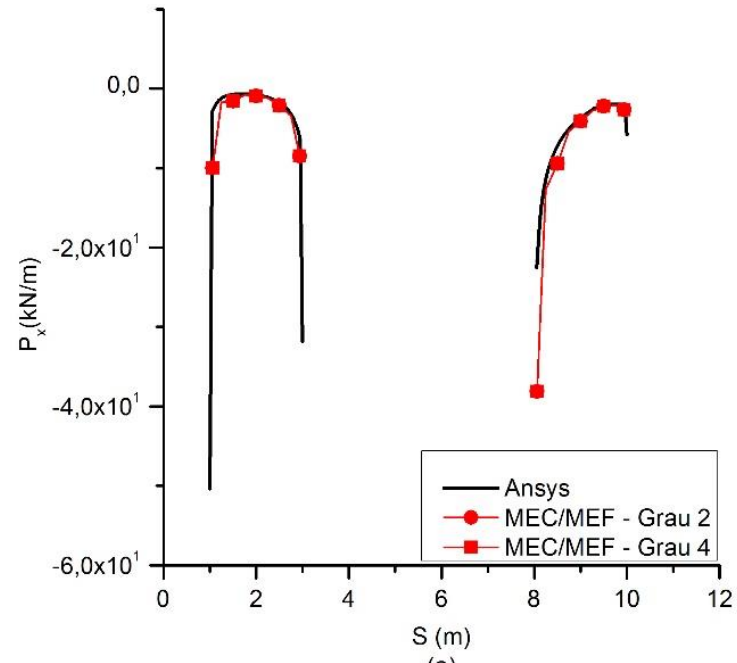

(a)

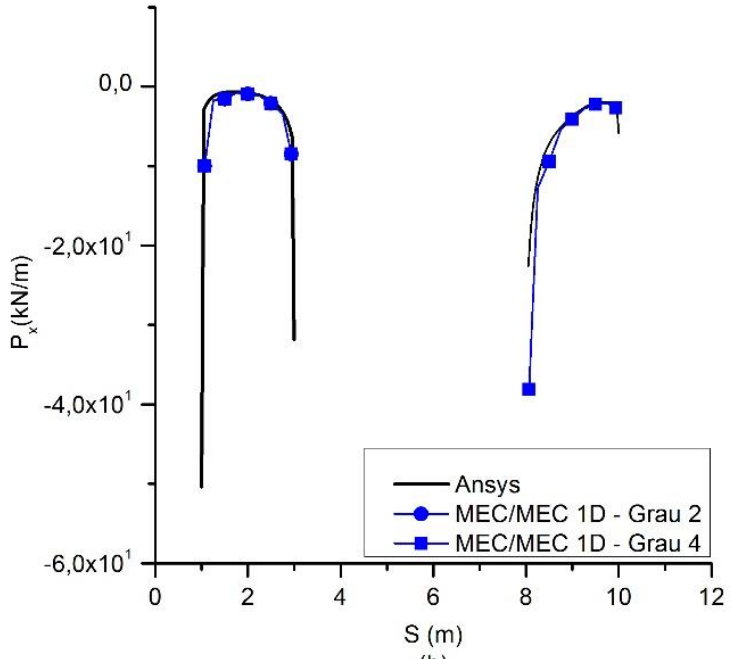

(b)

FONTE: O autor 
Figura 97. Reações de apoio na direção y - Acoplamento Ex.4

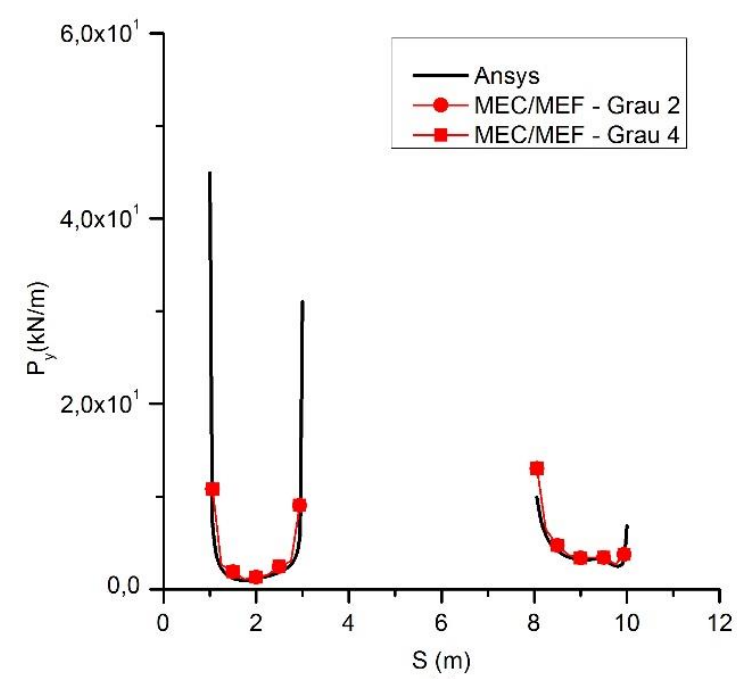

(a)

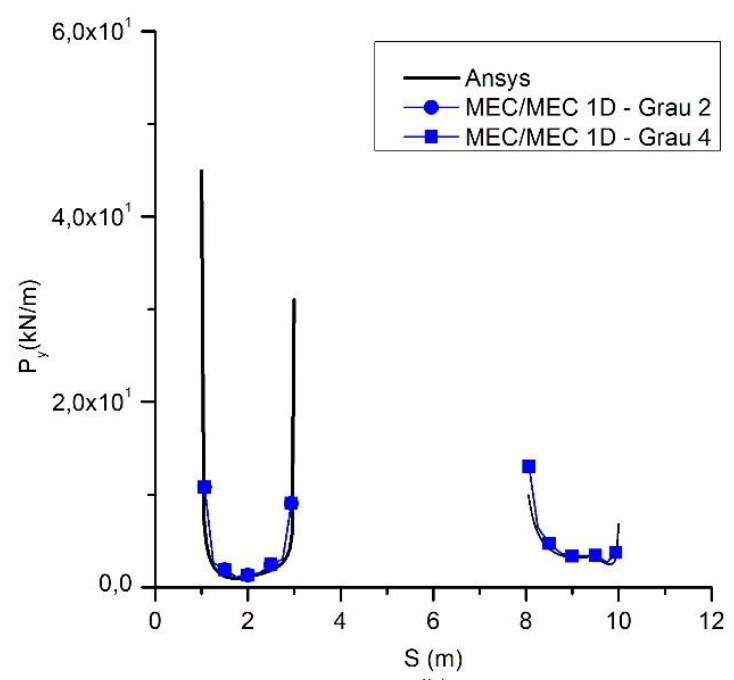

(b)

FONTE: O autor

\subsubsection{Fibra Inferior}

Os resultados em deslocamentos da fibra inferior foram próximos, sendo indiferente o método adotado:

Figura 98. Deslocamentos em x na fibra inferior - Acoplamento Ex.4

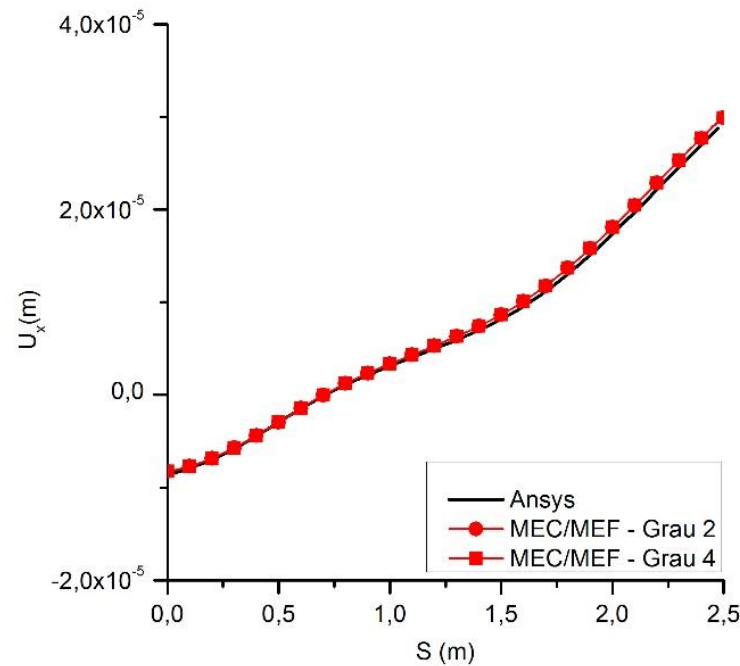

(a)

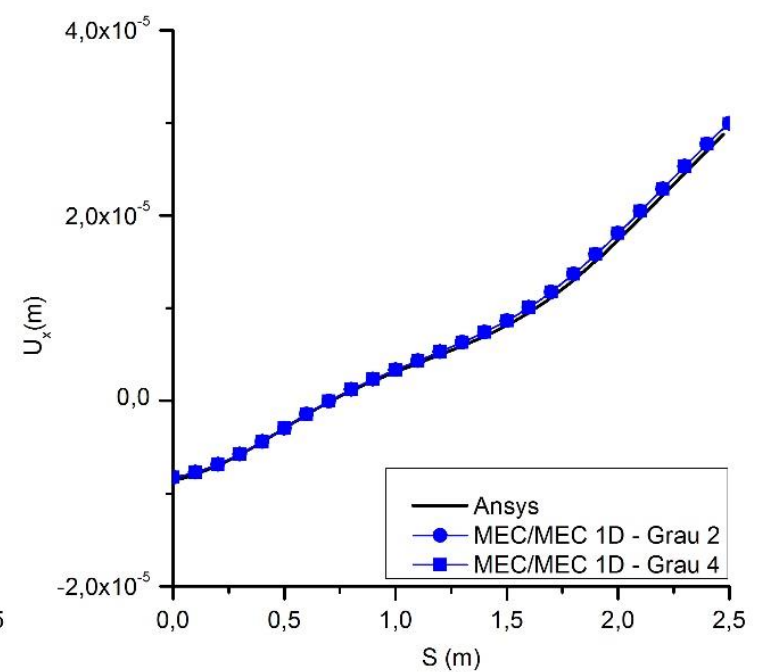

(b)

FONTE: O autor 
Figura 99. Deslocamentos em y na fibra inferior - Acoplamento Ex.4

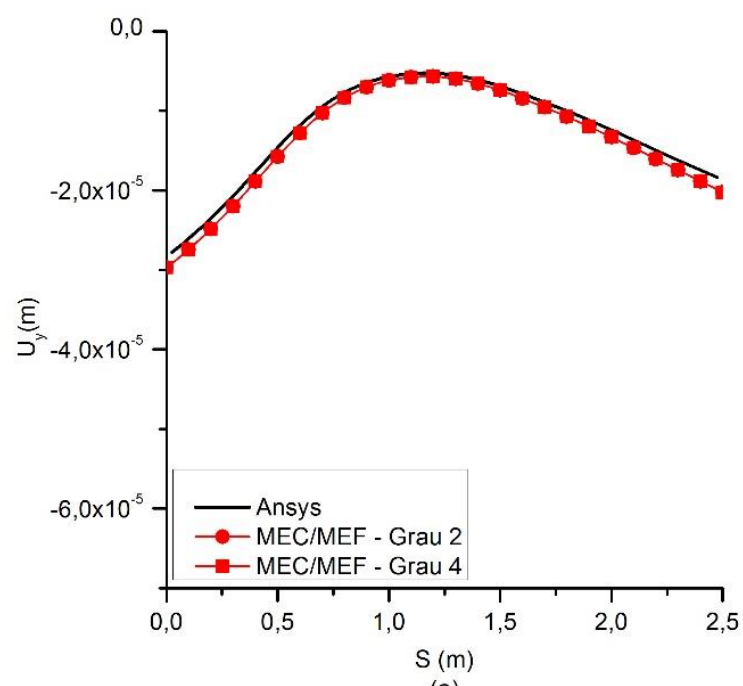

(a)

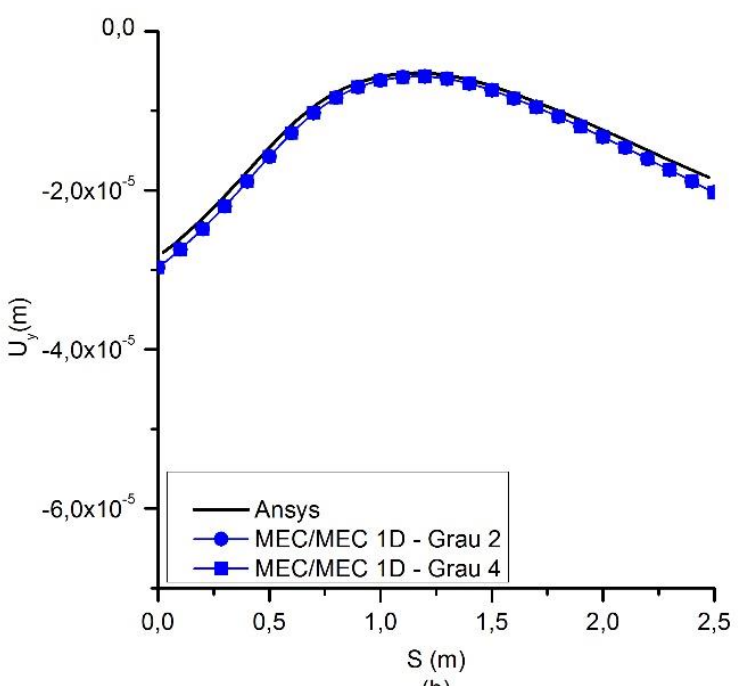

(b)

FONTE: O autor

Já quanto aos resultados de força de aderência e força normal, o acoplamento MEC/MEF teve resposta mais instável em relação ao MEC/MEC 1D. Verifica-se que próximo às pontas dos enrijecedores ocorre concentração de tensão, o MEF encontrando dificuldade em captá-la:

Figura 100. Forças normais e forças de aderência na fibra inferior - Grau 2 - Acoplamento Ex.4
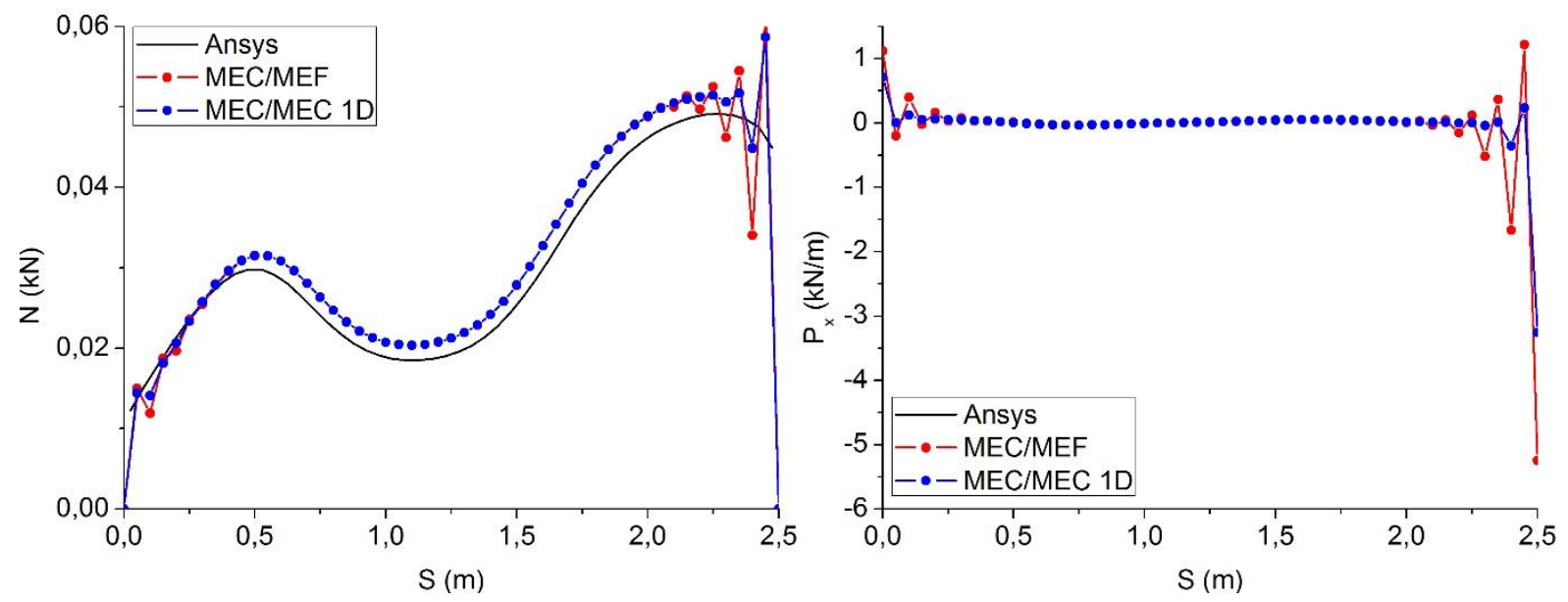

FONTE: O autor 
Com o uso de aproximação do quarto grau ocorre convergência dos resultados:

Figura 101. Forças normais e forças de aderência na fibra inferior - Grau 4 - Acoplamento Ex.4
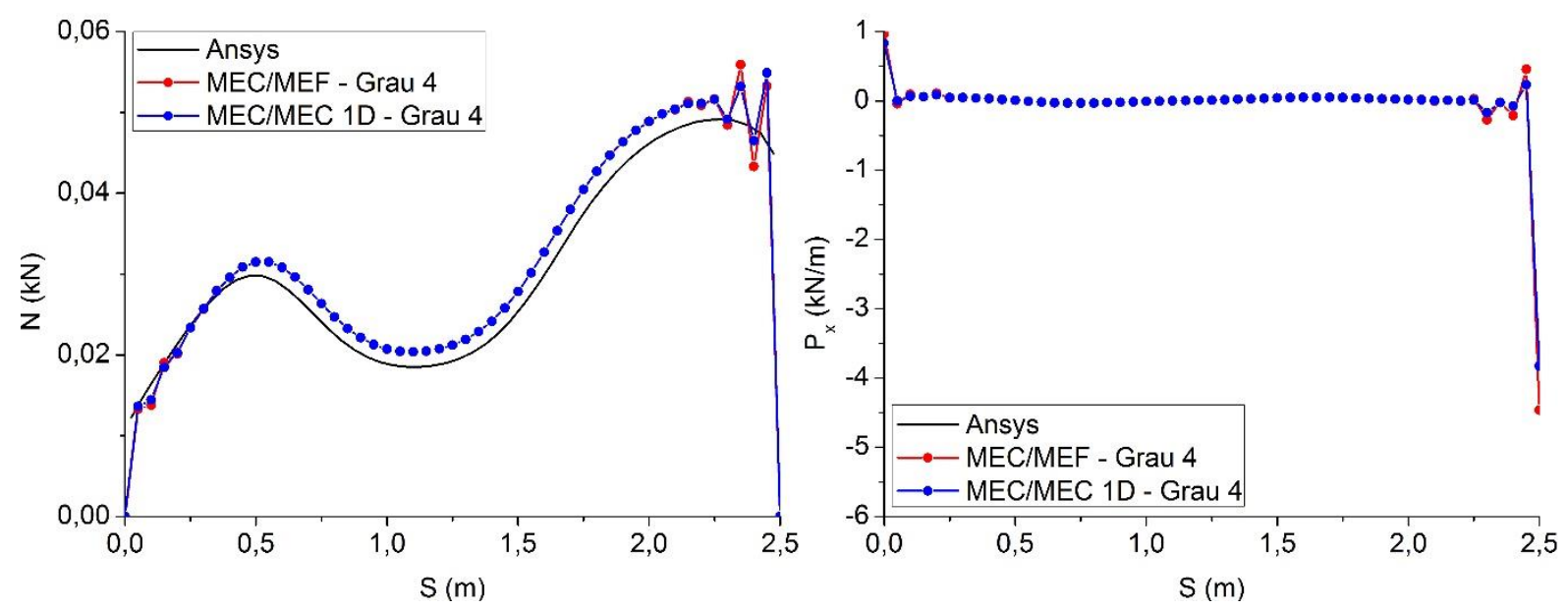

FONTE: O autor

\subsubsection{Fibra Superior}

Da mesma forma que a fibra inferior, os resultados em deslocamentos da fibra superior foram próximos:

Figura 102. Deslocamentos em x na fibra superior - Acoplamento Ex.4

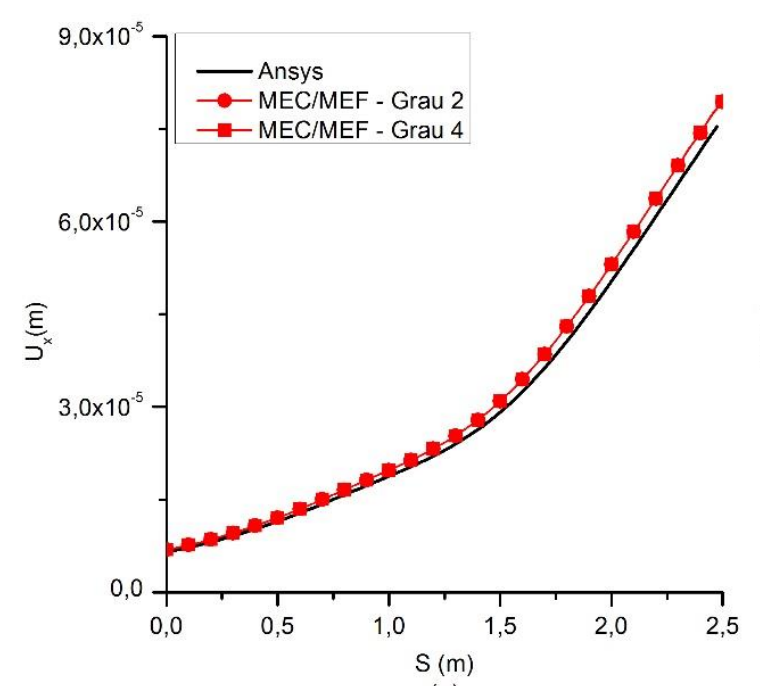

(a)

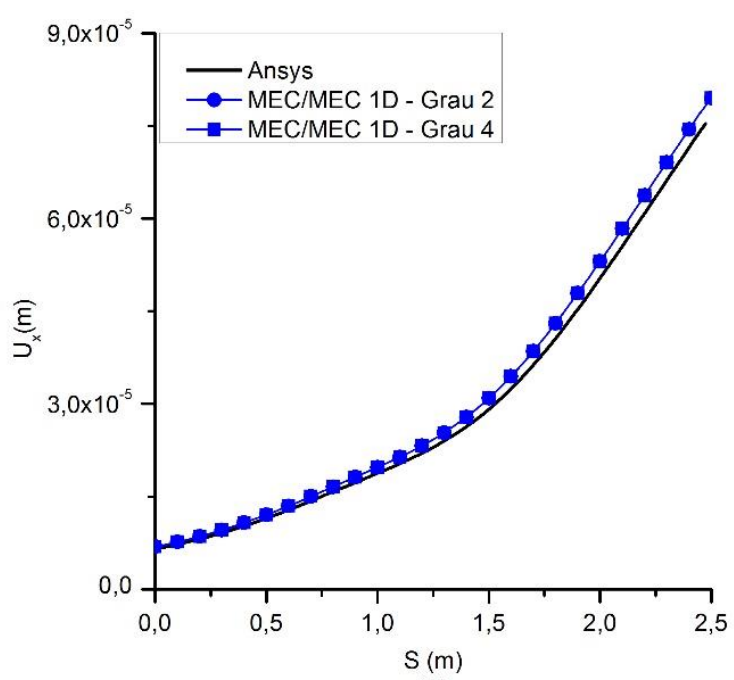

(b)

FONTE: O autor 
Figura 103. Deslocamentos em y na fibra superior - Acoplamento Ex.4

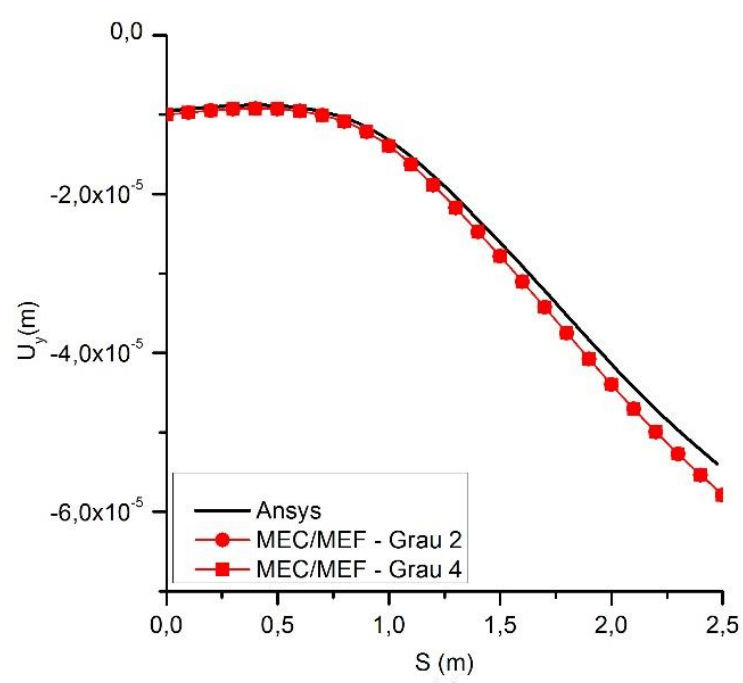

(a)

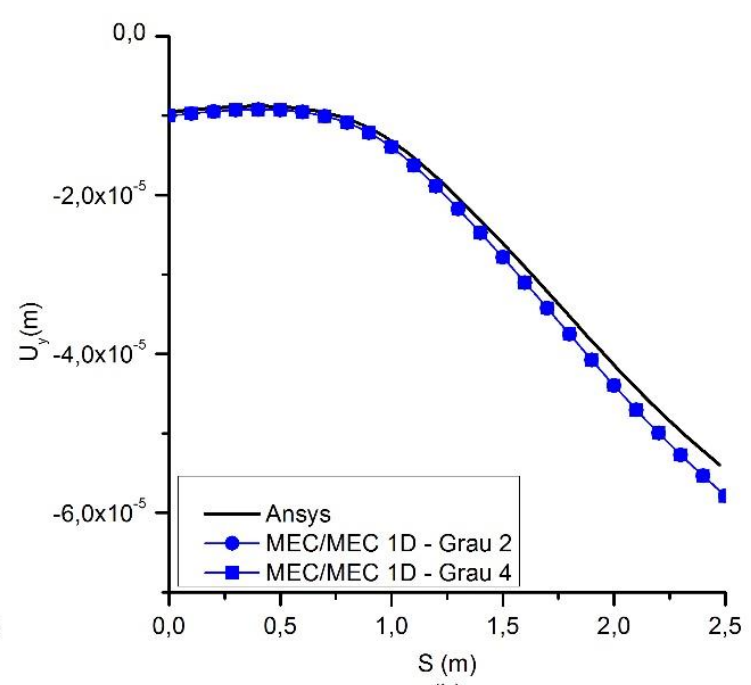

(b)

FONTE: O autor

Já no caso de força normal e força de aderência, o resultado do MEC/MEF também foi instável próximo às pontas:

Figura 104. Forças normais na fibra superior - Grau 2 - Acoplamento Ex.4
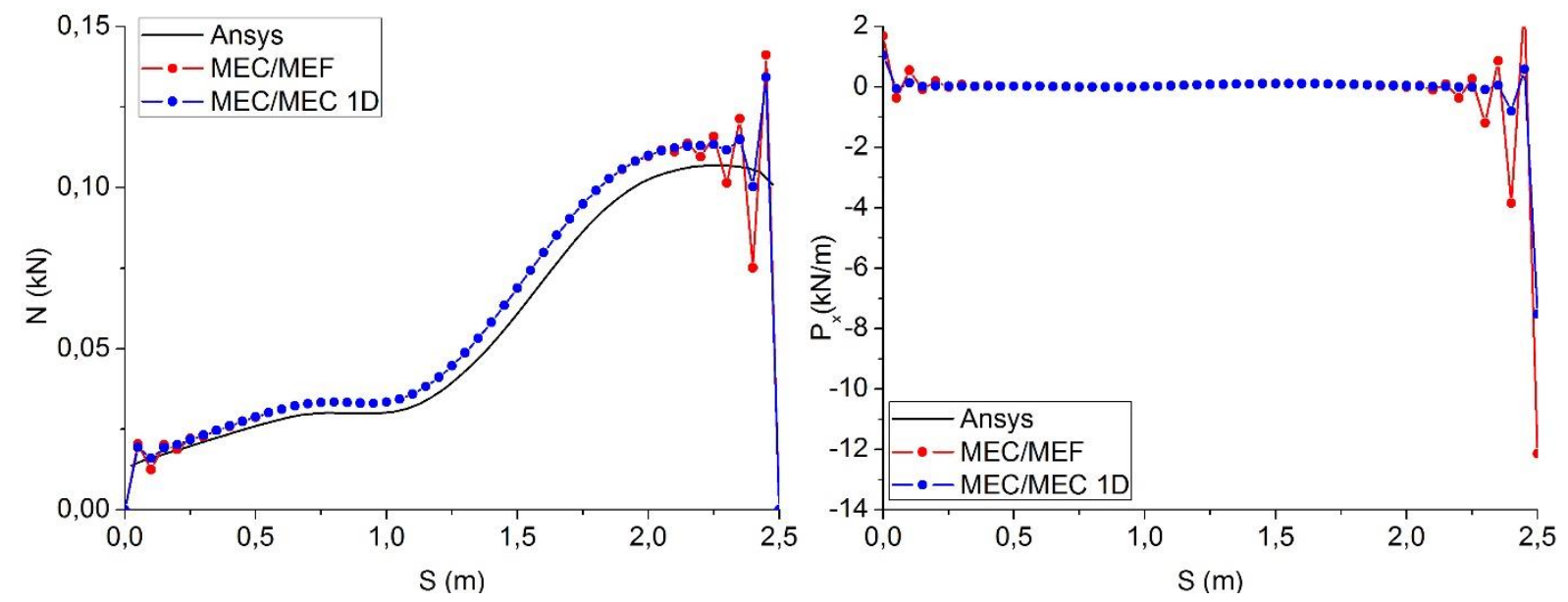

FONTE: O autor 
Novamente, como uso de aproximação do quarto grau ocorre convergência de resultados:

Figura 105. Forças normais na fibra superior - Grau 4 - Acoplamento Ex.4
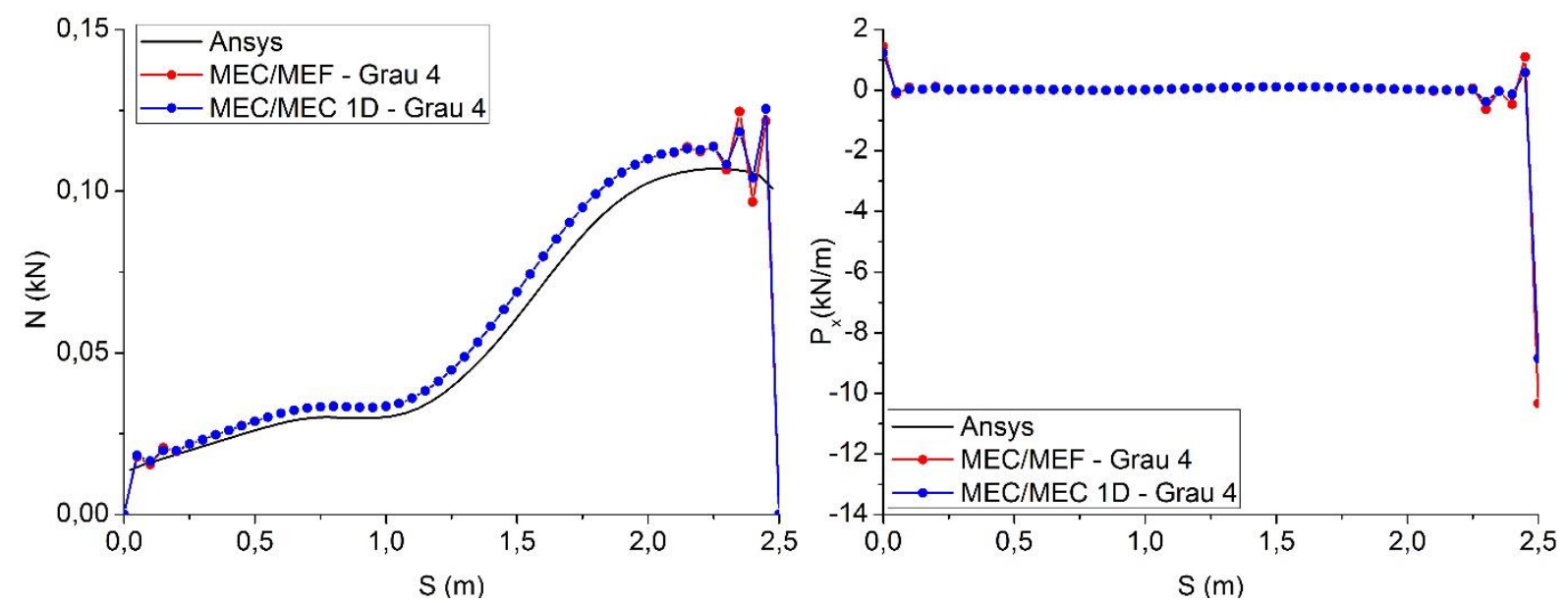

FONTE: O autor

\subsubsection{Conclusões Parciais}

Observa-se que mesmo no caso de problema com condições de contorno e carregamento adversas, com aplicação de inclusão isotrópica, manteve-se a lógica dos exemplos anteriores. Assim, o MEC/MEC 1D apresentou maior estabilidade de resultados de força de aderência e força normal independentemente do grau de aproximação adotado. No caso do MEC/MEF com uso de elementos de aproximação quadrática foram observadas perturbações próximo às pontas, sendo necessária maior discretização dos enrijecedores para evita-las, ou se aumentar o grau de aproximação. Entretanto, com o uso de aproximação do quarto grau os resultados de ambos métodos foram muito próximos. 


\section{CONSIDERAÇÕES FINAIS}

\subsection{Resultados Obtidos}

Definidas as bases matemáticas, de forma a validar a formulação adotada para o MEC 1D, foram avaliados três exemplos de barra de treliça com diferentes carregamentos. Em seguida foi avaliada a união e rotação de elementos, comparando-se com o programa computacional acadêmico FTOOL. Em todos foram obtidos bons resultados, demonstrando a consistência da formulação adotada.

Foram avaliados quatro exemplos de meios enrijecidos com diferentes discretizações e grau de aproximação das fibras. Mantendo-se a quantidade de nós, foi avaliado o uso de aproximação quadrática, cúbica e do quarto grau. Claramente pôde-se perceber que ocorre concentração de tensões nas extremidades das fibras. Avaliou-se que, por este motivo, a mudança de discretização e do grau de aproximação nestas áreas possui os maiores efeitos, sendo que o aumento da discretização possui o usual efeito positivo.

No primeiro exemplo estudou-se painel de material isotrópico. Em todos casos foram obtidos bons resultados para o contorno e para deslocamentos das fibras. O acoplamento com o MEC 1D em todos os casos se mostrou mais estável que o acoplamento com o MEF, este apresentando relevante perturbação no caso de menor discretização e grau de aproximação. Entretanto, mesmo com a menor discretização de fibras, o uso de aproximação do quarto grau em elementos próximos às extremidades leva a significativa melhora nos resultados de fibras no acoplamento com o MEF, tornando-os muito próximos ao acoplamento com o MEC 1D. No caso do acoplamento com o MEC 1D o efeito da mudança de grau de aproximação não foi tão relevante.

No segundo exemplo adotou-se o mesmo modelo e meio de material também isotrópico, mas com a diferença de ter sido aumentada significativamente a flexibilidade deste. Neste caso, os enrijecedores governam o comportamento mecânico do problema, possuindo influência no resultado inclusive do contorno. A modelagem deles influenciou principalmente no caso de aproximação quadrática, onde foram obtidas com o acoplamento MEC/MEF respostas melhores até mesmo que o MEC/MEC 1D, sendo significativamente mais estáveis que no primeiro exemplo. Avaliou-se que o motivo seja o fato de no acoplamento MEC/MEF ser realizada aproximação adicional. Com uso de aproximação cúbica e do quarto grau os resultados de ambos métodos convergiram, inclusive com o ANSYS. 
Foram avaliados em seguida dois exemplos de acoplamento com meio anisotrópico de flexibilidade similar à do primeiro exemplo. Observou-se que os resultados foram também similares aos do primeiro exemplo, não havendo efeito relevante sobre o contorno. Conclui-se então que a modelagem adotada para os enrijecedores influencia no resultado no contorno somente no caso de meio com rigidez muito mais baixa.

\subsection{Conclusões dos Resultados}

Com os diferentes exemplos realizados, pode-se concluir que a formulação adotada para o acoplamento com o MEC se mostrou consistente, apresentando convergência de resultados inclusive com o ANSYS. Foram obtidos bons resultados inclusive para o caso de maior diferença de rigidez entre enrijecedores e meio. A modelagem dos enrijecedores afetou principalmente no próprio resultado deles em força de aderência e força normal, o acoplamento com o MEC 1D se mostrando estável em todas situações adotadas. Com o uso de aproximação do quarto grau ocorre convergência MEC/MEF com o MEC/MEC 1D, sendo que no segundo exemplo ocorre significativa melhora de ambos métodos. Por esse motivo, recomenda-se então que priorize-se o uso de aproximações do quarto grau e, no caso de se utilizar aproximações de grau inferior, que seja evitado o acoplamento com o MEF.

Devido à sua complexidade o exemplo quatro do acoplamento com o MEC possuiu, entre os analisados, o maior custo computacional. Entretanto mesmo neste o tempo não foi elevado, sendo da ordem de 40 segundos $^{14}$. Não houve diferença relevante entre os métodos.

\subsection{Sugestões para pesquisas futuras}

No presente trabalho foram avaliados exemplos com o simples objetivo de se avaliar os resultados, sugere-se para pesquisas futuras a avaliação de exemplos práticos de domínios enrijecidos. Um exemplo de interesse seria o caso de concreto reforçado com fibras distribuídas aleatoriamente, onde com uso do MEC essa modelagem é facilitada em comparação com modelo do MEF. Outro exemplo seria o estudo diafragma rígido de lajes de concreto, onde elas possuem a função de distribuir esforços entre pilares, avaliando-se o comportamento da armadura e efeitos dos diferentes tipos de lajes.

\footnotetext{
${ }^{14}$ Em um computador Intel ${ }^{1}$ Core ${ }^{\mathrm{TM}}$ i7-4790K CPU @ $4.00 \mathrm{GHz}$, Memória instalada (RAM) 16GB
} 
O acoplamento foi realizado considerando-se o enrijecedor inteiramente imerso em um domínio modelado pelo MEC. Sugere-se o desenvolvimento de formulação onde é considerado nó do enrijecedor sobre o contorno. No trabalho é utilizada para os nós do enrijecedor formulação para pontos internos do MEC, caso haja ponto sobre o contorno esta resultará em erro.

Com a adoção de ponto sobre o contorno diversas aplicações se tornam possíveis. Passa a ser possível o acoplamento com estrutura, sendo possível inclusive o uso da formulação para modelagem de estaca de fundação, por exemplo. Passa a ser possível que o enrijecedor atravesse uma interface, como no caso dele pertencer a mais de um subdomínio, ou existir fratura no domínio da qual ele faz parte. A análise de fratura em domínio com presença de enrijecedor atravessando-a é interessante pelo fato de ser um caso onde o uso do MEC se mostra muito vantajoso, com o surgimento de concentração de tensão, neste tipo de problema o próprio uso do MEC 1D também pode apresentar maiores vantagens.

No caso de se analisar estaca de fundação, a rigidez a flexão já passa a ser relevante, dessa forma passa a ser necessária a implementação de acoplamento com elementos com resistência a flexão, surgindo nesse caso linha de carga entre o meio e enrijecedor na direção transversal ao eixo deste. Outro ponto que pode ser levado em conta é o efeito de ponta na extremidade da estaca, aplicando compressão sobre o meio.

Em todos os exemplos analisados verificou-se o surgimento de concentração de tensão nas extremidades dos enrijecedores. Na realidade há um limite para esta concentração de tensão, ele pode ser levado em conta incluindo-se na análise a consideração de escorregamento do enrijecedor, ocorrendo quando a carga superar o limite de aderência. 


\section{REFERÊNCIAS BIBLIOGRÁFICAS}

ANDRADE, H. DE C. E. Análise da propagação de fissuras em estruturas bidimensionais não-homogêneas via Método dos Elementos de Contorno. [s.1.] Universidade de São Paulo, 2017.

ANTES, H. Fundamental solution and integral equations for Timoshenko beams. Computers \& Structures, v. 81, n. 6, p. 383-396, 2003.

ANTES, H.; SCHANZ, M.; ALVERMANN, S. Dynamic analyses of plane frames by integral equations for bars and Timoshenko beams. Journal of Sound and Vibration, v. 276, n. $3-5$, p. 807-836, 2004.

AOUR, B.; RAHMANI, O.; NAIT-ABDELAZIZ, M. A coupled FEM/BEM approach and its accuracy for solving crack problems in fracture mechanics. International Journal of Solids and Structures, v. 44, n. 7-8, p. 2523-2539, abr. 2007.

ARMENTANI, E.; CITARELLA, R. DBEM and FEM analysis on non-linear multiple crack propagation in an aeronautic doubler-skin assembly. v. 28, n. 5-6, p. 598-608, maio 2006.

BANERJEE, P. K.; BUTTERFIELD, R. Boundary elements method in engineering science. [s.l: s.n.].

BIALECKI, R. A. et al. Coupling BEM, FEM and analytic solutions in steady-state potential problems. Engineering Analysis with Boundary Elements, v. 26, n. 7, p. 597-611, 2002.

BIRD, G. E.; TREVELYAN, J.; AUGARDE, C. E. A coupled BEM/scaled boundary FEM formulation for accurate computations in linear elastic fracture mechanics. Engineering Analysis with Boundary Elements, v. 34, n. 6, p. 599-610, 2010.

BOTTA, A. S.; VENTURINI, W. S. Reinforced 2d domain analysis using BEM and regularized BEM/FEM combination. CMES - Computer Modeling in Engineering and Sciences, v. 8, n. 1, p. 15-28, 2005.

BOUMAIZA, D.; AOUR, B. On the efficiency of the iterative coupling FEM-BEM for solving the elasto-plastic problems. Engineering Structures, v. 72, p. 12-25, 2014.

BREBBIA, C. A. Weighted residual classification of approximate methods. Applied Mathematical Modelling, v. 2, n. 3, p. 160-164, 1978a.

BREBBIA, C. A. The Boundary Element Method for Engineers. London: Pentech 
Press, 1978b.

BREBBIA, C. A.; GEORGIOU, P. Combination of boundary and finite elements for elastostatics. Applied Mathematical Modelling, v. 3, p. 212-220, 1979.

CARRER, J. A. M. et al. ANALYSIS OF EULER-BERNOULLI AND TIMOSHENKO BEAMS BY THE BOUNDARY ELEMENT METHOD. 10th World Congress on Computational Mechanics, 1, 2012, São Paulo. Anais...São Paulo: Blucher, 2014

CHEN, D.; DAI, S. Dynamic fracture analysis of the soil-structure interaction system using the scaled boundary finite element method. Engineering Analysis with Boundary Elements, v. 77, n. August 2016, p. 26-35, 2017.

CHENG, A. H. D.; CHENG, D. T. Heritage and early history of the boundary element method. Engineering Analysis with Boundary Elements, v. 29, n. 3, p. 268-302, 2005.

CITARELLA, R. Non-linear MSD crack growth by DBEM for a riveted aeronautic reinforcement. Advances in Engineering Software, v. 40, n. 4, p. 253-259, abr. 2009.

CODA, H. B. Dynamic and static non-linear analysis of reinforced media: A BEM/FEM coupling approach. Computers and Structures, v. 79, n. 31, p. 2751-2765, 2001.

CODA, H. B.; VENTURINI, W. S. On the coupling of 3D BEM and FEM frame model applied to elastodynamic analysis. International Journal of Solids and Structures, v. 36, n. 31-32, p. 4789-4804, 1999.

CODA, H. B.; VENTURINI, W. S.; ALIABADI, M. H. A general 3D BEM/FEM coupling applied to elastodynamic continua/frame structures interaction analysis. International Journal for Numerical Methods in Engineering, v. 712, n. February 1998, p. 695-712, 1999.

CORDEIRO, S. G. F. Formulações do Método dos Elementos de Contorno aplicadas à análise elástica e à fratura coesiva de estruturas compostas planas. São Carlos: Departamento de engenharia de estruturas, 2015.

CRUSE, T. A.; SWEDLOW, J. L. Interactive Program for Analysis and Design Problems Advanced Composites Technology. Pittsburgh, PA, United States: [s.n.]. Disponível em: <https://ntrs.nasa.gov/search.jsp?R=19720010933>.

CRUZ, J. M. F. Contribuição à análise estática e dinâmica de pórticos pelo método dos elementos de contorno. [s.1.] Universidade Federal da Paraíba, 2012. 
DE FREITAS, J. A. T.; DE ALMEIDA, J. P. M.; PEREIRA, E. M. B. R. Nonconventional formulations for the finite element method. Structural Engineering and Mechanics, v. 4, n. 6, p. 655-678, 1996.

DOS PASSOS, J. J. S. Análise da estabilidade estática e dinâmica de vigas pelo método dos elementos de contorno. [s.l.] Universidade Federal da Paraiba, 2014.

ELLEITHY, W. M.; TANAKA, M.; GUZIK, A. Interface relaxation FEM-BEM coupling method for elasto-plastic analysis. Engineering Analysis with Boundary Elements, v. 28 , n. 7, p. 849-857, 2004.

FALBY, W.; SHAWT, R. P. Febie - a combined finite element-boundary integral equation method. Computers and Fluids, v. 6, p. 153-160, 1977.

FERNANDES, G. R.; PITUBA, J. J. C.; DE SOUZA NETO, E. A. FEM/BEM formulation for multi-scale analysis of stretched plates. Engineering Analysis with Boundary Elements, v. 54, p. 47-59, 2015.

FERNANDES, G. R.; VENTURINI, W. S. Non-linear boundary element analysis of plates applied to concrete slabs. Engineering Analysis with Boundary Elements, v. 26, p. 169-181, 2002.

GANGULY, S.; LAYTON, J. B.; BALAKRISHNA, C. Symmetric coupling of multizone curved Galerkin boundary elements with finite elements in elasticity. Intemational Journal for Numerical Methods in Engineering, v. 48, n. 5, p. 633-654, 2000.

GÓIS, W. Elementos finitos híbridos e híbrido-mistos de tensão com enriquecimento nodal. São Carlos: Departamento de engenharia de estruturas, 2009.

GONZALEZ, M. et al. A new displacement-based approach to calculate stress intensity factors with the boundary element method. Latin American Journal of Solids and Structures, v. 12, n. 9, p. 1677-1697, 2015.

KZAM, A. K. L. Formulação Dual em Mecânica da Fratura Utilizando Elementos de Contorno Curvos de Ordem Qualquer. São Carlos: Departamento de engenharia de estruturas, 2009.

LE VAN, A.; ROYER, J. Boundary formulation for three-dimensional anisotropic crack problems. Applied Mathematical Modelling, v. 20, n. 9, p. 662-674, 1996.

LEE, C. Y.; WANG, H.; QIN, Q. H. Dual reciprocity boundary element method using 
compactly supported radial basis functions for 3D linear elasticity with body forces. International Journal of Mechanics and Materials in Design, v. 12, n. 4, p. 463-476, 2016.

LEITE, L. G. S.; CODA, H. B.; VENTURINI, W. S. Two-dimensional solids reinforced by thin bars using the boundary element method. Engineering Analysis with Boundary Elements, v. 27, n. 3, p. 193-201, 2003.

LEONEL, E. D. Método dos Elementos de Contorno Aplicado à Análise de Sólidos Multi-Fraturados. São Carlos: Universidade de São Paulo, 2006.

LEONEL, E. D. Modelos Não Lineares do Métododos Elementos de Contorno para Análise de Problemas de Fratura e Aplicação de Modelos de Confiabilidade e Otimização em Estruturas Submetidas à Fadiga. São Carlos: Departamento de engenharia de estruturas, 2009.

MENDONÇA, A. V.; PAIVA, J. B. An elastostatic FEM/BEM analysis of vertically loaded raft and piled raft foundation. Engineering Analysis with Boundary Elements, v. 27, n. 9, p. 919-933, 2003.

MESQUITA, A. D.; CODA, H. B. A boundary element methodology for viscoelastic analysis: Part II without cells. Applied Mathematical Modelling, v. 31, n. 6, p. 1171-1185, 2007.

OLIVEIRA, H. L. Uma formulação alternativa do Método dos Elementos de Contorno aplicada à análise da propagação de fissuras em materiais quase frágeis. São Carlos: Departamento de Engenharia de Estruturas, 2013.

OLIVEIRA, H. L. Modelos numéricos aplicados à análise viscoelástica linear e à otimização topológica probabilística de estruturas bidimensionais: uma abordagem pelo Método dos Elementos de Contorno. [s.1.] Universidade de São Paulo, 2017.

OLIVEIRA, H. L.; LEONEL, E. D. Cohesive crack growth modelling based on an alternative nonlinear BEM formulation. Engineering Fracture Mechanics, v. 111, p. 86-97, out. 2013.

PROENÇA, S. P. B. Set-5875 Introdução aos métodos numéricos - Notas de aulas. São Carlos: Universidade de São Paulo, 2010.

PROVIDASKIS, C. P.; BESKOS, D. E. Dynamic analysis of beams by the boundary element method. Computers \& Structures, v. 22, n. 6, p. 957-964, 1986. 
RAHNEMA, H.; MOHASSEB, S.; JAVIDSHARIFI, B. 2-D soil-structure interaction in time domain by the SBFEM and two non-linear soil models. Soil Dynamics and Earthquake Engineering, v. 88, p. 152-175, 2016.

RIBEIRO, D. B.; DE PAIVA, J. B. A new BE formulation coupled to the FEM for simulating vertical pile groups. Engineering Analysis with Boundary Elements, v. 41, p. 19, abr. 2014.

RIZOS, D. C.; WANG, Z. Coupled BEM-FEM solutions for direct time domain soilstructure interaction analysis. Engineering Analysis with Boundary Elements, v. 26, n. 10, p. 877-888, 2002.

ROCHA, F. C. DA et al. Sliding frame-solid interaction using BEM/FEM coupling. Latin American Journal of Solids and Structures, v. 11, n. 8, p. 1376-1400, 2014.

ROMERO, A.; GALVÍN, P.; DOMÍNGUEZ, J. 3D non-linear time domain FEM-BEM approach to soil-structure interaction problems. Engineering Analysis with Boundary Elements, v. 37, n. 3, p. 501-512, 2013.

SANTANA, A. et al. A BEM-FEM model for the dynamic analysis of building structures founded on viscoelastic or poroelastic soils. Bulletin of Earthquake Engineering, v. 14, n. 1, p. 115-138, 2016.

SCHEPERS, W. Fast 3D FEM-BEM coupling for dynamic soil-structure interaction. Procedia Engineering, v. 199, p. 391-396, 2017.

SEIXAS, R.; MARQUES, F. D. M.; FILGUEIRAS, J. M. Uma estratégia para análise estática de pórticos planos e espaciais utilizando-se o método dos elementos de contorno. Nono Simpósio de Mecânica Computacional, 2010.

SILVA, W. Q.; CODA, H. B. Numerical combination for nonlinear analysis of structures cou-. Latin American Journal of Solids and Structures, v. 1, p. 1-23, 2012.

SONG, C.; WOLF, J. The scaled boundary finite element method-alias consistent infinitesimal finite element cell method-for diffusion. International journal for numerical methods ..., v. 45, n. 10, p. 1403-1431, 1999.

STAMOS, A. A.; BESKOS, D. E. Dynamic analys is of large 3-D underground structures by the bem. Earthquake Engineering \& Structural Dynamics, v. 24, n. 6, p. $917-$ 934, 1995. 
TROYANI, N.; PÉREZ, A. A comparison of a finite element only scheme and a BEM/FEM method to compute the elastic-viscoelastic response in composite media. Finite Elements in Analysis and Design, v. 88, p. 42-54, 2014.

VASILEV, G. et al. Soil-structure interaction using BEM-FEM coupling through ANSYS software package. Soil Dynamics and Earthquake Engineering, v. 70, p. 104-117, 2015 .

WEARING, J. L.; BURSTOW, M. C. Elasto-plastic analysis using a coupled boundary element finite element technique. Engineering Analysis with Boundary Elements, v. 14, p. 39-49, 1994.

WILSON, R. B.; CRUSE, T. A. Efficient implementation of anisotropic three dimensional boundary integral equation analysis. International Journal for Numerical Methods in Engineering, v. 12, n. 9, p. 1383-1397, 1978.

ZIENKIEWICZ, O. C.; KELLY, D. W.; BETTESS, P. The coupling of the finite element method and boundary solution procedures. International Journal for Numerical Methods in Engineering, v. 11, n. 2, p. 355-375, 1977. 


\section{APÊNDICE A - CONCEITOSFUNDAMENTAIS}

Na mecânica das estruturas dificilmente é possível encontrar solução analítica para os problemas propostos, normalmente escritos na forma de equações diferenciais acompanhadas por condições de contorno, chamados de Problema de Valor de Contorno (PVC). Procura-se então encontrar soluções aproximadas.

Dentre os métodos existentes, como diferenças finitas, destacam-se os que envolvem a utilização do conceito de distribuição de erros dentro do domínio, de forma a minimiza-los. O conceito de distribuição de erros é um conceito matemático fundamental, com usos em diversas áreas. Pode ser citado como exemplo o Princípio dos Trabalhos Virtuais (PTV), muito utilizado na solução de problemas na engenharia, cuja demonstração foi realizada por meio do conceito de distribuição de erros por Lagrange.

Para o caso de uma equação diferencial qualquer, a substituição de suas variáveis pela aproximação gera um erro, ou resíduo, $\mathrm{R}$, procura-se então minimiza-lo dentro do domínio. Para a minimização é necessário considerar outra função, chamada $w$, ou função peso. Multiplica-se o resíduo por essa função arbitrária.

A ideia de distribuição de erros é que não seja necessário satisfazer a equação diferenc ial em todo o domínio, mas que o resultado da integração dos erros ponderados pela função $w$ seja nulo, ou seja:

$$
\int_{\Omega} R w d \Omega=0
$$

Essa equação é chamada de forma variacional direta, permite que seja encontrada solução aproximada desde que $w$ atenda a condição de ser contínua dentro do domínio e possuir derivadas contínuas até o mesmo grau da função solução. A forma variacional direta não incorpora condições de contorno, sendo necessário verifica-las.

A forma variacional direta dá origem a métodos chamados de resíduos ponderados. Esses se diferenciam de acordo com a escolha da função peso $w$.

Tomando como exemplo um domínio unidimensional, com limites de $\mathrm{x}=0$ à $\mathrm{x}=1$ apresentado em (BREBBIA, 1978b) com a seguinte equação governante (forma forte):

$$
\frac{d^{2} u}{d x^{2}}+\lambda^{2} u-b=0 \text { em } x
$$


Com as seguintes condições de contorno:

$$
\begin{gathered}
u=u_{0} \text { em } x=0 \\
q=\frac{d u}{d x}=q_{1} \text { em } x=1
\end{gathered}
$$

Sendo u a função governante do problema, $\lambda^{2}$ uma constante positiva conhecida e b uma função conhecida de $x$.

Chamando ũ a solução aproximada, a equação não é necessariamente satisfeita, definese então R como erro, ou resíduo do problema:

$$
R=\frac{d^{2} \tilde{\mathrm{u}}}{d x^{2}}+\lambda^{2} \tilde{\mathrm{u}}-b
$$

E no contorno:

$$
\begin{aligned}
& R_{1}=\tilde{\mathrm{u}}(0)-u_{0} \\
& R_{2}=\tilde{q}(1)-q_{1}
\end{aligned}
$$

Substituindo (A.4) na equação (A.1) obtém-se então a forma variacional direta:

$$
\int_{0}^{1}\left(\frac{d^{2} u}{d x^{2}}+\lambda^{2} u-b\right) w d x=0
$$

O processo de determinação de uma função aproximada parte da escolha de uma base de funções linearmente independentes, estas ponderadas por coeficientes, que serão então as incógnitas do problema:

$$
\tilde{u}=\alpha_{1} \phi_{1}+\alpha_{2} \phi_{2}+\cdots
$$

A partir da forma variacional direta, a solução do problema de valor de contorno é possível de três formas:

1- Método de Domínio: Se a solução aproximada satisfizer todas condições de contorno, mas não necessariamente a equação que governa o problema (forma forte) no domínio $\Omega$. Como exemplo há o Método dos Elementos Finitos (MEF), Método dos Elementos Finitos Generalizados (MEFG) e derivados.

2- Método de Contorno: Caso a solução aproximativa satisfaça a forma forte do problema, mas não necessariamente as condições de contorno; 
3- Método Misto: Caso a solução não satisfaça diretamente nem condições de contorno nem a forma forte do problema. Não será abordado.

\section{A.1 Método de domínio}

No exemplo, integrando-se por partes a equação (A.6) da forma variacional direta:

$$
\int_{0}^{1}\left\{-\frac{d u}{d x} \frac{d w}{d x}+\left(\lambda^{2} u-b\right) w\right\} d x+\left[\frac{d u}{d x} w\right]_{0}^{1}=0
$$

Observa-se que a integração por partes produziu dois termos, um no domínio das primeiras derivadas de u e w, e a outra no contorno (que neste caso são simplesmente os dois pontos $\mathrm{x}=0, \mathrm{x}=1$ ). São incorporadas as condições de contorno de $\mathrm{q}$, devido a isso essas condições de contorno são chamadas naturais. Condições de contorno de u são chamadas então essenciais.

Nesse caso o grau de continuidade necessário para a função governante do problema é reduzido, é exigida continuidade para o mesmo grau de derivadas tanto para a função aproximada quanto para a função peso. Por esses fatos essa equação é conhecida como forma fraca do problema.

A Eq. (A.8) também pode ser escrita na forma:

$$
\int_{0}^{1}\left\{-\frac{d u}{d x} \frac{d w}{d x}+\left(\lambda^{2} u-b\right) w\right\} d x=-[q w]_{x=1}+[q w]_{x=0}
$$

Em um método de domínio, a função peso w é escolhida de forma que seja homogênea nas condições de contorno essenciais, ou seja possuir valor nulo onde u possui valor prescrito, dessa forma elimina-se o termo $[q w]_{x=0}$, o que é interessante pelo fato de $\mathrm{q}(0)$ não ser conhecido. Chega-se então na seguinte equação, que forma a base dos resíduos ponderados:

$$
\int_{0}^{1}\left\{-\frac{d u}{d x} \frac{d w}{d x}+\left(\lambda^{2} u-b\right) w\right\} d x=-[q w]_{x=1}
$$

Sendo q(1) conhecido, resta realizar a integração. Uma vez que a integração é realizada em todo o domínio é necessário então que tanto a solução u quanto a função peso w sejam aproximadas nele todo. Uma vez que condições de contorno essenciais não foram incorporadas será necessária escolha de solução aproximada u que as satisfaça.

Destaca-se que a forma fraca de um problema também pode ser encontrada por meio do Princípio dos Trabalhos Virtuais ou por meio de teoremas variacionais da energia. 


\section{A.2 Método de contorno}

Para a integração no contorno são possíveis duas abordagens, de acordo com a escolha da função peso w:

1- Escolha de função peso que satisfaça a equação do problema na sua forma homogênea, formando o método de Trefftz;

2- Escolha de função peso especial, que satisfaça a equação do problema na sua forma homogênea, mas que também possibilite a integração somente no contorno.

Retornando ao exemplo unidimensional, caso a função w possua suficiente grau de continuidade é possível integrar por partes a equação (A.8) novamente, obtendo-se:

$$
\int_{0}^{1}\left\{u\left(\frac{d^{2} w}{d x^{2}}+\lambda^{2} w\right)-b w\right\} d x+\left[\frac{d u}{d x} w\right]_{0}^{1}-\left[u \frac{d w}{d x}\right]_{0}^{1}=0
$$

São incorporadas na equação então condições de contorno essenciais (para u) e naturais, (para q), escolhe-se função peso w de forma a eliminar a necessidade de integração no domínio, na primeira forma isso significa que w deverá satisfazer a seguinte equação:

$$
\frac{d^{2} w}{d x^{2}}+\lambda^{2} w=0
$$

Logo:

$$
-\int_{0}^{1} b w d x+\left[\frac{d u}{d x} w\right]_{0}^{1}-\left[u \frac{d w}{d x}\right]_{0}^{1}=0
$$

Essa é a equação base do método Trefftz.

Na segunda forma utiliza-se a função delta de Dirac:

$$
\frac{d^{2} w}{d x^{2}}+\lambda^{2} w+\Delta_{i}=0
$$

$\Delta_{i}$ indica a função delta de Dirac. A solução dessa equação é chamada solução fundamental.

O uso da função delta de Dirac é oportuno pelo fato de que sua integral em um domínio que contenha seu ponto fonte possui valor unitário, com isso é possível chegar ao seguinte resultado: 


$$
\int_{0}^{1} u \Delta_{i} d x=u_{i}
$$

Sendo $u_{i}$ o valor da função u no ponto fonte, ou seja, a integração no domínio é direta. Chega-se então à seguinte equação:

$$
-u_{i}-\int_{0}^{1} b w d x+\left[\frac{d u}{d x} w\right]_{0}^{1}-\left[u \frac{d w}{d x}\right]_{0}^{1}=0
$$

Analisando-se a equação anterior percebe-se que escolhendo o ponto fonte fora do domínio ou no contorno não é necessário aproximar a função u no domínio, uma vez que seu valor só é necessário no contorno, isso significa que, obtendo-se a solução para o contorno, a solução do interior do domínio é exata, ou seja, satisfaz a forma forte do problema.

Generalizando o método, uma vez que seja conhecida a forma forte do problema, escolhe-se função peso que satisfaça a forma homogênea, com isso somente será necessário realizar aproximações no contorno.

\section{A.3 Exemplo: equação de Poisson}

Será efetuada analogia do que foi definido anteriormente com a equação de Poisson, com o objetivo de mostrar a extensão dos conceitos abordados para o espaço bidimensional (BREBBIA, 1978b).

Nesse caso a forma forte do problema será a equação de Poisson:

$$
\frac{\delta^{2} u}{\delta x_{1}^{2}}+\frac{\delta^{2} u}{\delta x_{2}^{2}}=b
$$

De outra forma:

$$
\nabla^{2} u=b
$$

Com o contorno $\Gamma$ dividido em duas partes $\Gamma_{1}$ e $\Gamma_{2}$, as condições de contorno são:

$$
\begin{gathered}
u=\bar{u} \text { em } \Gamma_{1} \\
q=\frac{\delta u}{\delta n}=\bar{q} \text { em } \Gamma_{2}
\end{gathered}
$$

Sendo n vetor normal do contorno.

A forma variacional direta será então: 


$$
\int_{\Omega}\left(\nabla^{2} u-b\right) w d \Omega=0
$$

Integrando por partes nas duas direções obtêm-se:

$$
\int_{\Omega}\left(-\frac{\delta u}{\delta x_{1}} \frac{\delta w}{\delta x_{1}}-\frac{\delta u}{\delta x_{2}} \frac{\delta w}{\delta x_{2}}-b w\right) d \Omega+\int_{\Gamma} \frac{\delta u}{\delta n} w d \Gamma=0
$$

Nessa equação u deverá ser aproximado no domínio, sendo, portanto, um método de domínio. Ela pode ser escrita na forma:

$$
\int_{\Omega}\left(-\frac{\delta u}{\delta x_{1}} \frac{\delta w}{\delta x_{1}}-\frac{\delta u}{\delta x_{2}} \frac{\delta w}{\delta x_{2}}-b w\right) d \Omega+\int_{\Gamma_{1}} q w d \Gamma_{1}+\int_{\Gamma_{2}} q w d \Gamma_{2}=0
$$

Em $\Gamma_{1}$ o valor de q não é conhecido, portanto a função peso w deverá ter valor nulo nesses pontos. A solução aproximada u deverá conter as condições de contorno essenciais.

Integrando por partes novamente chegamos na forma utilizada no método de contorno:

$$
\int_{\Omega}\left(\left(\nabla^{2} w\right) u-b w\right) d \Omega+\int_{\Gamma} \frac{\delta u}{\delta n} w d \Gamma-\int_{\Gamma} u \frac{\delta w}{\delta n} d \Gamma=0
$$

Para ser realizada a integração a função peso pode ser escolhida de forma a satisfazer a equação:

1) $\nabla^{2} w=0$, para Trefftz

$$
-\int_{\Omega} b w d \Omega+\int_{\Gamma_{1}} q w d \Gamma_{1}+\int_{\Gamma_{2}} \bar{q} w d \Gamma_{2}-\int_{\Gamma_{1}} \bar{u} \frac{\delta w}{\delta n} d \Gamma_{1}-\int_{\Gamma_{2}} u \frac{\delta w}{\delta n} d \Gamma_{2}=0
$$

2) $\nabla^{2} w+\Delta_{i}=0$, para elementos de contorno

$$
\begin{gathered}
-u_{i}-\int_{\Omega} b w d \Omega+\int_{\Gamma_{1}} q w d \Gamma_{1}+\int_{\Gamma_{2}} \bar{q} w d \Gamma_{2}-\int_{\Gamma_{1}} \bar{u} \frac{\delta w}{\delta n} d \Gamma_{1} \\
-\int_{\Gamma_{2}} u \frac{\delta w}{\delta n} d \Gamma_{2}=0
\end{gathered}
$$

Portanto novamente nos métodos de contorno não é necessário aproximar a solução no domínio, aproxima-se para o contorno e caso essa solução seja exata a solução no domínio também o será. 


\section{APÊNDICE B - TEORIA DA ELASTICIDADE LINEAR}

São apresentadas abaixo as equações que governam o problema elástico linear, considerando o material como um meio elástico com isotropia. O corpo possui domínio $\Omega \mathrm{e}$ contorno $\Gamma$.

Figura 106. Corpo de domínio $\Omega$ e contorno $\Gamma$

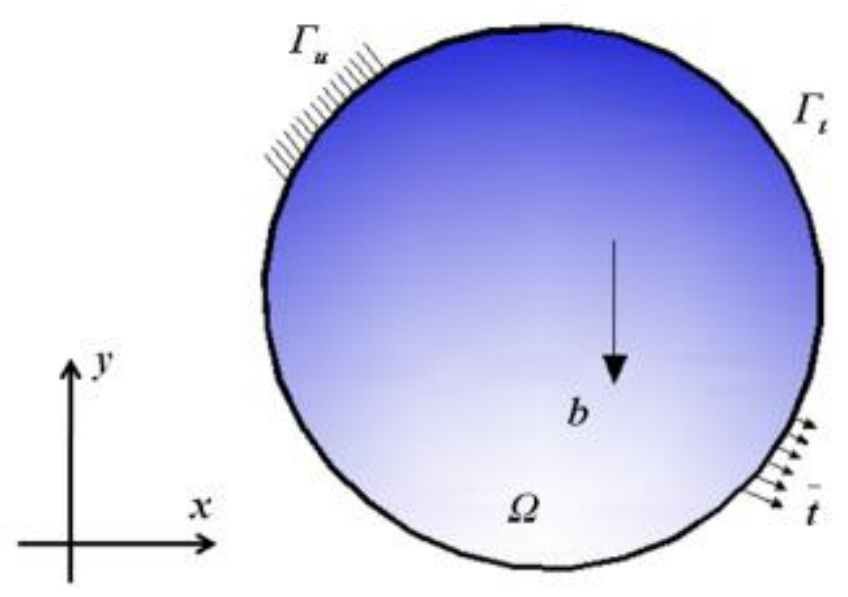

FONTE: (GÓIS, 2009)

\section{B.1 Equilíbrio infinitesimal}

No interior estático de um corpo, ou domínio $\Omega$, para um problema mecânico, a equação governante é dada pelo equilíbrio infinitesimal:

$$
\sigma_{i j, i}+b_{j}=0
$$

$\sigma_{i j}$ representa o tensor de tensão, $b_{j}$ representa as forças de volume do problema.

Essa equação pode ser considerada a forma forte do problema em tensões. Sendo que por equilibrio há a seguinte relação:

$$
\sigma_{i j}=\sigma_{j i}
$$

Para o contorno $\Gamma$ do corpo, a equação de equilibrio é dada por:

$$
p_{i}=\sigma_{i j} n_{j}
$$

$p_{i}$ representa as forças de superfície do corpo, $n_{j}$ representa o versor normal da superfície, orientado para fora do corpo. 


\section{B.2 Relação Constitutiva - Caso Geral}

Por meio da Lei de Hooke se estabelece a relação entre deformações e tensões, chamada relação constitutiva:

$$
\varepsilon_{k l}=D_{i j k l} \sigma_{i j}
$$

$\varepsilon_{k l}$ representa o tensor de deformações e $D_{i j k l}$ o tensor de quarta ordem de constantes elásticas, ou, em forma matricial, matriz de rigidez.

Também é possível escrever a relação em termos de tensões:

$$
\sigma_{i j}=C_{i j k l} \varepsilon_{k l}
$$

neste caso, $C_{i j k l}$ é o tensor de compliância, ou matriz de flexibilidade.

No caso de não haver nenhum eixo de simetria, o material é dito Anisotrópico, neste caso a princípio $D_{i j k l}$ e $C_{i j k l}$ possuiriam 81 termos independentes. Entretanto, considerando a estacionariedade de energia e o equilibrio $\left(\sigma_{i j}=\sigma_{j i}\right)$ os termos são reduzidos a 21 , podendo a equação (B.5) ser escrita da seguinte forma (matriz é simétrica):

$$
\left\{\begin{array}{l}
\varepsilon_{1} \\
\varepsilon_{2} \\
\varepsilon_{3} \\
\varepsilon_{4} \\
\varepsilon_{5} \\
\varepsilon_{6}
\end{array}\right\}=\left[\begin{array}{llllll}
C_{11} & C_{12} & C_{13} & C_{14} & C_{15} & C_{16} \\
& C_{22} & C_{23} & C_{24} & C_{25} & C_{26} \\
& & C_{33} & C_{34} & C_{35} & C_{36} \\
& & & C_{44} & C_{45} & C_{46} \\
& & & & C_{55} & C_{56} \\
\text { SIM. } & & & & & C_{66}
\end{array}\right\}\left\{\begin{array}{l}
\sigma_{1} \\
\sigma_{2} \\
\sigma_{3} \\
\sigma_{4} \\
\sigma_{5} \\
\sigma_{6}
\end{array}\right\}
$$

Desta forma, todos os termos podem ser escritos em função de constantes de engenharia:

$$
\left\{\begin{array}{c}
\varepsilon_{x} \\
\varepsilon_{y} \\
\varepsilon_{z} \\
2 \varepsilon_{y z} \\
2 \varepsilon_{x z} \\
2 \varepsilon_{x y}
\end{array}\right\}=\left[\begin{array}{cccccc}
\frac{1}{E_{x}} & -\frac{v_{y x}}{E_{x}} & -\frac{v_{z x}}{E_{x}} & \frac{\eta_{y z, x}}{E_{x}} & \frac{\eta_{x z, x}}{E_{x}} & \frac{\eta_{x y, x}}{E_{x}} \\
-\frac{v_{x y}}{E_{y}} & \frac{1}{E_{y}} & -\frac{v_{z y}}{E_{y}} & \frac{\eta_{y z, y}}{E_{y}} & \frac{\eta_{x z, y}}{E_{y}} & \frac{\eta_{x y, y}}{E_{y}} \\
-\frac{v_{x z}}{E_{z}} & -\frac{v_{y z}}{E_{z}} & \frac{1}{E_{z}} & \frac{\eta_{y z, z}}{E_{z}} & \frac{\eta_{x z, z}}{E_{z}} & \frac{\eta_{x y, z}}{E_{z}} \\
\frac{\eta_{x, y z}}{G_{y z}} & \frac{\eta_{y, y z}}{G_{y z}} & \frac{\eta_{z, y z}}{G_{y z}} & \frac{1}{G_{y z}} & \frac{\rho_{x z, y z}}{G_{y z}} & \frac{\rho_{x y, y z}}{G_{y z}} \\
\frac{\eta_{x, y z}}{G_{x z}} & \frac{\eta_{y, x z}}{G_{x z}} & \frac{\eta_{z, x z}}{G_{x z}} & \frac{\rho_{y z, x z}}{G_{x z}} & \frac{1}{G_{x z}} & \frac{\rho_{x y, x z}}{G_{x z}} \\
\frac{\eta_{x, x y}}{G_{x y}} & \frac{\eta_{y, x y}}{G_{x y}} & \frac{\eta_{z, x y}}{G_{x y}} & \frac{\rho_{y z, x y}}{G_{x y}} & \frac{\rho_{x z, x y}}{G_{x y}} & \frac{1}{G_{x y}}
\end{array}\right]\left\{\begin{array}{c}
\sigma_{x} \\
\sigma_{y} \\
\sigma_{z} \\
\sigma_{y z} \\
\sigma_{x z} \\
\sigma_{x y}
\end{array}\right\}
$$

$E_{i}$ representa os módulos de elasticidade longitudinais, ou módulos de Young 
$G_{i j}$ representa os módulos de elasticidade transversais, ou de cisalhamento

$v_{i j}$ representa os coeficientes de Poisson

$\eta_{i j, k}$ são chamados coeficiente de influência mútua de primeira espécie, representando influência de tensões tangenciais no plano $i j$ sobre um eixo $k$

$\eta_{i, j k}$ são chamados coeficiente de influência mútua de segunda espécie, representando influência de tensões normais no eixo $i$ sobre um plano $j k$

$\rho_{i j, j k}$ são chamados coeficientes de Chentsov, representando influência de tensões tangencia is em plano $i j$ sobre plano $j k$ ( LEKHNITSTKIII, 1963 apud CORDEIRO, 2015)

\section{B.3 Relação constitutiva - Material Isotrópico}

O material Isotrópico se trata de um caso particular do Anisotrópico, em que há simetria de propriedades em todos infinitos planos. Neste caso as constantes $\eta_{i j, k}, \eta_{i, j k}$ e $\rho_{i j, j k}$ possuem valor nulo, a equação (B.6) passa a ser escrita da seguinte forma:

$$
\left\{\begin{array}{c}
\varepsilon_{x} \\
\varepsilon_{y} \\
\varepsilon_{z} \\
2 \varepsilon_{y z} \\
2 \varepsilon_{x z} \\
2 \varepsilon_{x y}
\end{array}\right\}=\left[\begin{array}{cccccc}
\frac{1}{E} & -\frac{v}{E} & -\frac{v}{E} & 0 & 0 & 0 \\
& \frac{1}{E} & -\frac{v}{E} & 0 & 0 & 0 \\
& & \frac{1}{E} & 0 & 0 & 0 \\
& & & \frac{1}{G} & 0 & 0 \\
& & & & \frac{1}{G} & 0 \\
S I M . & & & & & \frac{1}{G}
\end{array}\right\}\left\{\begin{array}{c}
\sigma_{x} \\
\sigma_{y} \\
\sigma_{z} \\
\sigma_{y z} \\
\sigma_{x z} \\
\sigma_{x y}
\end{array}\right\}
$$

onde $E$ é o módulo de Young e $v$ é o coeficiente de Poisson

Em notação indicial a Lei de Hooke pode então ser escrita da forma:

$$
\sigma_{i j}=2 G \varepsilon_{i j}+\frac{2 G v}{1-2 v} \varepsilon_{k k} \delta_{i j}
$$

$G$ é o módulo de elasticidade transversal, $v$ é o coeficiente de Poisson

Nesse caso, $C_{i j k l}$, na equação (B.5), é dado por:

$$
C_{i j k l}=\frac{2 G v}{1-2 v} \delta_{i j} \delta_{k l}+G\left(\delta_{i k} \delta_{j l}+\delta_{i j} \delta_{j k}\right)
$$




\section{B.4 Relação de Compatibilidade}

Para pequenos deslocamentos e deformações o tensor de deformação específica de Cauchy $\varepsilon_{i j}$ é dado por:

$$
\varepsilon_{i j}=\frac{1}{2}\left(u_{i, j}+u_{j, i}\right)
$$

$u_{i}$ representa os componentes do vetor de deslocamentos

\section{B.5 Equações de Equilíbrio em Deslocamentos (Equações de Navier)}

No caso isotrópico, a substituição da relação de compatibilidade e constitutiva na equação de equilißbrio resulta nas equações de equilibrio em deslocamentos, chamadas de equações de Navier:

$$
G u_{j, k k}+\frac{G}{1-2 v} u_{k, k j}+b_{J}=0
$$

\section{B.6 Condições de Contorno}

Separando-se o contorno entre trechos com diferentes condições de contorno $\Gamma_{u}$ e $\Gamma_{\sigma}$, tal que:

$$
\begin{gathered}
\Omega \cap \Gamma=\phi \\
\Gamma=\Gamma_{u} \cup \Gamma_{\sigma} \\
\Gamma_{u} \cap \Gamma_{\sigma}=\phi
\end{gathered}
$$

A condição de contorno em deslocamentos é chamada de condição de contorno de Dirichlet:

$$
\Gamma_{u}: u_{i}=\bar{u}_{l}
$$

A condição de contorno em forças de superfície é por sua vez chamada de condição de contorno de Neumann:

$$
\Gamma_{\sigma}: \sigma_{i j} n_{j}=\bar{t}_{i}
$$

$\bar{u}_{\imath}$ e $\bar{t}_{\imath}$ representam os valores conhecidos no contorno de deslocamentos e forças de superfíc ie respectivamente. 


\section{B.7 Estado Plano de Tensões (EPT)}

O estado plano de tensões ocorre por exemplo no caso de chapas de aço, onde uma das dimensões é muito inferior às outras, sendo definido por não haverem componentes de tensão perpendiculares a um plano, ou seja:

$$
\sigma_{z}=\sigma_{z x}=\sigma_{x z}=\sigma_{z y}=\sigma_{y z}=0
$$

$\varepsilon_{-} Z$ passa a ser função dos alongamentos nas direções x e y. No caso isotrópico outras deformações em z passam a ser nulas.

O equilibrio infinitesimal no domínio $\Omega$ é dado por:

$$
L \sigma+\bar{b}=0
$$

$\sigma$ é um vetor coluna com as componentes do tensor de tensão, $\bar{b}$ representa as forças de volume do problema e $L$ o operador diferencial divergente:

$$
\sigma=\left\{\begin{array}{c}
\sigma_{x} \\
\sigma_{y} \\
\tau_{x y}
\end{array}\right\}, b=\left\{\begin{array}{l}
b_{x} \\
b_{y}
\end{array}\right\} \text { e } L=\left[\begin{array}{ccc}
\frac{\partial}{\partial \mathrm{x}} & 0 & \frac{\partial}{\partial \mathrm{y}} \\
0 & \frac{\partial}{\partial \mathrm{y}} & \frac{\partial}{\partial \mathrm{x}}
\end{array}\right]
$$

Para o contorno $\Gamma$ :

$$
\begin{gathered}
p=N \sigma \\
p=\left\{\begin{array}{l}
p_{x} \\
p_{y}
\end{array}\right\} \text { e } N=\left[\begin{array}{ccc}
n_{x} & 0 & n_{y} \\
0 & n_{y} & n_{x}
\end{array}\right]
\end{gathered}
$$

$p$ representa as forças de superfície do corpo, $N$ é a matriz contendo as componentes do vetor $n$ normal ao contorno, orientado para fora do corpo, $\sigma$ é um vetor coluna com as componentes do tensor de tensão.

Relação constitutiva:

$$
\varepsilon=f \sigma
$$

$\varepsilon$ é um vetor coluna com as componentes do tensor de deformação e $f$ é a matriz de flexibilidade do material. 
$O$ vetor $\varepsilon$ assume a seguinte forma no caso anisotrópico:

$$
\begin{gathered}
\varepsilon=\left\{\begin{array}{c}
\varepsilon_{x} \\
\varepsilon_{y} \\
\gamma_{x y}
\end{array}\right\} \\
f=\left[\begin{array}{lll}
C_{11} & C_{12} & C_{16} \\
S I M . & C_{22} & C_{26} \\
S I M & C_{66}
\end{array}\right]=\left[\begin{array}{ccc}
\frac{1}{E_{x}} & -\frac{v_{y x}}{E_{x}} & \frac{\eta_{x y, x}}{E_{x}} \\
-\frac{v_{x y}}{E_{y}} & \frac{1}{E_{y}} & \frac{\eta_{x y, y}}{E_{y}} \\
\frac{\eta_{x, x y}}{G_{x y}} & \frac{\eta_{y, x y}}{G_{x y}} & \frac{1}{G_{x y}}
\end{array}\right]
\end{gathered}
$$

Para o caso isotrópico $f$ assume a seguinte forma:

$$
e f=\frac{1}{E}\left[\begin{array}{ccc}
1 & -v & 0 \\
-v & 1 & 0 \\
0 & 0 & 2(1+v)
\end{array}\right]
$$

Destaca-se que a equação (B.19) também pode ser escrita em termos de tensões:

$$
\begin{gathered}
\sigma=k \varepsilon \\
k=f^{-1}
\end{gathered}
$$

onde $k$ é a matriz de rigidez do material.

Relação de compatibilidade:

$$
\varepsilon=L^{T} u
$$

Condições de Contorno:

$$
\begin{gathered}
\Gamma_{u}: \quad u=\bar{u} \\
\Gamma_{\sigma}: \quad N \sigma=\bar{t}
\end{gathered}
$$

$\bar{u}$ e $\bar{t}$ são os vetores de valores conhecidos de deslocamentos e deformações respectivamente. 


\section{B.8 Integração por partes}

Envolvendo equações integrais, como de resíduos ponderados, em diversos momentos é necessário fazer uso de integração por partes. São mostradas então as principais relações a serem utilizadas:

$$
\begin{aligned}
& \int_{\Omega} \sigma_{k j, j} u_{k}^{*} d \Omega=\int_{\Gamma} p_{k} u_{k}^{*} d \Gamma-\int_{\Omega} \sigma_{\mathrm{kj}} \varepsilon_{\mathrm{kj}}^{*} d \Omega \\
& \int_{\Omega} \sigma_{\mathrm{kj}} \varepsilon_{\mathrm{kj}}^{*} d \Omega=\int_{\Gamma} u_{k} p_{k}^{*} d \Gamma-\int_{\Omega} u_{k} \sigma_{k j, j}^{*} d \Omega
\end{aligned}
$$

Com essas equações pode-se comprovar a seguinte relação:

$$
\int_{\Omega} \sigma_{\mathrm{kj}} \varepsilon_{\mathrm{kj}}^{*} d \Omega=\int_{\Omega} \sigma_{\mathrm{kj}}^{*} \varepsilon_{\mathrm{kj}} d \Omega
$$

